\title{
ENGENHARIA DE
}

\section{PRODUÇÃO:}

ALICERCE DA COMPETITIVIDADE

VOLUME III

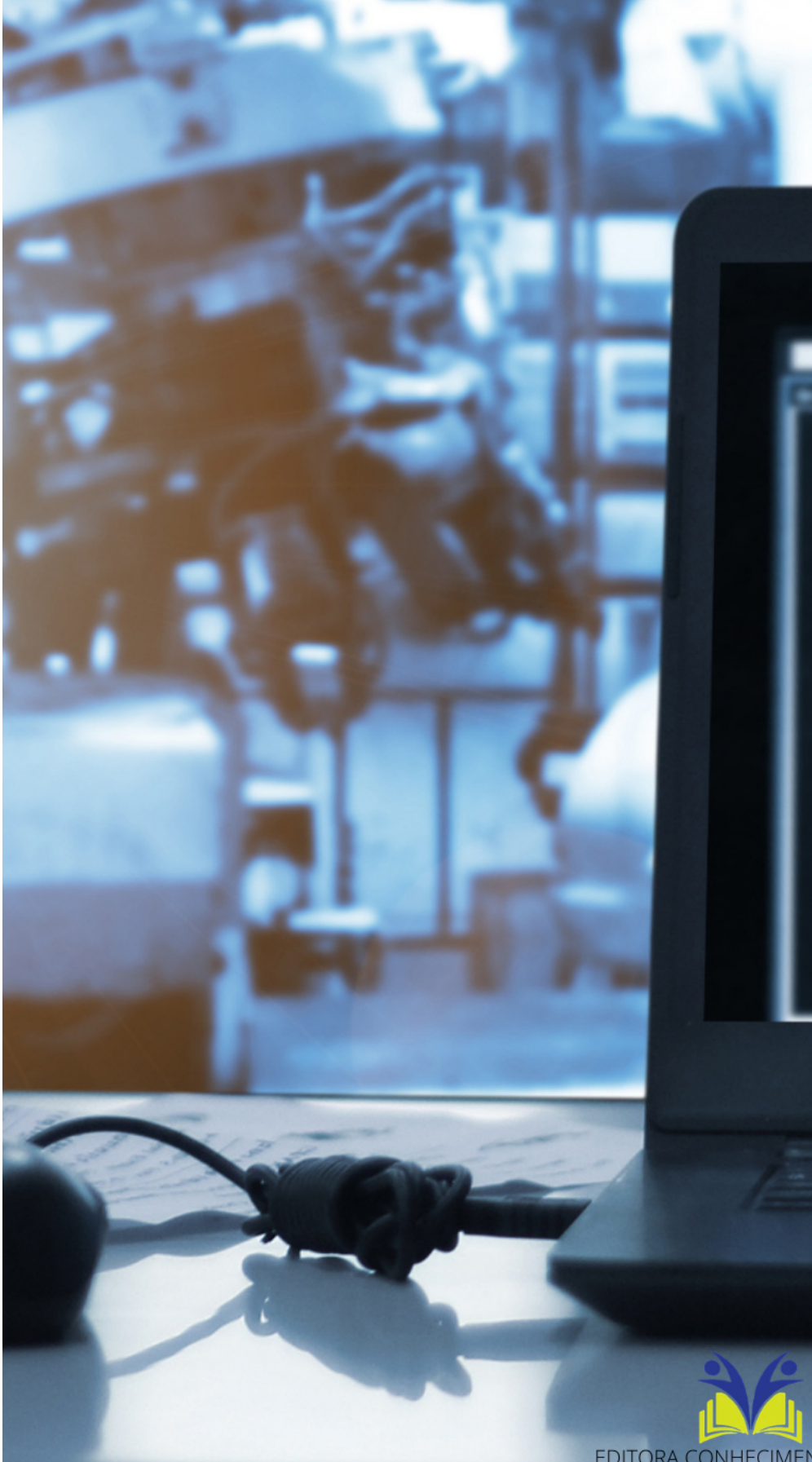


Frederico Celestino Barbosa

Engenharia de Produção: alicerce da competitividade

$1^{\text {a }}$ ed.

Piracanjuba-GO

Editora Conhecimento Livre

Piracanjuba-GO 
$1^{\mathrm{a}} \mathrm{ed}$

\section{Dados Internacionais de Catalogação na Publicação (CIP)}

Barbosa, Frederico Celestino
B238E Engenharia de Produção: alicerce da competitividade
/ Frederico Celestino Barbosa. - Piracanjuba-GO

Editora Conhecimento Livre, 2021

256 f.: il

DOI: $10.37423 / 2021$.edcl 226

ISBN: 978-65-89145-73-8

Modo de acesso: World Wide Web

Incluir Bibliografia

1. projeto 2. implantação 3. operação 4. manutenção 5. desenvolvimento I. Barbosa, Frederico Celestino II. Título

CDU: 620

https://doi.org/10.37423/2021.edc1226

O conteúdo dos artigos e sua correção ortográfica são de responsabilidade exclusiva dos seus respectivos autores. 


\section{EDITORA CONHECIMENTO LIVRE}

\section{Corpo Editorial}

Dr. João Luís Ribeiro Ulhôa

Dra. Eyde Cristianne Saraiva-Bonatto

MSc. Anderson Reis de Sousa

$\underline{\text { MSc. Frederico Celestino Barbosa }}$

MSc. Carlos Eduardo de Oliveira Gontijo

MSc. Plínio Ferreira Pires

Editora Conhecimento Livre

Piracanjuba-GO 


\section{SUMÁRIO}

CAPÍTULO 1

ANÁLISE DE SENSIBILIDADE PARA A COMPOSIÇÃO PROBABILÍSTICA DE PREFERÊNCIAS

COM INTEGRAIS DE CHOQUET NO APOIO À DECISÃO MULTICRITÉRIO

Luiz Octávio Gavião

Annibal Parracho Sant'Anna

Gilson Brito Alves Lima

Pauli Adriano de Almada Garcia

DOI 10.37423/210303666

CAPÍTULO 2

DESIGN E INOVAÇÃO NO APROVEITAMENTO SUSTENTÁVEL DE RESÍDUOS EM EMPRESAS DE PAPELÃO: REAPROVEITAMENTO DE APARAS COM MELHOR VALOR AGREGADO.

JAIR MELLO JAREK

DOI 10.37423/210303671

CAPÍTULO 3

ANÁLISE DO DESIGN DE APLICATIVOS PARA DISPOSITIVOS MÓVEIS COM FOCO EM

CRIANÇAS E ADOLESCENTES

Vinícius de Azevedo Botelho

Virginia Tiradentes Souto

DOI 10.37423/210303697

CAPÍTULO 4

ECOPISO DE FIBRA DE TURURI E RESINA DE MAMONA: ENSAIO DE RESISTÊNCIA À ABRASÃO E ANÁLISE DA MORFOLOGIA UTILIZANDO MEV

ANA KARLA FREIRE DE OLIVEIRA

José Roberto Moraes D'Almeida

DOI 10.37423/210303703

CAPÍTULO 5

DESIGN DA INFORMAÇÃO, DESIGN GRÁFICO E O PENSAR SUSTENTÁVEL

Suemmey Rocha Albuquerque Ramos

DOI 10.37423/210403767

CAPÍTULO 6

MARKETING PROMOCIONAL: UMA ANÁLISE QUANTITATIVA DAS INFLUÊNCIAS

PROMOCIONAIS NA TOMADA DE DECISÕES DE COMPRA DO CONSUMIDOR

Raphaela Pereira Rangel

Gustavo Lopes Olivares

DOI 10.37423/210403734 
COMPETEENCIAS DO NÍVEL DE COMANDO DE UM ÓRGÃO PÚBLICO MUNICIPAL

LUCILEILA DO ROSARIO QUEIROZ

ROBERTO KANAANE

DOI 10.37423/210403749

CAPÍTULO 8 104

ESTUDOS DE LIDERANÇA TRANSFORMACIONAL NO SETOR AUTOMOTIVO: UMA LACUNA PARA PESQUISAS

Bruno Provazi

Andreia Maria Pedro Salgado

Jorge Muniz Junior

DOI 10.37423/210403763

CAPÍTULO 9

CONCEITOS DE GESTÃO DE MARCA: COMPARATIVOS ENTRE AS VISÕES APRESENTADAS

POR LINDSTROM, MESHER E WHEELER

Arina Blum

Taís Vieira Pereira

Vanessa Neto Bischoff

DOI 10.37423/210403764

CAPÍTULO 10

BIM PARA A ANÁLISE DE DESEMPENHO TÉRMICO EM EDIFICAÇÕES DO PROGRAMA

MINHA CASA MINHA VIDA

Lais Guerle Tonso

Eduardo Sampaio Nardelli

DOI 10.37423/210403766

CAPÍTULO 11

SEMANAS ACADÊMICAS COMO POSSIBILIDADES DE EFETIVAÇÃO DO TRÂNSITO

DISCIPLINAR: UMA EXPERIÊNCIA NA ESCOLA DE BELAS ARTES DA PUCPR

Luciane Hilu

Rita de Cássia Veiga Marriott

Patricia Lupion Torres

DOI 10.37423/210403768

CAPÍTULO 12

ID-THINK: FACILITADOR DA VISUALIZAÇÃO DOS CONHECIMENTOS DA EMPRESA

ANA PAULA PERFETTO DEMARCHI

Cleuza Bittencourt Ribas Fornasier

Elingth Simoné Rosales Marquina

DOI 10.37423/210403769 
A EXPERIÊNCIA DO USUÁRIO NO PROCESSO EVOLUTIVO DO DESIGN

Renato do Nascimento Oliveira

Carlos Dias Limeira

José Guilherme Santa Rosa

DOI 10.37423/210403773

CAPÍTULO 14

A PRESENÇA FEMININA NOS CURSOS DE ENGENHARIA: UM ESTUDO QUANTITATIVO E QUALITATIVO

Joseline Melo Corrêa

Elen Priscila de Souza Lobato

Flávia de Cássia Martins Ribeiro

Isabelle da S. de Lima

Wellington da Silva Fonseca

DOI 10.37423/210403774

CAPÍTULO 15

DO DESENHO DE CRIANÇA À ILUSTRAÇÃO DO LIVRO INFANTIL José Salmo Dansa de Alencar

DOI 10.37423/210403777

CAPÍTULO 16

SELECIONANDO MEMBROS DE UMA EQUIPE DE PROJETO POR MEIO DE UM MÉTODO MULTICRITÉRIO DE APOIO À DECISÃO

Glauco Barbosa da Silva

Helder Gomes Costa

Phelipe Medeiros da Rocha

DOI 10.37423/210403778

CAPÍTULO 17

COMUNICAÇAO UBIQUA E PRODUÇAO DE PRESENÇA: O PENSAMENTO DA ARTE NOS METODOS DE PROJETO NO DESENVOLVIMENTO DE INTERFACES GRÁFICAS

Claudia Teixeira Marinho

Lara Silva Lima

Vitor Alencar Araripe Cordeiro

Ravi Passos

DOI 10.37423/210403821 
A CONTRIBUIÇÃO DA REALIDADE AUMENTADA PARA O DESENHO INDUSTRIAL

DANILO ÉMMERSON NASCIMENTO SILVA

JOÃO ROBERTO GOMES DE FARIA

OSMAR VICENTE RODRIGUES

DOI 10.37423/210403826 


\section{Capítulo 1}

doi $10.37423 / 210303666$

\section{ANÁLISE DE SENSIBILIDADE PARA A COMPOSIÇÃO PROBABILÍSTICA DE PREFERÊNCIAS COM INTEGRAIS DE CHOQUET NO APOIO À DECISÃO MULTICRITÉRIO}

Luiz Octávio Gavião

Annibal Parracho Sant'Anna

Gilson Brito Alves Lima

Pauli Adriano de Almada Garcia

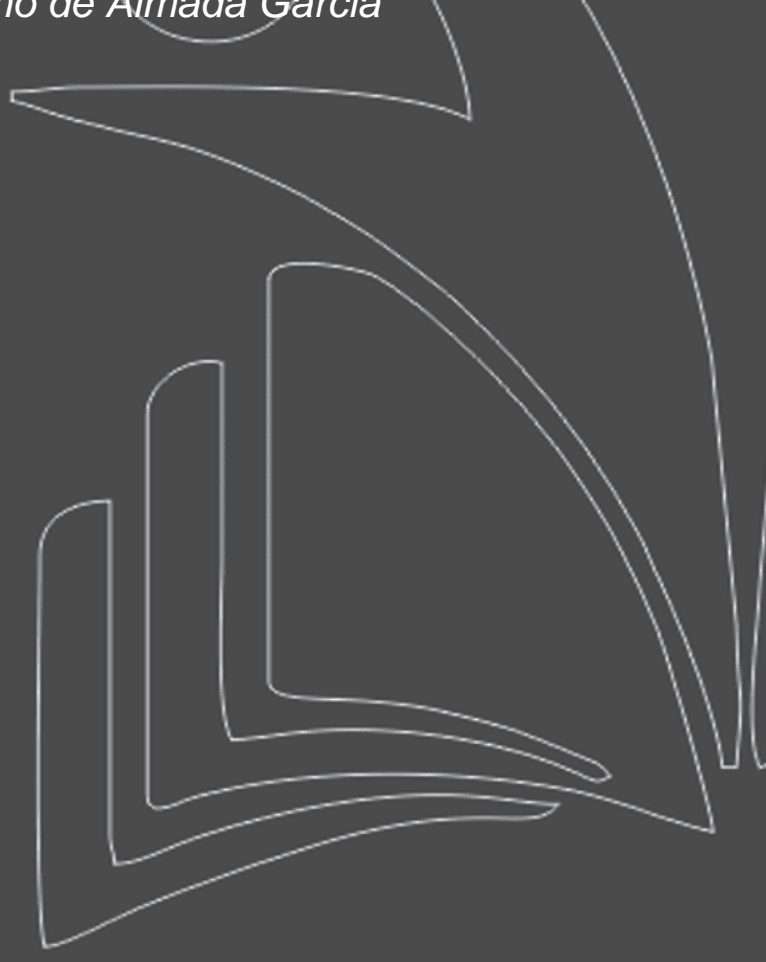

Escola Superior de Guerra (ESG)

Universidade Federal Fluminense (UFF)

Universidade Federal Fluminense (UFF)

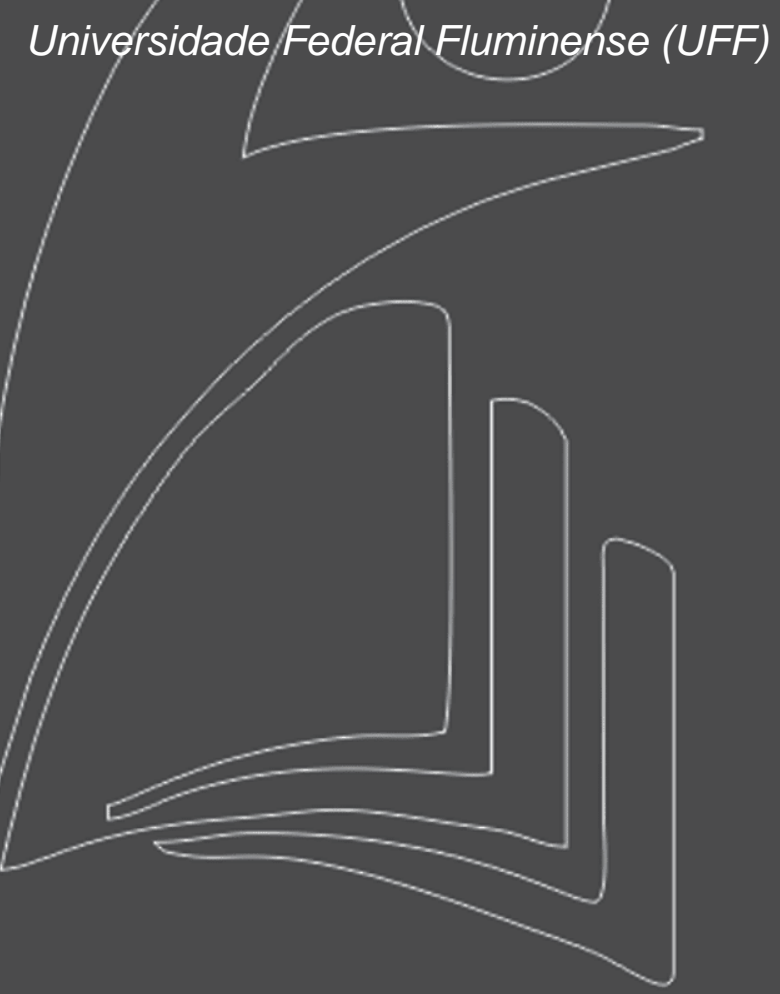


Resumo: Este artigo apresenta uma proposta de análise de sensibilidade à Composição Probabilística de Preferências (CPP) com integrais de Choquet. O método CPP-Choquet se destina à ordenação de alternativas em problemas de apoio à decisão multicritério, com base na interação probabilística de critérios. Esta pesquisa reavaliou os resultados obtidos por método similar, para uma base de dados composta por notas de 89 alunos (alternativas), em cinco disciplinas (critérios). A simulação de diversas interações entre os critérios permitiu avaliar o comportamento das alternativas em amplo espectro, indicando inversões de ordem das alternativas com melhor desempenho. A análise de sensibilidade do método pesquisado é original na literatura e relevante para adicionar novas perspectivas à avaliação do problema.

Palavras Chave. CPP. Choquet. Análise de Sensibilidade.

Tópicos MP - Modelos Probabilísticos. 


\section{INTRODUÇÃO}

Os modelos de apoio à decisão multicritério (Multiple Criteria Decision Aid - MCDA) empregam, em geral, cálculos com base no desempenho das alternativas isoladamente em cada critério (Pomerol \& Barba-Romero, 2012). Na prática, entretanto, a tomada de decisão pode envolver avaliações decorrentes de interações dos critérios. Isto requer uma modelagem não- aditiva, de modo a levar em consideração o desempenho das alternativas diante de diversas combinações de critérios. Nesse contexto, a teoria das capacidades de [Choquet 1953] foi adaptada com sucesso em problemas MCDA, com ampla variedade de aplicações [Grabisch e Labreuche 2010], [Grabisch e Roubens 2000], [Merad etal. 2013]. Sob o ponto de vista MCDA, uma "capacidade" pode ser interpretada como pesos atribuídos aos subconjuntos de critérios do problema, sendo agregados por integrais de Choquet para a obtenção de um escore final de cada alternativa, que indica uma ordem de preferências para a tomada de decisão [Grabisch et al. 2006].

A Composição Probabilística de Preferências (CPP) é um método MCDA que também pode explorar as integrais de Choquet. Em [Sant'Anna 2014a, 2014b, 2015a, 2015b], o CPP-Choquet foi utilizado para reavaliar a classificação de países, com base no Índice de Desenvolvimento Humano (IDH). Em [Souza et al. 2016], as integrais de Choquet foram utilizadas com o CPP para a avaliação de processos em gestão de resíduos, utilizando os índices de Shapley para a redução sucessiva de critérios. As capacidades também são necessárias aos cálculos dos índices de Shapley para cada critério, indicando sua importância relativa no processo de tomada de decisão, com a base de dados utilizada [Shapley 1953]. Em [Sant'Anna 2015a], o cálculo probabilístico das capacidades e suas composições por integrais de Choquet, para determinar a ordem de preferência de cada alternativa, estão detalhados.

O CPP-Choquet usa o cálculo da probabilidade de união dos critérios para definir as capacidades dos subconjuntos que eles formam. Dessa forma, os escores de probabilidade refletem a interação entre os critérios. Esse cálculo probabilístico se aplica tanto a pares de critérios quanto a maior quantidade de interações. Conforme [Šipošová et al. 2017], as interações dos critérios podem produzir estados de super e subaditividade, indicando situações de sinergia e redundância, respectivamente, para a solução do problema. Assim, a variedade de resultados revela o comportamento das preferências para maior espectro de interações, sendo então possível avaliar a sensibilidade da ordenação das alternativas.

Este artigo tem por finalidade apresentar uma análise de sensibilidade do CPP-Choquet aplicado a um problema MCDA. A proposta é inédita à literatura do CPP e se mostra relevante ao processo de tomada 
de decisão, ao indicar o comportamento da ordem de preferência das alternativas, antes indicadas em somente um estado de interação. Para atender à finalidade, o artigo está estruturado em seis Seções. Após a seção introdutória, a Seção 2 resume o método CPP. A Seção 3 descreve as etapas de cálculo do CPP-Choquet. A Seção 4 destaca a proposta de análise de sensibilidade do CPP-Choquet. A Seção 5 reavalia o problema apresentado por [Kojadinovic 2008], à luz do CPP-Choquet. Por fim, a Seção 6 traz as considerações finais desta pesquisa. Os cálculos foram efetuados no software "R", com auxílio do aplicativo "kappalab" [R-Core-Team 2016].

\section{O MÉTODO CPP}

O CPP é um método MCDA. O CPP aplica a abordagem probabilística ao problema de tomada de decisão, a partir do conceito-chave da "aleatorização" das alternativas. Esse conceito deriva da imprecisão das medidas, da natureza aleatória do problema ou mesmo da incerteza acerca do contexto que envolve a tomada de decisão. Caso esses elementos não estivessem presentes, outros métodos determinísticos poderiam ser aplicados ao problema com soluções satisfatórias. Porém, o tratamento probabilístico de um problema sob tais condições confere maior realismo à modelagem [Sant'Anna 2015a].

Nesse primeiro passo do CPP, as avaliações exatas das alternativas são interpretadas como medidas de posição (i.e. média, moda, mediana) de uma variável aleatória. Essa transformação permite o tratamento estatístico das avaliações por funções de probabilidade. A escolha da função probabilística que melhor se ajusta aos dados pode advir de informações a priori, de aplicações bem-sucedidas a problemas similares, do ajuste dos dados a distribuições conhecidas por técnicas estatísticas, denominado "goodness-of-fit" ou, na ausência dessas informações, arbitrada ao contexto do problema. De maneira geral, o uso de distribuições normais e triangulares têm suprido as necessidades da modelagem simétrica e assimétrica dos dados, respectivamente, com resultados satisfatórios. Nesta pesquisa são utilizadas distribuições Beta modificadas, também denominadas distribuições PERT, por referência ao modelo homônimo de análise de riscos em projetos. As distribuições PERT são parametrizadas a partir dos valores mínimos, modais e máximos de cada alternativa. $\mathrm{O}$ ajuste dos parâmetros das distribuições foi efetuado com auxílio do aplicativo "mc2d" do software " $R$ " [R-CoreTeam 2016]. 


$$
\begin{aligned}
& M_{i j}=\int_{D_{X_{i}}}\left[\prod F_{X_{-i}}\left(x_{-i}\right)\right] f_{X_{i}}\left(x_{i}\right) d x_{i} \\
& m_{i j}=\int_{D_{X_{i}}}\left[\prod\left(1-F_{X_{-i}}\left(x_{-i}\right)\right)\right] f_{X_{i}}\left(x_{i}\right) d x_{i}
\end{aligned}
$$

Após o processo de "aleatorização", as probabilidades da i-ésima alternativa ser superior ( $\left.\mathrm{M}_{\mathrm{ij}}\right)$ e inferior $\left(m_{i j}\right)$ às demais, conjuntamente, são calculadas para cada j-ésimo critério. Nas equações (1) e (2), um vetor aleatório, " $X$ ", simboliza as alternativas do problema. As funções relativas à i-ésima alternativa são indexadas por "i" e as demais por “-i". As notações FX, fX e DXi são, respectivamente, a função distribuição cumulativa (cdf), a função densidade de probabilidade (pdf) e o domínio da variável aleatória "X" [Sant'Anna et al. 2012].

As probabilidades " $M_{i j}$ " $e$ " $m_{i j}$ " precisam ser compostas para a obtenção do escore final, que conclui o método CPP. Com base nos escores finais, as alternativas são selecionadas para a escolha, agrupadas para a classificação, entre outras opções para a tomada de decisão. Em [Sant'Anna 2015a], são apresentadas diferentes formas de composição dessas probabilidades.

Nesta pesquisa é utilizada a composição por capacidades e integrais de Choquet, que inclui na modelagem as avaliações resultantes das interações dos critérios.

\section{O CPP-CHOQUET}

A expressão "CPP-Choquet" é aqui utilizada para denominar o uso do CPP na composição por capacidades e integrais de Choquet, para a ordenação de alternativas em problemas MCDA. O CPPChoquet é calculado em cinco etapas: (1) coleta dos dados, (2) cálculo das probabilidades de maximizar as avaliações originais, (3) cálculo das capacidades dos subconjuntos de critérios, (4) composição das integrais de Choquet para as alternativas e (5) cálculo dos índices de Shapley dos critérios.

Na etapa inicial, a coleta de dados é efetuada, de modo a configurar a matriz de decisão do problema MCDA. Os elementos dessa matriz são constituídos por avaliações das alternativas ao problema a ser solucionado, para cada critério de interesse à tomada de decisão. De maneira geral, convenciona-se que as linhas da matriz são destinadas às alternativas, as colunas aos critérios e os elementos internos às avaliações de cada alternativa em cada critério. Os cálculos do CPP não requerem a padronização das escalas de avaliação. 
Na Etapa 2, são calculadas as probabilidades de cada avaliação ser superior ao conjunto das demais, em cada critério. Esses cálculos são efetuados a partir da Equação (1). Dependendo do contexto da tomada de decisão, também é possível prosseguir nas demais etapas com os cálculos das probabilidades de cada avaliação ser a menor, em cada critério, conforme a Equação (2).

Na Etapa 3, das probabilidades dos conjuntos de alternativas são derivadas capacidades para os conjuntos de critérios. Para um conjunto $\mathrm{N}$ de $\mathrm{n}$ critérios, devem ser calculadas as capacidades $\mu$ para $2 \mathrm{n}$ subconjuntos de critérios. As capacidades pertencem ao intervalo [0,1] e devem satisfazer as condições: $\mu(\{\varnothing\})=0, \mu(\{N\})=1$ e, para quaisquer subconjuntos $E$ e $F \subset N$, se $E \subset F$, então $\mu(E) \leq \mu$ (F). Essa etapa envolve três passos. Inicialmente, para cada $\mathrm{S}$, subconjunto de $\mathrm{N}$ com $\mathrm{S}$ critérios, $\mathrm{S}=$ $\{C 1, . ., C s\}$, são calculadas as probabilidades conjuntas de maximizar as preferências em ao menos um critério do subconjunto, usando a Equação (3), em que, para cada i, Pai denota a avaliação da alternativa a pelo critério Ci. Esse cálculo representa um escore do ponto de vista progressista-otimista do CPP, para avaliações independentes [Sant'Anna 2015a, p. 42].

$$
P\left(\left\{C_{1}, \ldots, C_{s}\right\}\right)=1-\left[\left(1-P_{a 1}\right) \cdot\left(1-P_{a 2}\right) \ldots\left(1-P_{a s}\right)\right]
$$

Em seguida, ainda na Etapa 3, são selecionados os valores máximos das probabilidades de cada subconjunto, entre os resultados da aplicação da Equação (3) para as alternativas, conforme a Equação (4). Esses valores máximos são, por fim, padronizados, tornando-os proporções do de maior valor, indicado por $U$, conforme a Equação (5). Os resultados são associados a capacidades $\mu$ (S) dos subconjuntos dos critérios, sendo então utilizadas aos cálculos subsequentes.

$$
\begin{aligned}
& U=\operatorname{Max}\left\{C_{1}, \ldots, C_{s}\right\}=\max _{a}\left\{1-\left[\left(1-P_{a 1}\right) .\left(1-P_{a 2}\right) \ldots\left(1-P_{a s}\right)\right]\right\} \\
& \mu\left(\left\{C_{1}, \ldots, C_{s}\right\}\right)=P\left(\left\{C_{1}, \ldots, C_{s}\right\}\right) / P(U)
\end{aligned}
$$

$\mathrm{Na}$ Etapa 4, as avaliações probabilísticas das alternativas são compostas por integrais de Choquet. $\mathrm{O}$ maior resultado entre os escores finais define a preferência para a tomada de decisão.

$$
C H_{\mu}(A)=\sum_{j=1}^{n} p_{\tau(j)}(A)-p_{\tau(j-1)}(A) \mu(\{\tau(j), \ldots, \tau(n)\})
$$

O escore final " $\mathrm{CH}$ " pode ser obtido a partir da Equação (6). A notação descreve a integral de Choquet da alternativa $A$, em j critérios, em relação à capacidade $\mu$ em $S$, considerando ainda que $\tau$ é uma 
permutação de $S$ satisfazendo $p \tau(j)(A)>p \tau(j-1)(A)$ e arbitrando $p \tau(0)(A)=0$. Mais detalhes também podem ser obtidos em [Sant'Anna 2015a, p. 27].

$$
\left.S H_{\mu}(A)=\sum_{(K \subseteq S \backslash A)}[(\#(S \backslash A \backslash K)) !(\#(K))) ! /(\#(S \backslash A)+1) !\right] \sum_{L \subseteq A}(-1)^{\#(A \backslash L)} \mu(K \cup L)
$$

Na última etapa, as capacidades são utilizadas com o índice de Shapley, que pode ser associado à importância de cada critério, para a matriz de decisão do problema. A Equação (7) descreve o cálculo do índice de Shapley "SH $\mu(\{j\})$ ", para o j-ésimo critério isolado, considerando as capacidades " $\mu$ " nos subconjuntos "S". Mais detalhes também podem ser obtidos em [Shapley 1953] e [Sant'Anna 2015a, p. 15].

\section{ANÁLISE DE SENSIBILIDADE DO CPP-CHOQUET}

O modelo proposto para a análise de sensibilidade do CPP-Choquet envolve as mesmas etapas descritas na Seção 3, porém com a avaliação de diferentes cenários de interação entre os critérios. Na Etapa 3, são compostas as probabilidades dos subconjuntos $S$, formados com as combinações de $n$ critérios, com $2 n-2$ graus de liberdade, já que as capacidades de $\varnothing$ e $N$ possuem valores zero e um, respectivamente. De fato, o cálculo das probabilidades dos subconjuntos com escores progressistasotimistas no CPP-Choquet define um estado de interação dos critérios, conforme ilustrado no diagrama de Venn da Fig. 1(b). A proposta, então, é ampliar os cálculos das probabilidades de cada subconjunto, considerando os cenários de interação descritos nas Fig. 1(a) e Fig.1(c), genericamente representados por três critérios " $A$ ", " $B$ " e " $C$ ". Assim, considerando capacidades variando entre esses cenários extremos, se cobre um amplo espectro de interações entre os de critérios.

Simulação \# 1

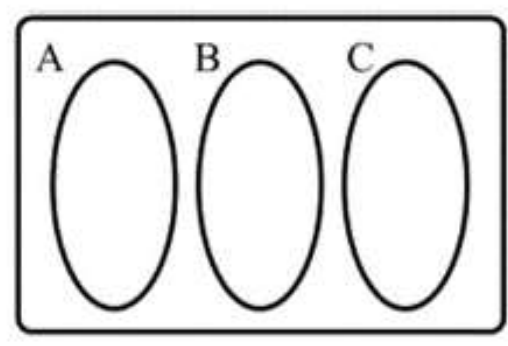

(a) $\mathrm{P}(\mathrm{AUBUC})=\mathrm{P}(\mathrm{A})+\mathrm{P}(\mathrm{B})+\mathrm{P}(\mathrm{C})$

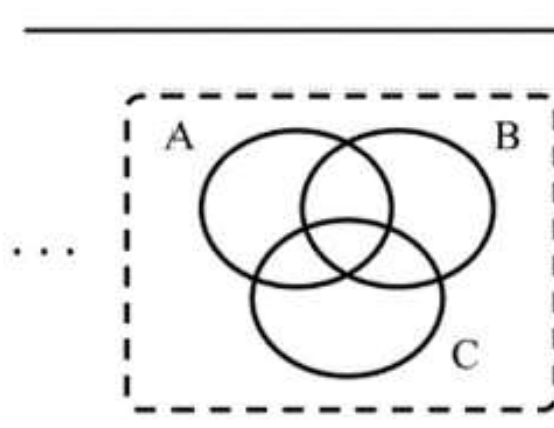

(b) $P(A \cup B U C)=1-[(1-P(A)) \cdot(1-P(B)) \cdot(1-P(C))]$
Simulação \# 500

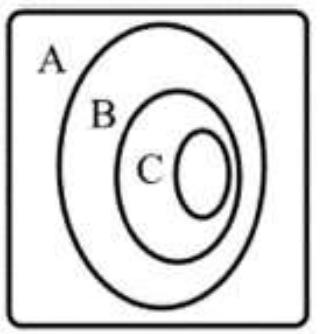

(c) $\mathrm{P}(\mathrm{AUBU})=\mathrm{Max}[\mathrm{P}(\mathrm{A}), \mathrm{P}(\mathrm{B}), \mathrm{P}(\mathrm{C})]$

Fig.1- Interações genéricas de três critérios " $A$ ", " $B$ " e " $C$ ". 
A Fig. 1(a) representa uma interação entre os conjuntos de critérios disjuntos " $A$ ", " $B$ " e " $C$ " maior que a da Fig. 1(b), enquanto a Fig. 1(c) ilustra uma interação com maior redundância.

Nas avaliações efetuadas, verificou-se que as probabilidades resultantes do cenário da Fig. 1(a) foram superiores aos da Fig. 1(b) e estas superiores as da Fig. 1(c), respeitando os axiomas de probabilidade [Ross 2009]. Em relação aos axiomas, cabe destacar que os cálculos dos cenários da Fig. 1(a) não excederam o valor unitário, em função dos baixos valores das probabilidades no problema, tornando inócua a restrição inserida no código de programação. Dessa forma, esses cenários puderam ser usados como extremos para a simulação das capacidades. Por limitação computacional do software $\mathrm{R}$, foram consideradas 500 capacidades igualmente espaçadas entre esses dois extremos. $O$ restante dos procedimentos da Etapa 3 e demais etapas são efetuados para cada valor de probabilidade dos subconjuntos de critérios. Ao final, é possível verificar o comportamento dos valores das integrais de Choquet das alternativas e índices de Shapley dos critérios para o espectro de interações possíveis entre eles, revelando, assim, a sensibilidade da ordenação das alternativas e critérios.

\section{APLICAÇÃO}

Este artigo reavaliou o problema de pesquisa apresentado por [Kojadinovic 2008]. O autor explorou um problema MCDA com auxílio de integrais de Choquet e capacidades geradas por técnicas de entropia. Naquela pesquisa, 89 alunos foram avaliados em cinco disciplinas (i.e. Inglês,

Computação, Álgebra, Análise e Física), conforme descreve a Tabela 1. As notas originais pertencem à escala $(0,20)$. O problema de pesquisa está relacionado à ordenação dos Alunos, levando-se em conta os desempenhos isolados e por interação das disciplinas, levando-se conteúdos acadêmicos em comum e que influenciam no desempenho global dos Alunos. Por necessidade de concisão do texto, algumas Tabelas apresentam somente um extrato dos resultados.

Tabela 1 - Notas dos Alunos

\begin{tabular}{|c|c|c|c|c|c|c|c|c|c|c|c|c|c|c|c|c|c|}
\hline Aluno & Ing & $\mathrm{Cmp}$ & Alg & Ana & Fis & Aluno & Ing & $\mathrm{Cmp}$ & Alg & Ana & Fis & Aluno & Ing & $\mathrm{Cmp}$ & Alg & Ana & Fis \\
\hline 1 & 7,7 & 14,3 & 3,9 & 3,7 & 9,4 & 31 & 9,3 & 12,5 & 2,5 & 3,1 & 3,1 & 61 & 11 & 11,9 & 8,1 & 5,5 & 6,9 \\
\hline 2 & 11 & 12 & 1,1 & 4,6 & 4,4 & 32 & 16,3 & 2 & 12,4 & 1,2 & 7,9 & 62 & 1 & 9,5 & 2,9 & 4,8 & 4,7 \\
\hline 3 & 14,3 & 1,3 & 4,9 & 3,6 & 7,6 & 33 & 5,3 & 9,9 & 6 & 3,2 & 4,3 & 63 & 8,7 & 6,8 & 4,4 & 4,9 & 4,3 \\
\hline 4 & 11,2 & 9,5 & 2,2 & 3,3 & 3,3 & 34 & 13,3 & 11,9 & 5,2 & 5,8 & 5,2 & 64 & 11 & 6,8 & 2,2 & 0,2 & 1,8 \\
\hline 5 & 6,3 & 7,3 & 8,7 & 6,3 & 11,5 & 35 & 11,3 & 9,9 & 9,5 & 6,9 & 8,1 & 65 & 1 & 3,6 & 7,2 & 5 & 5,7 \\
\hline 6 & 9,5 & 5,6 & 4,4 & 3,3 & 4,7 & 36 & 12,3 & 13,2 & 9,4 & 6,8 & 9,1 & 66 & 13,3 & 1 & 8,8 & 5,8 & 7 \\
\hline 7 & 9,7 & 9,7 & 1,5 & 2 & 1,7 & 37 & 15,7 & 13,7 & 13,2 & 1,8 & 12,9 & 67 & 6,3 & 9,5 & 5,5 & 2,8 & 1,2 \\
\hline
\end{tabular}




\section{Multicritério}

\begin{tabular}{|c|c|c|c|c|c|c|c|c|c|c|c|c|c|c|c|c|c|}
\hline Aluno & Ing & $\mathrm{Cmp}$ & $\mathrm{Alg}$ & Ana & Fis & Aluno & Ing & $\mathrm{Cmp}$ & Alg & Ana & Fis & Aluno & Ing & $\mathrm{Cmp}$ & Alg & Ana & Fis \\
\hline 8 & 9,7 & 8,9 & 9,8 & 7,9 & 8,4 & 38 & 8,5 & 7,1 & 6,1 & 5,6 & 5,2 & 68 & 18,7 & 12,7 & 13 & 6,2 & 5,5 \\
\hline 9 & 13 & 1,3 & 5,4 & 5,4 & 7 & 39 & 12,5 & 4,9 & 61 & 5,7 & 9,2 & 69 & 16,3 & 11,2 & 9,4 & 5,8 & 5,7 \\
\hline 10 & 6,7 & 5,6 & 3,7 & 4 & 5 & 40 & 12 & 7,7 & 5,9 & 5,7 & 7 & 70 & 9 & 1,7 & 4,9 & 4,7 & 6,7 \\
\hline 11 & 11,7 & 6,4 & 5 & 6,3 & 6,4 & 41 & 15,7 & 16,2 & 14,5 & 1,1 & 13,1 & 71 & 15,3 & 8,8 & 7,3 & 6,9 & 9,3 \\
\hline 12 & 14,7 & 11,4 & 7 & 5,9 & 1,8 & 42 & 12 & 1,2 & 5,8 & 6,3 & 6,5 & 72 & 12,3 & 5,8 & 5,3 & 3,3 & 2,9 \\
\hline 13 & 12,3 & 6,6 & 8 & 6,8 & 1,4 & 43 & 1 & 8,6 & 3,6 & 5,4 & 7,8 & 73 & 7 & 8,4 & 8,2 & 7,2 & 8,5 \\
\hline 14 & 13,7 & 9,6 & 5,3 & 4,9 & 8,7 & 44 & 16,3 & 9,9 & 3,9 & 5 & 7,3 & 74 & 11,7 & 13,7 & 9 & 6,7 & 7,6 \\
\hline 15 & 1 & 7,7 & 11 & 7,6 & 6,8 & 45 & 14,7 & 2 & 7,3 & 5,8 & 9,6 & 75 & 15 & 8,4 & 5,2 & 4,1 & 5,7 \\
\hline 16 & 15,7 & 2 & 3,2 & 3,9 & 6,3 & 46 & 15 & 14 & 11,5 & 8,5 & 7 & 76 & 8 & 1,7 & 0,5 & 3 & 2,2 \\
\hline 17 & 7 & 5,9 & 7,5 & 4,9 & 5,1 & 47 & 11,3 & 11,4 & 5,4 & 2,8 & 5,5 & 77 & 12 & 9,5 & 6,6 & 7,3 & 8,8 \\
\hline 18 & 14,7 & 13,6 & 11,6 & 8,6 & 1,4 & 48 & 3 & 4,5 & 0,2 & 3,5 & 1,7 & 78 & 1,7 & 5,9 & 5,1 & 2,5 & 7,7 \\
\hline 19 & 11,3 & 4,7 & 5,2 & 3,1 & 2,7 & 49 & 11 & 6,6 & 5,3 & 5,7 & 1,1 & 79 & 12,3 & 12,2 & 11 & 9,2 & 7,9 \\
\hline 20 & 17 & 17,8 & 9,3 & 6,5 & 7,8 & 50 & 9 & 6,9 & 0,8 & 3 & 4,1 & 80 & 11,3 & 11,6 & 2,5 & 1,9 & 1,4 \\
\hline 21 & 5 & 1,6 & 12,2 & 9,9 & 6,3 & 51 & 14 & 1,7 & 1,5 & 4,1 & 8,7 & 81 & 15,7 & 8,6 & 2,8 & 4,2 & 3,5 \\
\hline 22 & 7,7 & 1,6 & 4,3 & 5,3 & 7,5 & 52 & 14 & 1,4 & 5,3 & 6,4 & 8,2 & 82 & 1,5 & 13,8 & 1,9 & 1,8 & 6,9 \\
\hline 23 & 14,3 & 7,2 & 9,5 & 9,9 & 7,6 & 53 & 15,8 & 11,8 & 6 & 5,4 & 7,5 & 83 & 3,3 & 5,7 & 1,8 & 9,2 & 1,5 \\
\hline 24 & 1,3 & 13,8 & 4,5 & 2,3 & 12,2 & 54 & 9,7 & 14,9 & 11,5 & 5,6 & 5,9 & 84 & 12,7 & 7,2 & 3,4 & 4,5 & 5,6 \\
\hline 25 & 16,8 & 6,6 & 3,8 & 1,8 & 7,6 & 55 & 16 & 15,4 & 14,3 & 8,5 & 7,5 & 85 & 12,3 & 14,6 & 7,6 & 8,8 & 6,4 \\
\hline 26 & 11,3 & 5,4 & 8,5 & 6,3 & 4,4 & 56 & 7,7 & 6,9 & 1,5 & 4,3 & 8,3 & 86 & 16 & 12,4 & 1,3 & 10 & 8,7 \\
\hline 27 & 3,3 & 16,5 & 4,8 & 3,8 & 3,7 & 57 & 15 & 11,7 & 12,6 & 9,6 & 2 & 87 & 13 & 18,1 & 8,5 & 5,9 & 8 \\
\hline 28 & 5,8 & 1,3 & 0,7 & 1 & 1,6 & 58 & 13,3 & 8,3 & 6,4 & 4,6 & 5,7 & 88 & 7,5 & 7,8 & 7,1 & 7,8 & 7,6 \\
\hline 29 & 13 & 13,9 & 8,2 & 6,5 & 8,2 & 59 & 8 & 8,8 & 4,6 & 5,5 & 8,2 & 89 & 9 & 12,6 & 3,9 & 4,3 & 5,6 \\
\hline 30 & 4 & 7,6 & 3,2 & 2,5 & 1,4 & 60 & 16,7 & 11,3 & 1,3 & 4,2 & 7,9 & $\mathrm{x}$ & $\mathrm{x}$ & $\mathrm{x}$ & $\mathrm{x}$ & $\mathrm{x}$ & $\mathrm{x}$ \\
\hline
\end{tabular}

Fonte: [Kojadinovic 2008].

A Tabela 2 apresenta um extrato das probabilidades de maximizar as avaliações, obtidas com a aplicação da Equação (1). Esses resultados indicam, em cada disciplina, a probabilidade de cada nota ser superior às demais conjuntamente, atendendo ao princípio da aleatoriedade e independência das avaliações iniciais. 
Tabela 2 - Probabilidades de Maximizar as avaliações (Extrato)

\begin{tabular}{c|ccccc|c|ccccc}
\hline Aluno & Ing & Cmp & Alg & Ana & Fis & Aluno & Ing & Cmp & Alg & Ana & Fis \\
\hline 1 & $8,5 \mathrm{E}-05$ & $2,8 \mathrm{E}-02$ & $3,4 \mathrm{E}-04$ & $2,2 \mathrm{E}-03$ & $2,5 \mathrm{E}-02$ & 46 & $2,0 \mathrm{E}-02$ & $2,4 \mathrm{E}-02$ & $3,8 \mathrm{E}-02$ & $3,5 \mathrm{E}-02$ & $6,8 \mathrm{E}-03$ \\
2 & $1,2 \mathrm{E}-03$ & $7,1 \mathrm{E}-03$ & $2,8 \mathrm{E}-05$ & $4,0 \mathrm{E}-03$ & $1,3 \mathrm{E}-03$ & 47 & $1,5 \mathrm{E}-03$ & $4,9 \mathrm{E}-03$ & $1,0 \mathrm{E}-03$ & $1,1 \mathrm{E}-03$ & $2,7 \mathrm{E}-03$ \\
3 & $1,3 \mathrm{E}-02$ & $9,1 \mathrm{E}-07$ & $7,3 \mathrm{E}-04$ & $2,0 \mathrm{E}-03$ & $9,7 \mathrm{E}-03$ & 48 & $8,5 \mathrm{E}-07$ & $2,4 \mathrm{E}-05$ & $1,1 \mathrm{E}-05$ & $1,9 \mathrm{E}-03$ & $1,4 \mathrm{E}-04$ \\
4 & $1,4 \mathrm{E}-03$ & $1,3 \mathrm{E}-03$ & $8,1 \mathrm{E}-05$ & $1,6 \mathrm{E}-03$ & $5,5 \mathrm{E}-04$ & 49 & $1,2 \mathrm{E}-03$ & $1,5 \mathrm{E}-04$ & $9,8 \mathrm{E}-04$ & $7,8 \mathrm{E}-03$ & $8,3 \mathrm{E}-05$ \\
$\ldots$ & $\ldots$ & $\ldots$ & $\ldots$ & $\ldots$ & $\ldots$ & $\ldots$ & $\ldots$ & $\ldots$ & $\ldots$ & $\ldots$ & $\ldots$ \\
42 & $2,6 \mathrm{E}-03$ & $8,1 \mathrm{E}-07$ & $1,4 \mathrm{E}-03$ & $1,1 \mathrm{E}-02$ & $5,1 \mathrm{E}-03$ & 87 & $5,3 \mathrm{E}-03$ & $2,1 \mathrm{E}-01$ & $7,7 \mathrm{E}-03$ & $8,8 \mathrm{E}-03$ & $1,2 \mathrm{E}-02$ \\
43 & $8,0 \mathrm{E}-08$ & $7,0 \mathrm{E}-04$ & $2,7 \mathrm{E}-04$ & $6,5 \mathrm{E}-03$ & $1,1 \mathrm{E}-02$ & 88 & $7,1 \mathrm{E}-05$ & $3,8 \mathrm{E}-04$ & $3,3 \mathrm{E}-03$ & $2,5 \mathrm{E}-02$ & $9,7 \mathrm{E}-03$ \\
44 & $4,4 \mathrm{E}-02$ & $1,8 \mathrm{E}-03$ & $3,4 \mathrm{E}-04$ & $5,1 \mathrm{E}-03$ & $8,2 \mathrm{E}-03$ & 89 & $2,6 \mathrm{E}-04$ & $1,0 \mathrm{E}-02$ & $3,4 \mathrm{E}-04$ & $3,3 \mathrm{E}-03$ & $2,9 \mathrm{E}-03$ \\
45 & $1,6 \mathrm{E}-02$ & $2,0 \mathrm{E}-06$ & $3,7 \mathrm{E}-03$ & $8,3 \mathrm{E}-03$ & $2,8 \mathrm{E}-02$ & Soma & 1 & 1 & 1 & 1 & 1 \\
\hline
\end{tabular}

Com as probabilidades de maximizar, foram computadas as probabilidades de interação entre as disciplinas. Os cálculos descritos na Etapa 3 da Seção 4 produziram as capacidades dos subconjuntos $\mathrm{S}\{\mathrm{C} 1, \ldots, \mathrm{Cn}\}$, apresentadas na Tabela 3. Para cada subconjunto, as linhas da tabela indicam as 500 simulações efetuadas.

Tabela 3 - Capacidades das simulações (Extrato)

\begin{tabular}{|c|c|c|c|c|c|c|c|c|c|c|c|}
\hline Sim. & \{\} & $\{1\}$ & $\{2\}$ & $\{3\}$ & $\{4\}$ & $\{5\}$ & $\{1,2\}$ & $\{1,3\}$ & $\{1,4\}$ & $\{1,5\}$ & $(2,3\}$ \\
\hline 1 & 0 & 0,4548 & 0,5283 & 0,3737 & 0,1757 & 0,3440 & 0,6285 & 0,6510 & 0,4815 & 0,4616 & 0,5765 \\
\hline 2 & 0 & 0,4556 & 0,5292 & 0,3743 & 0,1761 & 0,3446 & 0,6292 & 0,6514 & 0,4823 & 0,4624 & 0,5773 \\
\hline 3 & 0 & 0,4564 & 0,5302 & 0,3750 & 0,1764 & 0,3452 & 0,6299 & 0,6518 & 0,4830 & 0,4632 & 0,5782 \\
\hline$\cdots$ & $\ldots$ & $\ldots$ & $\cdots$ & $\cdots$ & $\cdots$ & $\ldots$ & ... & $\cdots$ & $\ldots$ & ... & $\cdots$ \\
\hline 498 & 0 & 0,8592 & 0,9981 & 0,7059 & 0,3320 & 0,6499 & 0,9985 & 0,8600 & 0,8593 & 0,8592 & 0,9983 \\
\hline 499 & 0 & 0,8600 & 0,9991 & 0,7066 & 0,3323 & 0,6505 & 0,9993 & 0,8604 & 0,8601 & 0,8600 & 0,9992 \\
\hline 500 & 0 & 0,8608 & 1,0000 & 0,7073 & 0,3326 & 0,6511 & 1,0000 & 0,8608 & 0,8608 & 0,8608 & 1 \\
\hline Sim. & $\{2,4\}$ & $\{2,5\}$ & $\{3,4\}$ & $\{3,5\}$ & $\{4,5\}$ & $\{1,2,3\}$ & $\{1,2,4\}$ & $\{1,2,5\}$ & $\{1,3,4\}$ & $\{1,3,5\}$ & $\{1,4,5\}$ \\
\hline 1 & 0,5508 & 0,5594 & 0,4328 & 0,7177 & 0,3447 & 0,6792 & 0,6601 & 0,6563 & 0,6778 & 0,7964 & 0,4884 \\
\hline 2 & 0,5517 & 0,5603 & 0,4333 & 0,7176 & 0,3453 & 0,6799 & 0,6608 & 0,6570 & 0,6781 & 0,7966 & 0,4891 \\
\hline 3 & 0,5526 & 0,5612 & 0,4339 & 0,7176 & 0,3459 & 0,6805 & 0,6615 & 0,6576 & 0,6785 & 0,7967 & 0,4899 \\
\hline$\cdots$ & $\cdots$ & $\ldots$ & $\cdots$ & $\cdots$ & $\cdots$ & $\cdots$ & $\cdots$ & $\cdots$ & $\ldots$ & $\cdots$ & $\cdots$ \\
\hline 498 & 0,9982 & 0,9982 & 0,7062 & 0,7073 & 0,6499 & 0,9987 & 0,9986 & 0,9986 & 0,8601 & 0,8606 & 0,8593 \\
\hline 499 & 0,9991 & 0,9991 & 0,7067 & 0,7073 & 0,6505 & 0,9994 & 0,9993 & 0,9993 & 0,8604 & 0,8607 & 0,8601 \\
\hline 500 & 1 & 1 & 0,7073 & 0,7073 & 0,6511 & 1 & 1 & 1 & 0,8608 & 0,8608 & 0,8608 \\
\hline Sim. & $\{2,3,4\}$ & $\{2,3,5\}$ & $\{2,4,5\}$ & $\{3,4,5\}$ & $\{1,2,3,4\}$ & $\{1,2,3,5\}$ & $\{1,2,4,5\}$ & $\{1,3,4,5\}$ & $\{2,3,4,5\}$ & $\{1,2,3,4,5\}$ & \\
\hline 1 & 0,5772 & 0,9205 & 0,5819 & 0,7184 & 0,7060 & 0,9993 & 0,6879 & 0,7972 & 0,9212 & 1 & \\
\hline 2 & 0,5781 & 0,9206 & 0,5828 & 0,7183 & 0,7066 & 0,9993 & 0,6886 & 0,7973 & 0,9214 & 1 & \\
\hline 3 & 0,5789 & 0,9208 & 0,5836 & 0,7183 & 0,7072 & 0,9993 & 0,6892 & 0,7974 & 0,9215 & 1 & \\
\hline$\cdots$ & $\cdots$ & $\cdots$ & $\cdots$ & $\cdots$ & $\cdots$ & $\cdots$ & $\cdots$ & $\cdots$ & $\ldots$ & $\cdots$ & \\
\hline 498 & 0,9983 & 0,9997 & 0,9983 & 0,7073 & 0,9988 & 0,9999 & 0,9987 & 0,8606 & 0,9996 & 1 & \\
\hline 499 & 0,9992 & 0,9998 & 0,9992 & 0,7073 & 0,9994 & 0,9999 & 0,9994 & 0,8607 & 0,9998 & 1 & \\
\hline 500 & 1 & 1 & 1 & 0,7073 & 1 & 1 & 1 & 0,8608 & 1 & 1 & \\
\hline
\end{tabular}


Com as capacidades disponíveis, foram efetuados os cálculos das integrais de Choquet, descritos na Etapa 4 da Seção 3. A Tabela 4 expõe um extrato dos resultados dos Alunos e o ranking dos cenários extremos.

Tabela 4 - Resultados das integrais de Choquet das simulações (Extrato)

\begin{tabular}{c|cccc|c|cccc}
\hline Aluno & Sim 1 & Rank & Sim 2 & Rank & & Sim 499 & Rank & Sim 500 & Rank \\
\hline 1 & $1,6 \mathrm{E}-02$ & 25 & $1,6 \mathrm{E}-02$ & 25 & $\ldots$ & $2,8 \mathrm{E}-02$ & 25 & $2,8 \mathrm{E}-02$ & 25 \\
2 & $4,0 \mathrm{E}-03$ & 57 & $4,0 \mathrm{E}-03$ & 57 & $\ldots$ & $7,1 \mathrm{E}-03$ & 56 & $7,1 \mathrm{E}-03$ & 56 \\
3 & $6,1 \mathrm{E}-03$ & 49 & $6,1 \mathrm{E}-03$ & 49 & $\ldots$ & $1,1 \mathrm{E}-02$ & 46 & $1,1 \mathrm{E}-02$ & 46 \\
4 & $1,0 \mathrm{E}-03$ & 78 & $1,0 \mathrm{E}-03$ & 78 & $\ldots$ & $1,5 \mathrm{E}-03$ & 80 & $1,5 \mathrm{E}-03$ & 80 \\
5 & $2,7 \mathrm{E}-02$ & 12 & $2,7 \mathrm{E}-02$ & 12 & $\ldots$ & $4,5 \mathrm{E}-02$ & 13 & $4,5 \mathrm{E}-02$ & 13 \\
6 & $7,8 \mathrm{E}-04$ & 83 & $7,8 \mathrm{E}-04$ & 83 & $\ldots$ & $1,1 \mathrm{E}-03$ & 83 & $1,1 \mathrm{E}-03$ & 83 \\
7 & $9,0 \mathrm{E}-04$ & 81 & $9,0 \mathrm{E}-04$ & 81 & $\ldots$ & $1,5 \mathrm{E}-03$ & 78 & $1,5 \mathrm{E}-03$ & 78 \\
8 & $1,3 \mathrm{E}-02$ & 32 & $1,3 \mathrm{E}-02$ & 32 & $\ldots$ & $1,5 \mathrm{E}-02$ & 38 & $1,5 \mathrm{E}-02$ & 38 \\
9 & $3,4 \mathrm{E}-03$ & 62 & $3,4 \mathrm{E}-03$ & 62 & $\ldots$ & $5,6 \mathrm{E}-03$ & 64 & $5,6 \mathrm{E}-03$ & 64 \\
10 & $9,2 \mathrm{E}-04$ & 80 & $9,2 \mathrm{E}-04$ & 80 & $\ldots$ & $1,5 \mathrm{E}-03$ & 79 & $1,5 \mathrm{E}-03$ & 79 \\
11 & $3,3 \mathrm{E}-03$ & 65 & $3,3 \mathrm{E}-03$ & 65 & $\ldots$ & $5,6 \mathrm{E}-03$ & 62 & $5,6 \mathrm{E}-03$ & 62 \\
12 & $8,7 \mathrm{E}-03$ & 39 & $8,7 \mathrm{E}-03$ & 39 & $\ldots$ & $1,5 \mathrm{E}-02$ & 39 & $1,5 \mathrm{E}-02$ & 39 \\
13 & $4,9 \mathrm{E}-03$ & 55 & $4,9 \mathrm{E}-03$ & 55 & $\ldots$ & $7,5 \mathrm{E}-03$ & 52 & $7,5 \mathrm{E}-03$ & 52 \\
14 & $7,8 \mathrm{E}-03$ & 43 & $7,8 \mathrm{E}-03$ & 43 & $\ldots$ & $1,4 \mathrm{E}-02$ & 41 & $1,4 \mathrm{E}-02$ & 41 \\
15 & $1,4 \mathrm{E}-02$ & 30 & $1,4 \mathrm{E}-02$ & 30 & $\ldots$ & $2,1 \mathrm{E}-02$ & 31 & $2,1 \mathrm{E}-02$ & 31 \\
16 & $1,4 \mathrm{E}-02$ & 31 & $1,4 \mathrm{E}-02$ & 31 & $\ldots$ & $2,6 \mathrm{E}-02$ & 27 & $2,6 \mathrm{E}-02$ & 27 \\
17 & $2,5 \mathrm{E}-03$ & 69 & $2,5 \mathrm{E}-03$ & 69 & $\ldots$ & $3,2 \mathrm{E}-03$ & 72 & $3,2 \mathrm{E}-03$ & 72 \\
18 & $2,2 \mathrm{E}-02$ & 19 & $2,2 \mathrm{E}-02$ & 19 & $\ldots$ & $3,4 \mathrm{E}-02$ & 21 & $3,4 \mathrm{E}-02$ & 21 \\
19 & $9,7 \mathrm{E}-04$ & 79 & $9,7 \mathrm{E}-04$ & 79 & $\ldots$ & $1,3 \mathrm{E}-03$ & 82 & $1,3 \mathrm{E}-03$ & 82 \\
20 & $1,0 \mathrm{E}-01$ & 3 & $1,1 \mathrm{E}-01$ & 3 & $\ldots$ & $1,8 \mathrm{E}-01$ & 2 & $1,8 \mathrm{E}-01$ & 2 \\
21 & $2,6 \mathrm{E}-02$ & 14 & $2,7 \mathrm{E}-02$ & 14 & $\ldots$ & $4,2 \mathrm{E}-02$ & 15 & $4,2 \mathrm{E}-02$ & 15 \\
22 & $3,3 \mathrm{E}-03$ & 64 & $3,3 \mathrm{E}-03$ & 64 & $\ldots$ & $6,0 \mathrm{E}-03$ & 60 & $6,0 \mathrm{E}-03$ & 60
\end{tabular}




\begin{tabular}{|c|c|c|c|c|c|c|c|c|c|}
\hline Aluno & $\operatorname{Sim} 1$ & Rank & $\operatorname{Sim} 2$ & Rank & & Sim 499 & Rank & $\operatorname{Sim} 500$ & Rank \\
\hline 23 & $1,9 \mathrm{E}-02$ & 23 & $1,9 \mathrm{E}-02$ & 23 & $\ldots$ & $2,9 \mathrm{E}-02$ & 24 & $2,9 \mathrm{E}-02$ & 24 \\
\hline 24 & $3,7 \mathrm{E}-02$ & 8 & $3,7 \mathrm{E}-02$ & 8 & $\ldots$ & $6,8 \mathrm{E}-02$ & 8 & $6,8 \mathrm{E}-02$ & 8 \\
\hline 25 & $2,7 \mathrm{E}-02$ & 11 & $2,7 \mathrm{E}-02$ & 11 & $\ldots$ & $5,1 \mathrm{E}-02$ & 9 & $5,2 \mathrm{E}-02$ & 9 \\
\hline 26 & $4,5 \mathrm{E}-03$ & 56 & $4,5 \mathrm{E}-03$ & 56 & $\ldots$ & $6,8 \mathrm{E}-03$ & 57 & $6,8 \mathrm{E}-03$ & 57 \\
\hline 27 & 4,9E-02 & 7 & $4,9 \mathrm{E}-02$ & 7 & $\ldots$ & $9,2 \mathrm{E}-02$ & 7 & $9,3 \mathrm{E}-02$ & 7 \\
\hline 28 & $7,6 \mathrm{E}-05$ & 89 & $7,6 \mathrm{E}-05$ & 89 & $\ldots$ & $1,3 \mathrm{E}-04$ & 89 & $1,3 \mathrm{E}-04$ & 89 \\
\hline 29 & $1,5 \mathrm{E}-02$ & 27 & $1,5 \mathrm{E}-02$ & 27 & $\ldots$ & $2,2 \mathrm{E}-02$ & 28 & $2,2 \mathrm{E}-02$ & 28 \\
\hline 30 & $3,2 \mathrm{E}-04$ & 87 & $3,2 \mathrm{E}-04$ & 87 & $\ldots$ & $5,2 \mathrm{E}-04$ & 88 & $5,2 \mathrm{E}-04$ & 88 \\
\hline 31 & $5,3 \mathrm{E}-03$ & 51 & $5,3 \mathrm{E}-03$ & 51 & $\ldots$ & $9,7 \mathrm{E}-03$ & 49 & $9,8 \mathrm{E}-03$ & 49 \\
\hline 32 & $3,6 \mathrm{E}-02$ & 9 & $3,6 \mathrm{E}-02$ & 9 & $\ldots$ & $4,8 \mathrm{E}-02$ & 12 & $4,8 \mathrm{E}-02$ & 12 \\
\hline 33 & $1,4 \mathrm{E}-03$ & 76 & $1,4 \mathrm{E}-03$ & 76 & $\ldots$ & $1,8 \mathrm{E}-03$ & 77 & $1,8 \mathrm{E}-03$ & 77 \\
\hline 34 & $5,0 \mathrm{E}-03$ & 53 & $5,0 \mathrm{E}-03$ & 53 & $\ldots$ & $7,2 \mathrm{E}-03$ & 55 & $7,2 \mathrm{E}-03$ & 55 \\
\hline 35 & $1,0 \mathrm{E}-02$ & 36 & $1,0 \mathrm{E}-02$ & 36 & $\ldots$ & $1,1 \mathrm{E}-02$ & 47 & $1,1 \mathrm{E}-02$ & 47 \\
\hline 36 & $1,6 \mathrm{E}-02$ & 26 & $1,6 \mathrm{E}-02$ & 26 & $\ldots$ & $1,9 \mathrm{E}-02$ & 34 & $1,9 \mathrm{E}-02$ & 34 \\
\hline 37 & $8,0 \mathrm{E}-02$ & 5 & $8,0 \mathrm{E}-02$ & 5 & $\ldots$ & $9,3 \mathrm{E}-02$ & 6 & $9,3 \mathrm{E}-02$ & 6 \\
\hline 38 & $2,4 \mathrm{E}-03$ & 70 & $2,4 \mathrm{E}-03$ & 70 & $\ldots$ & $3,3 \mathrm{E}-03$ & 70 & $3,3 \mathrm{E}-03$ & 70 \\
\hline 39 & $9,0 \mathrm{E}-03$ & 38 & $9,0 \mathrm{E}-03$ & 38 & $\ldots$ & $1,6 \mathrm{E}-02$ & 37 & $1,6 \mathrm{E}-02$ & 37 \\
\hline 40 & $3,4 \mathrm{E}-03$ & 63 & $3,4 \mathrm{E}-03$ & 63 & $\ldots$ & $5,4 \mathrm{E}-03$ & 66 & $5,4 \mathrm{E}-03$ & 66 \\
\hline 41 & $1,2 \mathrm{E}-01$ & 1 & $1,2 \mathrm{E}-01$ & 1 & $\ldots$ & $1,3 \mathrm{E}-01$ & 4 & $1,3 \mathrm{E}-01$ & 4 \\
\hline 42 & $3,6 \mathrm{E}-03$ & 61 & $3,6 \mathrm{E}-03$ & 61 & $\ldots$ & $5,8 \mathrm{E}-03$ & 61 & $5,8 \mathrm{E}-03$ & 61 \\
\hline 43 & $4,0 \mathrm{E}-03$ & 58 & $4,0 \mathrm{E}-03$ & 58 & $\ldots$ & $7,3 \mathrm{E}-03$ & 54 & $7,3 \mathrm{E}-03$ & 54 \\
\hline 44 & $2,1 \mathrm{E}-02$ & 22 & $2,1 \mathrm{E}-02$ & 22 & $\ldots$ & $3,8 \mathrm{E}-02$ & 18 & $3,8 \mathrm{E}-02$ & 18 \\
\hline 45 & $1,3 \mathrm{E}-02$ & 33 & $1,3 \mathrm{E}-02$ & 33 & $\ldots$ & $2,2 \mathrm{E}-02$ & 29 & $2,2 \mathrm{E}-02$ & 29 \\
\hline 46 & $2,4 \mathrm{E}-02$ & 16 & $2,4 \mathrm{E}-02$ & 16 & $\ldots$ & $3,4 \mathrm{E}-02$ & 20 & $3,4 \mathrm{E}-02$ & 20 \\
\hline 47 & $3,2 \mathrm{E}-03$ & 66 & $3,2 \mathrm{E}-03$ & 66 & $\ldots$ & $4,9 \mathrm{E}-03$ & 67 & $4,9 \mathrm{E}-03$ & 67 \\
\hline 48 & $3,7 \mathrm{E}-04$ & 86 & $3,7 \mathrm{E}-04$ & 86 & $\ldots$ & $6,8 \mathrm{E}-04$ & 86 & $6,8 \mathrm{E}-04$ & 86 \\
\hline 49 & $2,0 \mathrm{E}-03$ & 73 & $2,0 \mathrm{E}-03$ & 73 & $\ldots$ & $3,3 \mathrm{E}-03$ & 71 & $3,3 \mathrm{E}-03$ & 71 \\
\hline 50 & $4,8 \mathrm{E}-04$ & 85 & $4,8 \mathrm{E}-04$ & 85 & $\ldots$ & $8,4 \mathrm{E}-04$ & 85 & $8,4 \mathrm{E}-04$ & 85 \\
\hline 51 & $7,4 \mathrm{E}-03$ & 44 & $7,4 \mathrm{E}-03$ & 44 & $\ldots$. & $1,4 \mathrm{E}-02$ & 40 & $1,4 \mathrm{E}-02$ & 40 \\
\hline 52 & $6,5 \mathrm{E}-03$ & 46 & $6,5 \mathrm{E}-03$ & 46 & $\ldots$ & $1,1 \mathrm{E}-02$ & 45 & $1,1 \mathrm{E}-02$ & 45 \\
\hline 53 & $1,7 \mathrm{E}-02$ & 24 & $1,7 \mathrm{E}-02$ & 24 & $\ldots$ & $2,9 \mathrm{E}-02$ & 23 & $2,9 \mathrm{E}-02$ & 23 \\
\hline 54 & $2,4 \mathrm{E}-02$ & 18 & $2,4 \mathrm{E}-02$ & 18 & $\ldots$ & $3,9 \mathrm{E}-02$ & 16 & $3,9 \mathrm{E}-02$ & 16 \\
\hline 55 & $6,8 \mathrm{E}-02$ & 6 & $6,8 \mathrm{E}-02$ & 6 & $\ldots$ & $1,1 \mathrm{E}-01$ & 5 & $1,1 \mathrm{E}-01$ & 5 \\
\hline 56 & $5,0 \mathrm{E}-03$ & 54 & $5,0 \mathrm{E}-03$ & 54 & $\ldots$ & $9,4 \mathrm{E}-03$ & 50 & $9,4 \mathrm{E}-03$ & 50 \\
\hline 57 & $3,2 \mathrm{E}-02$ & 10 & $3,2 \mathrm{E}-02$ & 10 & $\ldots$ & $4,9 \mathrm{E}-02$ & 11 & $4,9 \mathrm{E}-02$ & 11 \\
\hline 58 & $3,8 \mathrm{E}-03$ & 60 & $3,8 \mathrm{E}-03$ & 60 & $\ldots$ & $5,6 \mathrm{E}-03$ & 63 & $5,6 \mathrm{E}-03$ & 63 \\
\hline 59 & $5,1 \mathrm{E}-03$ & 52 & $5,1 \mathrm{E}-03$ & 52 & $\ldots$ & $9,1 \mathrm{E}-03$ & 51 & $9,1 \mathrm{E}-03$ & 51 \\
\hline 60 & $2,7 \mathrm{E}-02$ & 13 & $2,7 \mathrm{E}-02$ & 13 & $\ldots$ & $4,9 \mathrm{E}-02$ & 10 & $4,9 \mathrm{E}-02$ & 10 \\
\hline 61 & $6,1 \mathrm{E}-03$ & 48 & $6,1 \mathrm{E}-03$ & 48 & $\ldots$ & $6,8 \mathrm{E}-03$ & 58 & $6,8 \mathrm{E}-03$ & 58 \\
\hline 62 & $1,4 \mathrm{E}-03$ & 75 & $1,4 \mathrm{E}-03$ & 75 & $\ldots$ & $2,5 \mathrm{E}-03$ & 75 & $2,5 \mathrm{E}-03$ & 75 \\
\hline 63 & $1,3 \mathrm{E}-03$ & 77 & $1,3 \mathrm{E}-03$ & 77 & $\ldots$ & $2,1 \mathrm{E}-03$ & 76 & $2,1 \mathrm{E}-03$ & 76 \\
\hline 64 & $6,3 \mathrm{E}-04$ & 84 & $6,3 \mathrm{E}-04$ & 84 & $\ldots$ & $1,1 \mathrm{E}-03$ & 84 & $1,1 \mathrm{E}-03$ & 84 \\
\hline 65 & $2,7 \mathrm{E}-03$ & 68 & $2,7 \mathrm{E}-03$ & 68 & $\ldots$ & $3,0 \mathrm{E}-03$ & 73 & $3,0 \mathrm{E}-03$ & 73 \\
\hline 66 & $6,4 \mathrm{E}-03$ & 47 & $6,4 \mathrm{E}-03$ & 47 & $\ldots$ & $7,5 \mathrm{E}-03$ & 53 & $7,5 \mathrm{E}-03$ & 53 \\
\hline 67 & $8,0 \mathrm{E}-04$ & 82 & $8,0 \mathrm{E}-04$ & 82 & $\ldots$ & $1,3 \mathrm{E}-03$ & 81 & $1,3 \mathrm{E}-03$ & 81 \\
\hline 68 & $9,7 \mathrm{E}-02$ & 4 & $9,7 \mathrm{E}-02$ & 4 & $\ldots$ & $1,5 \mathrm{E}-01$ & 3 & $1,5 \mathrm{E}-01$ & 3 \\
\hline 69 & $2,4 \mathrm{E}-02$ & 17 & $2,4 \mathrm{E}-02$ & 17 & $\ldots$ & $3,9 \mathrm{E}-02$ & 17 & $3,9 \mathrm{E}-02$ & 17 \\
\hline 70 & $2,3 \mathrm{E}-03$ & 71 & $2,3 \mathrm{E}-03$ & 71 & $\ldots$ & $3,8 \mathrm{E}-03$ & 68 & $3,8 \mathrm{E}-03$ & 68 \\
\hline 71 & $1,3 \mathrm{E}-02$ & 34 & $1,3 \mathrm{E}-02$ & 34 & $\ldots$ & $2,1 \mathrm{E}-02$ & 32 & $2,1 \mathrm{E}-02$ & 32 \\
\hline 72 & $1,8 \mathrm{E}-03$ & 74 & $1,8 \mathrm{E}-03$ & 74 & $\ldots$ & $2,8 \mathrm{E}-03$ & 74 & $2,8 \mathrm{E}-03$ & 74 \\
\hline 73 & $8,4 \mathrm{E}-03$ & 41 & $8,4 \mathrm{E}-03$ & 41 & $\ldots$ & $1,2 \mathrm{E}-02$ & 43 & $1,2 \mathrm{E}-02$ & 43 \\
\hline 74 & $1,5 \mathrm{E}-02$ & 28 & $1,5 \mathrm{E}-02$ & 28 & $\ldots$ & $2,0 \mathrm{E}-02$ & 33 & $2,0 \mathrm{E}-02$ & 33 \\
\hline 75 & $9,5 \mathrm{E}-03$ & 37 & $9,5 \mathrm{E}-03$ & 37 & $\ldots$ & $1,7 \mathrm{E}-02$ & 35 & $1,7 \mathrm{E}-02$ & 35 \\
\hline 76 & $2,9 \mathrm{E}-04$ & 88 & $2,9 \mathrm{E}-04$ & 88 & $\ldots$ & $5,3 \mathrm{E}-04$ & 87 & $5,3 \mathrm{E}-04$ & 87 \\
\hline 77 & $7,9 \mathrm{E}-03$ & 42 & 7,9E-03 & 42 & $\ldots$ & $1,3 \mathrm{E}-02$ & 42 & $1,3 \mathrm{E}-02$ & 42 \\
\hline 78 & $3,9 \mathrm{E}-03$ & 59 & $3,9 \mathrm{E}-03$ & 59 & $\ldots$ & $6,7 \mathrm{E}-03$ & 59 & $6,8 \mathrm{E}-03$ & 59 \\
\hline 79 & $2,1 \mathrm{E}-02$ & 21 & $2,1 \mathrm{E}-02$ & 21 & $\ldots$ & $2,9 \mathrm{E}-02$ & 22 & $3,0 \mathrm{E}-02$ & 22 \\
\hline 80 & $3,1 \mathrm{E}-03$ & 67 & $3,1 \mathrm{E}-03$ & 67 & $\ldots$ & $5,5 \mathrm{E}-03$ & 65 & $5,5 \mathrm{E}-03$ & 65 \\
\hline 81 & $1,4 \mathrm{E}-02$ & 29 & $1,4 \mathrm{E}-02$ & 29 & $\ldots$ & $2,7 \mathrm{E}-02$ & 26 & $2,7 \mathrm{E}-02$ & 26 \\
\hline
\end{tabular}




\begin{tabular}{c|cccc|c|cccc}
\hline Aluno & Sim 1 & Rank & $\operatorname{Sim} 2$ & Rank & & Sim 499 & Rank & Sim 500 & Rank \\
\hline 82 & $1,1 \mathrm{E}-02$ & 35 & $1,1 \mathrm{E}-02$ & 35 & $\ldots$ & $2,1 \mathrm{E}-02$ & 30 & $2,1 \mathrm{E}-02$ & 30 \\
83 & $8,5 \mathrm{E}-03$ & 40 & $8,5 \mathrm{E}-03$ & 40 & $\ldots$ & $1,6 \mathrm{E}-02$ & 36 & $1,6 \mathrm{E}-02$ & 36 \\
84 & $2,2 \mathrm{E}-03$ & 72 & $2,2 \mathrm{E}-03$ & 72 & $\ldots$ & $3,7 \mathrm{E}-03$ & 69 & $3,7 \mathrm{E}-03$ & 69 \\
85 & $2,1 \mathrm{E}-02$ & 20 & $2,2 \mathrm{E}-02$ & 20 & $\ldots$ & $3,6 \mathrm{E}-02$ & 19 & $3,6 \mathrm{E}-02$ & 19 \\
86 & $2,5 \mathrm{E}-02$ & 15 & $2,5 \mathrm{E}-02$ & 15 & $\ldots$ & $4,4 \mathrm{E}-02$ & 14 & $4,4 \mathrm{E}-02$ & 14 \\
87 & $1,1 \mathrm{E}-01$ & 2 & $1,1 \mathrm{E}-01$ & 2 & $\ldots$ & $2,1 \mathrm{E}-01$ & 1 & $2,1 \mathrm{E}-01$ & 1 \\
88 & $7,3 \mathrm{E}-03$ & 45 & $7,3 \mathrm{E}-03$ & 45 & $\ldots$ & $1,2 \mathrm{E}-02$ & 44 & $1,2 \mathrm{E}-02$ & 44 \\
89 & $5,8 \mathrm{E}-03$ & 50 & $5,8 \mathrm{E}-03$ & 50 & $\ldots$ & $1,0 \mathrm{E}-02$ & 48 & $1,0 \mathrm{E}-02$ & 48 \\
\hline
\end{tabular}

Os valores das integrais de Choquet, referentes aos quatro Alunos melhor ranqueados, foram transportados ao gráfico da Fig. 2. O eixo vertical destacado no gráfico indica uma "fotografia" da interação dos critérios, definida pelo escore progressista-otimista do CPP-Choquet.

Esse instante indica certa cautela em relação ao desempenho do Aluno 41, dada a instabilidade de ordem aos diferentes cenários, variando do $1^{\circ}$ ao $4^{\circ}$ lugar. Ele se mantém em primeiro lugar em somente 39 das 500 simulações (i.e. 7,8\%), que equivale ao contexto de aditividade dos critérios, em que os critérios interagem de maneira disjunta (i.e. interações similares à Fig. 1(a)).

Considerando que as disciplinas apresentam conteúdos em comum, no sentido da abordagem de assuntos relacionados ao raciocínio matemático (i.e. Álgebra e Física), conforme descrito por [Kojadinovic 2008], é lícito admitir que a permanência do Aluno 41 em primeiro lugar pode ser menos realista quando comparada a colocações mais intermediárias. É importante, ainda, ressaltar que o sentido dos cenários (i.e. para a direita ou esquerda) não indica, em geral, evolução do desempenho, apenas a variação de ranking com a mudança na interação entre os critérios. 0 Aluno 87, na maior parcela de cenários, se comporta com o melhor desempenho entre os 89 alunos, seguido dos Alunos 20 e 68. 


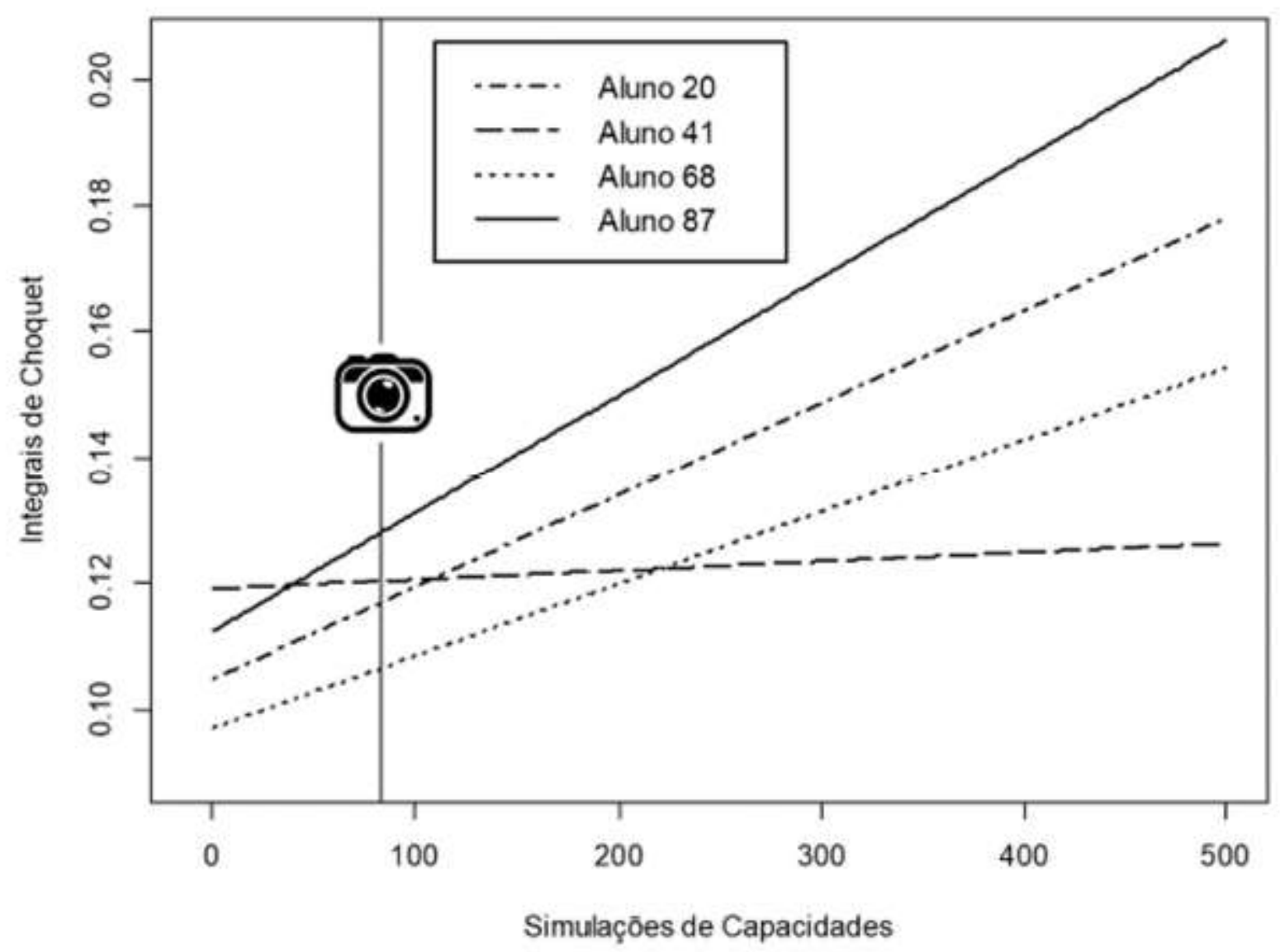

Figura 2 - Resultados dos quatro Alunos com melhores escores da integral de Choquet

Com as capacidades disponíveis, também foram efetuados os cálculos dos índices de Shapley, descritos na Etapa 5 da Seção 3. A Tabela 5 apresenta um extrato dos resultados desses índices dos critérios. Os resultados demonstraram maior estabilidade nos índices de Shapley, sendo destacados os cenários intermediários em que se verificaram inversões de ordem dos pesos dos critérios. A disciplina "Computação" , de maneira geral, se comportou como o critério de maior importância no problema. Os pesos, em cada cenário, respeitam os axiomas de capacidades. 
Tabela 5 - Resultados dos índices de Shapley das simulações (Extrato)

\begin{tabular}{c|cc|cc|cc|cc|cc}
\hline Sim & Inglês & Rank & Computação & Rank & Álgebra & Rank & Análise & Rank & Fisica & Rank \\
\hline 1 & 0,192258475 & 4 & 0,259114896 & 2 & 0,277512119 & 1 & 0,047377260 & 5 & 0,223737250 & 3 \\
2 & 0,192357419 & 4 & 0,259358795 & 2 & 0,277286381 & 1 & 0,047415642 & 5 & 0,223581762 & 3 \\
3 & 0,192456363 & 4 & 0,259602694 & 2 & 0,277060644 & 1 & 0,047454024 & 5 & 0,223426275 & 3 \\
$\ldots$ & $\ldots$ & $\ldots$ & $\ldots$ & $\ldots$ & $\ldots$ & $\ldots$ & $\ldots$ & $\ldots$ & $\ldots$ & $\ldots$ \\
130 & 0,205022273 & 3 & 0,290577843 & 1 & 0,248391940 & 2 & 0,052328545 & 5 & 0,203679399 & 4 \\
131 & 0,205121217 & 3 & 0,290821742 & 1 & 0,248166202 & 2 & 0,052366927 & 5 & 0,203523912 & 4 \\
132 & 0,205220161 & 3 & 0,291065640 & 1 & 0,247940464 & 2 & 0,052405309 & 5 & 0,203368425 & 4 \\
$\ldots$ & $\ldots$ & $\ldots$ & $\ldots$ & $\ldots$ & $\ldots$ & $\ldots$ & $\ldots$ & $\ldots$ & $\ldots$ & $\ldots$ \\
498 & 0,241433729 & 2 & 0,380332605 & 1 & 0,16532042 & 3 & 0,066453141 & 5 & 0,146460105 & 4 \\
499 & 0,241532673 & 2 & 0,380576504 & 1 & 0,165094682 & 3 & 0,066491523 & 5 & 0,146304618 & 4 \\
500 & 0,241631617 & 2 & 0,380820403 & 1 & 0,164868944 & 3 & 0,066529905 & 5 & 0,146149130 & 4 \\
\hline
\end{tabular}

\section{CONSIDERAÇÕES FINAIS}

Este artigo teve por finalidade apresentar uma proposta de análise de sensibilidade ao CPPChoquet.

Esse método se destina à solução de problemas MCDA, que requeiram a ordenação de alternativas, com base na interação de critérios. O método calcula as capacidades de subconjuntos de critérios de avaliações por probabilidades do escore progressista-otimista do CPP. Essas interações refletem, de fato, um estado de relacionamento entre os critérios. A proposta ampliou a quantidade desses estados, de forma a simular uma quantidade de capacidades que permitisse avaliar o comportamento das alternativas em amplo espectro.

Algumas futuras pesquisas podem decorrer desta. O cálculo das capacidades, apresentado na Etapa 3, pode ser correlacionado à entropia dos subconjuntos de critérios, pois as probabilidades são proporcionais aos valores máximos dos subconjuntos. Isto, de certa forma, é acompanhado pelo valor de entropia, utilizado por [Kojadinovic 2008], na referência-base desta pesquisa. Assim, estima-se uma elevada correlação entre os resultados do CPP-Choquet e de capacidades por entropia, o que pode estimular nova pesquisa. Outra possibilidade seria explorar o cálculo da importância dos critérios com outros índices, além do de Shapley, como os de Penrose-Banzhaf [Sant'Anna 2015a, p. 15]. 


\section{REFERÊNCIAS}

Choquet, G. (1953). Theory of capacities. In Annales de l’ institut Fourier (Vol. 5, pp. 131-295). Institut Fourier.

Grabisch, M., Kojadinovic, I., Nantes, S. P., \& Meyer, P. (2006). Using the Kappalab R package for capacity identification in Choquet integral based MAUT. In 11th International Conference on Information Processing and Management of Uncertainty in Knowledge-based Systems (pp. 17021709).

Grabisch, M., \& Labreuche, C. (2010). A decade of application of the Choquet and Sugeno integrals in multi-criteria decision aid. Annals of Operations Research, 175(1), 247-290.

Grabisch, M., \& Roubens, M. (2000). Application of the Choquet integral in multicriteria decision making. Fuzzy Measures and Integrals-Theory and Applications, 348-374.

Kojadinovic, I. (2008). Unsupervized Aggregation of Commensurate Correlated Attributes by Means of the Choquet Integral and Entropy Functionals. International Journal of Intelligent Systems, 23(1), 128154.

Merad, M., Dechy, N., Serir, L., Grabisch, M., \& Marcel, F. (2013). Using a multi-criteria decision aid methodology to implement sustainable development principles within an organization. European Journal of Operational Research, 224(3), 603-613.

Pomerol, J.-C., \& Barba-Romero, S. (2012). Multicriterion decision in management: principles and practice. New York: Springer.

R-Core-Team. (2016). R: A language and environment for statistical computing. Http://www. RProject. Org. Vienna, Austria.

Ross, S. (2009). Probabilidade: um curso moderno com aplicaçoes (8th ed.). São Paulo: Bookman Editora.

Sant'Anna, A. P. (2014a). Alternativas probabilísticas para a composição do Indicador de Desenvolvimento Humano. In Congresso Nacional de Excelência em Gestão - X CNEG (pp. 1-16).

Sant' Anna, A. P. (2014b). Aplicação do CPP-Tri à classificação dos países pelos critérios do IDH. In Encontro Nacional de Engenharia de Produção - XXXVI ENEGEP (pp. 1-15). Curitiba.

Sant'Anna, A. P. (2015a). Probabilistic Composition of Preferences, Theory and Applications.New York: Springer.

Sant'Anna, A. P. (2015b). Probabilistic Human Development Indices. Brazilian Journal of Operations \& Production Management, 12(1), 136-146.

Sant'Anna, A. P., Gomes, L. F. A. M., Costa, F. F. da, Rangel, L. A. D., Faria, M. J. da S., Ferreira, R. G., '. Senna, V. de. (2012). Análise multicritério baseada em probabilidades de preferência. In V. F. de Oliveira, V. Cavenaghi, \& F. S. Másculo (Eds.), Tópicos emergentes e desafios metodológicos em 
Engenharia de Produção: casos, experiências e proposições - Volume V (p. 258). Rio de Janeiro: ABEPRO.

Shapley, L. S. (1953). A Value for n-Person Games. In Contributions to the Theory of Games, vol II, by H.W. Kuhn and A.W. Tucker (Eds) Annals of Mathematical Studies (Vol. 28, pp. 307-317). Princeton University Press.

Šipošová, A., Šipeky, L., Rindone, F., Greco, S., \& Mesiar, R. (2017). Super- and subadditive constructions of aggregation functions. Information Fusion, 34, 49-54.

Souza, R. G. de, Clímaco, J. C. N., Sant' Anna, A. P., Rocha, T. B., Valle, R. de A. B. do, \& Quelhas, O. L. G. (2016). Sustainability assessment and prioritisation of e-waste management options in Brazil. Waste Management. 


\section{Capítulo 2}

doi) $10.37423 / 210303671$

\section{DESIGN E INOVAÇÃO NO APROVEITAMENTO SUSTENTÁVEL DE RESÍDUOS EM EMPRESAS DE PAPELÃO: REAPROVEITAMENTO DE APARAS COM MELHOR VALOR AGREGADO.}

JAIR MELLO JAREK

Universidade Federal do Paraná - Programa de Pós-graduação em Design - UFPR

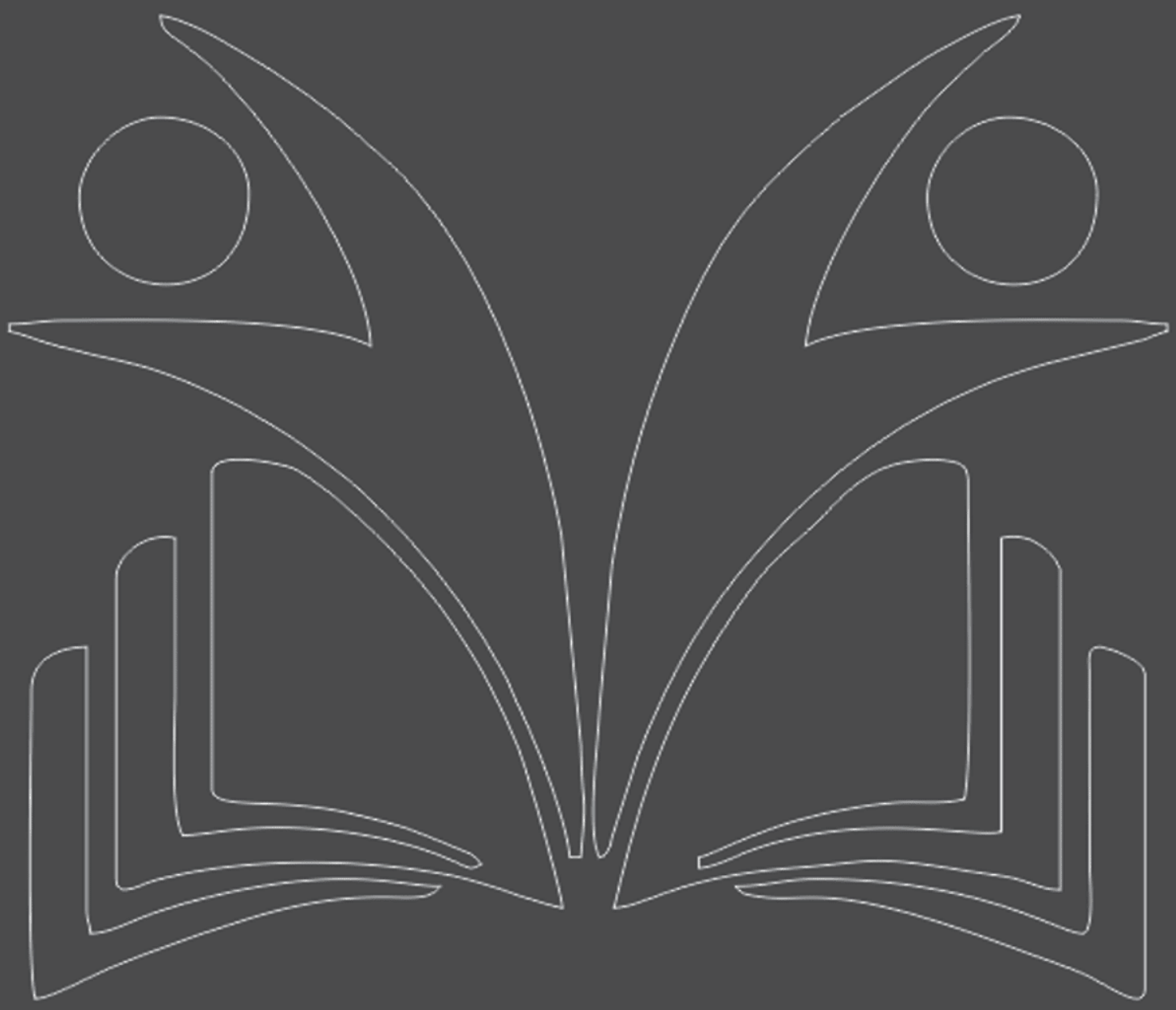


Resumo: Este trabalho mostra os experimentos realizados com resíduos resultantes da fabricação de caixas de papelão ondulado. Esses resíduos são chamados aparas e são geralmente vendidos pelas empresas de cartonagem para serem reciclados por terceiros por uma fração do valor da matéria prima original, o papelão. Por meio de ensaios de compressão com moldes de alumínio baseados em tecnologia com dois materiais formando um compósito, procurou-se analisar as características (resistência a compressão e flexibilidade) e o comportamento e qualidades do material como um novo produto com maior valor agregado e orientado ao uso como acessório em embalagens de transporte realçando o isolamento à choques no transporte, modulação para proteger diferentes tamanhos de produtos, estabilidade dentro da caixa de transporte, etc.

Palavras-chave: Sustentabilidade, Embalagens de Transporte, Resíduos de Papelão, Compósitos. 


\section{INTRODUÇÃO}

A melhoria na relação das empresas com o meio ambiente pode otimizar a produtividade dos recursos utilizados, com benefícios diretos na economia de matéria-prima e insumos resultantes do processamento mais eficiente na substituição, reutilização ou reciclagem, menor consumo de água, redução do custo de atividades envolvidas nas descargas ou manuseio, transporte e descarte de resíduos, (COELHO et al., 2011).

A proposta desta pesquisa de aproveitamento de resíduos de embalagens de papelão é uma continuação do estudo de iniciação científica conduzido pelo Departamento de PPDesign - UFPR. Este artigo descreve o experimento de moldagem por compressão de aparas recolhidas das sobras de fabricação de embalagens de papelão ondulado (PO). A proposta adiciona um novo processo e analisa as características e qualidades apresentadas pelas aparas no uso em embalagens de transporte. $\mathrm{Na}$ pesquisa foram identificados dois tipos de empresas do setor de embalagens (Fabricantes de Papelão Ondulado e Empresas de Cartonagem) com material residual e volumes contínuos em relação ao ciclo de reciclagem, Figura 1;

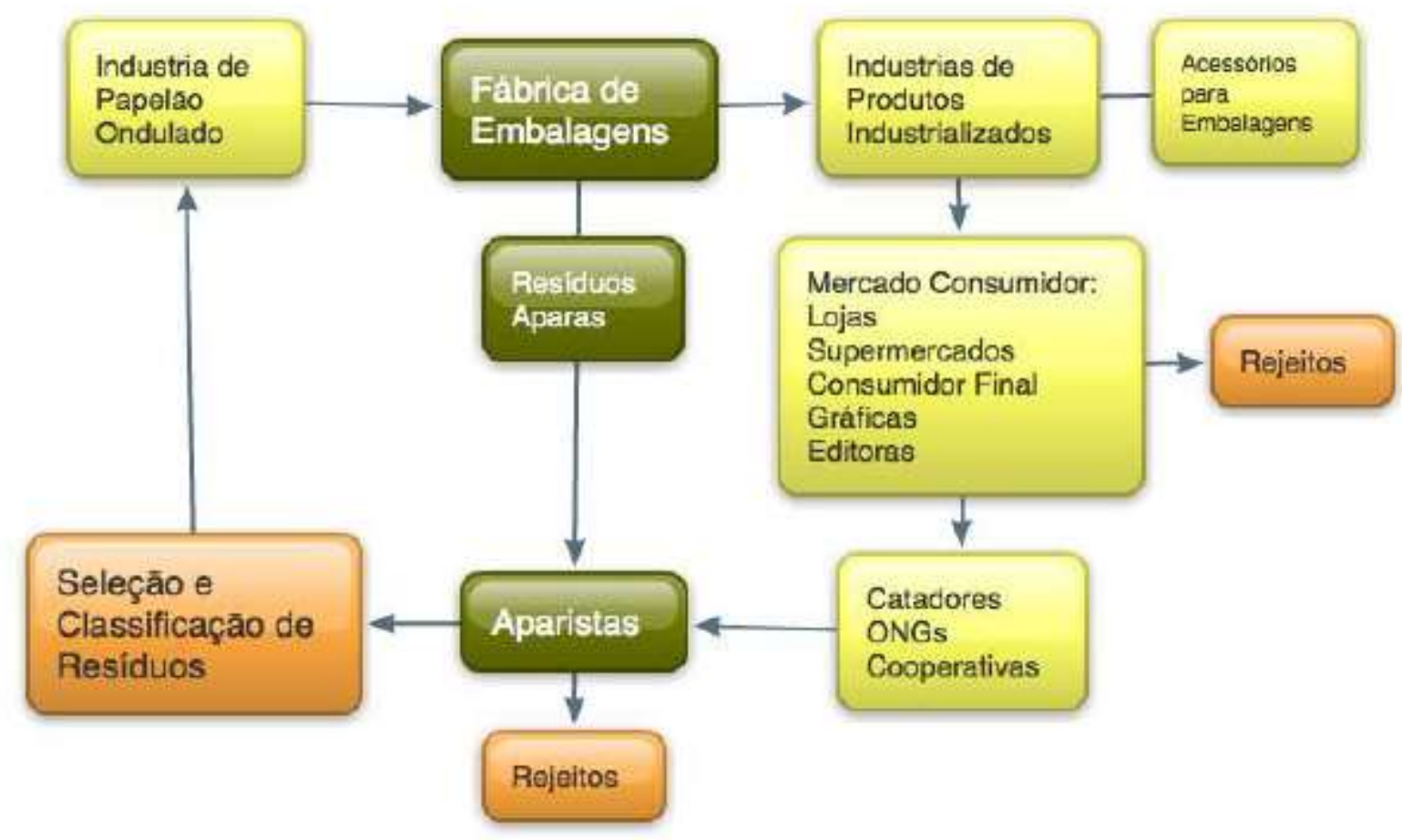

Figura 1 - reciclagem de aparas de papelão. Fonte: modificado pelo autor.

1. Indústrias fabricantes de PO, apresentam um ciclo fechado, fabricam celulose, papel Kraft, chapas de papelão ondulado, e embalagem de caixas rígidas. Na reciclagem as aparas são transformadas em 
papelão reciclado pela própria empresa, utilizado na confecção do miolo (onda) do papelão ondulado, também agregam cerca de $20 \%$ de PO reciclado coletado externamente se pré-selecionado.

2. Fábricas de embalagens ou empresas de cartonagem, ciclo aberto: fabricam caixas padrão produzidos em máquinas de corte e vinco com ângulos ortogonais que geram "aparas" de chapas pré-cortadas de PO, recicladas através de terceiros, empresas chamadas aparistas que compram as aparas por $12 \%$ do valor por quilo da matéria prima utilizada original. A empresa de cartonagem Embrart, usada como um recorte dos dados do setor produz cerca de 3,5\% de aparas de uma produção mensal aproximada de 600 toneladas de chapas de papelão ondulado (PO), em embalagens de transporte. Após visitas à empresa Embrart, selecionou-se aparas resultantes da fabricação das caixas de PO da linha "normal" para uso nos ensaios por serem as mais homogêneas em relação ao tamanho e frequência na produção, Figura 1.

Figura 2 - aparas de papelão ondulado. Fonte: elaborado pelo autor.

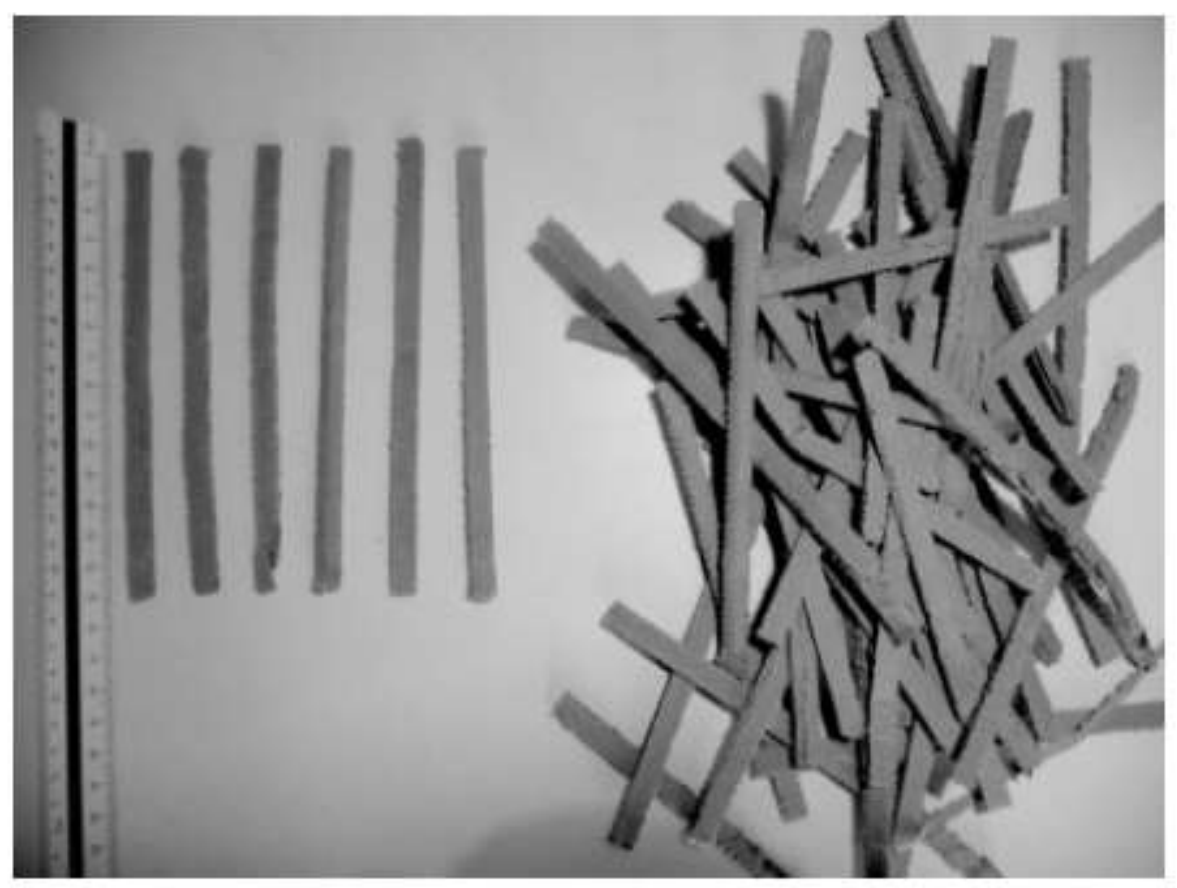

O objetivo do estudo foi propor o uso de uma tecnologia de baixa complexidade baseada em compósitos de fibras e papel com a compressão das aparas com o mesmo adesivo (amido de mandioca), utilizado na fabricação do PO e facilmente reciclável junto com o material das caixas. Nos ensaios, para facilitar o manuseio, foi utilizado adesivo PVA a base de água, (RAZERA, 2009). 
No processo, as aparas, material que se comporta como reforço no compósito, as fibras colocadas em configuração aleatória, foram primeiramente impregnadas com adesivo, a matriz contínua, que envolve o reforço. Figura 3.
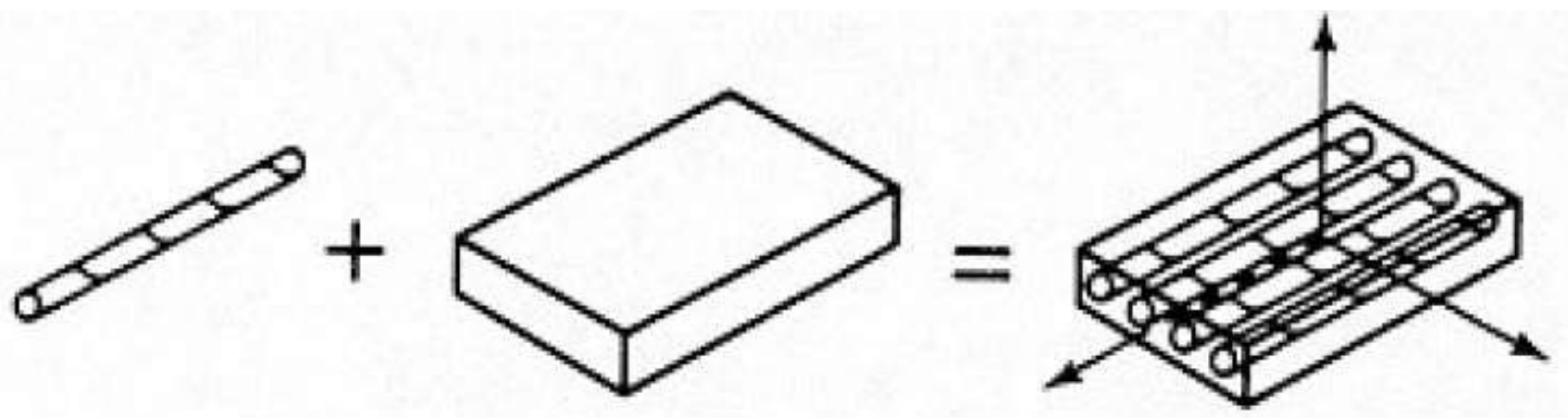

Figura 3 - configuração do compósito. Aparas como reforço + adesivo homogeneamente distribuído = compósito a ser moldado. Fonte: alterada pelo autor.

Após o material ser preparado os ensaios foram prensados a quente em moldes de alumínio fundido, Figura 3.

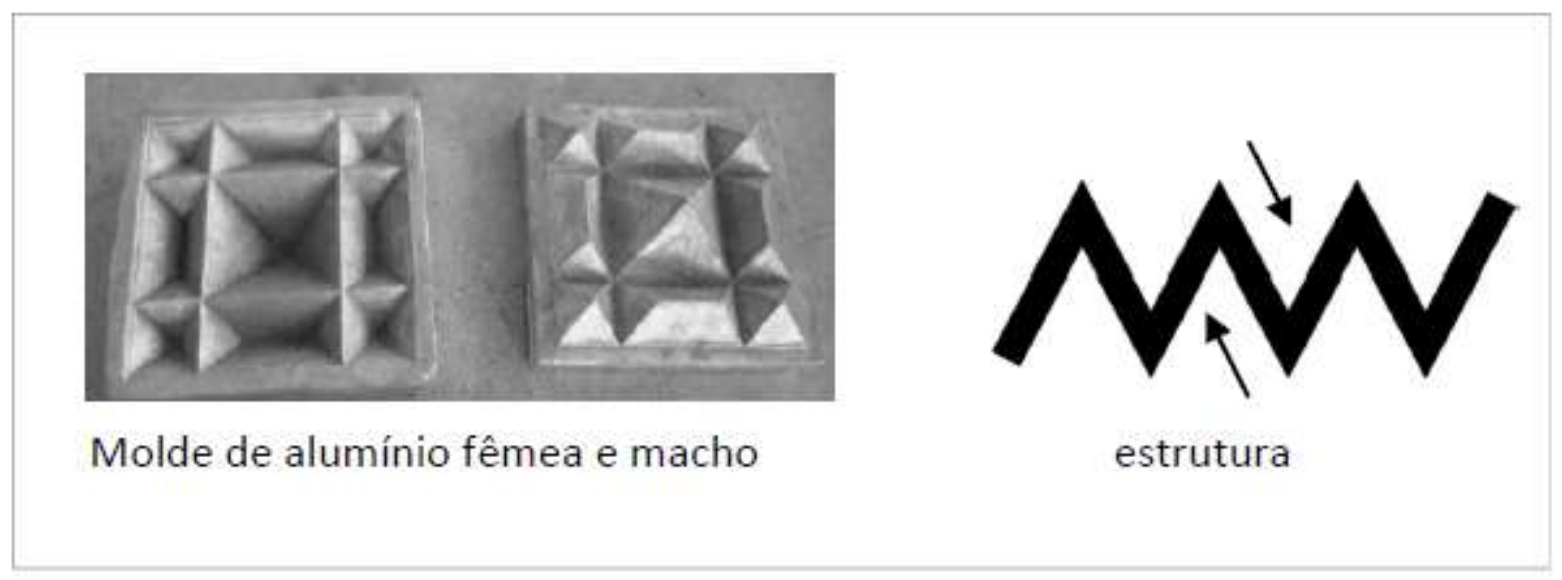

Figura 3 - molde de alumío para compressão das aparas. Fonte: elaborado pelo autor

O resultado obtido com o colchão de aparas após a prensagem evidenciou a estrutura tridimensional do design do molde definidas como áreas de acolchoamento.

O molde foi preparado a partir de um módulo de malha com design geométrico para que pudesse ser reproduzido em escala e quantidades posteriormente. Esse molde foi finalizado em alumínio para resistir a compressão e temperatura de secagem. 
As linhas de compressão orientaram a flexão das aparas. A malha quadrada manteve a flexibilidade procurada. O ângulo das figuras foi determinado pela maior possibilidade de dobras, desmoldagem e distribuição das tensões durante o transporte.

Essas aparas foram então impregnadas com adesivo termoplástico, semelhante ao adesivo utilizado originalmente na produção das chapas de papelão, e prensadas contra o molde de alumínio medindo $14 \times 14 \mathrm{~cm}$ representando um módulo teste, com pressão controlada variando de 3 a 4 toneladas pela área do molde. $\mathrm{O}$ uso de estufa com temperatura de 80 graus ajudou a acelerar a secagem e manter o material na espessura desejada, Figura 4.
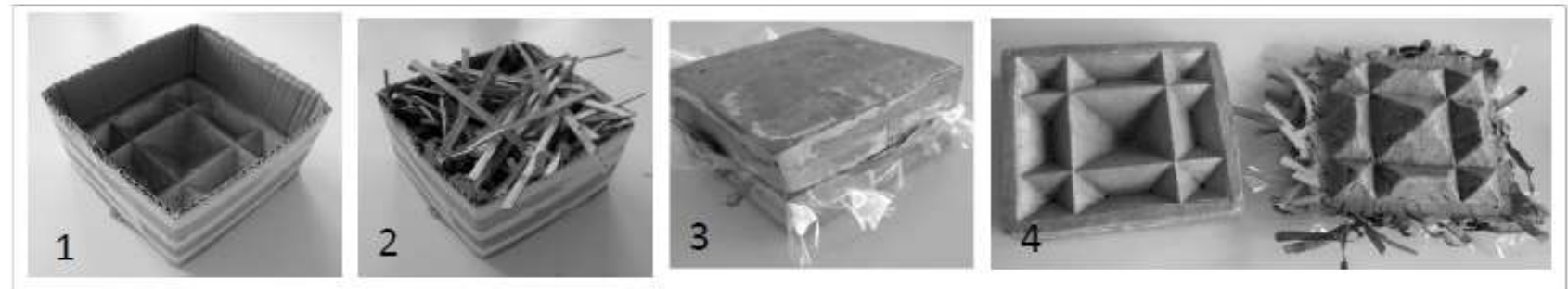

Figura 4 - procedimentos dos ensaios: 1 molde alumínio com caixa formadora, 2 aparas impregnadas de adesivo sobre molde fêmea, 3 molde macho e fêmea com desmoldante de papel celofane, 4 desmoldagem. Fonte: elaborado pelo autor

\section{DESENVOLVIMENTO}

A pesquisa direcionou as características e propriedades buscadas nas funções básicas de embalagens de transporte vendidas pela empresa: leveza e resistência no transporte, estocagem e proteção no manuseio dos produtos. As variáveis com suas grandezas trabalhadas no compósito foram: a porcentagem de adesivo $(\mathrm{ml})$; a pressão utilizada na compressão das aparas no molde de alumínio (kg $/ \mathrm{cm} 2$ ); quantidade e densidade das aparas (gr); a temperatura de secagem ( ${ }^{\circ} \mathrm{C}$ ); o tempo de secagem do adesivo (min.) e ainda facilitadores do processo como desmoldante (papel celofane resistente ao calor) e uma caixa formadora para melhor direcionar a colocação do material no molde, Tabela 1. 
Tabela 1 - Variáveis de ensaios com molde de alumínio e aparas de PO.

\begin{tabular}{|c|c|c|c|c|c|}
\hline Ensaios & 1 & 2 & 3 & 4 & 5 \\
\hline Aparas & $50 \mathrm{~g}$ & $75 \mathrm{~g}$ & $50 \mathrm{~g}$ & $30 \mathrm{~g}$ & $20 \mathrm{~g}$ \\
\hline Adesivo & $40 \mathrm{ml}$ & $40 \mathrm{ml}$ & $30 \mathrm{ml}$ & $3 \mathrm{ml}$ & $20 \mathrm{ml}$ \\
\hline $\begin{array}{l}\text { Compressão } \\
\mathrm{Kg} / \mathrm{cm}^{2}\end{array}$ & 15,3 & 20,4 & 20,4 & 15,3 & 15,3 \\
\hline Temperatura & $25^{\circ}$ & $80^{\circ}$ & $80^{\circ}$ & $80^{\circ}$ & $80^{\circ}$ \\
\hline \multicolumn{6}{|l|}{${ }^{\circ} \mathrm{C}$} \\
\hline $\begin{array}{l}\text { Tempo } \\
\text { minutos }\end{array}$ & 120 & 15 & 15 & 15 & 15 \\
\hline Complemento & & desmoldante & $\begin{array}{l}\text { Caixa } \\
\text { formadora }+ \\
\text { desmoldante }\end{array}$ & $\begin{array}{l}\text { Caixa } \\
\text { formadora }+ \\
\text { desmoldane }\end{array}$ & $\begin{array}{l}\text { Caixa } \\
\text { formadora + } \\
\text { desmoldante }\end{array}$ \\
\hline
\end{tabular}

Fonte - Elaborado pelo autor com base na pesquisa realizada.

O peso específico do produto foi feito comparando-se diferentes amostras com variações entre o peso das aparas (material seco e classificado por tamanho) e a quantidade de cola, em uma escala decrescente para chegar ao mínimo peso mantendo a integridade e resistência do material após moldado. O adesivo utilizado para encolamento variou de 40 a $20 \mathrm{ml}$ com a progressāo dos experimentos, foi adotado a diluição de $50 \%$ de água. A aspersāo do adesivo nas aparas foi feita com uma pistola de ar comprimido localizada no interior do encoladeira, que ao girar proporciona a dispersāo do adesivo por todas as faces das aparas.

Este trabalho foca na criação de um produto mantendo o processo de fabricação dentro da própria empresa e o aproveitamento dos resíduos resultantes da fabricação das embalagens. Estes resíduos atualmente sāo revendidos a baixo custo para empresas aparistas. A proposta se manteve dentro do mercado de embalagens em que a empresa atua, mas tenta oferecer uma nova opção de um serviço 
diferencial para seus clientes, diminuir a quantidade de resíduo dentro da empresa e aumentar o valor agregado desse material na sua eliminação final, figura 5.

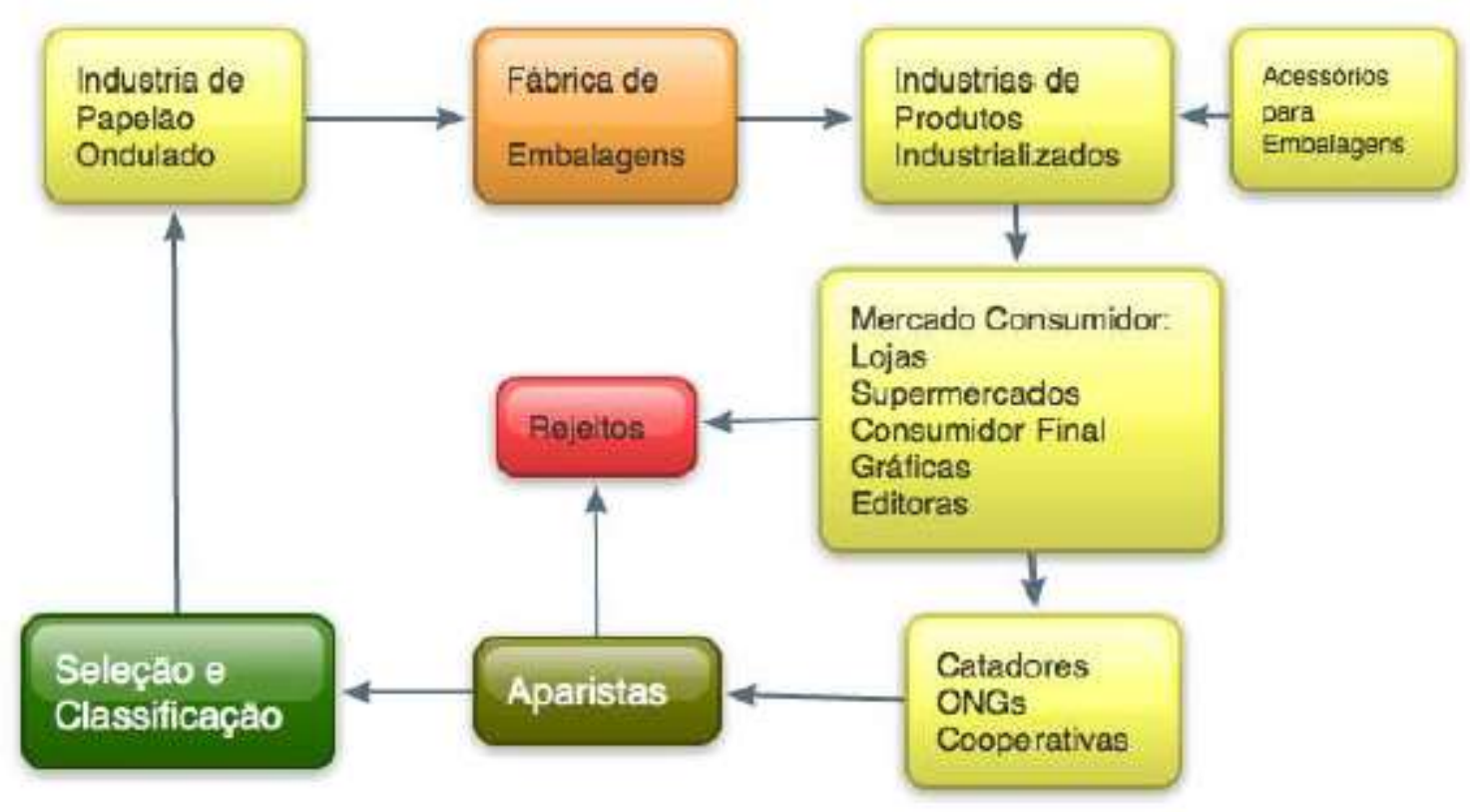

Figura 5 - ciclo de aproveitamento das aparas dentro das fabricas de embalagens. Fonte elaborado pelo autor.

O aproveitamento das aparas como um produto altera o ciclo dos resíduos mas introduz um novo ciclo onde a fabrica de embalagens repassa aos fabricantes um acessório para as embalagens com possibilidade de maior valor agregado.

\section{CONCLUSÃO}

Os ensaios comprovaram as possibilidades de várias linhas de produtos, utilizando-se somente as aparas e adesivo para sua união como um compósito. Estes diferentes conceitos foram demonstrados por pequenos ajustes e variações quantitativas das principais variáveis propostas neste trabalho.

Um estudo mais aprofundado com testes mais controlados pode encontrar o tamanho mais adequado das aparas para desenvolver um processo industrial, que possa aproveitar todos os tamanhos de aparas independente do tipo de embalagem produzida.

A introdução, em linha de produção, de um produto novo envolve profunda pesquisa mercadológica antes de seu lançamento. Esse é um processo que deve envolver varias áreas como: engenharia de produção; marketing; engenharia de materiais, etc. O design posiciona-se como o guia para novas tendências e propostas. 
A fabricação de um produto com as aparas depende do desenvolvimento de maquinário de baixa tecnologia apropriado ainda não existente.

Devem constar os resultados obtidos ou análise de resultados, as conclusões ou considerações finais, limitações, trabalhos futuros, etc. 


\section{REFERÊNCIAS}

COELHO, H. M. G., Lange, L. C., Jesus, L. F. L., Sartori, M. R. Proposta de um Índice de Destinaçāo de Resíduos Sólidos Industriais. Engenharia Sanitária Ambiental, v.16, n.3, p. 307-316, 2011.

CEMPRE - Compromisso Empresarial para Reciclagem. Ficha Técnica -Papel Ondulado. Disponível: http://www.cempre.org.br/servicos_mercado.php Acesso em: 24/10/2012

Macedo, A.R.P., Valença, A.C. de V. Reciclagem de Papel - Papel e Celulose. BNDES, p.20. 1995.

RAZERA, D.L., Estudo sobre as Interações entre as variáveis do processo de produção de painéis aglomerados e produtos moldados de madeira. Tese Doutorado Ciências Florestais Universidade Federal do Paraná, 2006. 


\section{Capítulo 3}

\section{doi) $10.37423 / 210303697$}

\section{ANÁLISE DO DESIGN DE APLICATIVOS PARA DISPOSITIVOS MÓVEIS COM FOCO EM CRIANÇAS E ADOLESCENTES}

Vinícius de Azevedo Botelho

Virginia Tiradentes Souto

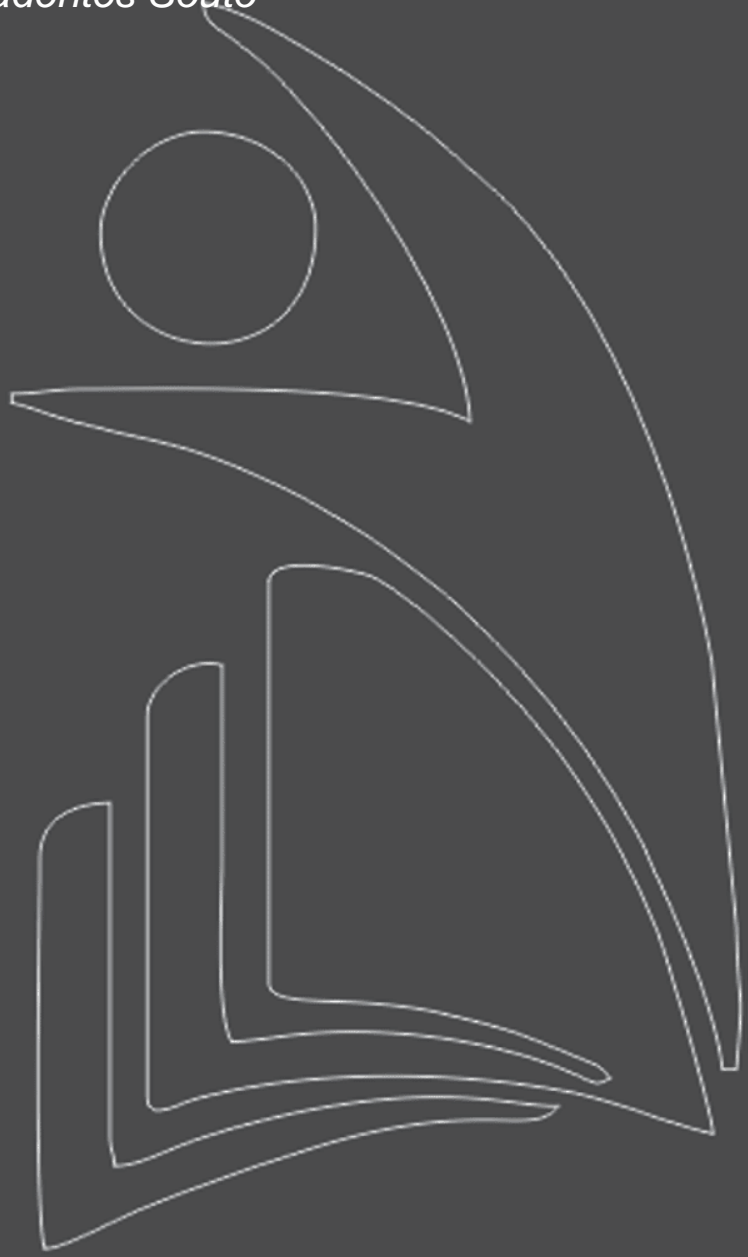

Universidade de Brasília

Universidade de Brasília

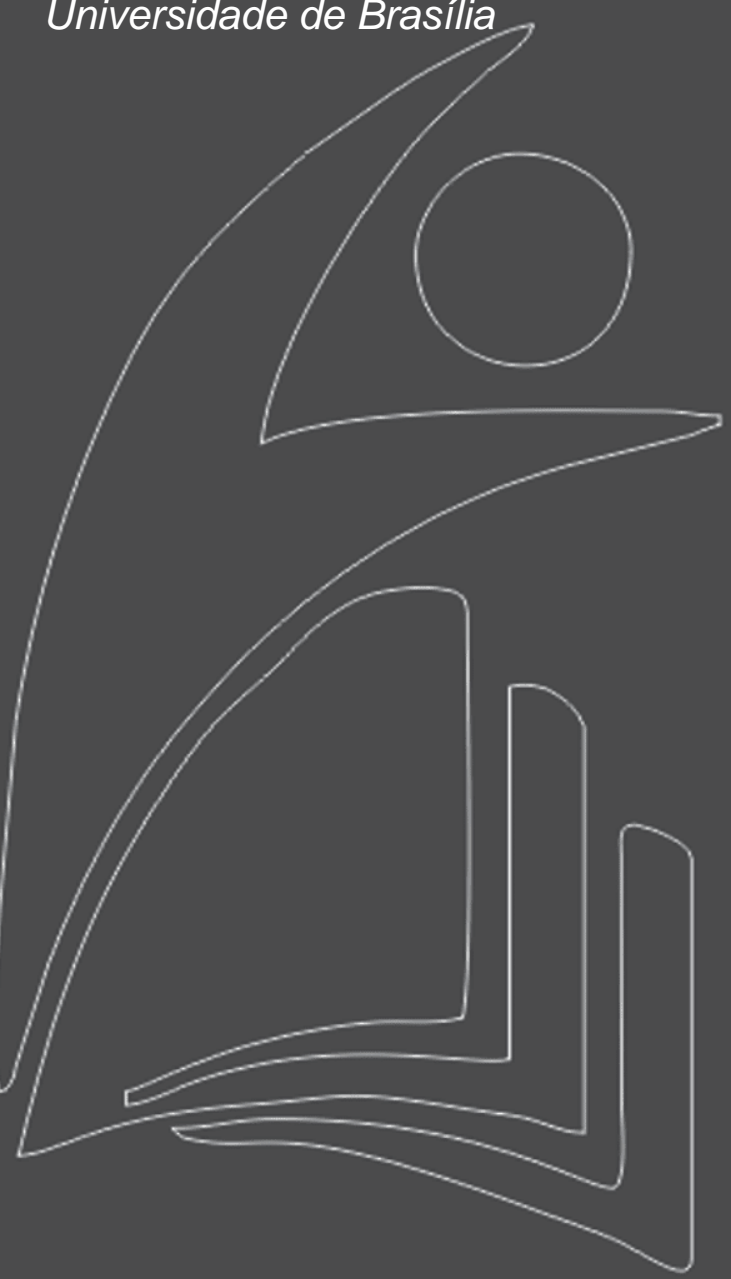


Resumo: O estudo aqui descrito analisa e compara os componentes visuais de aplicativos para celulares com o foco em adolescentes com o objetivo de descobrir se há similaridades e diferenças entre estes ambientes, como elas ocorrem e a sua frequência. $O$ estudo é baseado em uma estrutura de análise (framework) que descreve ambientes interativos digitais para crianças e adolescentes proposto por Souto (2013). Verificou-se, entre outros aspectos, que existe um padrão quanto à hierarquia da informação desses aplicativos. Tal análise mostrou-se relevante para entender as características da interface, as possibilidades na criação de interface, entender onde estão os limites relevantes, e como os usuários podem interagir com tais ambientes interativos.

Palavras-chave: ambientes digitais, crianças e adolescentes, design de aplicativos, design de interação, dispositivos móveis. 


\section{INTRODUÇÃO}

A necessidade de estudos na área de design de interação cresce na medida em que cresce o número de aplicativos para celulares e tablets, como cresce também o seu uso por pessoas no mundo. Muitos desses ambientes são criados com foco em crianças e adolescentes, e objetivam ajudar esses públicos em suas atividades de aprendizado (Oblinger, 2008). Sabe-se que crianças e adolescentes interagem com esses ambientes de uma forma mais natural do que adultos de meia idade ou mais velhos (Prensky, 2001; Barnes, Marateo and Ferris, 2008; Oblinger, 2008) e tal geração é conhecida por Geração Net (Tapscott, 2008). Apesar do número crescente de investigações sobre interação dos usuários com tais aplicativos, ainda há poucos estudos que focam na interface gráfica de ambientes interativos para crianças e adolescentes (Druin, 2009).

O porquê do interesse nas finanças está no quão relevante é para a vida ainda em fase tenra. Ao contrário do que se pensa, a criança entra em contato com as finanças muito cedo. O ser humano começa a compreender finanças, de uma forma mais substancial, por volta dos dois anos e meio de idade, segundo a pesquisadora em educação infantil Cássia D’Aquino (Portal Brasil, 2010). Esse momento ocorre quando a criança pede aos pais para que compra algo para ela. Ou seja, a própria criança anuncia que está pronta para lidar com educação financeira.

O estudo aqui apresentado analisa e compara os componentes visuais de aplicativos para celulares com foco em adolescentes com objetivo de descobrir se há pontos de paridade e de diferença entre os mesmos, como elas ocorrem e qual a sua frequência. Ele também tem o objetivo de auxiliar no desenvolvimento de um aplicativo que visa através de interfaces visuais, amparar as crianças e adolescentes no aprendizado de matemática.

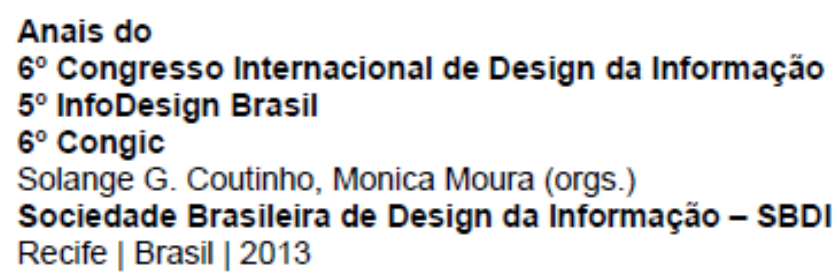

Proceedings of the

$6^{\text {th }}$ Information Design International Conference

$5^{\text {th }}$ InfoDesign Brazil

$6^{\text {th }}$ Congic

Solange G. Coutinho, Monica Moura (orgs.)

Sociedade Brasileira de Design da Informação - SBDI

Recife | Brazil | 2013

\section{MÉTODO}

Foram analisados três aplicativos de educação financeira, voltado para o público infanto-juvenil, a saber: Cashflow for kids, do designer Robert Kyiosaki, publicado pela Cashflow Technologies (denominado aplicativo A); P2k Money da Loconuts, Inc. (denominado aplicativo B) e Kids Money da 
Apps Rocket (denominado aplicativo C). Estes aplicativos foram escolhidos por apresentarem requisitos estabelecidos relacionados ao conteúdo e público-alvo do projeto em desenvolvimento. $A$ análise foi dividida de acordo com os componentes do framework.

O estudo é baseado em uma estrutura de análise (framework) que descreve ambientes educacionais interativos digitais para crianças e adolescentes (Souto, 2013). O framework foi desenvolvido para orientar o design de ambientes digitais de aprendizagem para os jovens, e também para fornecer uma estrutura de características da interface, compreensão de tais ambientes e como usuários interagem com eles. O framework é dividido em três componentes principais: aprendizado, interação com o usuário e componente visual, e 12 subcomponentes que os compõem.

Os elementos de aprendizado estão relacionados aos aspectos de aprendizado da interface e tem como sub-componentes as características do usuários, habilidades e conteúdo. Já o componente interação refere-se a plataforma tecnológica utilizada suas características e requisitos assim como com a interação do usuário com a mesma. Está relacionado com os aspectos de acessibilidade, usabilidade e interação. Finalmente, o componente visual descreve os elementos visuais do ambiente tais como a tipografia, as imagens, ícones, estrutura da interface e visualização da informação.

\section{ESTUDO DE CASOS}

O primeiro aplicativo, Cashflow for Kids pela Cashflow Technologies, nada mais é que ensinar educação financeira através de jogo (gaming). A história gira em torno do ratinho Reno que passa por questões financeiras cotidianamente, e nos momentos de resolução dessas questões, a tarefa é concedida ao usuário. Animações são o ponto forte, pela necessidade de contar a história e mostrar as recompensas que Reno consegue quando soluciona uma questão financeira.

O aplicativo B, P2K Money, da Loconuts, Inc. já se diferencia por ter um tratamento estético mais formal, neutro. A autonomia é mais focada nesse aplicativo, existe uma central de comando que o usuário atua integralmente, delimitando seus objetivos, aspirações e verificando saldos. Operadores matemáticos se fazem presentes nesse tipo de aplicativo, mas não fazem parte do processo de aprendizado, não se apresentam como desafios a matemática em sim, mas o controle e manutenção de gastos. Os ícones são mais simples, a divisão e hierarquia da informação são bem evidentes.

O aplicativo C, Kids Money da Apps Rocket é o mais simples. Funciona como um desafio cotidiano de manutenção e controle de gastos. Nesse aplicativo a matemática como aprendizado, e não só como ferramenta superficial, é colocada em evidência. $O$ aplicativo tende a revisar cotidianamente os gastos 
e aspirações através de um personagem. Este personagem permite uma interação direta com o usuário, fazendo com que o usuário atente diariamente ao sinal de gastos. Outro ponto interessante é a presença de medidores comparativos entre as diferentes categorias de elementos financeiros, não só os dados substanciais, como também previsões.

\section{RESULTADOS}

Os resultados foram divididos nos três componentes principais do framework: aprendizado, interação com o usuário e visual.

\section{COMPONENTE APRENDIZADO}

O componente aprendizado está relacionado com as características do usuário, habilidades e conteúdos. Os resultados de análise mostram que os aplicativos apresentam diferentes níveis de detalhamento e formato. Enquanto o aplicativo A, apresenta minuciosos detalhes em vários aspectos da interface, o aplicativo B tem conteúdo focado e o aplicativo C apresenta um detalhamento superficial, possibilitando apenas interações básicas. Em relação às habilidades de aprendizagem, os aplicativos B e C oferecem um banco de dados que auxilia os usuários com algumas operações matemáticas, já o aplicativo A exige habilidades relacionadas à operações matemáticas. Finalmente, os aplicativos são similares em relação às características do público-alvo: aplicativo A partir dos seis anos de idade, B e C a partir de quatro anos, ambos os sexos, sem características sociais ou culturais exigidas.

\section{COMPONENTE INTERAÇÃO COM O USUÁRIO}

No que tange à interação com o usuário, os aplicativos apresentam certas semelhanças no que diz respeito ao dinamismo e praticidade. Os aplicativos são todos voltados para a execução rápida de suas ações. Todo um sistema projetado para precisa, intuitiva e leve navegação, o que torna a mesma confortável e responsiva. Assemelham-se também quanto a sua acessibilidade, sendo completamente inteligíveis e orgânicos. Na interação em si, o aplicativo A se destaca pelos vários elementos responsivos de acordo com as decisões do usuário. Já nos aplicativos B e C, na interação, esses possuem uma característica mais semelhante a um banco de dados interativo que permite maior autonomia por parte do usuário. 


\section{COMPONENTE VISUAL}

Os três aplicativos primam pela imagem bidimensional (2D) e desdobramentos a partir desse tipo de imagem, como por exemplo, noção mínima de profundidade a partir de contornos mais acentuados e movimentação de peças da imagem. Entretanto, eles se diferenciam principalmente no que diz respeito aos ícones, que se apresentam com singulares tratamentos estéticos e de formato. Sendo mais sóbrios e minimalistas nos aplicativos B e C, e mais vibrantes em A, que possui uma proposta de divertimento, sistema-recompensa bem definida. Na tipografia, há predominância no uso de tipos não serifados, com dutos mais finos e entrelinhas mais condensadas. Há uma exploração de ritmo vibrante nos aplicativos B e C, uso de cores quentes em maior quantidade que cores frias, atentando ao contraste, mas deixando de modo geral o aplicativo mais colorido e dinâmico.

\section{DISCUSSÃO E CONCLUSÕES}

A análise mostrou similaridades e diferenças entre os aplicativos pesquisados. Percebeu-se uma variedade expressiva no uso de elementos visuais e tipos de interação. Entretanto, verificou-se que existe um padrão quanto à hierarquia da informação desses aplicativos. Pode-se notar a divisão em três áreas de atuação bem distintas e definidas durante a pesquisa: manutenção, tela de amostragem e interação indireta. A área manutenção reservada ao controlador. Nesta área se aplicam as customizações, e outras tarefas de gerenciamento, que não se limitam ao aplicativo necessariamente, mas do sistema do dispositivo móvel como um todo. Já a tela de amostragem é a área reservada para a visualização passiva de dados e informações. A terceira área identificada, chamada de interação direta, é a área mais importante onde o usuário influi diretamente nas ações que o aplicativo permite. Uma verificação importante e que se faz notável dentro da ideia de autonomia é o acesso a informações, não importando datas ou qualquer outro limitante. Percebe-se que para que se tenha autonomia, é necessário também que se tenha acesso, controle, domínio nas diferentes camadas de interação. Então provavelmente haverá uma edificação consistente na geração de banco de dados, não só para acesso à informação, mas também para geração da própria informação, como listas de metas e estratégias adotadas.

Finalmente, verificou-se a importância de sistema responsivo eficiente e a necessidade de maior autonomia concedida ao usuário, e por fim, um esquema de dicas que podem ajudar no gerenciamento de finanças do usuário sem necessariamente tornar obrigatória a sua conduta, permitindo que o usuário não perca tempo em funções ou procedimentos desnecessários. 


\section{CONSIDERAÇÕES FINAIS}

A análise apresentada aqui é relevante para entender as características da interface, as possibilidades na criação de interface, entender onde estão os limites relevantes, e como os usuários podem interagir com tais ambientes. Isto porque a partir desta análise foi identificado diversos componentes das interfaces.

Além disso, o framework proposto por Souto (2013) demonstrou ser uma ferramenta de auxílio no processo de criação de design, uma vez que identifica, classifica e categoriza as características da interface. Desta forma, ela pode ser utilizada para guiar designers a criarem ambientes digitais interativos mais criativos, dinâmicos e saudáveis.

\section{AGRADECIMENTO}

Agradecemos a Universidade de Brasília e ao Programa de Iniciação Científica pelo apoio à esta pesquisa. Vinícius de Azevedo Botelho é aluno de iniciação científica do ProlC/DPP/UnB. 


\section{REFERÊNCIAS}

BARNES, K., Marateo, R. and Ferris, S. 2007. Teaching and Learning with the Net Generation. Innovate. 3, (4). <http://www.innovateonline.info/index.php?view=article\&id=382>, 20/10/2012.

DRUIN, A. (Ed.) 2009. Mobile Technology for children: Designing for interaction and Learning. Burlington: Morgan Kauffman Series in Interactive Technologies.

OBLINGER, D. G. 2008. Growing up with Google What it Means to Education. Emerging technologies for learning. EDUCAUSE. Vol. 3.

PORTAL BRASIL 2010.Educação Financeira para as crianças.

<http://www.brasil.gov.br/sobre/economia/educacao-financeira/economia-para-criancas>, 28/05/2013.

TAPSCOTT, D. 2009. Grown up Digital: How the Net Generation is Changing You World. New York: McGraw-Hill.

SOUTO, V. T. 2013. A framework for designing interactive digital learning environments for young people. In Katherine Blashki and Pedro Isaias (Ed.) Emerging Research and Trends in Interactivity and the Human-Computer Interface. IGI Global. 


\section{Capítulo 4}

doi $10.37423 / 210303703$

\section{ECOPISO DE FIBRA DE TURURI E RESINA DE} MAMONA: ENSAIO DE RESISTÊNCIA À ABRASÃO E ANÁLISE DA MORFOLOGIA UTILIZANDO MEV

ANA KARLA FREIRE DE OLIVEIRA

José Roberto Moraes D'Almeida

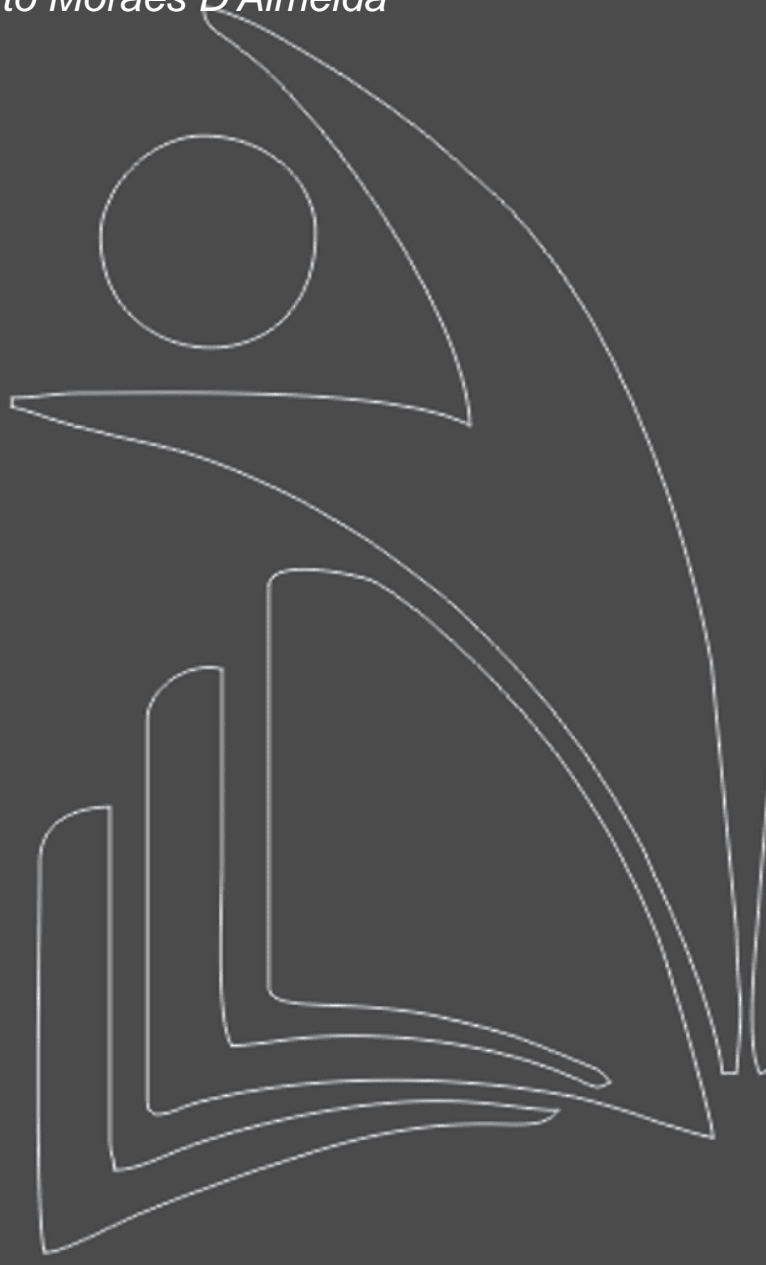

Universidade Federal do Rio de Janeiro

Pontifícia Universidade Católica do Rio de Janeiro

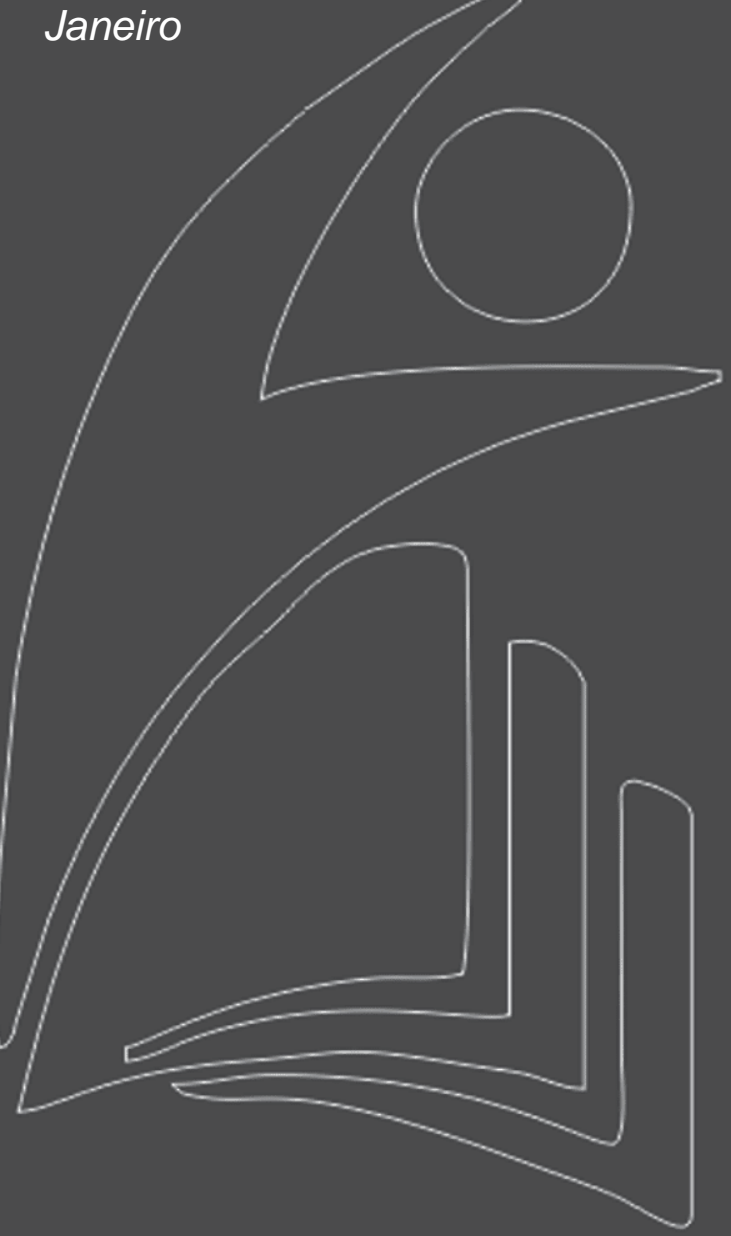


Resumo: Pesquisa de Doutorado desenvolvida no curso de Engenharia de Materiais que teve como objetivo o estudo da viabilidade técnica de uso do compósito de fibra de tururi (Manicaria saccifera) e resina à base de óleo de mamona na fabricação de pisos e revestimentos. Neste artigo estão expostos os resultados dos ensaios de Resistência à Abrasão e Análise de MEV (Microscopia Eletrônica de Varredura). Os resultados apontaram que o compósito produzido apresenta resistência ao desgaste abrasivo, tornando---o um material apto à aplicação em pisos e revestimentos, acarretando em uma Patente de material. Foi gerado um piso do tipo taco que foi selecionado para exposição no $24^{\circ}$ Prêmio Design Museu da Casa Brasileira.

Palavras---chave: Design Sustentável, Ecocompósito, , Fibra de Tururi, Resina de Mamona, pisos. 


\section{INTRODUÇÃO}

O Design é um tema dinâmico e sujeito à constantes transformações e interações. Dentre essas interações, a que mais me desperta a atenção é a relação e necessária integração entre Design \& Materiais, especialmente os materiais com caráter sustentável. A sustentabilidade requer que se esteja em consonância com vários requisitos, entre estes, o uso de recursos renováveis e a otimização do emprego de recursos não renováveis.

Na obra O Desenvolvimento de Produtos Sustentáveis (2005), MANZINI \& VEZZOLI tratam da relação entre design e ambiente dando particular atenção ao desenvolvimento de produtos com baixo impacto ambiental, tendo se concentrado nas estratégias de projeto que, considerando o uso de materiais de origem renovável, permitem obter produtos mais ecoeficientes. Tanto na primeira obra citada, quanto em Design para Inovação Social e Sustentabilidade (2008), MANZINI nos apresenta e coloca em evidência diversos aspectos que indicam para a mesma direção: o design para a sustentabilidade requer mudanças sistêmicas. Sobre o papel do design em tais mudanças, o autor afirma: "Hoje em dia, a sustentabilidade deveria ser meta---objetivo de todas as possíveis pesquisas em design (e não, como foi visto nos últimos anos, como um tipo de setor especializado, que corre paralelo a outros setores especializados).

Os ecocompósitos são resultados de pesquisas que utilizam, em sua maioria, materiais renováveis como fibras vegetais e resinas poliméricas derivadas de fontes naturais, como a resina de mamona, de lignina, de amido de batata, de bagaço de cana de açúcar, entre tantas outras. Ou seja, estamos falando de materiais não oriundos de fontes petrolíferas e com grande capacidade de diminuição da pegada de carbono no seu desenvolvimento, pois implica em um gasto energético menor, se comparado com outros materiais de origem sintética, além de beneficiar comunidades rurais, ao utilizar fibras vegetais.

Nesse contexto, a área de materiais compósitos possui atualmente como um de seus maiores pontos de interesse, o desenvolvimento de compósitos poliméricos reforçados por fibras vegetais. Este interesse tem origem no fato de que os compósitos poliméricos mais utilizados são reforçados em sua maioria, por fibras sintéticas, porém, em razão da sua baixa biodegradabilidade e origem não renovável (petróleo), é preciso substituí---los por materiais ecológicos e amigáveis ao homem. Neste sentido, os ecocompósitos representam uma boa alternativa no campo dos materiais para aplicações de Engenharia e Design comprometidos com o meio ambiente. 
Os principais objetivos deste trabalho foram o processamento, caracterização e análise de viabilidade de aplicação do compósito formado por uma resina poliuretano derivada do óleo de mamona (Castor oil) e fibras de ubuçu/tururi (Manicaria saccifera) na fabricação de pisos e revestimentos. Para tanto, foram realizados vários ensaios de caracterização térmica, mecânica e abrasiva, sendo apresentados aqui os resultados dos ensaios de Resistência à Abrasão e o estudo de sua morfologia utilizando a técnica de Microscopia Eletrônica de Varredura (MEV). Ao final, apresentamos o piso residencial como produto gerado a partir do compósito pesquisado.

\section{DESENVOLVIMENTO}

No cenário ambiental preocupante em que vivemos, a comunidade científica é chamada para apresentar sua contribuição para a indústria e sociedade em geral, ao desenvolver estudos relacionados a novos materiais com filosofia mais sustentável, provenientes de recursos renováveis. Desse modo, será possível diminuir a nossa dependência dos materiais derivados do petróleo e, simultaneamente, minimizar o impacto ambiental decorrente de seu uso. Neste contexto, a biomassa vegetal e animal, resultante das atividades agrícolas, florestais e agro alimentares, constituem uma alternativa sustentável de fontes renováveis para novos materiais.

Assim, surgem os ecocompósitos, da síntese de materiais a partir de matérias--- primas provenientes da biomassa, em que a matriz e o reforço são ambos de recursos renováveis, constituindo---se no objeto de pesquisa desse estudo. Por ser obtido da combinação de fibras naturais e matrizes poliméricas de origem vegetal, é de se esperar que o compósito criado seja menos agressor ao meio ambiente.

De fato, as fibras naturais, em particular as de origem vegetal, apresentam inúmeras vantagens comparativamente às fibras de vidro, o que contribui para o seu uso crescente no desenvolvimento de materiais compósitos. Na Tabela 1, encontra---se uma análise comparativa de algumas características das fibras naturais e de vidro.

As principais características das fibras naturais em relação às fibras de vidro, se referem ao seu caráter renovável, biodegradabilidade, reciclabilidade e baixa densidade. Pode---se ainda frisar a natureza renovável das fibras naturais, sua disponibilidade quase ilimitada e o fato de que, quando analisamos seu ciclo de vida, compostadas ou queimadas, geram dióxido de carbono (CO2) em quantidades requeridas para o crescimento das plantas, traduzindo---se num impacto ambiental positivo. O mesmo não se pode dizer da combustão de produtos de fontes fosseis, já que liberta 
quantidades consideráveis de CO2 para a atmosfera, contribuindo para o efeito estufa e, consequentemente para as alterações climáticas a que o mundo tem assistido (LARBIG, et al., 2005).

Tabela 1 - Fibras Naturais X Fibras de Vidro.

\begin{tabular}{lll}
\hline & Fibras Naturais & Fibras de Vidro \\
\hline Densidade & Baixa & Elevada \\
Preço & Baixo & Baixo \\
Caráter renovável & Sim & Não \\
Caráter reciclável & Sim & Não \\
Caráter biodegradável & Sim & Não \\
Neutralização CO2 & Sim & Não \\
Caráter abrasivo & Não & Sim \\
Consumo energético & Baixo & Elevador \\
\hline
\end{tabular}

Fonte: Fernandes, 2008.

A baixa densidade das fibras naturais (cerca de duas vezes inferior às das fibras de vidro) associada à sua natureza não abrasiva, permite a incorporação de uma maior fração de reforço no material compósito, conduzindo à obtenção de materiais com propriedades mecânicas superiores, mas mais leves. Para além disso, as diversas formas de processamento de compósitos reforçados com fibras naturais exigem um menor consumo energético e provocam um menor desgaste dos equipamentos envolvidos no seu processamento (FERNANDES, 2008).

\subsection{FIBRA DE TURURI E RESINA DE MAMONA: O COMPÓSITO DESTE ESTUDO.}

A fibra de tururi, oriunda da palmeira ubuçu (Manicaria saccifera) é encontrada no estuário amazônico brasileiro. Esta fibra é utilizada no setor de artesanato e moda (produção de roupas e acessórios), bem como, pela população ribeirinha do Estado do Amapá na cobertura de suas casas. OLIVEIRA \& D'ALMEIDA (2010), caracterizaram a fibra de tururi química e morfologicamente e como conclusão desta pesquisa, considerou---se a viabilidade da fibra ser utilizada como reforço em matrizes poliméricas.

A Manicaria saccifera é uma palmácea encontrada em países da América Central e do Sul. A sua classificação científica obedece a seguinte ordem: Reino - Plantae; Divisão - Magnoliophyta; Classe Liliopsid; Ordem - Arecales; Família - Arecaceae; Gênero - Manicaria; Espécie - Manicaria saccifera. Esta palmácea é encontrada na Região Amazônica sendo conhecida popularmente por Buçu, Coqueiro-- Buçu, Obuçu, Tururi, Ubuçu. Na Guiana Inglesa, Troolie---Palm e na Venezuela, Timiche. No Brasil 
esta planta é encontrada nas matas das várzeas e ilhas da Região Norte, especialmente na Amazônia, e Amapá (CORREA, 1978). Nesse estudo focaremos a Manicaria saccifera oriunda do Estado do Amapá. A ubuçu em geral mede de 3 a 6 metros de altura. Suas folhas são grandes e quase inteiras, muito semelhantes as das bananeiras, medindo de 4 a 8 metros de comprimento, por 1,5 metros de largura (BRT, 2008). A palmeira possui frutos que são protegidos por um invólucro constituído por um saco de tecido fibroso, flexível e resistente denominado "tururi", que apresenta cor natural castanho escuro. A Figura 1 ilustra respectivamente, a estrutura da Ubuçu e o aspecto geral da fibra desse estudo. 0 uso dessa fibra na confecção de roupas ditas "ecologicamente corretas" por parte de pequenas empresas do Amapá e Santa Catarina já faz com que a mesma seja divulgada em âmbito nacional e internacional (Figura 2). Porém, no meio científico tal fibra ainda não havia sido testada como elemento de reforço em compósitos poliméricos, o que faz com esta pesquisa apresente um grau de originalidade bastante singular.

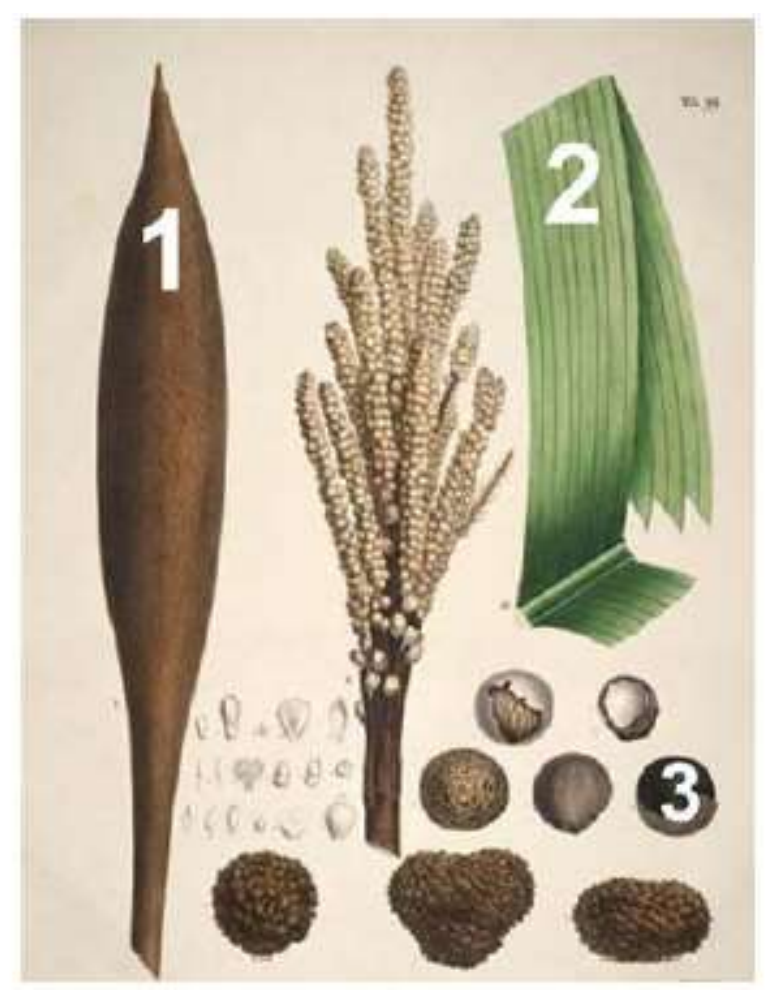

Figura 1 - Estrutura da palmeira ubuçu. 1. Invólucro/saco fibroso denominado "Tururi". 2. Folhas. 3. Frutos. MARTIUS (1823). Adaptada. 

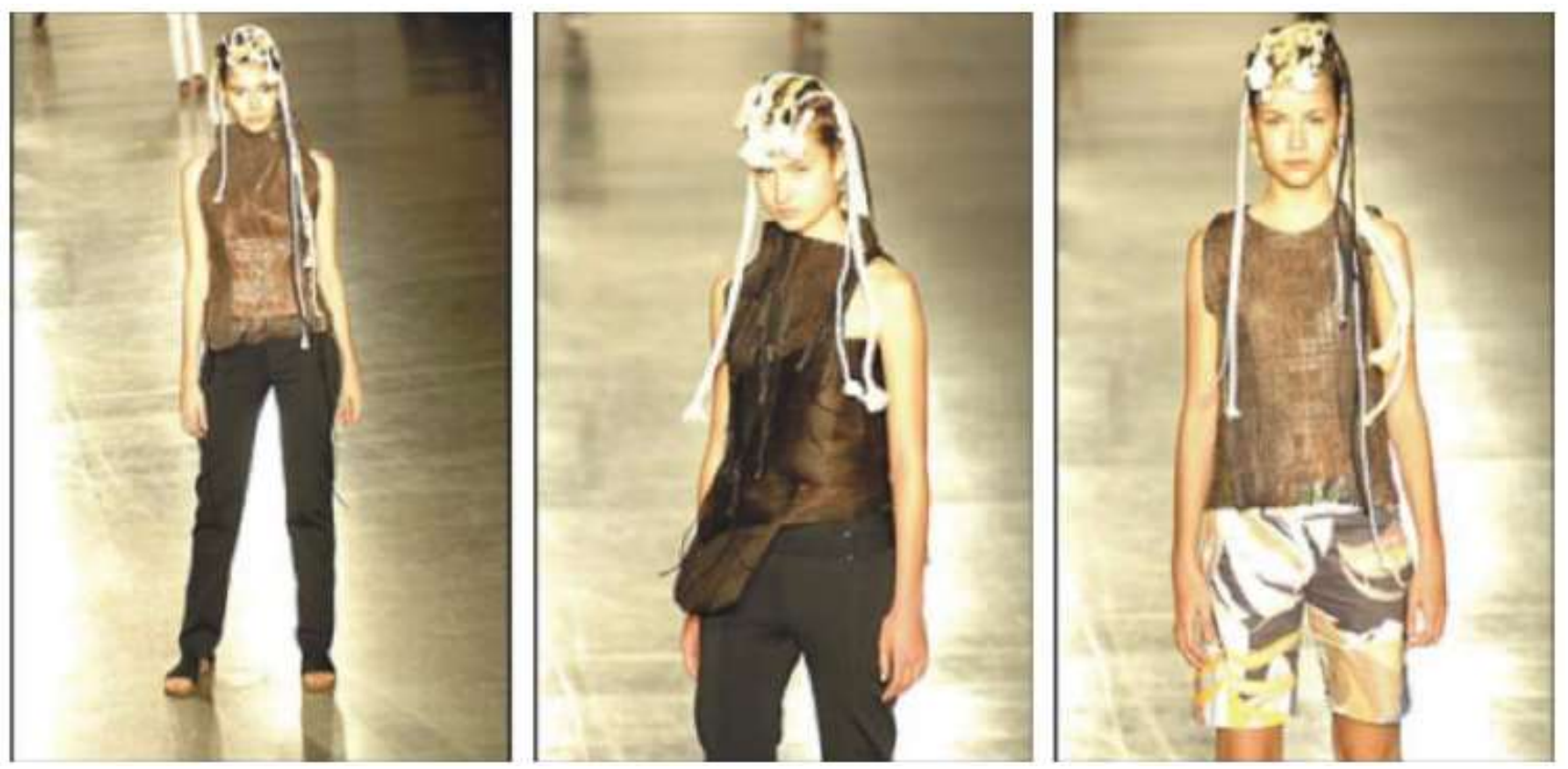

Figura 2 - Coleção de roupas criadas com fibras da ubuçu/ tururi. Fonte: Kulig (2006).

O desenvolvimento das poliuretanas derivadas de óleo de mamona teve origem nos primeiros trabalhos propostos na década de 40. Essas poliuretanas se apresentam como um líquido viscoso, obtido pela compressão das sementes da mamoneira ou por extração com solventes (VILAR, 1993).

Segundo a Empresa de Pesquisa Agropecuária S.A (EMBRAPA) da Bahia e a Secretaria da Agricultura, a mamona mais comum no Brasil é a espécie Ricinus communis L. De acordo com WOODS (1990), as resinas poliuretanas podem ser encontradas como elastômero de alta flexibilidade ou de maior dureza.

A resina poliuretana derivada do óleo de mamona apresenta ao menos 700 aplicações diferentes e a quantidade de materiais desenvolvidos aumenta significativamente a cada pesquisa, a ponto de abranger diferentes segmentos de aplicação (telecomunicações, setor médico, automotivo, etc.). Esta resina pode se apresentar de forma mono ou bicomponente, sendo que esta última foi utilizada nesse estudo.

A resina bicomponente é formada por: um pré---polímero com terminação isocianato e um poliol. Sintetizados por poliadição, esses dois componentes reagem entre si, formando um composto poliuretano. Na mistura dos componentes, quanto maior for a proporção do poliol, mais flexível fica a estrutura da resina. Enquanto que, se houver maior concentração de pré---polímero, mais rígida se torna a estrutura, GODOY (2007). A polimerização final ocorre em torno de 24 horas e sua secagem 
ao toque entre 10 e 30 minutos, dependendo da umidade e temperatura ambiente. Possui viscosidade de 7,5 Pa.s e densidade de 0,959 g/cm3 ambas a 25oC. (ARAúJO, 1992).

As poliuretanas à base de óleo de mamona diferem muito das derivadas de petróleo. A começar por sua matéria---prima ser proveniente de recursos vegetais renováveis, sendo bastante resistentes aos agentes agressivos, tais como, ácidos, álcalis e bases. Ao contrário das poliuretanas de petróleo, as de base vegetal não são inflamáveis e, quando queimadas, não emitem gases tóxicos.

\subsection{MATERIAIS E MÉTODOS}

Obtenção dos Materiais --- A fibra utilizada nesse trabalho foi extraída da palmeira ubuçu pela população ribeirinha do Amapá, passando posteriormente por um processo de amaciamento, que consiste em nada mais do que lavar o invólucro em água corrente para retirar as impurezas. Este é, portanto, um processo totalmente ecológico, pois não gera resíduos químicos ao meio ambiente. Para este trabalho a fibra foi recebida na forma do invólucro (saco) in natura, medindo em média, $60 \mathrm{~cm}$ de comprimento e $12 \mathrm{~cm}$ de largura (Figura 3).

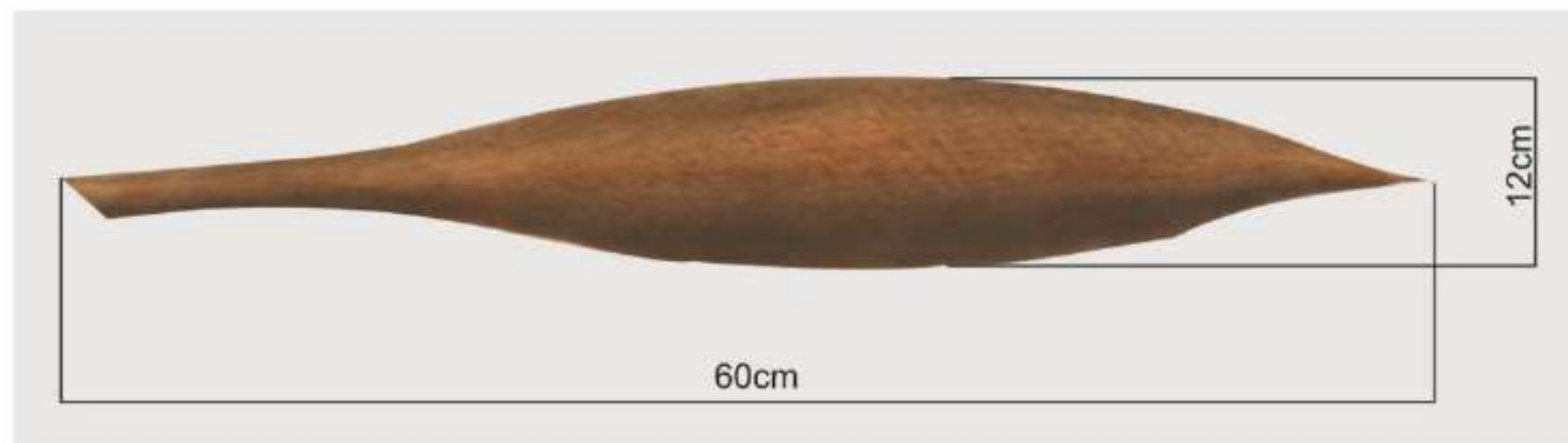

Figura 3 - Folha de ubuçu coletada neste estudo e suas dimensões aproximadas. Elaborado pelo autor com base na pesquisa realizada.

A fibra foi coletada em setembro de 2008 , na cidade de Macapá, localizada a $00^{\circ} 22^{\prime} 0^{\prime \prime}$ de latitude, $51^{\circ} 03^{\prime} 59^{\prime \prime}$ de longitude e 16 metros de altitude. O clima do município de Macapá é equatorial quente--úmido, com temperatura máxima de $32,6^{\circ} \mathrm{C}$ e a mínima de $20^{\circ} \mathrm{C}$, e uma pluviometria de no máximo $3.000 \mathrm{~mm}$. Já o solo é classificado em lato solo amarelo nos terrenos terciários dendrítico---argilosos. A resina de mamona foi obtida da empresa ZORITE - Resinas Ecológicas, situada na cidade do Rio de Janeiro, revendedora da empresa POLIVEG, fabricante da resina. Foram utilizadas duas relações para a mistura dos componentes, ou seja, 1:1 e 2:1 (poliol e pré---polímero, respectivamente). A proporção 1:1 é comumente utilizada na preparação da resina. Já a proporção 2:1 foi utilizada 
visando analisar o comportamento da resina de natureza mais flexível na fabricação do compósito, semelhante ao proposto por BOYNARD et al., (1997) para modificar as propriedades de uma resina de mamona. A mistura dos componentes foi realizada à temperatura ambiente. De acordo com o fabricante os dados técnicos do poliuretano são: Densidade: $900 \mathrm{Kg} / \mathrm{m}^{3}$; Resistência à Impacto: 2,36 kJ/m²; Tensão de Flexão: 19,1 x 10--- $6 \mathrm{MPa}(19,1 \mathrm{~N} / \mathrm{m} 2)$; Resistência à Tração: 12,9 x 10---6 MPa (12,9N/m2); Alongamento de Ruptura: 30\% ; e Dureza Shore (ASTM D2240): 70 a 80.

A preparação do poliuretano com a mistura dos dois componentes, poliol e pré--- polímero, e relações de 1:1 e 2:1 em massa se deu da seguinte forma: primeiramente pesaram---se as quantidades de cada componente em balança digital com precisão de 0,001g; em seguida os componentes foram misturados (em misturador), por três minutos, com velocidade de rotação baixa (30 rpm), a fim de evitar bolhas. Esta mistura era ao final, espalhada nas folhas de fibra de ubuçu a serem prensadas. Para fins de comparação também foi utilizada como matriz polimérica a resina epóxi, material de origem petrolífera. Ou seja, tivemos aqui três tipos de compósitos, com a mesma fibra vegetal, dois com resina de mamona (em duas proporções diferentes de seus componentes) e outro com resina epóxi.

Fabricação dos Compósitos --- A fabricação das placas do compósito se deu utilizando a técnica de moldagem por compressão e envolveu as etapas descritas a seguir:

a) Fabricação de um molde metálico para prensar os compósitos, com dimensões gerais de $200 \mathrm{x}$ $150 \times 5 \mathrm{~mm}$ (comprimento, largura e espessura interna).

b) Visando um comportamento mais isotrópico do compósito, optou---se por trabalhar com folhas de fibras organizadas em duas direções, ou seja, 0 e $90^{\circ}$. Assim, respeitando---se o sentido preferencial das fibras, as folhas de ubuçu foram abertas e cortadas de acordo com as dimensões do molde metálico em que seriam prensadas $(200 \times 150 \mathrm{~mm})$;

c) Após o corte das folhas, foi realizada a pesagem das fibras e da quantidade de resina em balança digital com precisão de 0,001g;

d) Após a pesagem das fibras e da resina, foi feita a mistura dos componentes da resina de mamona (mistura do poliol com o pré---polímero). Logo após, a resina era vertida nas fibras de ubuçu previamente organizadas. Após as fibras serem embebidas na resina, suas folhas foram colocadas no molde respeitando a posição $\left(0^{\circ}\right.$ e $\left.90^{\circ}\right)$. As resinas foram espalhadas nas fibras com a ajuda de um pincel de cerdas duras;

e) Com o compósito posto no molde, o mesmo foi posteriormente fechado e prensado com uma força de 6 ton. Todo o processo foi realizado à temperatura ambiente e a desmoldagem do compósito foi feita após um mínimo de 8h. Os corpos de prova para os ensaios de abrasão, foram usinados a partir das placas de compósitos moldadas conforme a descrição anterior. 
Ensaio de Abrasão - Como nessa pesquisa pretende---se desenvolver um compósito que possa ser utilizado na fabricação de pisos e revestimentos, o ensaio de abrasão é considerado essencial. O ensaio de resistência à abrasão foi executado conforme as recomendações da Norma DIN 53516 (1987), e consiste em determinar a resistência do material ao desgaste, em um abrasímetro, para um percurso estimado de 40 metros. Este ensaio foi realizado no Laboratório de Compósitos da PUC Rio, com o emprego de um abrasímetro da marca Parabor, com lixa (grânulos de areia) número

180 e índice de ataque de 219,73 mg (correspondente a abrasividade da lixa). Empregaram---se 3 repetições para cada material a ser ensaiado. A resistência à abrasão foi calculada em função da perda de massa sofrida pelo material para o percurso de 40 metros. A Figura 4 ilustra três momentos do ensaio de abrasão.
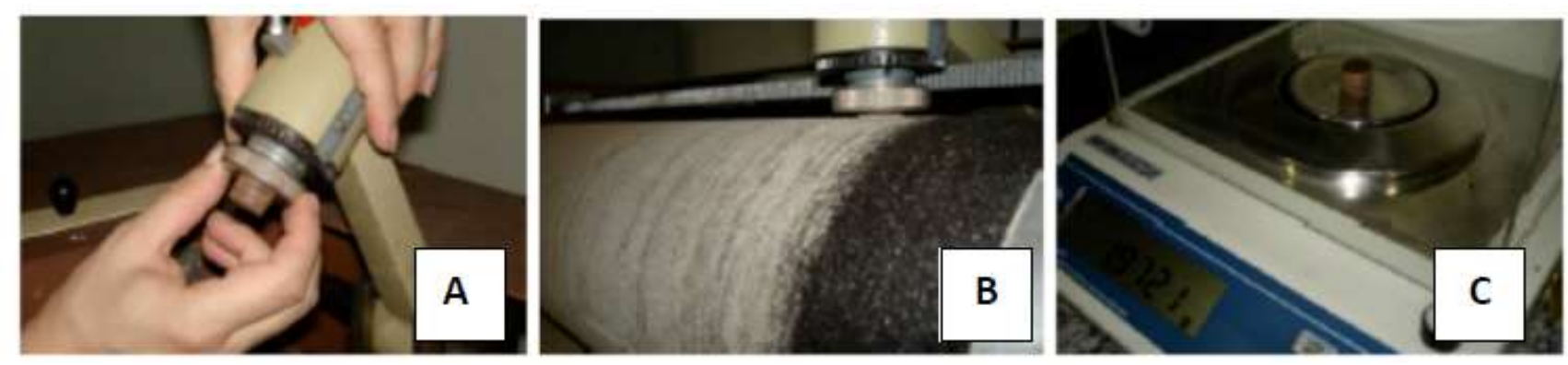

Figura 4 --- Corpo de prova a ser ensaiado (A); corpo de prova ao final do ensaio (B) e corpo de prova pesado ao final do ensaio (C)

MEV - A análise por MEV teve como objetivo observar a superfície dos corpos de prova dos compósitos após o ensaio de abrasão, comparando---os com outras madeiras utilizadas para confecção de pisos. As madeiras utilizadas para comparar as propriedades de resistência à abrasão com os compósitos deste estudo foram pupunha e coqueiro, por serem madeiras ditas alternativas. As amostras foram analisadas em um câmara de amostra em baixo vácuo (entre 1 e 10 torr). Portanto, não houve metalização prévia nas amostras do compósito.

\subsection{RESULTADOS E DISCUSSÕES}

Ensaio de Resistência à Abrasão - Para agilizar a leitura, convencionou---se Material 1 (para o compósito de fibra de ubuçu e resina de mamona com proporção 1:1 de seus componentes) e Material 2 (para o compósito de fibra de ubuçu e resina de mamona com proporção 1:1 de seus componentes) e Material 3 (para o compósito de fibra de ubuçu e resina epóxi). A Figura 5 ilustra os valores 
computados para as médias das massas (g) das amostras. A Figura 6 ilustra o desgaste abrasivo em (\%) para cada material analisado.

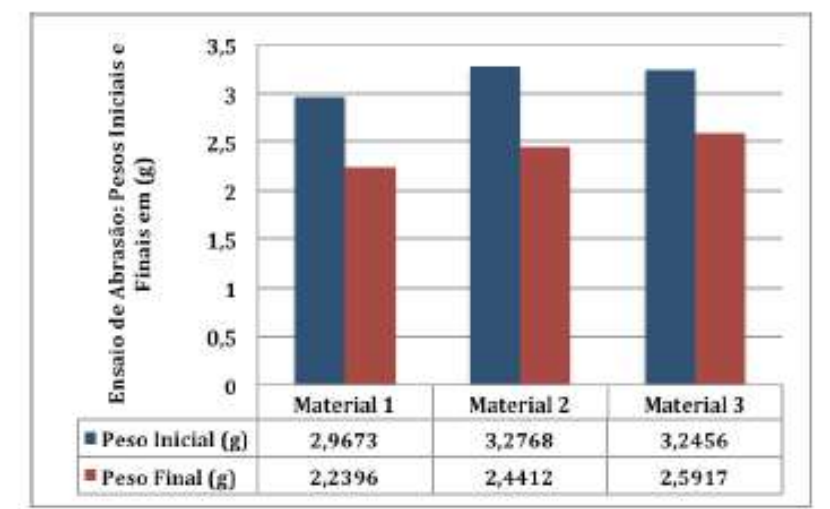

Figura 5 - Abrasão - Pesos iniciais e finais.

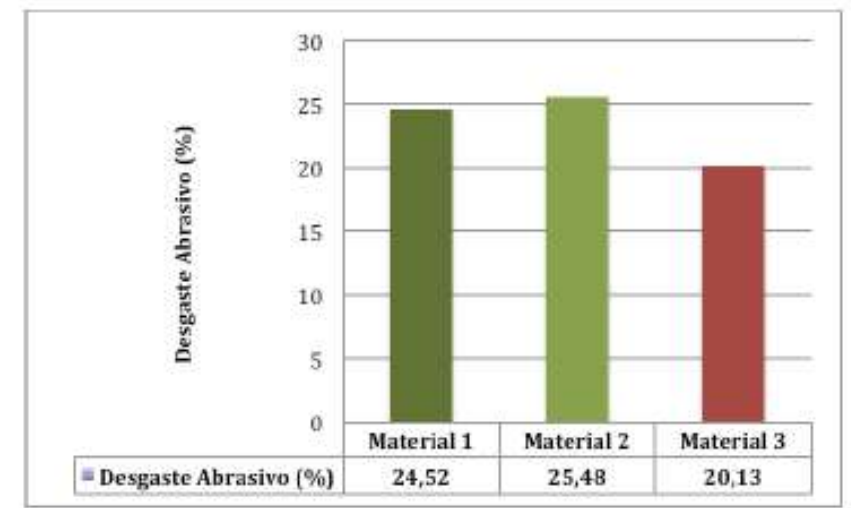

Figura 6 - Desgaste abrasivo (\%).

Os valores das médias das massas foram transformados em porcentagem na Figura 6, a fim de se analisar o desgaste abrasivo sofrido por cada material. Assim, é possível observar que Material 1 apresentou um desgaste abrasivo (24,52 $\pm 0,08 \%)$ e o Material 2 um desgaste abrasivo $(20,13 \pm 0,07 \%)$. O que se pode concluir em relação ao desgaste abrasivo destes materiais é que ambos apresentaram uma massa final de mais de $60 \%$ de massa inicial após o percurso de $40 \mathrm{~m}$, o que tecnicamente os torna viáveis para serem utilizados como material para pisos. O resultado de menor desgaste abrasivo para o Material 3 esta diretamente relacionado com o fato de a resina epóxi ser mais rígida que a resina de mamona.

Observando---se resultados da literatura, OLIVEIRA (2005) pesquisou o uso do bambu laminado colado na fabricação de pisos e encontrou um desgaste abrasivo para esta gramínea de 20,34\%, comparável com os valores aqui encontrados. OLIVEIRA (2005) também reportou valores de desgaste abrasivo para o ipê (12,63\%), sucupira (15,68\%) e jatobá $(23,67 \%)$. Comparando os valores de desgaste abrasivo para as madeiras de lei com os encontrados nesta pesquisa, é possível concluir que os compósitos ora analisados, apresentam viabilidade técnica de utilização na fabricação de pisos, já que o desgaste abrasivo apresentado foi menor que $26 \%$ para todas as amostras. É importante frisar que a realização de uma comparação entre os compósitos e estas madeiras se deu pelo fato de as madeiras serem consideradas compósitos naturais. 
Em função das propriedades das matérias primas até então apresentadas e discutidas, das disponibilidades regionais e da problemática ecológica em relação a algumas madeiras, o uso desse compósito alternativo, pode ser uma fonte de renda para a população que o produzir, especificamente, a população ribeirinha do Estado do Amapá. Dessa forma, os resultados do ensaio de abrasão vêm fortalecer essa ideia, fornecendo dados técnicos sobre o uso desse compósito na fabricação de pisos do tipo taco.

MEV - Após a realização do ensaio de abrasão, as amostras testadas foram acondicionadas e levadas ao laboratório de microscopia eletrônica de varredura a fim de se analisar as superfícies que sofreram abrasão. Desta forma, coletou---se uma amostra de cada grupo de material analisado e capturaram---se imagens em quatro aumentos, ou seja, 50; 100; 150; e 200 vezes.

A Figura 7 apresenta o bloco de micrografias obtidas para o Material 1. É possível observar na Figura 7A os riscos causados pelos grânulos da lixa abrasiva (seta branca). De forma geral, não é perceptível a existência de fibras expostas na superfície. Na Figura 7B é possível observar em maior detalhe que a superfície apresenta uma maior quantidade de riscos (setas brancas) causados pelos grânulos da lixa, bem com a existência de fibras expostas (setas pretas). As Figuras 7C e 7D apresentam mais detalhadamente a superfície (setas brancas), sem maiores quantidades de fibras expostas.

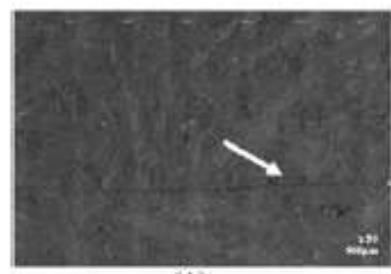

(A)

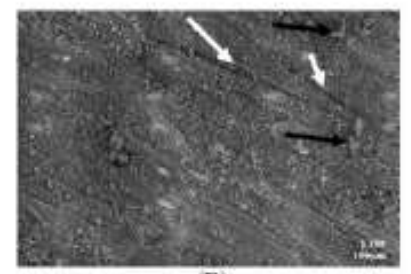

(B)

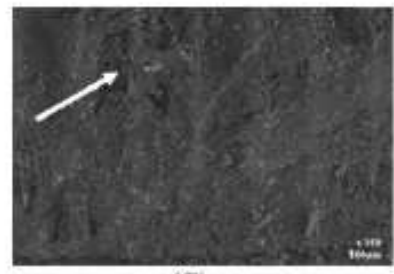

(C)

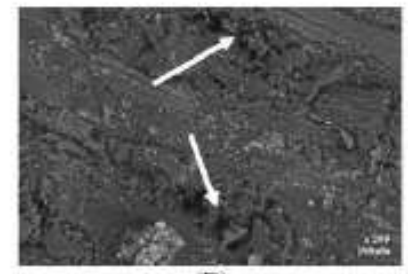

(D)

Figura 7 - Micrografias da superfície que sofreu abrasão do Material 1

A Figura 8 apresenta o bloco de micrografias obtidas para o Material 2. Nas Figuras 8A e 8B é possível observar que a superfície do Material 2 é bastante irregular e apresenta um número grande de fibras expostas (setas brancas). Nas Figuras $8 \mathrm{C}$ e 8D já é possível observar em maior detalhe as fibras expostas (setas brancas) na superfície. Comparando---se este bloco de micrografias com as do Material 1, é possível concluir que maiores quantidades de fibras foram expostas na superfície do Material 2, o que o faz menos resistente à abrasão. De fato, esse compósito foi o que mostrou o maior desgaste abrasivo. 


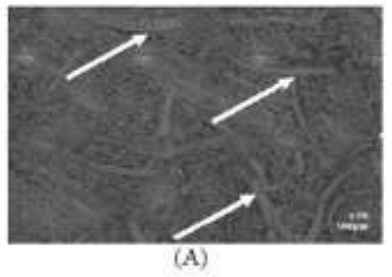

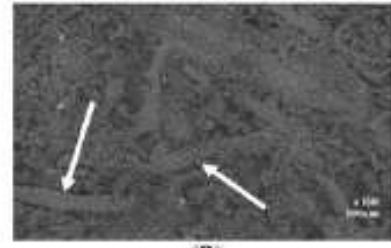

(B)

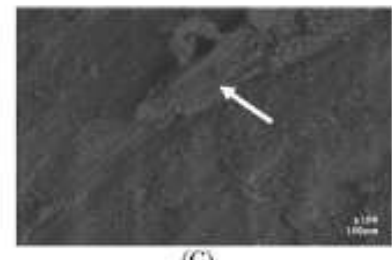

(C)

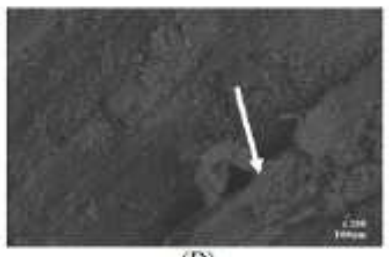

(D)

Figura 8 - Micrografias da superfície que sofreu abrasão do Material 2

A Figura 9 apresenta o bloco de micrografias para o Material 3. De forma geral, a superfície se apresenta mais regular em termos de danos do que a do Material 2. Nas Figuras 9A e 9B é possível observar que a superfície do Material 3 é bastante regular, porém apresenta algumas fibras expostas (setas brancas), o que não acontece com a superfície do Material 1. Nas Figuras 9C e 9D já é possível observar em maior detalhe as fibras expostas (setas brancas), bem como a presença de alguns sulcos causados pelos grânulos da lixa abrasiva (setas pretas). Comparando---se este bloco de micrografias com o Material 2, é possível concluir que menores quantidades de fibras foram expostas na superfície do Material 3, bem como a superfície se apresentou mais regular ou menos danificada que as outras, devendo---se este fato, a natureza rígida da matriz epóxi. De maneira geral, os três materiais compósitos aqui analisados não apresentaram trincas em sua superfície, o que demonstra a eficácia de reforço das fibras de ubuçu nas matrizes poliméricas.

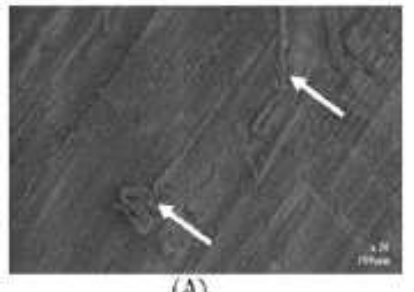

(A)

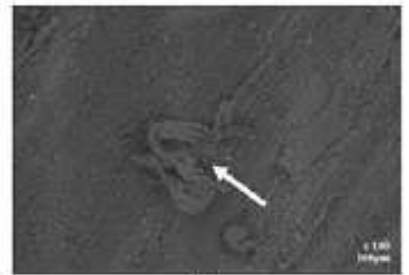

(B)

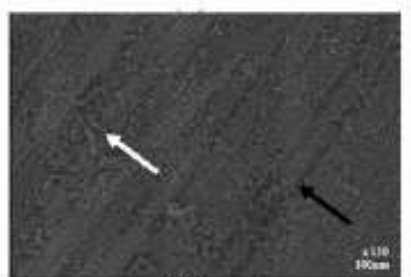

(C)

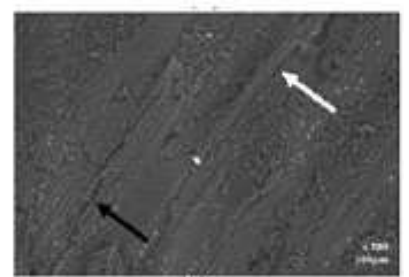

(D)

Figura 9 - Micrografias da superfície que sofreu abrasão do Material 3

Amostras de pupunha e coqueiro foram também testadas em abrasão e suas superfícies analisadas em MEV para serem comparadas com as dos materiais compósitos aqui estudados, pois apresentam desgaste abrasivo pequeno (BACELLAR, 2010). A Figura 10 apresenta o bloco de micrografias obtidas para a madeira de pupunha. Nas Figuras 10A e 10B é possível observar que a superfície da pupunha apresenta como principal característica a presença de trincas (setas pretas). Nas Figuras 10C e 10D já é possível observar em maior detalhe que também existem as fibras expostas (setas brancas). A presença de grandes sulcos causados pelos grânulos da lixa abrasiva (setas pretas) e trincas também são evidentes nessas micrografias. 


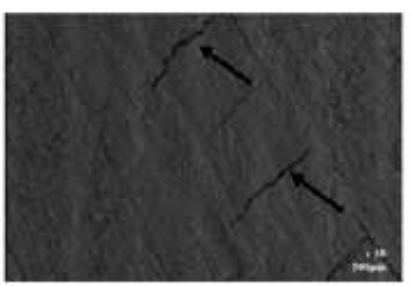

(A)

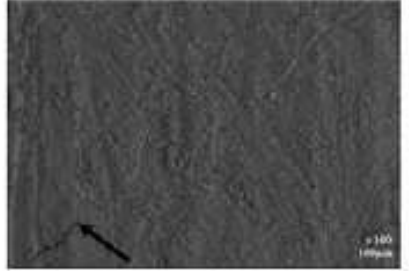

(B)

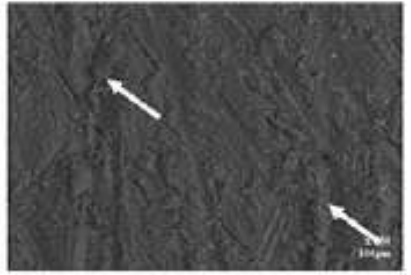

(C)

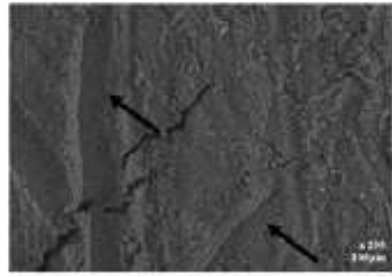

(D)

Figura 10 - Micrografias da superfície que sofreu abrasão da pupunha

Comparando---se as micrografias da pupunha com as micrografias dos compósitos analisados, é possível verificar que esta madeira apresentou três tipos de falhas na superfície: fibras expostas, presença de sulcos (mais severos que os existentes nos compósitos) e, principalmente a presença de trincas, faz com que haja infiltração de umidade no material. As trincas não foram detectadas nos compósitos, o que pode indicar que tais materiais podem ser utilizados na fabricação de pisos e revestimentos sem a problemática da existência de trincas.

A Figura 11 apresenta o bloco de micrografias obtidas para a madeira de coqueiro. A principal caraterística observada nas Figuras 11A e 11B é a presença de trincas na superfície do coqueiro, bem parecidas com as da pupunha (setas brancas). Nas Figuras 11C e 11D já é possível observar em maior detalhe a superfície irregular, a presença de sulcos causados pelos grânulos da lixa abrasiva (setas brancas). A existência de trincas pode vir do fato de que as madeiras de coqueiro e pupunha são compactas, o que as torna mais propícias ao surgimento dessas trincas. Em relação a este fato, JANKOWSKY (2002), cita que as rachaduras ou trincas aparecem como consequência da diferença de retração nas direções radial e tangencial da madeira e de diferenças de umidade entre regiões contíguas de uma peça, durante o processo de secagem. Essas diferenças levam ao aparecimento de tensões que, tomando---se superiores à resistência dos tecidos lenhosos, provocam a ruptura da madeira.

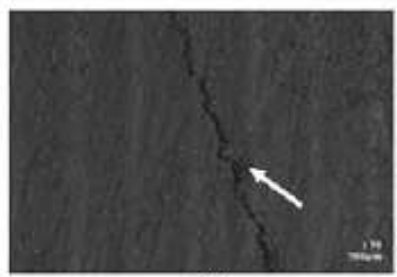

(A)

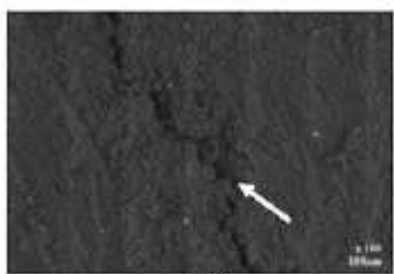

(B)

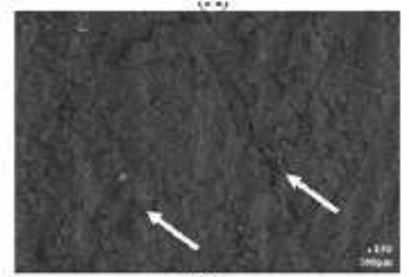

(C)

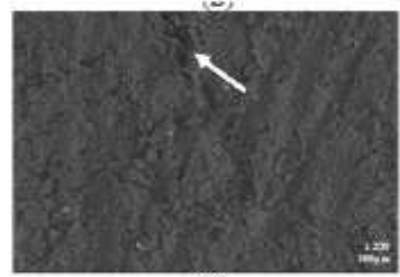

(D)

Figura 11 - Micrografias da superfície que sofreu abrasão do coqueiro

Comparando---se as madeiras de coqueiro e pupunha com os compósitos fabricados nesta pesquisa, é possível concluir que as trincas encontradas nas ditas "madeiras alternativas" são 
prejudiciais ao seu uso em pisos. Mesmo os três compósitos analisados apresentando um desgaste abrasivo maior que as madeiras de pupunha e coqueiro, eles não apresentaram trincas na superfície, o que os torna eficientes para a fabricação de pisos e revestimentos.

Projeto do Piso - Com os excelentes resultados obtidos, optou---se por fabricar um piso do tipo "taco" residencial com o Material 1. A Figura 12 ilustra três possíveis configurações do piso, a saber: Tijolinho (A), Espinha de Peixe (B) e Quadrado (C).
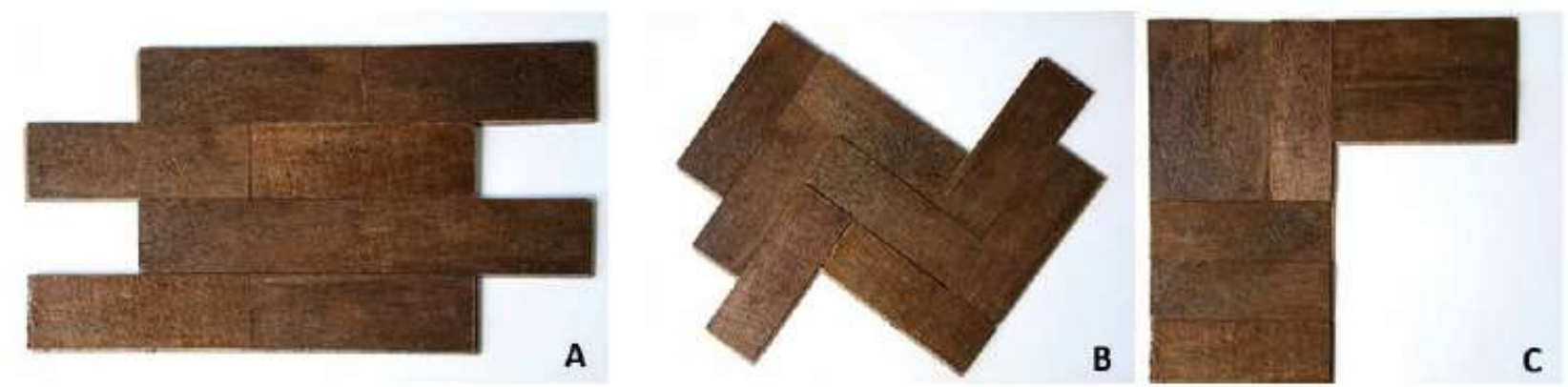

Figura 12 - Configurações formais do piso projetado com o compósito do Material 1.

\section{CONCLUSÃO}

Os compósitos pesquisados apresentaram bons resultados de resistência à abrasão, tornando---os aplicáveis para a fabricação de pisos e revestimentos diversos. O Design de Produtos pode apresentar sua contribuição para com o meio ambiente ao utilizar como matéria---prima em seus projetos, materiais com menor impacto ambiental, não sendo este, logicamente o único caminho, mas uma entre tantas outras formas de se trabalhar em consonância com as condições ambientais atuais de nosso planeta. A transição rumo a sustentabilidade requer dos designers, qualidades como criatividade e comprometimento com o meio ambiente, pois estes são parte da solução que se vem buscando para nosso caótico quadro ambiental em que nos encontramos. 


\section{REFERÊNCIAS}

ARAÚJO, C.R.; PERLAZA, L.C.; MOTHÉ, C.G. Thermal properties of commercial and castoir oil polyurethane composites with curaua fiber. In: Fouth International Symposium on Natural Polymers and Composites, São Paulo. 2002.

ASTM D2240---05: Standard test method for rubber property - Durometer 2010.

BACELLAR, R.S.; D'ALMEIDA, J.R.M. Caracterização microestrutural e mecânica de resíduos da agroindústria. Dissertação (Mestrado). Programa de Pós---Graduação em Engenharia de Materiais. PUC Rio. 120p. 2010.

BRT. Serviço Brasileiro de Resposta Técnica. Fibra de Tururi. Disponível em: http://www.brt.com.br/htm acesso em: 08 de maio de 2008.

BOYNARD, C.A.; D'ALMEIDA, J.R.M.; CARVALHO, L.H. Avaliação da adição da mistura isocianato/poliol sobre as propriedades mecânicas de uma resina poliéster. 4을 Congresso Brasileiro de Polímeros. Salvador---Ba. CD---Rom, p.13. 1997.

CORRÊA, M. P. Dicionário das plantas úteis do Brasil e das exóticas cultivadas (v. 6). Rio de Janeiro: Imprensa Nacional, 1978.

DIN 53516 - Deutsches Institute fur Normung. Tested a borracha, elastômeros: determinação da resistência a abrasão. Berlin: DIN, 12p.1987.

FERNANDES, Tania Freitas. Preparação e caracterização de novos materiais compósitos baseados em fibras de celulose. Dissertação de Mestrado. Universidade de Aveiro. Departamento de Química. 2005. Páginas 93.

GODOY, J. Estudo de um novo compósito madeira---resina poliuretano para o desenvolvimento de um isolador híbrido. Dissertação (Mestrado), Escola de Engenharia de São Carlos. Universidade de São Paulo. 122p. 2007.

JANKOWSKY, L.P. Defeitos na Secagem de Madeiras. LCF/ESALQ/USP. Revisado em 20/08/2002. Disponível em: http://www.ipef.br/tecprodutos/defsecagem.asp. Acesso em: 18 de junho de 2011.

MANZINI, E.; VEZZOLI, C. O desenvolvimento de produtos sustentáveis - Os requisitos ambientais dos produtos industriais. 1. Ed. São Paulo: Editora da Universidade de São Paulo, 2005.

MANZINI, E. Design para a inovação social e sustentabilidade: comunidades criativas, organizações colaborativas e novas redes projetuais. Rio de Janeiro: E---papers, 2008. (Caderno do Grupo de Altos Estudos; v.1).

MARTIUS, C. F. P. Historia naturalis palmarum: opus tripartitum. 1. ed. Germany. 1823. 550p.

OLIVEIRA, A.K.F.; D `ALMEIDA, J.R.M. Caracterização da fibra de tururi como elemento para fabricação de eco---compósitos. Anais do 9o P\&D Design. 2010. 9o Congresso Brasileiro de Pesquisa e Desenvolvimento em Design. 2010. 
OLIVEIRA, A.K.F.; PAES, J.B.P. Caracterização físico---mecânicas de laminado colado de bambu (Dendrocalamus giganteus) para revestimento de pisos. Dissertação (Mestrado). Programa de Pós--- Graduação em Engenharia Agrícola, Universidade Federal de Campina Grande. 70p. 2005.

VILAR, W.D. Química e tecnologia dos poliuretanos. Rio de Janeiro: Vilar, 340p, 1993. WOODS, G. The ICl polyurethanes book. New York: John Willey. 1990.

Este artigo foi publicado inicialmente no 11ㅇ P\&D Design - Congresso Brasileiro de Pesquisa e Desenvolvimento em Design/2014. Gramado, RS.

Blucher Design Proceedings / Novembro de 2014, Número 4, Volume1

www.proceedings.blucher.com.br/evento/11ped 


\section{Capítulo 5}

\section{doi) $10.37423 / 210403767$}

\section{DESIGN DA INFORMAÇÃO, DESIGN GRÁFICO E O PENSAR SUSTENTÁVEL}

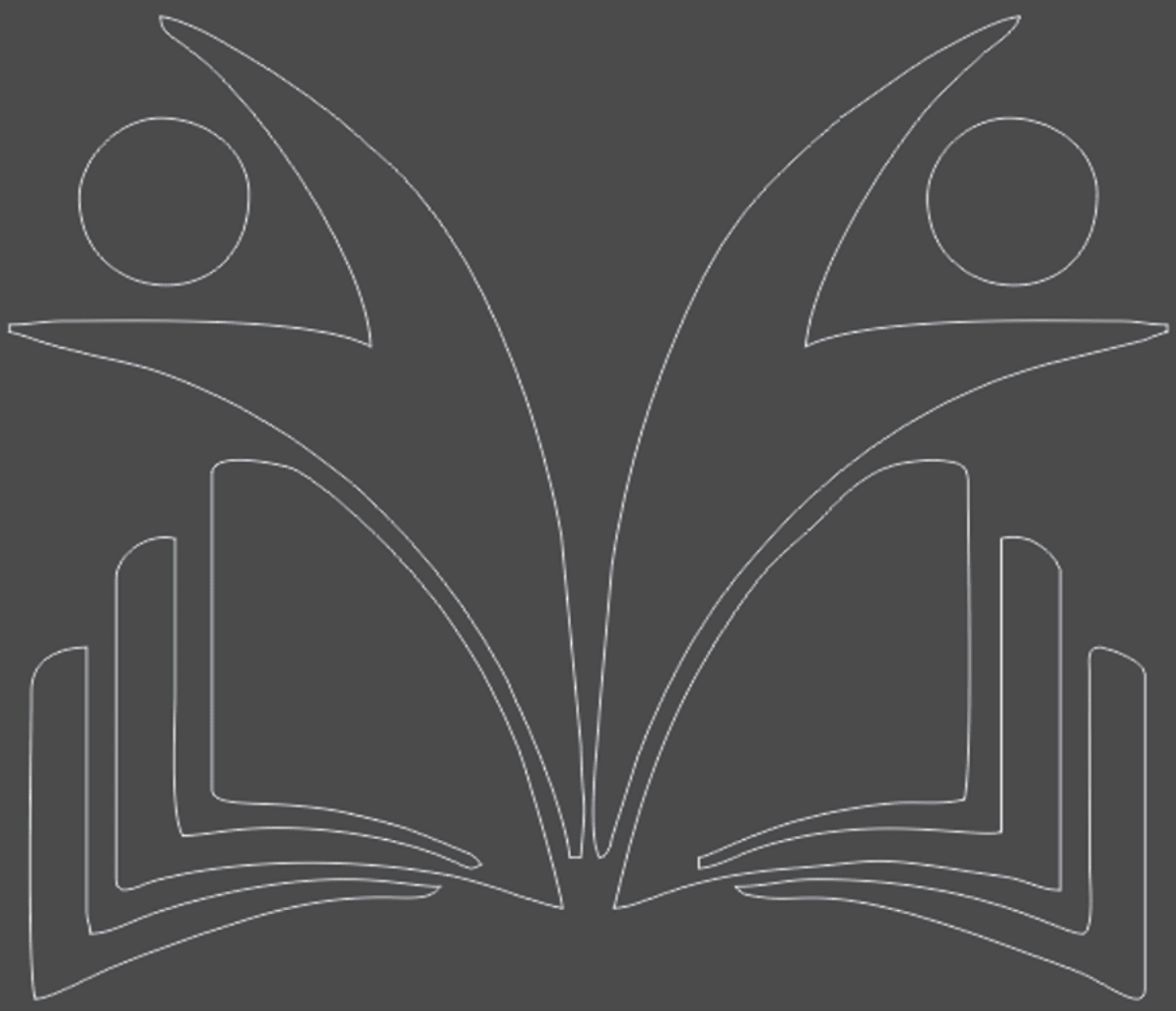




\section{Design Da Informação, Design Gráfico E O Pensar Sustentável}

Resumo: O presente artigo propõe evidenciar a contribuição do Design da Informação com o pensar e agir sustentavelmente nos cursos de design, principalmente nos de design gráfico. A sustentabilidade é um tema necessário para ser debatido entre alunos e professores, facilitando desta maneira a percepção dos mesmos e propondo práticas que possam minimizar os impactos ambientais, seja por reutilizar ou reciclar matérias, seja pela escolha de materiais biodegradáveis. Entretanto, com base bibliográfica, a maioria dos cursos nem se quer apresenta o debate sobre o ambiente. Para tanto, é necessário haver reconhecimento da importância dessa duas instancias, o design da informação como veículo propulsor de informação e organização dos conteúdos, e os cursos de design, para a teoria e prática.

Palavras-chave: design da informação, design gráfico, sustentabilidade. 


\section{Design Da Informação, Design Gráfico E O Pensar Sustentável}

\section{INTRODUÇÃO}

Discorrer sobre sustentabilidade é ao mesmo tempo um assunto antigo e novo. Essa dualidade se dá porque se por um lado, sua presença se fortifica em várias áreas do conhecimento, por outro ela não é nem citada. Embora ela seja um tema transversal no Brasil, muitas escolas não trabalham esse assunto.

Quanto ao ensino superior, se faz importante tanto para o corpo administrativo quanto docente e discente, o pensar e agir ecologicamente, gerando uma relação de ensino/aprendizagem tanto na sala de aula quanto extraclasse, envolvendo assim a comunidade de entorno para encontrar soluções sustentáveis (PONTES, 2015).

É nessa parte que o Design da Informação mostra a sua importância: otimizar o processo de aquisição da informação através de elementos facilitadores, organizando o conteúdo para que seja compreensível, fácil e assimilável.

A organização da informação bem como a sua apresentação, são tão importantes quanto o próprio conteúdo apresentado. E o resultado, em reflexão e ação para minimizar os impactos ambientais produzidos por designers e estudantes de design, é o alvo da presente pesquisa.

\section{FUNDAMENTAÇÃO TEÓRICA}

O material utilizado por um designer gráfico paira entre digital e físico, com elementos textuais e nãotextuais (VILLAS-BOAS, 1999), em que aquele pode apresentar lixos eletrônicos, e este, lixos nocivos ao meio ambiente.

Muitos dos materiais descartados pelo profissional de designer, e até mesmo enquanto alunos de graduação, poderiam ser reutilizados, reaproveitados e/ou reciclados, ao invés de simplesmente comporem o lixo. E além disso, a própria escolha do material pode ser pensando na sustentabilidade, com materiais recicláveis e biodegradáveis (CALEGARI \& DE OLIVEIRA, 2014).

O papel do design é a solução de problemas, e isso também inclui a oportunidade e possibilidade de combinar com o comportamento sustentável - Design for Sustainable Behavior (MUNIZ \& DOS SANTOS, 2015), incluindo estratégias para o bom design. Diante disso, o design atua como um incentivador entre inovação e sustentabilidade, entre ações estratégicas e sensibilização ambiental, entre desafiador e conscientizador, simplesmente porque insere e projeta o design com o sustentável, 


\section{Design Da Informação, Design Gráfico E O Pensar Sustentável}

incluindo termos e ações como Eco-design, Eco-innovation, Life cycle thinking, Eco-efficient, Green Design, Ecodesign tools, Bio-ispired design approach (ALANO \& FIGUEIREDO, 2014).

O reduzir ou eliminar materiais danosos ambientalmente, bem como inserir a reutilização e reciclagem de produtos, poderá ser visto como inadequado no mercado, já que o foco é apenas no impacto ambiental e não as necessidades dos clientes. Chaves (2010) considera sim possível o desenvolvimento de estratégias eficientes para ambos os lados, sendo preciso a criação de ferramentas e estratégias e métodos específicos para tal.

É aqui onde o Design da Informação consegue seu espaço, tanto para fazer essa correlação entre o design com o meio ambiente, quanto em trazer à tona essa reflexão, conscientização, e a informação de que é possível essa união.

\section{MÉTODO E RESULTADO}

Quanto à realização da pesquisa, foi utilizada uma revisão bibliográfica.

De um modo geral, o pensar holisticamente o papel do design gráfico é um grande desafio, visto a falta e o pouco espaço que essa temática ocupa em cursos superiores no Brasil. Segundo Calegari \& De Oliveira (2014), poucas são as instituições de ensino superior que apresentam este tema no seu currículo, sendo indispensável essa abordagem para minimizar os impactos ambientais, sociais e econômicos. Para tanto, é preciso haver na grade curricular dos cursos de design os fundamentos teóricos e práticos da sustentabilidade, seja em uma disciplina, seja nas discursões interdisciplinares Segundo Abbonizio (2009), é na relação entre design e prática educativa que pode haver mudanças. Essas transformações são processos, que se iniciam em conhecimentos, valores e práticas, resignificando os conceitos e as práticas. Desta maneira, alunos, professores, administração de ensino, e a comunidade, poderão ser cidadãos conscientes ambientalmente.

Segundo Castillo \& Gómez (2014), sobre os rótulos ambientais nas embalagens, evidenciam que os consumidores precisam fazer a sua parte antes da compra. Entretanto, se não há incentivo para essa leitura, percepção e até mesmo alfabetização sobre o que significa os símbolos, torna-se difícil alcançar o conhecimento do papel do consumidor bem como sobre a informação do selo. Se faz necessário informações sobre o impacto que certos materiais causam no ambiente, e consequentemente na saúde e na economia. O design da informação é extremamente imprescindível. 


\section{Design Da Informação, Design Gráfico E O Pensar Sustentável}

\section{CONSIDERAÇÕES FINAIS}

Embora hoje no Brasil, na grande maioria cursos de design gráfico, não há aprofundamento nem debate sobre o pensar sustentavelmente, as pressões ambientais poderão fazer surgir essa necessidade, a não ser que o design da informação atue como propulsor, através de ilustrações, gráficos, organização de conteúdo e exemplos da possiblidade de unir ações efetivas ambientalmente entre professores e alunos de design, atingindo a sociedade de maneira positiva, encorajando um pensar mundial sustentável.

É evidente que se existe uma problemática ambiental, e o adiar desse debate e ação afasta cada vez mais os propósitos do design da informação e do design gráfico, como facilitadores de comunicação e solucionadores de problemas.

A identificação no problema ambiental, e sua solução, começa entre os que detém essa informação, e dos profissionais que propõem produtos a serem consumidos, e também passa pela comunidade, que as vezes percebe o que está acontecendo. A informação precisa alcançar todos esses indivíduos, seja explicando os rótulos dos produtos, seja proporcionando esclarecimento do impacto de certos produtos, mas só será possível se houve mudança sobre o espaço de teoria e prática deste tema no Brasil. 


\section{Design Da Informação, Design Gráfico E O Pensar Sustentável}

\section{REFERÊNCIAS}

ABBONIZIO, M. A. O. 2009. Aproximação teórica das intervenções de design no artesanato com os princípios pedagógicos de Paulo Freire: caminhos para uma prática emancipatória. Dissertação (Mestrado em Design) - Universidade Federal do Paraná. Curitiba.

ALANO, A. B. \& FIGUEIREDO, L. F. G. de.2014. Design como inovação em sustentabilidade: uma revisão sistemática da literatura. 11ㅇ P \& D Design. Gramado - RS; 2014. Blucher Design Proceedings Novembro de 2014, Número 4, Volume 1.

CALEGARI, E. P. \& DE OLIVEIRA, B. F. 2014. Design para a sustentabilidade e o ciclo de vida dos materiais: uma reflexão acerca da produção de compósitos biodegradáveis. 11 $P$ \& D Design. Gramado - RS; 2014. Blucher Design Proceedings Novembro de 2014, Número 4, Volume 1.

CHAVES, L. I. 2010. Design para a sustentabilidade ambiental: estratégias, métodos e ferramentas de design para o setor de móveis. Estudos em Design (Online), v. 18.1, p. 4.

CASTILLO, L. \& GÓMEZ, C. R. P. 2014. Percepção dos usuários sobre selos e rótulos ambientais em embalagens. In: Coutinho, Solange G.; Moura, Monica; Campello, Silvio Barreto; Cadena, Renata A.; Almeida, Swanne (orgs.). Proceedings of the 6th Information Design International Conference, 5th InfoDesign, 6th CONGIC [= Blucher Design Proceedings, num.2, vol.1]. São Paulo: Blucher.

MUNIZ, M O. \& DOS SANTOS, A. 2015. A pesquisa em Design para o comportamento sustentável: lacunas e desafios. SBDS 15. 5 Simpósio de Design Sustentável. Rio de Janeiro. P. 365 - 376.

PONTES, A. S. M.; et al. 2015. Sustentabilidade e educação superior: análise das ações de sustentabilidade de duas instituições de ensino superior de Santa Catarina. Rev. Adm. UFSM, Santa Maria, v. 8, Edição Especial, p. 84-103, AGO. 2015.

VILLAS-BOAS, A. 2003. O que [é e o que nunca foi] Design. Rio de Janeiro.5a ed. Ed. 2AB; 2003. 


\section{Capítulo 6}

doi $10.37423 / 210403734$

\section{MARKETING PROMOCIONAL: UMA ANÁLISE QUANTITATIVA DAS INFLUÊNCIAS PROMOCIONAIS NA TOMADA DE DECISÕES DE COMPRA DO CONSUMIDOR}

Raphaela Pereira Rangel

Gustavo Lopes Olivares

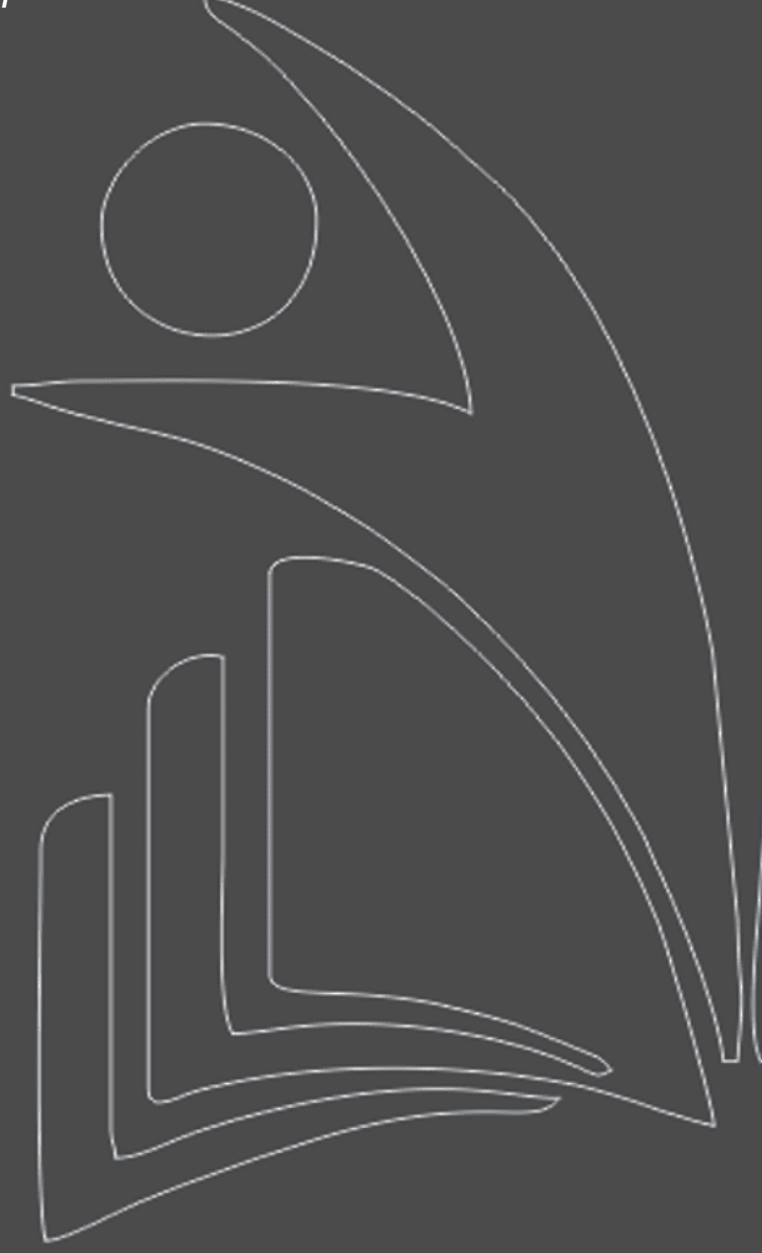

Universidade Federal Rural do Rio de Janeiro

Universidade Federal Rural do Rio de Janeiro 
Resumo: O mundo multinacionalizado está sujeito a passar por várias mudanças. Todos os dias estão surgindo novos métodos de gestão, fazendo com que as empresas criem estratégias pensando nas mudanças. Dentro dos processos organizacionais, o marketing desempenha uma função precisa e assertiva, disponibiliza a união das ferramentas para que estas empresas elaborarem diferentes técnicas para alcançar todas as suas metas. Uma dessas ferramentas é a análise dos movimentos de todos os consumidores em relação as suas necessidades e desejos. Neste contexto, o propósito desse estudo é avaliar como funciona as promoções sob as decisões dos consumidores, observando os recursos efetivos utilizados pelas instituições para acompanharem as atividades características do mundo contemporâneo. Com esta finalidade, foram realizados questionários virtuais através do Google Forms, onde foram alcançados 37 respondentes. Todos estes dados foram analisados pelo software SPSS, onde os resultados mostraram um percentual de que $80 \%$ das participantes consomem produtos pela possibilidade de obter alguma vantagem ou promoção. Posto isto, os estudos contribuíram parar corroborar com teorias de planejamento de marketing, bem como para maiores benefícios de sua gestão.

Palavras-Chave: Gestão, marketing promocional, comportamento do consumidor 


\section{INTRODUÇÃO}

As organizações mais modernas investem estratégias direcionadas para as mudanças no meio ambiente e as tonicidades impostas por cada uma delas. Os clientes estão cada vez mais exigentes por um bom serviço, bons produtos e seus ciclos de vida, além das mudanças tecnológicas nas áreas de informação e comunicação. A maneira intensa como essas mudanças impactam de forma direta em todas as práticas, necessidades e formas de se comportar dos consumidores potenciais são tidos como desejos de todos os segmentos de mercado.

Com essa perspectiva, torna-se um requisito realizar a comunicação e a venda de produtos e serviços de forma efetiva afim de preservar a concorrência no mercado. Deste modo, o Marketing tem propósitos importantes ao lidar com necessidades de possíveis clientes, buscando que estes se sintam satisfeitos. Ainda assim, devem considerar que que estes possíveis clientes, podem não ser capazes de terem percepções de acordo com todas as motivações e agirem com certas influências fazendo modificações ao longo desse processo (KOTLER, 2012)

Com base nisso, surge o conceito de marketing necessário para a elaboração deste estudo, o Comportamento do Consumidor. Conforme Solomon (2002), o comportamento dos consumidores é o procedimento pelo qual o indivíduo ou grupo, seleciona, compra, utiliza ou contrata serviços para obter experiências e satisfazer necessidades e desejos.

De acordo com Las Casas (2005), é preciso compreender o porquê e de que forma os consumidores realizam suas compras, pois é preciso que as empresas consigam atingir essas metas mercadorias e atendimento razoável, tendo em vista que existe muitas categorias diversificadas de consumidores e os seus motivos de efetuarem compras.

A escolha para realização da compra começa com a identificação da necessidade ou simples desejo, que pode se manifestar através de uma percepção interna ou estímulos externos, como por exemplo, as atividades promocionais. Os motivos para compra surgem como causas da percepção de uma necessidade, por parte do consumidor (CHURCHILL;PETTER, 2003). Ao passo que, Kotler (2006) defende que esse desejo são tipos de necessidades básicas do indivíduo, como tipos de carências de satisfação específica criadas pelas forças e empresas sociais.

Com base nesta lógica, o propósito essencial desta pesquisa foi identificar as influências que os consumidores sofrem na tomada de decisão de compras por parte do marketing promocional das empresas. 


\section{FUNDAMENTAÇÃO TEÓRICA}

\subsection{COMUNICAÇÃO INTEGRADA DE MARKETING (CIM)}

A Comunicação Integrada de Marketing (CIM) é defendida por Dias (2003), como algo que possibilita o reconhecimento da comunicação de marketing tornando-o eficaz em atingir suas metas somente se seus elementos do programa de comunicação forem utilizados de formas coordenadas e integradas, ao ponto de conseguirem emitir uma única mensagem que seja consistente para todos os consumidores finais de um determinado serviço ou produto.

De acordo com Crescitelli e Figueiredo (2011), as demasiadas e distintas informações no mercado atual tornam mais complexa a comunicação das empresas com seus clientes. Consequentemente, essas empresas tentam buscar cada vez mais por novas metodologias. Diferentes maneiras que surgem do desejo de se obter muitas informações e codificá-las em uma única só mensagem de forma mais exclusiva com a ajuda da CIM. Essa compreensão movimentou a busca por outras operações além da comunicação, tendo como foco as "tentativas de olhar o cliente" como um início para o processo de concepção de uma "rede" comunicativa na empresa (ZUCO;REIS, 2010).

Desta forma, a CIM tem propósito em atingir os consumidores com uma única mensagem que seja eficaz, através de um conjunto de ferramentas comunicacionais que crie um "elo perene" entre as empresas e seus clientes (SANTOS;FERREIRA;PAIXÃO, 2017), fortalecendo a representação da empresa no mercado, aprimorando estratégias comunicativas apropriadas (OGDEN;CRESCITELI, 2007), e ainda, uma ação construtiva perante as demais empresas que precisam fazer sua marca no mercado de multinacionais (OLIVA;SERRALVO; JOÃO; FURLANI, 2015).

\subsection{MARKETING PROMOCIONAL}

O Marketing Promocional é definido pela Associação de Marketing Promocional (2017), como uma comunicação com o propósito de fomentar a "percepção de valor" por meio de ferramentas de promoção e diálogo com clientes levando-os a compra, e os fidelizando através de experiências com seus produtos e serviços (AMPRO, 2017). Segundo a AMPRO (2017), o marketing promocional deve ser dividido em distribuição e apresentação dos serviços ou produtos, com o incentivo de algumas técnicas de promoção como ofertas (sejam elas monetárias ou não) e eventos promocionais com distribuição de prêmios e brindes. 
Construir uma boa estratégia de marketing promocional traz um grande significado, aumentando maiores chances de se obter novos clientes e transformá-los em clientes fidelizados. Os incentivos de curto prazo, conforme Kotler e Armstrong (2001), serve como um ato de impulsionar a decisão de compra ou venda, lembrando que as ofertas promocionais tem o propósito de incentivar a compra de forma imediata.

\section{PROCEDIMENTOS METODOLÓGICOS}

Os procedimentos metodológicos empregados para o alcance dos objetivos deste estudo, são apresentados nesta seção.

Quanto à sua finalidade, este estudo pode ser apresentado como descritivo, visto que, possuem características de pesquisa de opinião. E segundo Vergara (2007), a pesquisa de opinião se insere como pesquisa descritiva.

Ainda conforme, Vergara (2007), a pesquisa deve ser classificada quanto aos seus meios de investigação. Dessa forma este estudo se caracteriza como pesquisa de campo, documental e bibliográfica.

\subsection{COLETA DE DADOS}

Um questionário virtual foi desenvolvido e aplicado com o auxílio da ferramenta Google Forms, visando obter dados importantes para a realização deste estudo. O questionário virtual foi disponibilizado para 50 (cinquenta) indivíduos, sendo que 37 (trinta e sete) retornaram, constando $100 \%$ (cem por cento) das questões respondidas, conforme o próprio Google Forms.

Para efeito deste estudo, optou-se por dividir o questionário em duas partes: a primeira visava variáveis referentes aos fatores socioeconômicos, já a segunda parte visava, de forma mais direta o foco deste estudo, as influências de promoções na decisão de compra.

\subsection{TRATAMENTO DOS DADOS}

Para o tratamento dos dados da pesquisa optou-se por recorrer a uma ferramenta quantitativa. Escolheu-se, portanto, o software SPSS (Statistical Package for Social Sciences), muito aplicado para análises estatísticas. Com a ajuda do software SPSS, os dados foram tabulados e transformados em tabelas e gráficos. 
Após a inserção de todos os dados, eles foram interpretados, observando questão por questão, procurando sempre analisar todas as variáveis nominais pela sua frequência e seu percentual, e as variáveis ordinais por meio de moda e média.

\section{ANÁLISE DOS DADOS}

Os dados obtidos através da aplicação do questionário, foram divididos em duas partes: variáveis socioeconômicas e variáveis de marketing, e são apresentados nesta seção.

\subsection{VARIÁVEIS SOCIOECONÔMICAS}

A primeira questão do questionário abordou a idade dos indivíduos entrevistados. Conforme o apresentado no Gráfico 1, 54,1\% da amostra são indivíduos com idades entre 26 e 35 anos. Ao passo que $24,3 \%$ são indivíduos entre 18 e 25 anos. Dessa forma, entende-se que 78,4\% dos respondentes são jovens adultos entre 18 e 35 anos de idades, ou seja, perfis de consumidores importantes para a maioria das empresas de produtos e serviços disponibilizados no mercado.

Tabela 1 - Idade dos entrevistados

\begin{tabular}{|l|r|r|r|r|}
\hline & Frequência & Porcentagem & $\begin{array}{c}\text { Porcentagem } \\
\text { válida }\end{array}$ & $\begin{array}{c}\text { Porcentagem } \\
\text { acumulativa }\end{array}$ \\
\hline 26 a 35 anos & 20 & 54,1 & 54,1 & 54,1 \\
\hline & & & & \\
18 a 25 anos & 9 & 24,3 & 24,3 & 78,4 \\
36 a 45 anos & 5 & 13,5 & 13,5 & 91,9 \\
46 a 50 anos & 2 & 5,4 & 5,4 & 97,3 \\
Acima de 50 anos & 1 & 2,7 & 2,7 & 100,0 \\
Total & 37 & 100,0 & 100,0 & \\
\hline
\end{tabular}

Fonte: Elaborado pelos autores. 
Gráfico 1 - Distribuição percentual das idades dos entrevistados

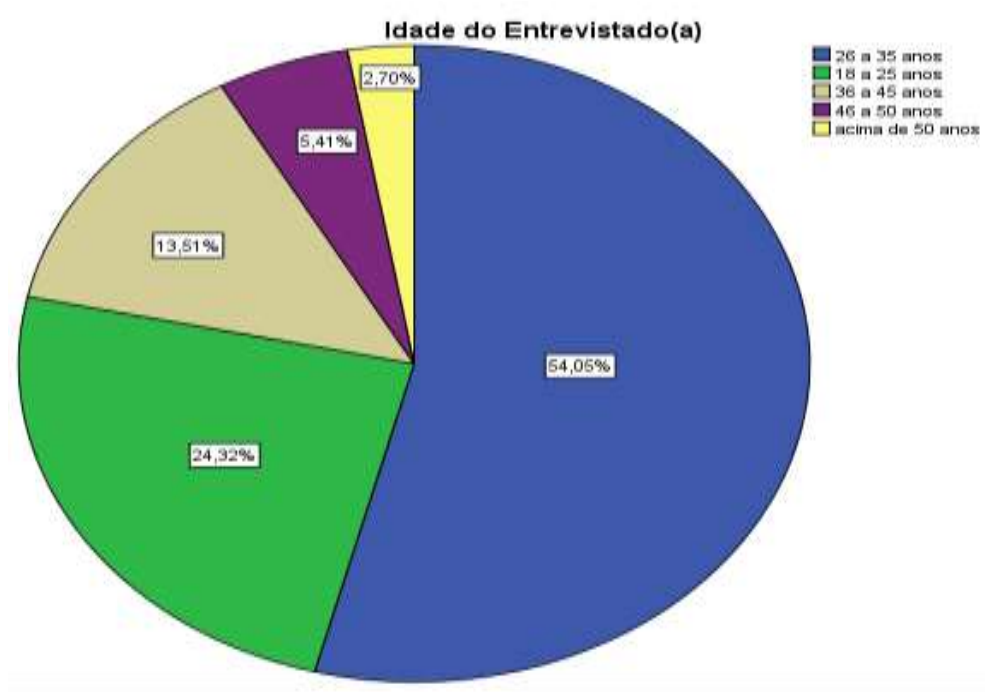

A segunda questão do questionário abordou o gênero que a pessoa respondente se identifica. Conforme o apresentado no Gráfico 2, a maior parte dos indivíduos são mulheres com 62,2\% da amostra e, 37,8\% são do sexo masculino. Vale ressaltar que não se obteve outra identificação de gênero nas respostas dos questionários.

Com os dados obtidos na Tabela 2 e Gráfico 2, também é possível caracterizar um perfil de consumidor com algumas especificidades para determinados produtos e serviços.

Tabela 2 - Sexo dos entrevistados

\begin{tabular}{|rl|r|r|r|r|}
\hline & & & \multicolumn{1}{c|}{$\begin{array}{c}\text { Porcentagem } \\
\text { válida }\end{array}$} & $\begin{array}{c}\text { Porcentagem } \\
\text { acumulativa }\end{array}$ \\
\hline Válido & Fequequecia & Porcentagem & 62,2 & 62,2 \\
& Masculino & 23 & 62,2 & 37,8 & 100,0 \\
Total & 14 & 37,8 & 100,0 & \\
\hline
\end{tabular}

Fonte: Elaborado pelos autores 


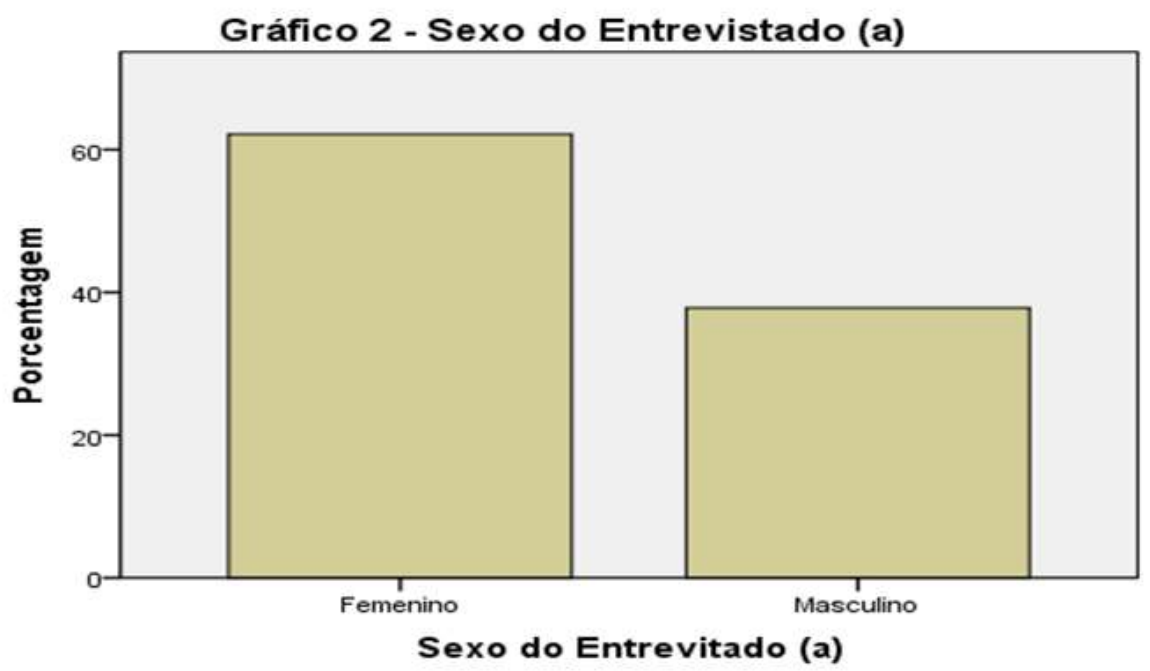

Na terceira e quarta questão do questionário, respectivamente, foi abordado os estados civis dos indivíduos e se estes tinham ou não filhos. Uma vez que para o marketing promocional, o cenário em que o consumidor vive e seu estágio de vida, muitas vezes retrata as suas preferências e a decisão de compra de produtos ou serviços.

Tabela 3 - Estado civil dos entrevistados

\begin{tabular}{|c|c|c|c|c|c|}
\hline & & Frequência & Porcentagem & $\begin{array}{c}\text { Porcentagem } \\
\text { válida }\end{array}$ & $\begin{array}{l}\text { Porcentagem } \\
\text { acumulativa }\end{array}$ \\
\hline \multirow[t]{5}{*}{ Válido } & Solteiro & 28 & 75,7 & 75,7 & 75,7 \\
\hline & Casado & 5 & 13,5 & 13,5 & 89,2 \\
\hline & Outro & 3 & 8,1 & 8,1 & 97,3 \\
\hline & Separado & 1 & 2,7 & 2,7 & 100,0 \\
\hline & Total & 37 & 100,0 & 100,0 & \\
\hline
\end{tabular}

Fonte: Elaborado pelos autores

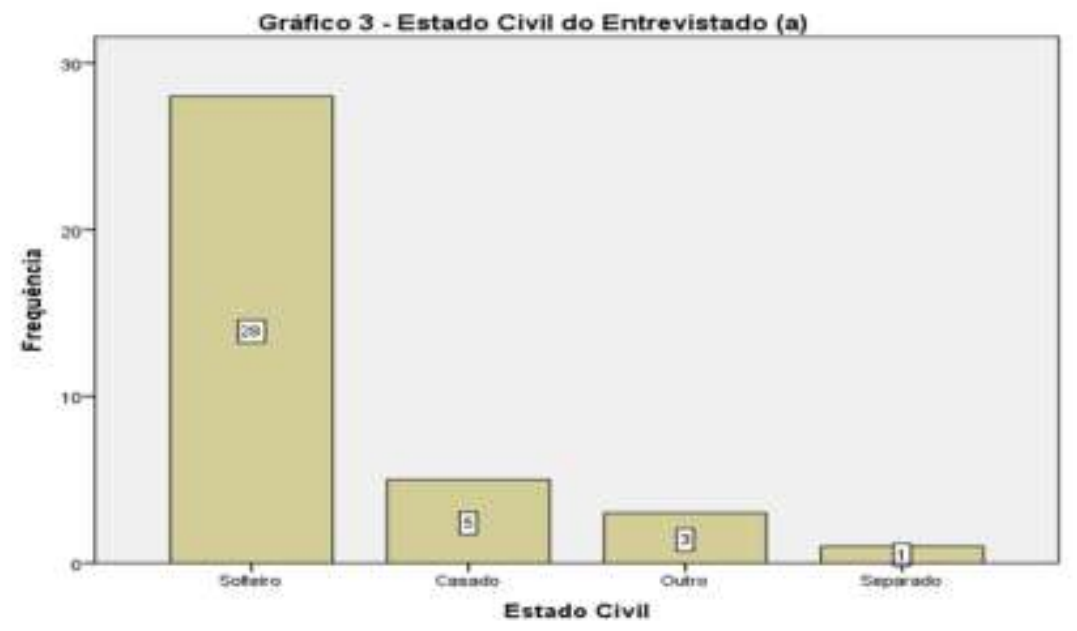


Tabela 4 - Existência de filhos dos entrevistados

\begin{tabular}{|rr|r|r|r|r|}
\hline & & & \multicolumn{2}{|c|}{$\begin{array}{c}\text { Porcentagem } \\
\text { válida }\end{array}$} & $\begin{array}{r}\text { Porcentagem } \\
\text { acumulativa }\end{array}$ \\
\hline Válido & Fão & 30 & 81,1 & 81,1 & 81,1 \\
& Sim & 7 & 18,9 & 18,9 & 100,0 \\
& Total & 37 & 100,0 & 100,0 & \\
\hline
\end{tabular}

Fonte: Elaborado pelos autores

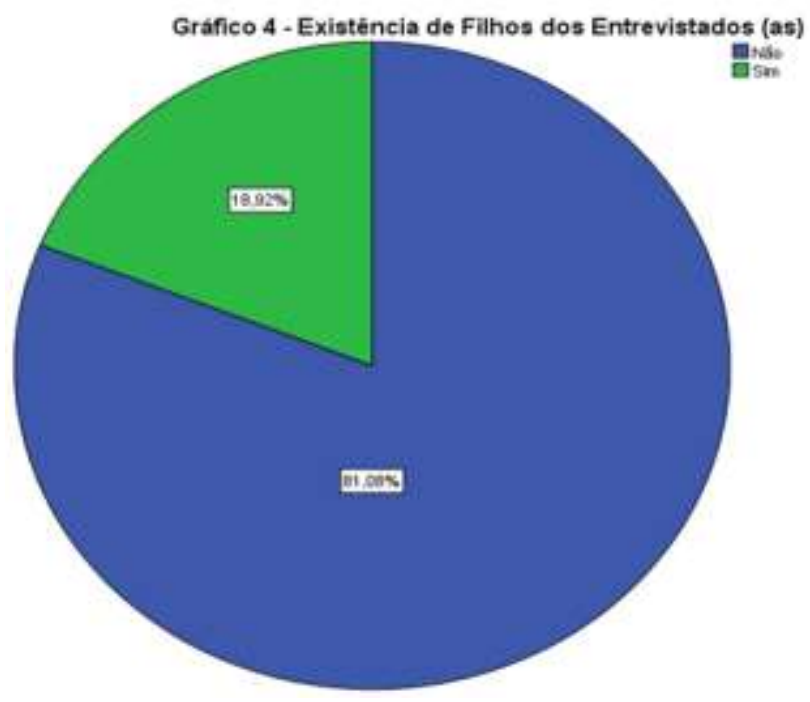

Desta forma, pode-se compreender que mais de $75 \%$ dos indivíduos se consideram como solteiros e mais de $81 \%$ não possuem filhos. Sendo assim, é possível notar que boa parte da amostra, certamente, usa de suas rendas para benefício próprio ao invés de investir em consumo para filhos ou cônjuges.

Na quinta questão do questionário, foram abordados o grau de instrução de cada indivíduo. Considerando para isto, os níveis de ensino: fundamental, médio, superior e pós-graduação. Conforme a Tabela 5, 59,5\% possuem nível superior, enquanto isso, 29,7\% possuem pós-graduação e 10,8\% o ensino médio completo. 
Tabela 5 - Nível de escolaridade dos entrevistados

\begin{tabular}{|c|c|c|c|c|}
\hline & Frequência & Porcentagem & $\begin{array}{c}\text { Porcentagem } \\
\text { válida }\end{array}$ & $\begin{array}{c}\text { Porcentagem } \\
\text { acumulativa }\end{array}$ \\
\hline Válido Superior & 22 & 59,5 & 59,5 & 59,5 \\
Pós-Graduação & 11 & 29,7 & 29,7 & 89,2 \\
Médio & 4 & 10,8 & 10,8 & 100,0 \\
Total & 37 & 100,0 & 100,0 & \\
\hline
\end{tabular}

Fonte: Elaborado pelos autores.

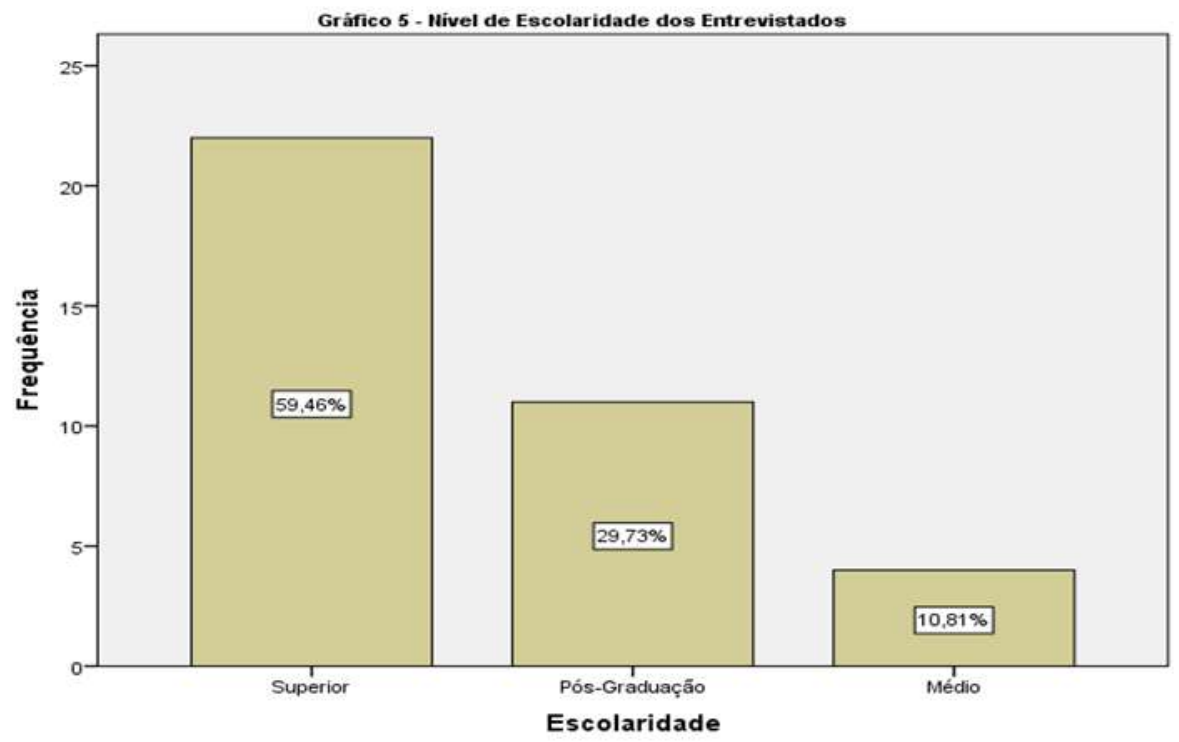

A sexta questão do questionário procurou verificar se os entrevistados possuíam algum vínculo empregatício, conforme a Tabela 6 e o Gráfico 6.

Caso os respondentes estivessem empregados, a sétima questão do questionário buscava identificar em quais setores econômicos os indivíduos desempenhavam funções, como pode ser observado na Tabela 7 e Gráfico 7. 


\section{Consumidor}

Tabela 6 - O entrevistado trabalha atualmente

\begin{tabular}{|rr|r|r|r|r|}
\hline & & & Porcentagem & Porcentagem \\
válida & acumulativa \\
\hline \multirow{2}{*}{ Válido } & Frequência & Porcentagem & 78,4 & 78,4 & 78,4 \\
& 29 & 21,6 & 21,6 & 100,0 \\
& Não & 8 & 100,0 & 100,0 & \\
Total & 37 & & \\
\hline
\end{tabular}

Fonte: Fonte: Elaborado pela autora.

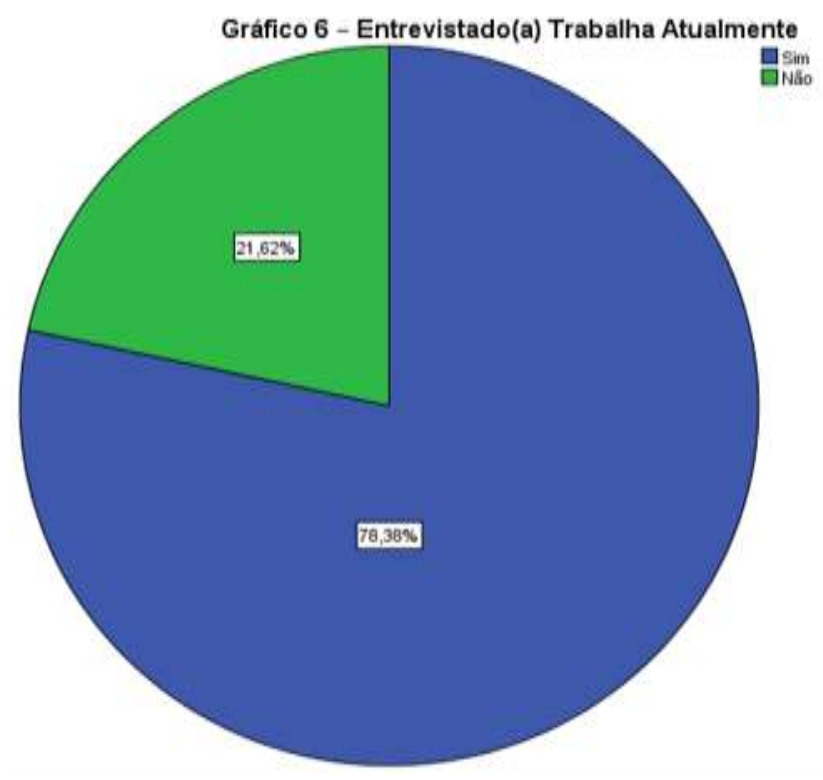

Tabela 7 - Setor de atuação profissional dos entrevistados

\begin{tabular}{|c|c|c|c|c|c|}
\hline & & Frequência & Porcentagem & $\begin{array}{c}\text { Porcentagem } \\
\text { válida }\end{array}$ & $\begin{array}{l}\text { Porcentagem } \\
\text { acumulativa }\end{array}$ \\
\hline \multirow[t]{4}{*}{ Válido } & Serviço & 25 & 67,6 & 67,6 & 67,6 \\
\hline & Outro & 9 & 24,3 & 24,3 & 91,9 \\
\hline & Indústria & 3 & 8,1 & 8,1 & 100,0 \\
\hline & Total & 37 & 100,0 & 100,0 & \\
\hline
\end{tabular}

Fonte: Elaborado pelos autores. 


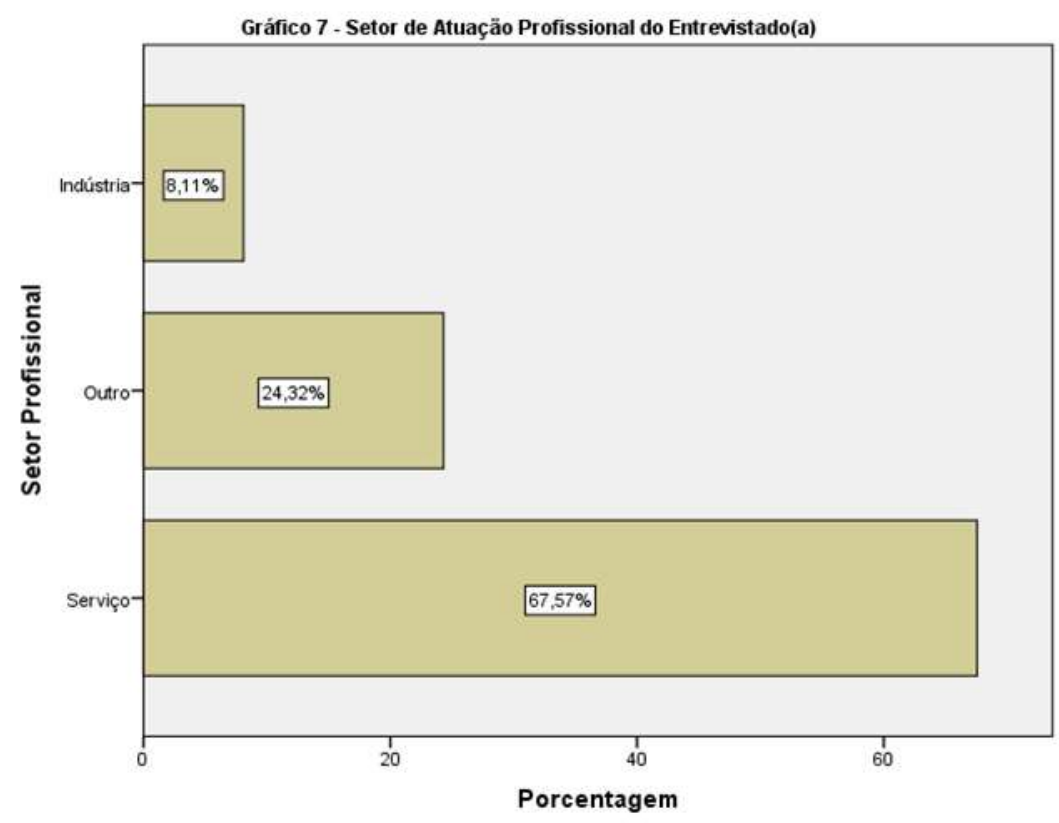

Segundo o que pode ser observado nas Tabela 6, Tabela 7 e Tabela 8, 78,4\% fazem parte de atividades com alguma remuneração. Para efeitos desse estudo, não houve preocupação em especificar o exercício que cada indivíduo trabalha, se seria algo fixo ou temporário ou se seriam autônomos ou não.

De acordo com Gráfico 6 e 7, daqueles participantes que trabalham, 67,6\% atuam em especialidades do setor de serviço, 8,1\% atuam em área industrial e $0 \%$ em setores comerciais, o que demonstra algo inusitado, atualmente. De forma mais sintética, os Gráficos 6 e 7 mostram dados sobre os setores profissionais.

Por último, a oitava questão procurou identificar a faixa de renda familiar dos participantes (Tabela 8 e Gráfico 8), encerrando essa primeira parte sobre variáveis socioeconômicas.

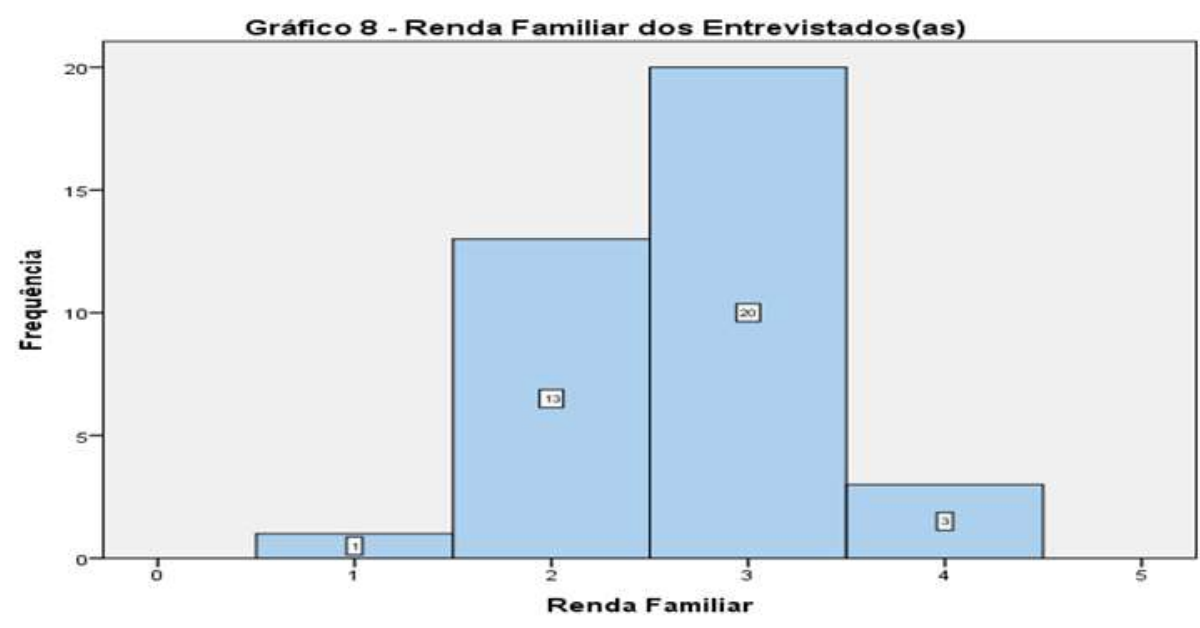


Tabela 8 - Renda familiar dos entrevistados

\begin{tabular}{|ll|r|r|r|r|}
\hline & & & $\begin{array}{c}\text { Porcentagem } \\
\text { válida }\end{array}$ & $\begin{array}{c}\text { Porcentagem } \\
\text { acumulativa }\end{array}$ \\
\hline Válido & Frequência & Porcentagem & 2,7 & 2,7 & 2,7 \\
& Até um salário mínimo & 1 & 35,1 & 35,1 & 37,8 \\
1 a 3 salários mínimos & 13 & 54,1 & 54,1 & 91,9 \\
4 a 10 salários mínimos & 20 & 3,1 & 8,1 & 100,0 \\
Acima de 10 salários & 3 & & & \\
mínimos & & 37 & 100,0 & 100,0 & \\
Total & & & \\
\hline
\end{tabular}

Fonte: Elaborado pelos autores.

Sendo assim, é possível verificar que a amostra desse estudo é caracterizada por indivíduos que possuem renda familiar entre 4 a 10 salários mínimos, com uma porcentagem de 54,1\% dessa amostra. Seguindo de integrantes que apresentaram rendas entre 1 e 3 salários mínimos, com uma porcentagem de $35,1 \%$.

Todos esses dados são importantes, pois definem que tipo de produto ou serviço os indivíduos respondentes são capazes de consumir.

\subsection{VARIÁVEIS DE MARKETING}

A questão de número 9 do questionário, buscou identificar qual era o meio prioritário que o participante buscava ter acesso a informação. O marketing costuma guardar relações bem próximas com a informação, quase sempre sendo definidas pelos meios de comunicação mais utilizados pelos consumidores. Na Tabela 9 e Gráfico 9 é possível averiguar quais as mídias mais acessadas pelos respondentes.

Tabela 9 - Meios de acesso à informação dos entrevistados

\begin{tabular}{|rl|r|r|r|r|}
\hline & Frequência & Porcentagem & \multicolumn{1}{c|}{$\begin{array}{c}\text { Porcentagem } \\
\text { válida }\end{array}$} & $\begin{array}{c}\text { Porcentagem } \\
\text { acumulativa }\end{array}$ \\
\hline Válido & TV & 17 & 45,9 & 45,9 & 45,9 \\
& Internet & 20 & 54,1 & 54,1 & 100,0 \\
& Total & 100,0 & 100,0 & \\
\hline
\end{tabular}

Fonte: Elaborado pelos autores. 


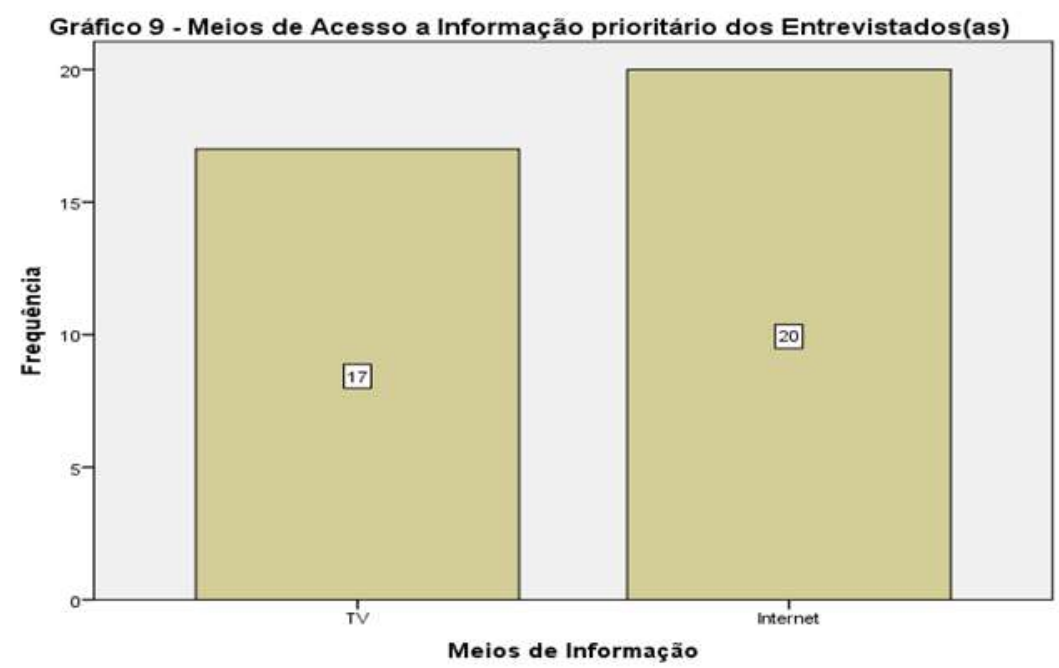

Observe que a amostra acabou se dividindo entre aqueles que buscam a TV como meio (45,9\%) e a internet $(54,1 \%)$, somente. Vale ressaltar que as mídias de comunicação como rádio, jornais impressos e revistas impressas, não foram apontadas como fontes significativas nessa questão, por parte dos participantes. O que pode ser justificado pela maior parte da amostra desse estudo serem, em maioria, jovens adultos.

Na décima questão do questionário, o intuito foi investigar dos principais meios comunicativos, qual era a mídia que mais influenciava na decisão de compra desses consumidores, de forma a complementar a questão anterior. Conforme a Tabela 10 e Gráfico 10, é possível identificar que 89,2\% da amostra são pessoas que se sentem influenciadas pelas propagandas via internet. Certamente, esses indivíduos passam uma maior quantidade de horas acessando a internet do que assistindo a televisão, ou outro meio. Também é possível constar que não se obteve nenhuma resposta para mídias impressas ou rádio.

Tabela 10 - Mídia que mais influência em relação a propaganda

\begin{tabular}{|c|c|c|c|c|c|}
\hline & & Frequência & Porcentagem & $\begin{array}{r}\text { Porcentagem } \\
\text { válida }\end{array}$ & $\begin{array}{r}\text { Porcentagem } \\
\text { acumulativa }\end{array}$ \\
\hline \multirow[t]{4}{*}{ Válido } & Internet & 33 & 89,2 & 89,2 & 89,2 \\
\hline & Televisão & 3 & 8,1 & 8,1 & 97,3 \\
\hline & Outra & 1 & 2,7 & 2,7 & 100,0 \\
\hline & Total & 37 & 100,0 & 100,0 & \\
\hline
\end{tabular}

Fonte: Elaborado pelos autores. 


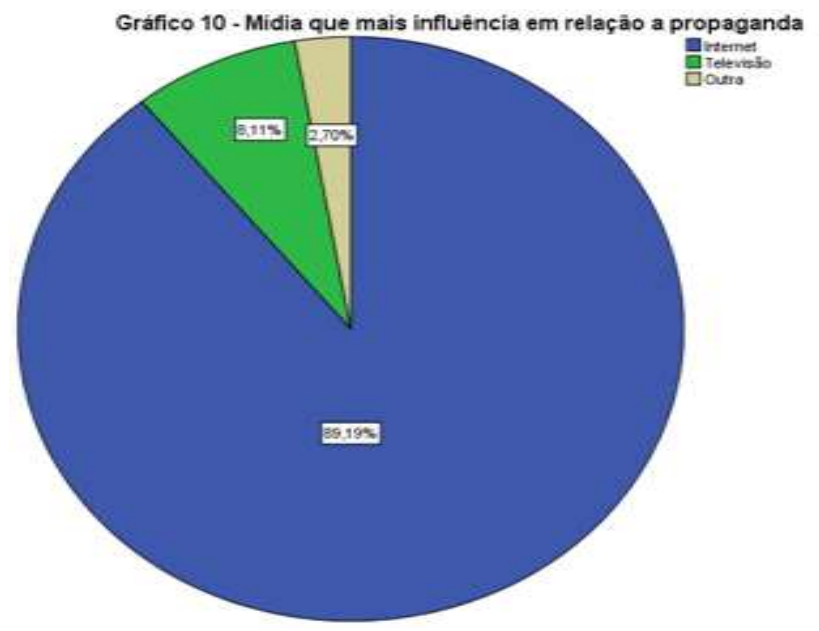

Na questão de número 11 do questionário procurou investigar se promoções de produtos ou serviços possuem alguma relação com a sua decisão de compra por parte do consumidor. Para isto, foi abordado a dimensão de tempo das últimas aquisições feias pelos respondentes. Esses dados são apresentados pelas Tabela 11 e Gráfico 11.

Tabela 11 - Comprou produtos por causa de promoção

\begin{tabular}{|ll|r|r|r|r|}
\hline & & & $\begin{array}{c}\text { Porcentagem } \\
\text { válida }\end{array}$ & $\begin{array}{c}\text { Porcentagem } \\
\text { acumulativa }\end{array}$ \\
\hline Válido & Frequência & Porcentagem & 56,8 & 56,8 & 56,8 \\
& No mês atual & 21 & 24,3 & 24,3 & 81,1 \\
A mais de um ano & 9 & 13,5 & 13,5 & 94,6 \\
A mais de um mês & 5 & 5,4 & 5,4 & 100,0 \\
A um ano & 2 & 100,0 & 100,0 & \\
Total & 37 &
\end{tabular}

Fonte: Elaborado pelos autores.

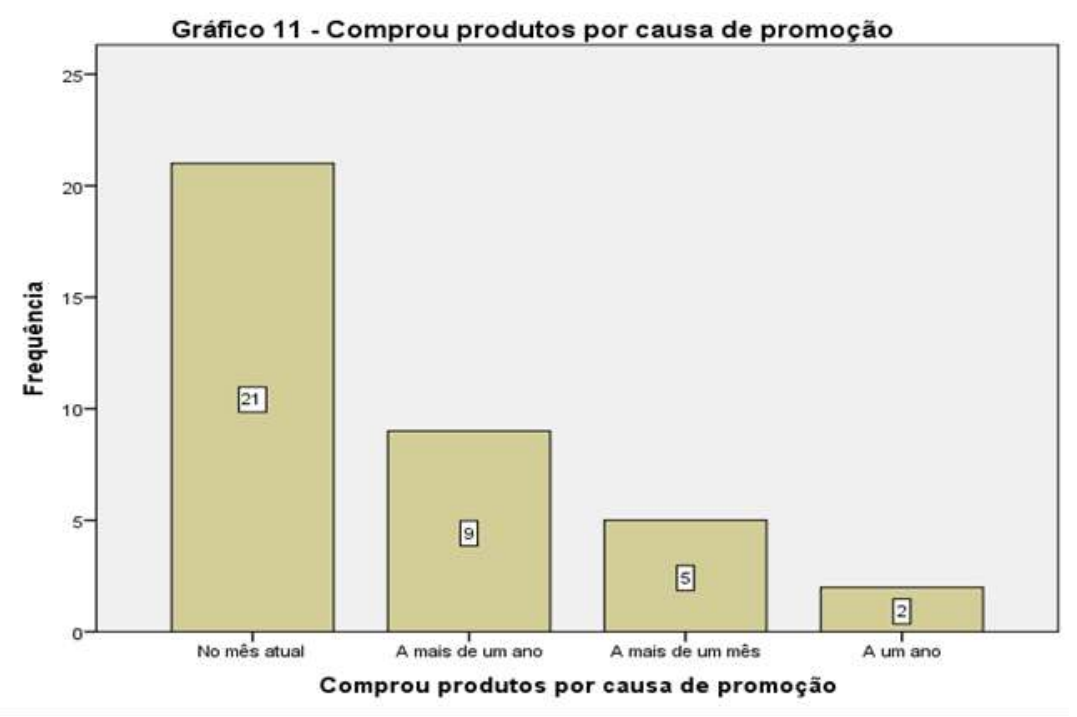


É possível verificar que a maior parte dos entrevistados foram influenciados atualmente $(56,8 \%$ no mês atual). Aproximadamente, $25 \%$ da amostra afirma não terem adquiridos produtos ou serviços de forma influenciada por promoções a mais de um ano.

Estabelecendo um corte temporal de no máximo um ano, é possível constatar que 26 indivíduos afirmam comprar induzidos por algum tipo de promoção dentro de um ano, enquanto 11 indivíduos (ou seja, 29,7\%) afirmam que em um ano não adquiriram nenhum tipo de produto ou serviço por estímulos promocionais.

Nessa mesma perspectiva, a questão de número 12 do questionário procurou complementar a questão anterior, com o intuito de identificar a probabilidade do indivíduo adquirir novamente o produto ou serviço que comprou estimulado pelos benefícios de uma promoção (Tabela 12 e Gráfico 12).

\section{Tabela 12 - Compraria o produto novamente}

\begin{tabular}{|l|r|r|r|r|r|r|}
\hline & Frequência & Porcentagem & $\begin{array}{c}\text { Porcentagem } \\
\text { válida }\end{array}$ & $\begin{array}{r}\text { Porcentagem } \\
\text { acumulativa }\end{array}$ & Ausen & Álido \\
Válido 1-Muito \\
$\begin{array}{l}\text { Provável } \\
\text { 2-Provável }\end{array}$
\end{tabular}

Fonte: Elaborado pelos autores.

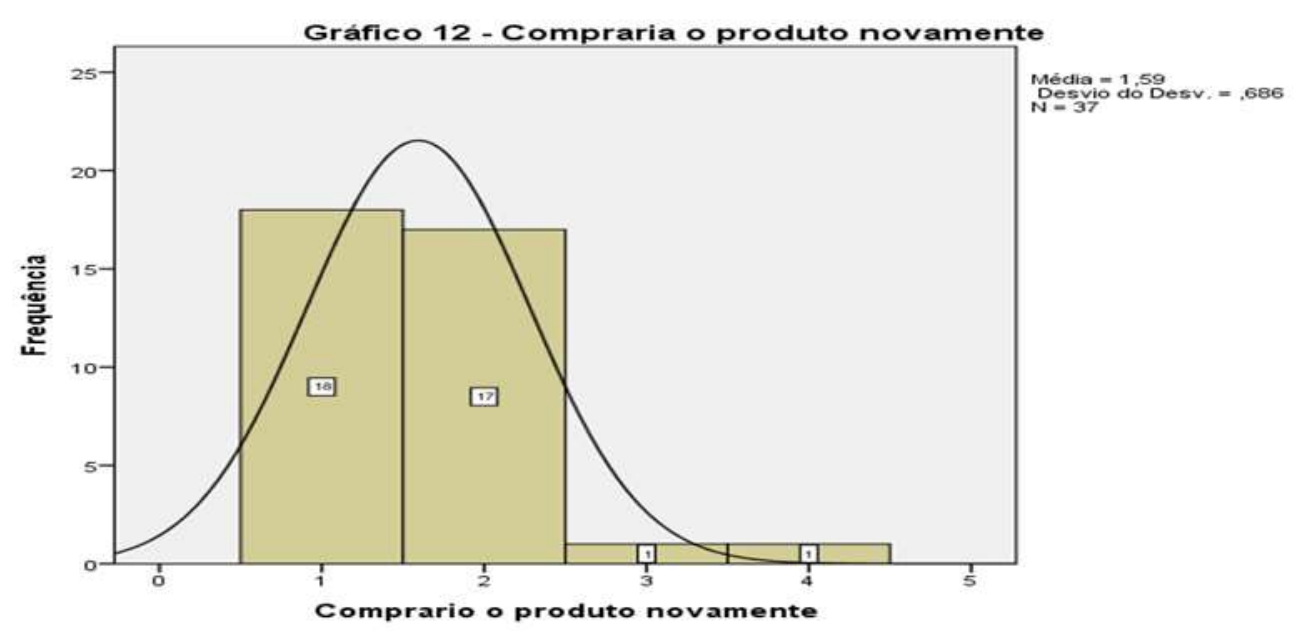


Por meio da Tabela 12, é possível explorar informações mais relevantes para a análise dos dados dessa pesquisa. A moda da amostra é 1, dos 37 respondentes, 18 são prováveis de voltarem a adquirir algum produto ou serviço por indução de promoções. A média desta amostra é 1.59, o que significa que a média das respostas encontram-se entre 1 (muito provável) e 2 (provável), com uma tendência pequena para o valor 2, uma vez que se verifica a ocorrência de duas respostas, 3 (pouco provável) e 4 (improvável) pressionando os valores de média para 4.

A questão de número 13 buscou identificar se os participantes recomendariam o mesmo produto ou serviço adquirido para outras pessoas, legitimando a sua decisão de compra. Todos os dados referentes foram apresentados pela Tabela 13 e Gráfico 13.

Tabela 13 - Recomendaria o produto

\begin{tabular}{|c|c|c|c|c|c|}
\hline & & Frequência & Porcentagem & $\begin{array}{c}\text { Porcentagem } \\
\text { válida }\end{array}$ & $\begin{array}{l}\text { Porcentagem } \\
\text { acumulativa }\end{array}$ \\
\hline \multirow[t]{4}{*}{ Válido } & 1-Muito Provável & 13 & 35,1 & 35,1 & 35,1 \\
\hline & 2-Provável & 23 & 62,2 & 62,2 & 97,3 \\
\hline & 3-Pouco Provável & 1 & 2,7 & 2,7 & 100,0 \\
\hline & Total & 37 & 100,0 & 100,0 & \\
\hline
\end{tabular}

Fonte: Elaborado pelos autores.

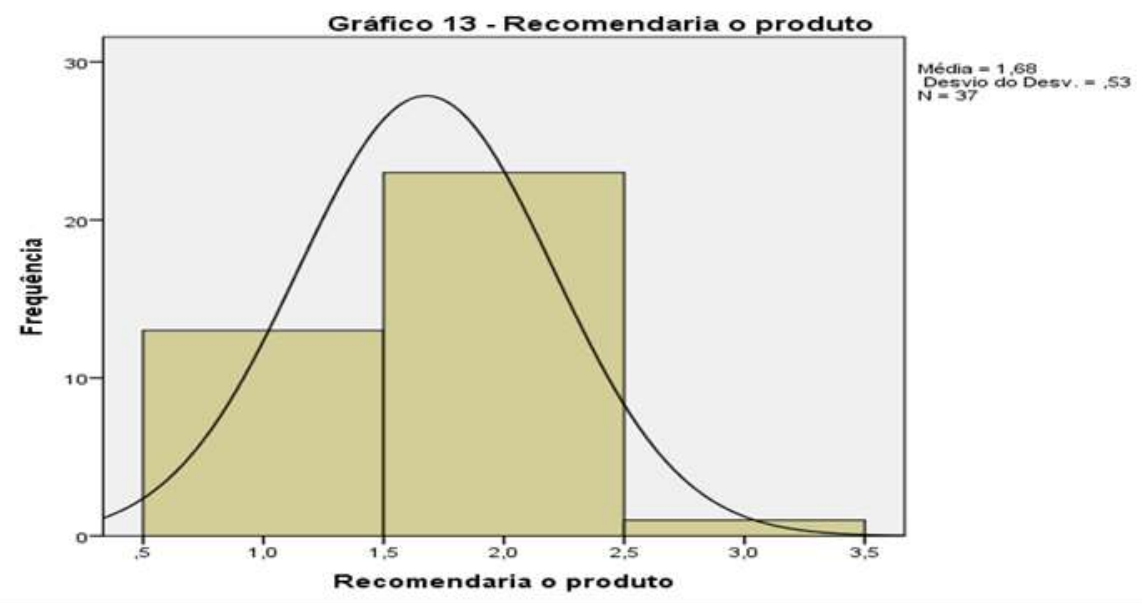

Com base na Tabela 13 e Gráfico 13, é possível notar que 97,3\% dos respondentes afirmam que recomendariam o mesmo produto/serviço para outras pessoas, ratificando os dados da questão anterior. Vale ressaltar que ocorreu uma maior incidência nas respostas 2 (provável), mudando o valor de moda para 2, e consequentemente, deslocando a média para a direita, conforme apresentando no Gráfico 13. 
A questão 14 do questionário abordou uma premissa fundamental de marketing, buscando investigar se as propagandas influenciam de maneira direta a decisão de compras do consumidor (Tabela 14 e Gráfico 14).

Tabela 14 - Propaganda influenciam na compra de um produto ou serviço

\begin{tabular}{|rl|r|r|r|r|}
\hline & & & \multicolumn{2}{c|}{$\begin{array}{c}\text { Porcentagem } \\
\text { válida }\end{array}$} & $\begin{array}{c}\text { Porcentagem } \\
\text { acumulativa }\end{array}$ \\
\hline Válido & Frequência & Porcentagem & 67,6 & 67,6 \\
& 25 & 67,6 & 18,9 & 86,5 \\
Não & 7 & 18,9 & 13,5 & 100,0 \\
Não sei & 5 & 13,5 & 100,0 & \\
Total & 37 & 100,0 & \\
\hline
\end{tabular}

Fonte: Elaborado pelos autores.

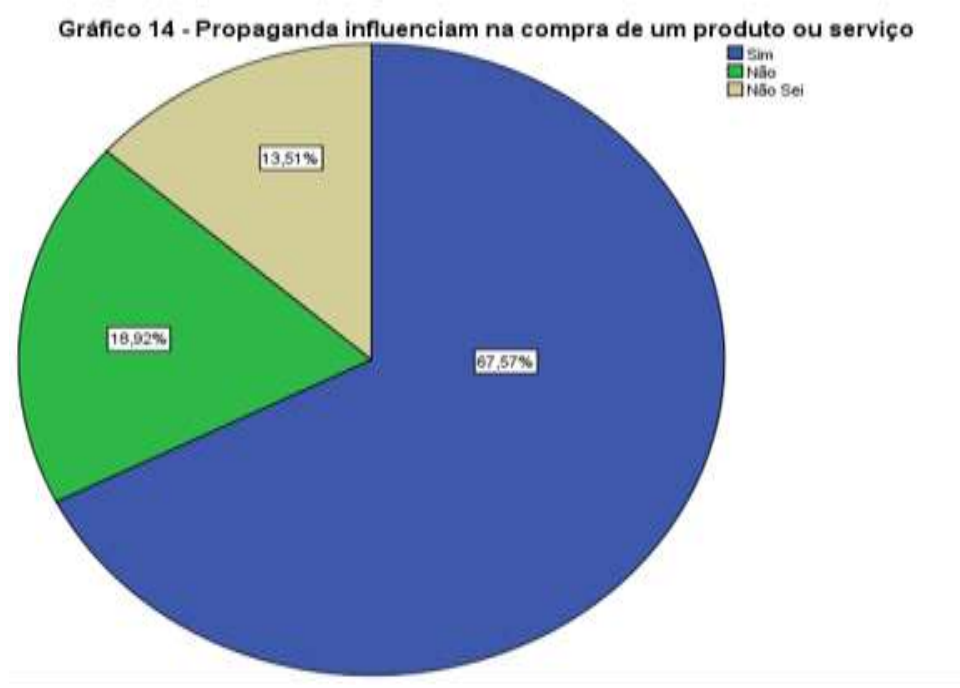

Provavelmente, esses dados tenham sido os mais óbvios de toda pesquisa, contudo no processo de investigação seja interesse o propósito de retificar ou ratificar alguns paradigmas. Dessa forma, podese ratificar que a maior parte dos respondentes se sentem influenciados de alguma forma por propagandas.

A questão 15 do questionário teve como objetivo identificar quais os tipos de produtos (segmento) que a as propagandas provocam mais influência de compra nos consumidores. Segundo a Tabela 15 e o Gráfico 15, 27\% dos produtos são do setor de roupas, 27\% eletrônicos, 16,2\% produtos de beleza, $16,2 \%$ alimentos, $10,8 \%$ outros produtos e $2,7 \%$ móveis e eletrodomésticos. 
Dentre os produtos que tem seus consumos mais estimulados pelas propagandas, moda e eletrônicos possuem 54,1\%. Produtos que podem ser adquiridos, normalmente, em grandes lojas de departamentos com preços bastante convidativos. Vale lembrar que a amostra desta pesquisa é constituída em sua maioria por pessoas do sexo feminino, jovens adultas.

Tabela 15 - Propagandas influenciam a comprar

\begin{tabular}{|c|c|c|c|c|c|}
\hline & & Frequência & Porcentagem & $\begin{array}{c}\text { Porcentagem } \\
\text { válida }\end{array}$ & $\begin{array}{l}\text { Porcentagem } \\
\text { acumulativa }\end{array}$ \\
\hline \multirow[t]{7}{*}{ Válido } & Roupas & 10 & 27,0 & 27,0 & 27,0 \\
\hline & Eletrônicos & 10 & 27,0 & 27,0 & 54,1 \\
\hline & Produtos de beleza & 6 & 16,2 & 16,2 & 70,3 \\
\hline & Alimentos & 6 & 16,2 & 16,2 & 86,5 \\
\hline & Outro & 4 & 10,8 & 10,8 & 97,3 \\
\hline & $\begin{array}{c}\text { Móveis e } \\
\text { eletrodomésticos }\end{array}$ & 1 & 2,7 & 2,7 & 100,0 \\
\hline & Total & 37 & 100,0 & 100,0 & \\
\hline
\end{tabular}

Fonte: Elaborado pelos autores.

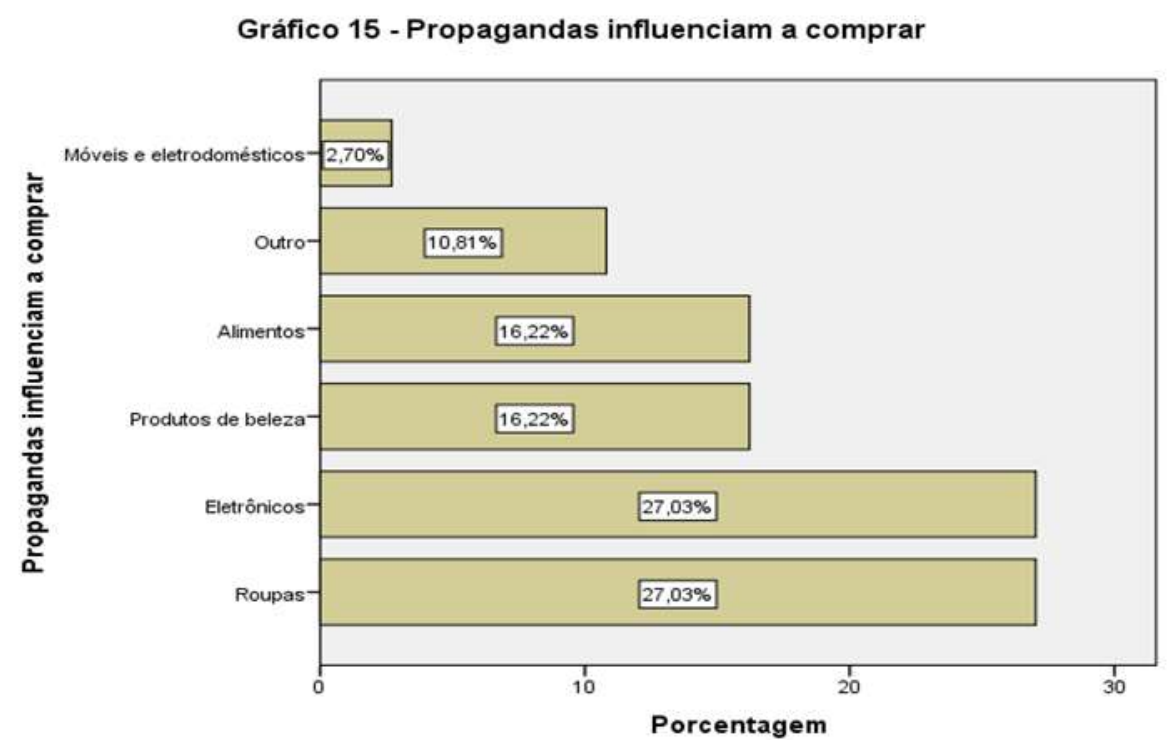


Na questão 16 foi possível detectar que sentimento as propagandas costumam gerar nos indivíduos. Através dos dados obtidos pode-se afirmar que se trata de uma ratificação da questão anterior. A Tabela 16 evidencia que 43,2\% dos indivíduos são indiferentes a propagandas genéricas, 37,8\% não souberam definir entre os sentimentos, $13,5 \%$ se sentem completamente seguros com as informações passadas nas propagandas, e 5,4\% sentem-se irritados. Esses percentuais são apresentados no Gráfico 16.

Tabela 16 - Propagandas causam que sentimento

\begin{tabular}{|c|c|c|c|c|c|}
\hline & & Frequência & Porcentagem & $\begin{array}{c}\text { Porcentagem } \\
\text { válida }\end{array}$ & $\begin{array}{c}\text { Porcentagem } \\
\text { acumulativa }\end{array}$ \\
\hline \multirow[t]{5}{*}{ Válido } & Indiferença & 16 & 43,2 & 43,2 & 43,2 \\
\hline & Outro & 14 & 37,8 & 37,8 & 81,1 \\
\hline & Segurança & 5 & 13,5 & 13,5 & 94,6 \\
\hline & Irritação & 2 & 5,4 & 5,4 & 100,0 \\
\hline & Total & 37 & 100,0 & 100,0 & \\
\hline
\end{tabular}

Elaborado pelos autores.

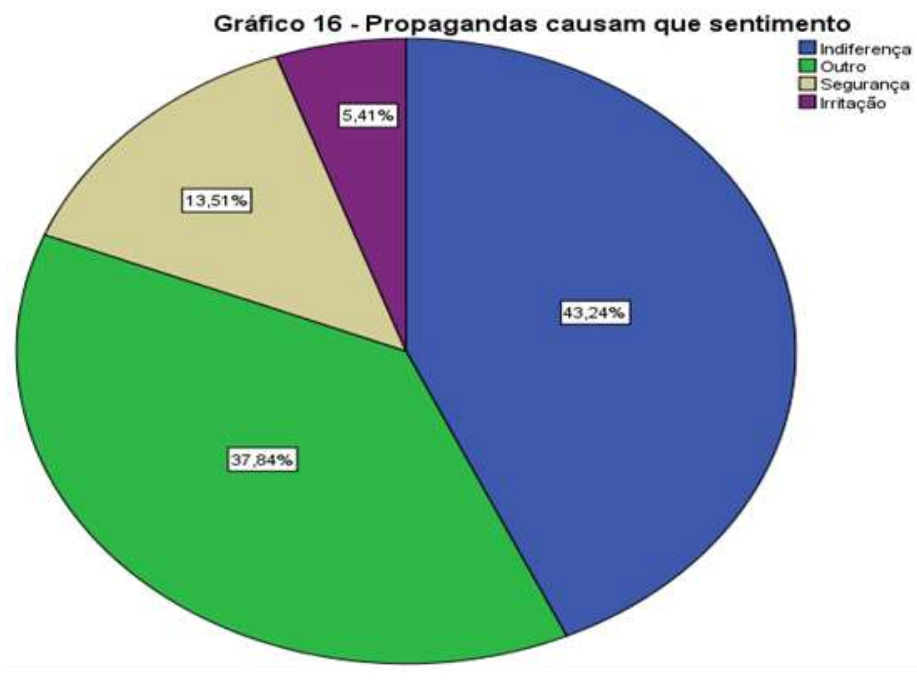

A questão de número 17 buscou identificar qual a principal motivação do consumidor para adquirir produtos ou serviços. 
Tabela 17 - Estimulou a compra do produto/serviço

\begin{tabular}{|c|c|c|c|c|c|}
\hline & & Frequência & Porcentagem & $\begin{array}{c}\text { Porcentagem } \\
\text { válida }\end{array}$ & $\begin{array}{l}\text { Porcentagem } \\
\text { acumulativa }\end{array}$ \\
\hline \multirow[t]{5}{*}{ Válido } & Necessidade de consumo & 26 & 70,3 & 70,3 & 70,3 \\
\hline & Promoções & 6 & 16,2 & 16,2 & 86,5 \\
\hline & Benefícios & 4 & 10,8 & 10,8 & 97,3 \\
\hline & Outra & 1 & 2,7 & 2,7 & 100,0 \\
\hline & Total & 37 & 100,0 & 100,0 & \\
\hline
\end{tabular}

Fonte: Elaborado pelos autores.

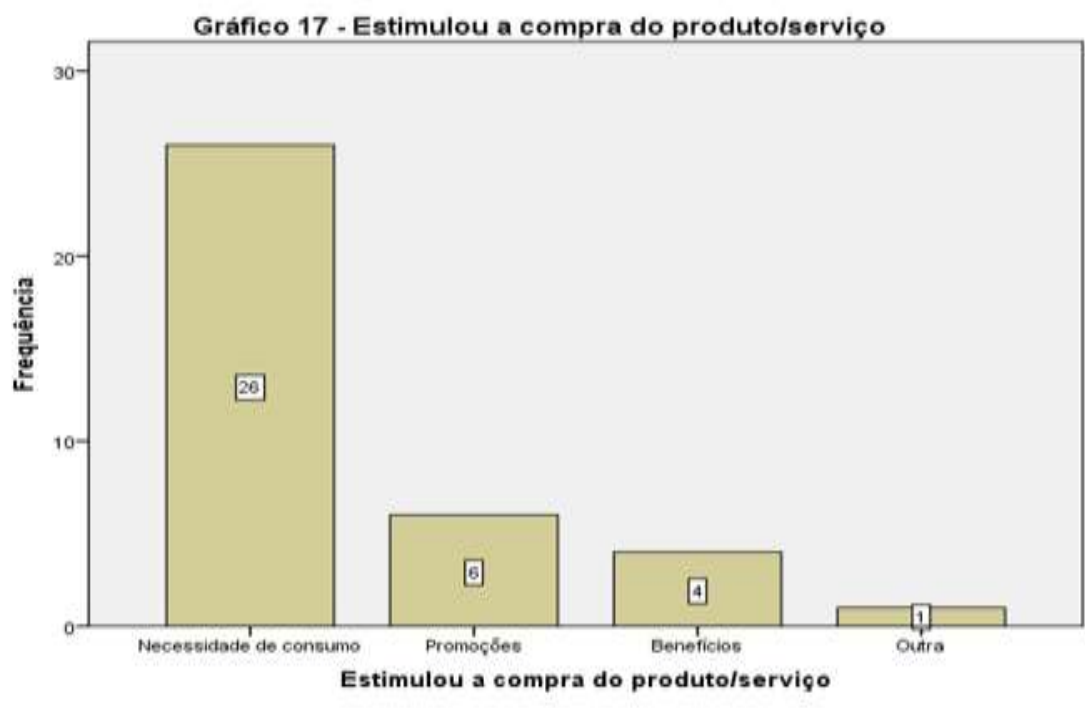

Deste modo, 70,3\% dos indivíduos afirmam que ter uma necessidade pelo produto/serviço é a razão fundamental para o adquirir. Enquanto isso, 16,2\% afirmam que as promoções os levaram a adquirir produtos/serviços, mesmo sem uma aparente necessidade. E 10,8\% afirmaram serem impelidos por alguma vantagem oriunda da compra, conforme o Gráfico 17.

A questão 18 do questionário trouxe dados complementares para a questão anterior. Para a maior parte dos respondentes (64,9\%), as propagandas são vistas como propósito de informação e não como um método de influenciar o possível cliente. Enquanto que somente 16,2\% dos participantes acreditam que a comunicação na propaganda é convincente para a efetiva compra de um produto ou serviço (Tabela 18 e Gráfico 18). 
Tabela 18 - Percepção sobre as propagandas

\begin{tabular}{|ll|r|r|r|r|}
\hline & & & Porcentagem & Porcentagem \\
válida & Frequência & Porcentagem & acumulativa \\
\hline Válido Informações sobre o produto & 24 & 64,9 & 64,9 & 64,9 \\
& Convence da necessidade & 6 & 16,2 & 16,2 & 81,1 \\
Outra & 4 & 10,8 & 10,8 & 91,9 \\
Convence pela aquisição & 3 & 8,1 & 8,1 & 100,0 \\
Total & 37 & 100,0 & 100,0 & \\
\hline
\end{tabular}

Fonte: Elaborado pelos autores.

Quadro 19 - Satisfação em relação a estratégias de promoção

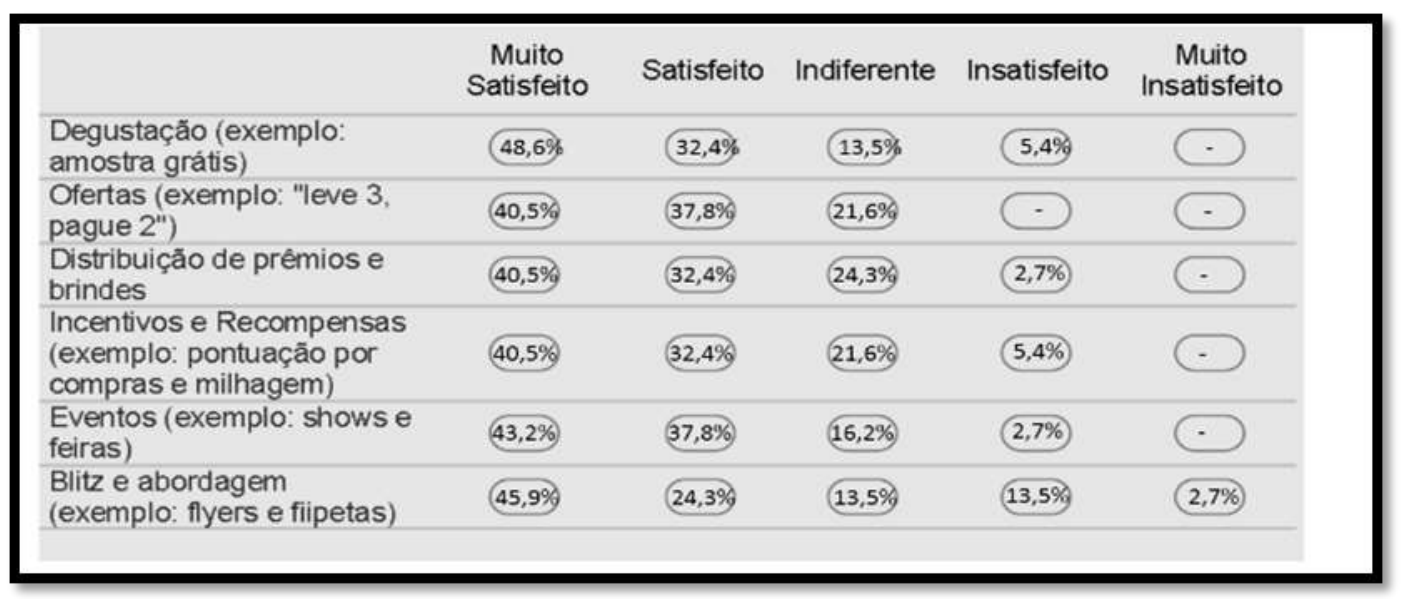

Fonte: Elaborado pelos autores.

A questão de número 19 do questionário identificava o grau de satisfação em relação à algumas técnicas utilizadas para promover produtos ou serviços. Através do Quadro 19 e Tabela 19 é possível verificar em síntese os processamentos dos dados desta questão.

Por último, a questão de número 20 procurou apurar com os respondentes a importância que cada um dá às estratégias promocionais apresentadas no Quadro 19. Com o intuito de entender qual o participante considera como mais importante. O resultado pode ser observado no Gráfico 19. 


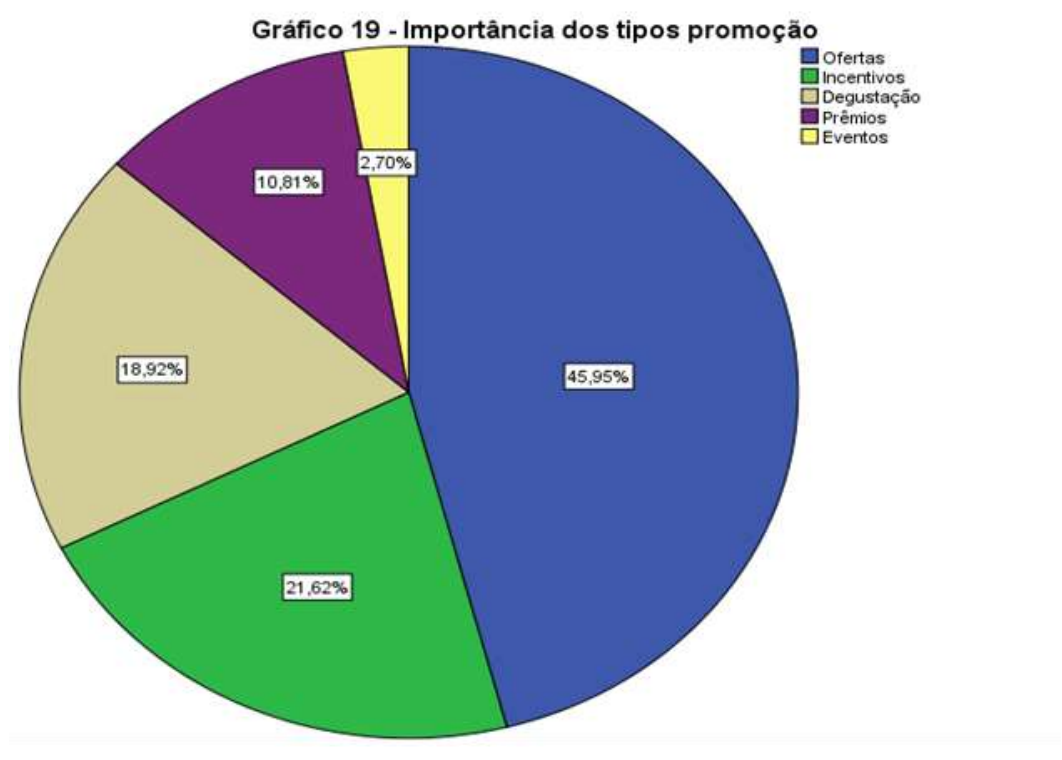

É possível observar que 45,95\% dos indivíduos desta amostra dão importância maior a ofertas do tipo "Leve 3, pague 2 ", ao passo que $21,56 \%$ são mais impulsionados por algum tipo de recompensa ou incentivo, como as "milhagens" oferecidas por companhias aéreas. Destaca-se ainda que para 18,92\% preferem algum tipo de degustação ou amostras grátis como o fator mais relevante, 10,81\% consideram a oferta de prêmios ou brindes como mais importantes, e 2,70\% acreditam que eventos como feiras e shows são fundamentais.

\section{CONSIDERAÇÕES FINAIS}

Esse estudo é caracterizado por uma amostra fundamentalmente feminina. Mulheres com idades entre 26 a 35 anos, algumas solteiras e sem filhos. Com curso superior completo, inseridas no mercado de trabalho e que possuem uma renda familiar entre 4 a 10 salários mínimos.

A pesquisa teve como propósito fundamental a verificação da influência de propagandas no processo de tomada de decisão por parte de prováveis consumidores. Para tal, foi considerado um corte temporal de até um ano. Onde foi observado que $81,1 \%$ dos respondentes afirmaram que adquiriram produtos ou serviços induzidos diretamente por algum tipo de promoção, o que demonstra que o objetivo principal desta pesquisa foi alcançado.

Além dos outros resultados alcançados, um dado que também merece destaque é o tipo de mídia que mais influência na decisão de compra desse público observado na amostra. Com um percentual de $89,2 \%$, a internet foi considerada como um papel necessário nesse processo. Esse dado se justifica pelo fato de que as pessoas estão cada dia mais inserida num "mundo online", passando mais parte 
do seu tempo conectadas. E em segundo plano, uma determinada quantidade de horas também assistindo televisão, outra mídia que apareceu em destaque.

Vale destacar também que a maior parte dos produtos adquiridos com alguma influência das propagandas nas mídias são roupas e eletrônicos, o que são considerados como aderentes, conforme ao perfil identificado na amostra deste estudo.

Em conclusão, como orientação para futuras investigações, podem ser criados substratos dessa amostra, como por exemplo, a influência da promoção entre homens casados e com filhos e em contraste homens solteiros sem filhos. Também seria interessante a realização desta pesquisa com demais gêneros já que não foram identificados nesta pesquisa e gerariam resultados significativos. 


\section{REFERÊNCIAS}

AMPRO. Associação de Marketing Promocional. Disponível em: <http://ampro.com.br/> Acesso em: 17 de out. 2019.

CHURCHILL, Gilbert; PETTER, Paul. Marketing: criando valor para os clientes. 2 ed. São Paulo: Saraiva, 2003.

CRESCITELLI, E. FIGUEIREDO, J. C. B. Ouso de mapas conceituais para ensino de comunicação integrada de marketing. Revista Administração em Diálogo, v.13, n.3, p. 1-24, 2011.

DIAS, Sérgio Roberto. Gestão de Marketing. São Paulo: Saraiva, 2003.

KOTLER, Philip.; ARMSTRONG, G. Princípios de Marketing. São Paulo: Prentice Hall, 2001.

KOTLER, Philip; KELLER, Kevin L. Marketing Management. 14th Edition, Pearson Education, 2012.

KOTLER, Philip; KELLER Kevin L. Administração de Marketing. A bíblia do marketing. 12 ed. São Paulo: Pearson, 2006.

LAS CASAS, Alexandre Luzzi. Qualidade Total em Serviços: Conceitos, Casos Práticos. 5. Ed. São Paulo: Atlas, 2005.

LUCAS JR., D.; SOUZA, C. A. Estabelecendo estratégias de comunicação integrada nas redes sociais: análise de uma instituição financeira brasileira. Pensamento \& Realidade, v. 26, n.3, p.45-60, 2011.

OGDEN, J. R.; CRESCITELLI, E. Comunicação Integrada de Marketing: Conceitos, técnicas e práticas. 2aㅡ Ed. São Paulo: Prentice Hall, 2007.

OLIVEIRA, E. R.; SERRALVO, F.A.; JOÃO, B. N.; FURLAN, R. M. O Papel da Comunicação Integrada de Marketing na Construção do Valor da Marca: O Caso Bunge Fertilizantes. Revista Organizações em Contexto. V.11, n. 21, p. 127-159, 2015.

SANTOS, G.; FERREIRA, R.; PAIXÃO, M. R. Análise na Aplicabilidade de um Plano de Comunicação Integrada de Marketing (CIM) em um Centro Varejista (Mall). Revista de Tecnologia Aplicada, v.6, n.1, p.48-65, 2017.

SOLOMON, Michael R. Comportamento do Consumidor: Comprando, Possuindo, Sendo. 5a Ed. São Paulo: Bookman, 2002.

VERGARA, Sylvia Constant. Projetos e Relatórios de pesquisa em Administração. 12a Ed. São Paulo: Atlas, 2007.

ZIMMER, P.; REINERT, V. Criando vantagem competitiva na micro e pequena empresa por meio da comunicação integrada em marketing. Revista da Administração da Unimep. v.3, n.2, p. 133-149, 2005.

ZUCCO, F. D.; REIS, C. Comunicação integrada de marketing em eventos turísticos: um estudo da Oktoberfest de Blumenau-SC. Revista Brasileira de Marketing. v.9, n. 3, p. 127-143, 2010. 


\section{Capítulo 7}

\section{doi $10.37423 / 210403749$}

\section{COMPETÊNCIAS DO NÍVEL DE COMANDO DE UM ÓRGÃO PÚBLICO MUNICIPAL}

LUCILEILA DO ROSARIO QUEIROZ

ROBERTO KANAANE

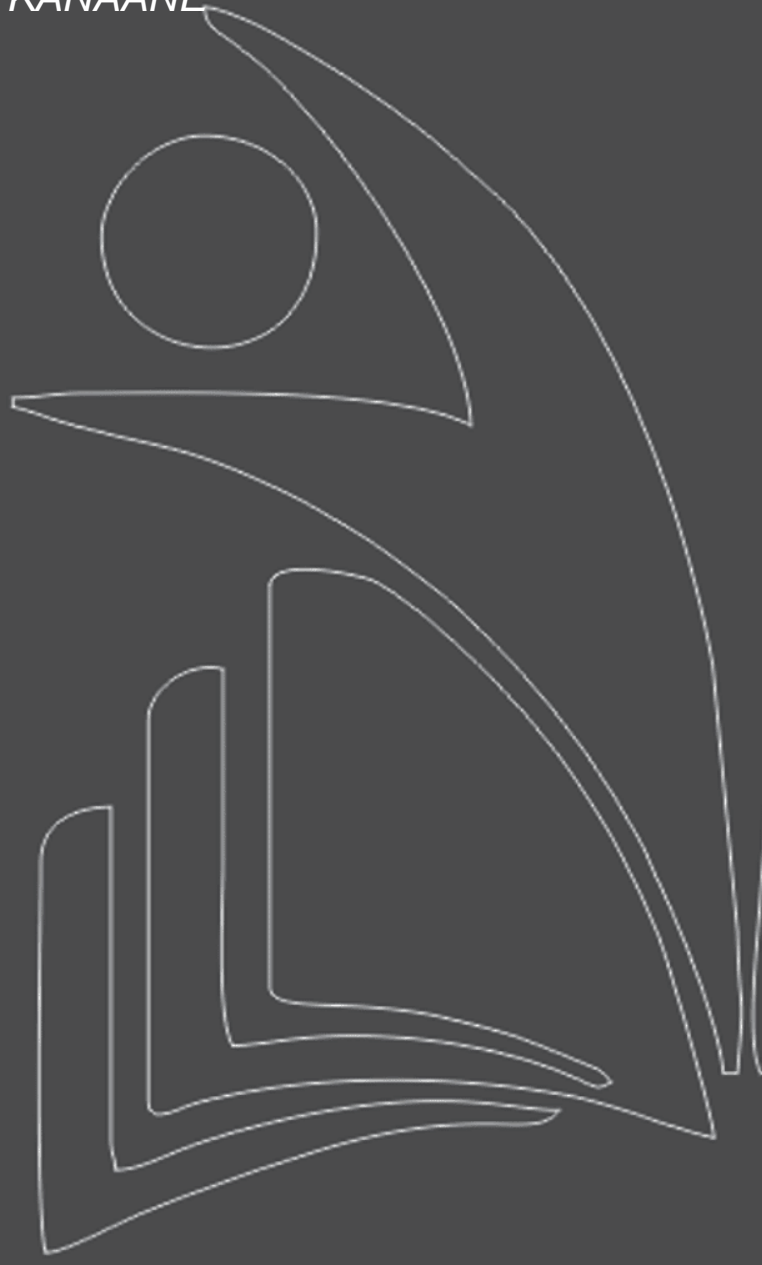

Centro Estadual de Educação Tecnológica Paula Souza

Centro Estadual de Educação Tecnológica Paula Souza

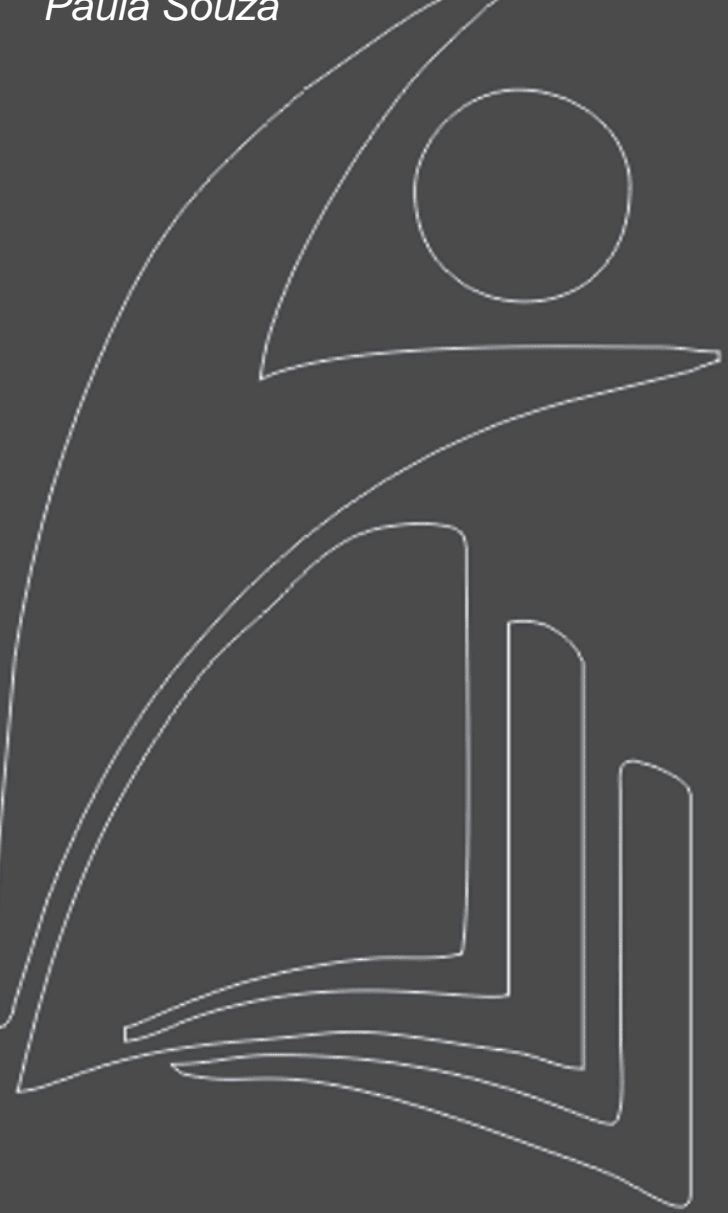


Resumo: O objetivo deste artigo caracterizou-se pela identificação do quadro de competências gerenciais dos servidores que ocupam cargos de comando de uma Subprefeitura da Cidade de São Paulo. Foi realizada pesquisa quantiquali, com abordagem descritiva conjugada com estudo de caso. Os dados empíricos foram coletados por meio de observação participante e aplicação de dois questionários semiestruturados e embasados no referencial teórico e nos objetivos da pesquisa. Como resultado identificou-se que: das 17 competências gerenciais analisadas, o nível de comando possui duas, "aprender a aprender" e "vitalidade"; o que sugere que ações estratégicas sejam mobilizadas no intuito de ampliar as competências dos gestores, visando implementar ações proativas e os respectivos impactos na Instituição.

Palavras-chaves: Sistemas Produtivos; Administração pública; Gestão por competências no setor público; Competências gerenciais e individuais. 


\section{INTRODUÇÃO}

A Administração Pública é constituída por órgãos a serviço do Estado (SIGOLLO; SOARES, 2013) e tem por atribuições gerir os bens públicos e interesses das pessoas de uma determinada comunidade. No entanto, a percepção da sociedade sobre os serviços públicos prestados é de que não possuem qualidade (SALES, 2010), são ineficientes e onerosos, os recursos são desperdiçados, os bens públicos são tratados com desmazelo, os servidores públicos são descompromissados, além de não haver planejamento, controle, coordenação ou transparência (RIBEIRO; MANCEBO, 2013).

Por outro lado, as mudanças tecnológicas, econômicas, políticas e sociais vem transformando as relações em todo o mundo (em virtude da globalização e do nível de complexidade existente nas sociedades e consequentemente nas organizações) e têm contribuído para a necessidade de aperfeiçoamento dos modelos de gestão dos órgãos públicos, tendo em vista a perspectiva de atingir melhores resultados e prestar um serviço público com qualidade (GLÓRIA JR., 2012; MOURA; SOUZA, 2016; SIGOLLO; SOARES, 2013).

A gestão por competências tem sido evidenciada pela literatura científica, como estratégia assertiva para alavancar a gestão de pessoas com foco no desempenho individual e coletivo visando a efetiva prestação dos serviços.

O Sistema de Gestão por Competência refere-se a uma ferramenta gerencial que apoia o planejamento, o monitoramento e a avaliação das ações de desenvolvimento a partir da identificação dos conhecimentos, das habilidades e das atitudes necessárias ao desempenho das funções e as lacunas a serem superadas pelos servidores (MARQUES, 2013, p. 6).

Neste sentido, há uma tendência que destaca a Gestão por Competências como uma prática que engloba o planejamento, a captação, o desenvolvimento e a avaliação das pessoas, em todos os níveis (individuais, gerenciais, coletivos e organizacionais), levando-se em consideração o conjunto de capacidades, habilidades e comportamentos que os funcionários precisam ter para a plena execução de suas atividades (BAHRY; BRANDÃO, 2005). Tal estratégia vem sendo disseminada no intuito de contribuir para a eficiência e eficácia organizacional.

Carbone et al (2009, p. 50) salientam que "a gestão por competências, [...] propõe-se a alinhar esforços para que as competências humanas possam gerar e sustentar as competências organizacionais necessárias à consecução dos objetivos estratégicos da organização".

As organizações públicas têm a responsabilidade de bem gerir o dinheiro público, "gastando de forma mais criteriosa e responsável os recursos públicos, visando atender precípua e estrategicamente às 
demandas da população" (PINHEIRO; SILVA, 2012, p. 199). Assim, a gestão por competências apresenta-se como uma estratégia contemporânea de gerenciamento de pessoas, visando a qualificação dos servidores e a melhoria dos resultados organizacionais na prestação dos serviços públicos.

Em função do exposto, o presente estudo visa caracterizar o quadro de competências gerenciais dos servidores do nível de comando de uma Subprefeitura, consideradas pela literatura pertinente ao tema, essenciais ao alcance do efetivo desempenho gerencial.

\section{GESTÃO POR COMPETÊNCIAS}

A gestão por competências contempla, entre outros pontos, ações voltadas ao planejamento, captação, desenvolvimento e avaliação das pessoas, nos níveis individuais, coletivos, gerenciais e organizacionais, de acordo com o conjunto de capacidades, habilidades e comportamentos que os indivíduos necessitam possuir para a execução de suas atividades e alcance dos objetivos organizacionais (BAHRY; BRANDÃO, 2005; SILVA; MELLO, 2013).

Mello e Silva (2013) defendem que na gestão por competências não importa somente identificar os conhecimentos que o indivíduo possui, mas sim a aptidão que ele apresenta para utilizar esses conhecimentos na resolução de problemas, com foco no alcance de resultados. Argumentam ainda que não há separação entre competência e ação.

Segundo Marques (2013, p. 6), Sistema de Gestão por Competência é uma "ferramenta gerencial que apoia o planejamento, o monitoramento e a avaliação das ações de desenvolvimento a partir da identificação dos conhecimentos, das habilidades e das atitudes necessárias ao desempenho das funções e as lacunas a serem superadas pelos servidores".

A organização precisa mapear quais são as competências que seus funcionários necessitam para contribuir com o alcance dos objetivos organizacionais, além de diagnosticar também quais as competências existentes. A diferença entre as competências existentes e as necessárias, caracterizase como sendo lacunas de competências, ou ainda gap de competências. Os objetivos organizacionais necessitam decorrer das estratégias, que foram definidas com base na missão, visão e valores organizacionais (BAHRY; BRANDÃO, 2005; CARBONE et al, 2009; PANTOJA et al, 2012).

Identificado o gap de competências, é necessário empenho por parte da organização para desenvolvêlas internamente e/ou externamente via treinamento e desenvolvimento (CARBONE et al, 2009). 
A gestão de competências tende a ser um sistema cíclico e contínuo, que implica em considerar as estratégias, objetivos e metas organizacionais, definidas periodicamente.

\subsection{COMPETÊNCIAS}

A gestão por competências implica na compreensão do que se concebe por competências. Entretanto, não há um consenso sobre o que vem a ser competência, pois os autores que investigam o assunto tendem a delimitar o seu significado, levando em consideração uma série de indagações, tendo em vista o contexto de análise e sua aplicação prática (BÜNDCHEN; ROSSETTO; SILVA, 2011).

Os estudos sobre competência individual surgiram nos Estados Unidos e na França. No Brasil, os autores Fleury (2002), Dutra (2004) e Meister (2005) foram os pioneiros em revisar os conceitos de competência e sob influência dos norte-americanos e franceses buscaram concepções contemporâneas, mais aplicáveis ao contexto nacional.

Para Fleury (2002), o conceito de competência engloba as capacidades do indivíduo em saber agir com responsabilidade diante das situações nas quais está inserido. Essa aptidão (do saber agir) necessita ser reconhecida pelos pares e engloba a mobilização, integração e transferência de conhecimentos, recursos e habilidades, contribuindo para a agregação de valores econômico à organização e social à pessoa.

Segundo Dutra (2004), competência abrange o conjunto de conhecimentos, habilidades e atitudes de um indivíduo, associados à capacidade de entregá-las à organização, fazer o que se espera e o que é necessário que se faça.

Para Meister (2005), existe um conjunto de competências básicas que os empregados necessitam possuir para que a organização consiga apresentar um bom desempenho e superar seus concorrentes. Essas competências são: aprender a aprender, comunicação e colaboração, raciocínio criativo e resolução de problemas, conhecimento tecnológico, conhecimento de negócios globais, desenvolvimento de liderança e autogerenciamento da carreira.

Além das competências individuais, os empregados precisam possuir competências que facilitem seu relacionamento com os demais integrantes da equipe, chamadas de competências coletivas.

\subsection{COMPETÊNCIAS GERENCIAIS}

A responsabilidade quanto ao envolvimento e engajamento das pessoas está vinculada ao papel dos gestores. A estes, por sua vez não basta apenas serem detentores de amplas competências técnicas, 
ou seja, é necessário que tenham competências no relacionamento interpessoal e conhecimento das pessoas com as quais trabalham para estimular as potencialidades de cada indivíduo e canalizá-las ao trabalho em equipe, contribuindo para o alcance de resultados positivos. Santos, Caetano e Jesuíno (2012) afirmam que a liderança é um aspecto importante, pois tende a influir nos processos de trabalho e nos resultados das equipes.

Ao gestor se concebe o papel de facilitador do trabalho da equipe, cabendo-lhe solucionar conflitos, criar alternativas motivacionais dos colaboradores, ampliar espaços para que as pessoas possam expressar seus pensamentos e incentivar a busca coletiva de soluções aos problemas organizacionais, visando o alcance dos objetivos organizacionais (FERREIRA; KANAANE; SEVERINO, 2010; SANTOS; CAETANO; JESUÍNO, 2012).

Entende-se que a principal atribuição do líder é articular os diversos membros da equipe, integrando as atividades exercidas, com foco no alcance de resultados, o que requer dos gestores possuir as respectivas competências: aprender a aprender, criar visões compartilhadas, planejar e conduzir transições, colaboração ambiental, análise organizacional, configuração organizacional, potencialização de si e dos outros e vitalidade; posicionamento da empresa, identificar mudanças externas, integrar a equipe, avaliar pessoas, moldar equipes, estabelecer objetivos, fixar prioridades e enfrentar forças externas (FERREIRA; KANAANE; SEVERINO, 2010; KANAANE, 2013; KANAANE; ORTIGOSO, 2010; GAMEIRO, 2012; MOSCOVICI, 1988; SPENCER; PRUSS, 1994).

\subsection{COMPETÊNCIAS DE GESTÃO NO SETOR PÚBLICO}

O modelo gerencial contemporâneo tem solicitado aos gestores alternativas de ação que incentive a qualidade e amplie a prestação dos serviços públicos. A gestão por competências apresenta-se como uma estratégia necessária para gerir o desempenho dos servidores com intuito de atingir a eficiência e os resultados na prestação de serviços.

Para viabilizar a implantação da gestão por competências no serviço público, a União editou o Decreto no 5.707/06, (posteriormente alterado pelo Decreto 9.991/19), que instituiu a Política Nacional de Desenvolvimento de Pessoal - PNDP. A PNDP é a referência existente na área de gestão de pessoas para os órgãos públicos, visando a sua implementação nos órgãos da administração pública federal direta, autarquias e fundações públicas (SILVA; MELLO, 2013). Tem-se constatado que está atuando, também, como parâmetro para os órgãos estaduais e municipais. 
A partir do instrumento normativo, os órgãos da administração pública federal utilizam a gestão por competências para planejar, executar e avaliar as ações de capacitação, além de implementar o planejamento de pessoal, a gestão de recrutamento e a avaliação de desempenho, visando inclusive, otimizar melhorar a qualidade da prestação dos serviços públicos à sociedade (PANTOJA et al, 2012).

Pantoja et al (2012), afirmam que a PNDP demandou a necessidade de construir novos perfis de qualificação profissional necessários à transformação de um sistema baseado em normas regulamentares e procedimentos administrativos para um modelo de gestão com foco em resultados. Assim, "a ênfase no desenvolvimento estratégico de servidores possibilita a relação da PNDP com as perspectivas teóricas de gestão estratégica de pessoas (GEP), as quais preveem o alinhamento dos processos de gestão de pessoas e das competências dos indivíduos à estratégia organizacional” (FONSECA et al, 2013, p. 1452).

O modelo de gestão por competências, assim como os objetivos estratégicos do órgão público atuam como parâmetro para a definição das competências necessárias ao seu alcance. Consequentemente, identifica-se as competências existentes e as necessárias, traçando-se um plano de desenvolvimento de competências voltado aos servidores (MOURA; SOUZA, 2016; SILVA; MELLO, 2013).

Segundo Pantoja et al (2012), embora o modelo de gestão tenha por objetivo melhorar a qualidade e eficiência dos serviços públicos, poucos são os órgãos que conseguiram implementá-lo. Nesse sentido, Moura e Souza (2016) fundamentam que a implantação da gestão por competência implica numa ruptura com os paradigmas em gestão até então existentes, como padrões gerenciais, traços culturais e a própria formação histórica da administração pública.

Nesse sentido, o mapeamento e o estudo das competências do nível de comando em uma instituição pública no município de São Paulo, buscou angariar dados sob a ótica dos gestores e funcionários a eles subordinados, traçando um prisma das competências emergentes dos gestores. A seguir os procedimentos metodológicos.

\section{PROCEDIMENTOS METODOLÓGICOS}

O estudo foi realizado em uma das 32 (trinta e duas) Subprefeituras da Cidade de São Paulo. A Subprefeitura é um órgão da administração direta da Prefeitura de São Paulo, criada segundo a Lei 13.399/2002. Compõe-se de um complexo de atividades de serviços públicos destinados a atender à população local nas suas necessidades, dentre elas: a democratização da gestão pública; o planejamento, execução e controle dos sistemas locais; a promoção do desenvolvimento a partir da 
implementação de políticas públicas definidas pela instância central da administração; a ampliação e melhoria da qualidade dos serviços públicos, envolvendo as competências.

A relevância do objeto de estudo repousa na possibilidade em verificar as competências gerenciais apontadas pela literatura científica presentes e necessárias aos gestores públicos.

Foi realizada pesquisa qualitativa e quantitativa, com abordagem descritiva, conjugada com estudo de caso. A pesquisa descritiva busca especificar as propriedades relevantes de pessoas, grupos, comunidades ou qualquer outro fenômeno que seja submetido a análise (SAMPIERI; COLLADO; LUCIO, 2006).

Quanto à fundamentação teórica, utilizou-se pesquisa bibliográfica, documental e a legislação disponível. Pesquisa bibliográfica "é o estudo sistemático desenvolvido com base em material publicado em livros, revistas, jornais, redes eletrônicas, isto é, material acessível ao público em geral" (VERGARA, 2014, p. 43), enquanto a investigação documental referiu-se aos documentos existentes nas instituições públicas e/ou privadas (VERGARA, 2014).

Os dados empíricos foram coletados pela utilização de observação participante. Segundo Silva (1986, p. 828), observação participante "consiste no fato de que o pesquisador passa a fazer parte do grupo estudado a fim de observar os fenômenos sociais". Foram adotados também dois questionários.

O primeiro instrumento de pesquisa continha perguntas de auto-avaliação, onde o próprio servidor que compõe o nível de comando da organização, assinalou o grau de "importância" das competências gerenciais para o desempenho de suas funções, bem como o grau de "domínio" de cada competência. O segundo, mensurou a percepção dos subordinados, (também relacionada aos dois critérios, "domínio" e "importância”) quanto as competências gerenciais de sua chefia imediata.

A elaboração das questões, do instrumento de pesquisa, foi constituída considerando-se as competências gerenciais indicadas por Kanaane (2013), Kanaane e Ortigoso (2010), Moscovici (1998), Spencer e Pruss (1994) e Gameiro (2012), pesquisadores/estudiosos da área de gestão de pessoas.

Foram distribuídos 119 questionários, tendo obtido resposta de 108 pessoas, correspondendo a $90,76 \%$. Destes, 30 foram respondidos pelos ocupantes dos cargos de comando $(27,8 \%)$ e 78 pelos subordinados $(72,2 \%)$.

As respostas aos questionários foram tabuladas e calculadas a média referente a cada uma das competências pesquisadas. Segundo Vieira (2013, p. 38), a "média de um conjunto de dados é obtida somando todos os dados e dividindo o resultado pelo número deles". 
Critérios de evidenciação das competências:

I. $\quad$ A escala de graduação das respostas ( 1 = não domina a competência; 2 = tem pouco domínio; 3 = tem médio domínio; 4 = tem alto domínio; e 5 = tem domínio completo); considerou-se como existentes as competências cuja média resultou entre 4 e 5; as que apresentaram média inferior a 4 foram consideradas como não dominadas, demandando desenvolvimento (GLÓRIA JR., 2012);

II. Adotou-se como referência a posição de Carbone, et al, 2009 para aferir "a relação entre a carência (por parte da pessoa) de determinada competência e a importância dessa competência para o papel ocupacional ou para o contexto organizacional no qual a pessoa está inserida" (CARBONE et al, 2009, p. 68); bem como mapear o gap de competências, adotou-se a equação: $\mathrm{N}=$ I (4 - D), apresentada por Carbone et al (2009), onde N representa a lacuna, I o grau de importância e D o grau de domínio da competência. Neste estudo, para o cálculo da equação foram considerados como valores de I e D, a média dos resultados das respostas respectivas. Quanto maior o N, maior o gap e, consequentemente, maior a necessidade de desenvolver a competência; se o $\mathrm{N}$ for igual a 0 , significa que não há lacuna na competência, ou seja, a competência é considerada como dominada.

III. Com relação à "importância", foi considerada a escala do instrumento de pesquisa: $1=$ nenhuma importância; 2 = pouca importância; 3 = média importância; 4 = alta importância; e 5 = extrema importância, ou seja, a competência cuja média aritmética do grau de importância se situou entre 4 e 5 foi considerada como "necessária" ao nível de comando; se o valor resultou igual a 5 significa que a competência foi entendida como “imprescindível” (GLÓRIA JR., 2012).

\section{RESULTADOS E DISCUSSÕES}

Aplicando-se os critérios I e II de evidenciação do domínio das competências, os dados da pesquisa informam na figura 1 que, das 17 competências gerenciais, o nível de comando possui duas, "aprender a aprender" e "vitalidade". Constatou-se assim, que para a melhoria dos resultados organizacionais é necessário minimizar o gap de competências, por meio de um plano de desenvolvimento, haja vista que das 17 competências investigadas, 15 necessitam ser aperfeiçoadas, pois não são dominadas pelo nível de comando. 
Figura 1 - Comparação entre os graus de "domínio" e "importância"

\begin{tabular}{r|c|c|c} 
Competências Gerenciais & D & I & N \\
\hline Configuração organizacional & 3,6 & 4,4 & 1,68 \\
\hline Identificar mudanças externas & 3,6 & 4,3 & 1,54 \\
\hline Estabelecer objetivos & 3,7 & 4,4 & 1,46 \\
\hline Avaliar as pessoas & 3,7 & 4,4 & 1,41 \\
\hline Envolver a equipe & 3,7 & 4,4 & 1,30 \\
\hline Desenvolver equipes & 3,7 & 4,4 & 1,18 \\
\hline Criar visões compartilhadas & 3,7 & 4,4 & 1,12 \\
\hline Enfrentar forças externas & 3,8 & 4,4 & 1,09 \\
\hline Posicionar a unidade/departamento & 3,8 & 4,4 & 0,90 \\
\hline Análiseorganizacional & 3,8 & 4,6 & 0,72 \\
\hline Planejare conduzir transições & 3,9 & 4,4 & 0,67 \\
\hline Potencialização desi e dos outros & 3,9 & 4,5 & 0,58 \\
\hline Fixar as prioridades & 3,8 & 4,5 & 0,54 \\
\hline Integrar a equipe & 3,9 & 4,6 & 0,51 \\
\hline Colaboração ambiental & 3,9 & 4,4 & 0,25 \\
\hline Vitalidade & 4,2 & 4,5 & $-0,84$ \\
\hline & & 4,6 & 0 \\
\hline
\end{tabular}

Fonte: Dados da pesquisa

Quanto ao grau de importância, aplicando-se o critério III de evidenciação das competências, percebeu-se que todas as 17 competências gerenciais foram consideradas pelos respondentes como "necessárias", apresentando resultados de média entre 4 e 5 (figura 1). Este resultado permite aferir que as competências consideradas essenciais pelos autores do tema "gestão por competências" e que embasaram o referencial teórico deste estudo, também foram consideradas pelos respondentes da pesquisa como necessárias ao alcance de um alto desempenho.

No tocante ao quadro geral de competências evidenciadas no estudo, concebe-se que os resultados sinalizaram a possibilidade de implementar ações que vão ao encontro de programas de desenvolvimento gerencial, contemplando a atuação dos componentes do comportamento gerencial, como conhecimentos gerenciais e organizacionais e habilidades administrativas. Ao mesmo tempo fica evidente que as competências interpessoais se fazem necessárias para implementação do desenvolvimento dos gestores. 


\section{CONCLUSÕES}

A viabilidade de implementação da gestão por competência no setor público, como estratégia para melhoraria dos resultados organizacionais foi o que motivou a realização deste estudo. Nesse sentido, o presente trabalho teve como objetivo: "caracterizar o quadro de competências gerenciais dos servidores do nível de comando da Subprefeitura, consideradas pela literatura científica pertinente ao tema, essenciais ao alcance de um efetivo desempenho".

Para tanto realizou-se levantamento bibliográfico sobre gestão por competências, onde foram identificadas quais as competências gerenciais que os pesquisadores do tema consideram fundamentais à obtenção de uma alta performance.

Posteriormente, passou-se ao desenvolvimento da pesquisa de campo, visando verificar a percepção que os servidores têm acerca das competências gerenciais dos ocupantes de cargos de chefia.

As respostas sinalizaram como resultado que, embora todas as 17 competências gerenciais estudadas tenham sido consideradas como "necessárias" aos ocupantes do nível de comando, para que a organização melhorasse seus resultados, o nível de comando da Subprefeitura possui duas competências desenvolvidas, "aprender a aprender" e "vitalidade", caracterizando o quadro geral comportamental dos gestores envolvidos. O que sugere a perspectiva de programas de desenvolvimento de postura do gestor público, o que contribuirá para ampliar o escopo de excelência desta categoria profissional.

Sugere-se para pesquisas futuras, investigar outras Subprefeituras da Cidade de São Paulo, além de outros órgãos de esferas políticas distintas, Estaduais e/ou Federais, com o intuito de compreender o contexto vigente no serviço público quanto a postura dos gestores, e ampliar o rol de análise. Tal investigação requer a aferição da percepção dos superiores e pares, com a finalidade de estender o mapeamento a todos os servidores da organização, visando estabelecer diretrizes e táticas voltadas ao dimensionamento das competências dos gestores das respectivas Subprefeituras, tendo em vista os impactos nos resultados decorrentes das demandas e necessidades emergentes da comunidade, ou seja, os munícipes, frente aos serviços públicos e o papel político-social exercido pelos respectivos órgãos. 


\section{REFERÊNCIAS}

BAHRY, Carla P.; BRANDÃO, Hugo. P. Gestão por competências: métodos e técnicas para mapeamento de competências. Revista do Serviço Público, p. 179-194, abr-jun. 2005.

BRASIL. Decreto 5.707, de 23 de Fevereiro de 2006. Institui a Política e as Diretrizes para o Desenvolvimento de Pessoal da Administração Pública Federal Direta, Autárquica e Fundacional. Disponível em:

<http://www.planalto.gov.br/ccivil_03/_Ato2004-2006/2006/Decreto/D5707.htm>. Acesso em 04 fev. 2020.

BRASIL. Decreto 9.991, de 28 de Agosto de 2019. Dispõe sobre a Política Nacional de Desenvolvimento de Pessoas da Administração Pública Federal Direta, Autárquica e Fundacional. Disponível em:

<http://www.planalto.gov.br/ccivil_03/_Ato2019-2022/2019/Decreto/D9991.htm\#art35>. Acesso em 04 fev. 2020.

BÜNDCHEN, Edson; ROSSETTO, Carlos R.; SILVA, Anielson B. Competências Gerenciais em Ação - O Caso do Banco do Brasil. REAd, ed. 69, vol. 17, n. 2, p. 396-423, mai-ago. 2011.

CANFILD, Anderson A. Uma Nova Ótica nos Relacionamentos Interpessoais. Centro Tecnológico OPET, v. 5, n.2, p. 14-15. Curitiba, 2005. Disponível em

<http://www.comportamento.com.br/site2015_pt/936-2/>. Acesso em: 26 maio 2016.

CARBONE, Pedro P. et al. Gestão por Competências e Gestão do Conhecimento. Rio de Janeiro: FGV, 2009. Definição de Prebenda. Disponível em <http://www.dicionario-aberto.net/dict.pdf>. Acesso em: 21 set. 2016.

DUTRA, Joel S. Competências: Conceitos e Instrumentos para a Gestão de Pessoas na Empresa Moderna. São Paulo: Atlas, 2004.

FERREIRA, Maria G.; KANAANE, Solange; SEVERINO, Fátima R. Aspectos Comportamentais na Gestão de Pessoas. In: KANAANE, Roberto; FIEL FILHO, Alécio; FERREIRA, Maria G. (Org.). Gestão Pública: Planejamento, Processos, Sistemas de Informação e Pessoas. São Paulo: Atlas, 2010.

FLEURY, Maria T. L. A Gestão de Competência e a Estratégia Organizacional. In: FLEURY, M. T. L. (org.).

As Pessoas na Organização. São Paulo: Editora Gente, 2002.

FONSECA, Diogo R. et al. Autonomia para Gestão Estratégica de Pessoas no Setor Público Federal: Perspectivas de Análise e Agenda de Pesquisa. Revista de Administração Pública, v. 47, n. 6, p. 14511476, 2013.

GAMEIRO, Ricardo A. As 8 Competências Essenciais no Século 21. Época Negócios, fev, 2012. Disponível em <http://epocanegocios.globo.com/Revista/Common/0,,EMI21920-16642,00COMPETENCIAS+ESSENCIAIS+NO+SECULO.html>. Acesso em: 21 maio 2016. 
GLÓRIA JR., Odair S. Competências e Habilidades Relevantes para um Chefe de Unidade Descentralizada de Perícia da Polícia Federal. Dissertação de Mestrado, FGV/RJ, 2012.

KANAANE, Roberto. Comportamento Humano nas Organizações: o Homem Rumo Ao Século XXI. 2a ed. São Paulo: Atlas, 2013.

KANAANE, Roberto.; ORTIGOSO, Sandra A. F. Manual de Treinamento e Desenvolvimento do Potencial Humano. São Paulo: Atlas, 2010.

MARQUES, Fernanda. Guia de Mapeamento e Avaliação de Competências para a Administração Pública Poder Executivo. Brasília, jun. 2013. Disponível em

<http://www.gespublica.gov.br/sites/default/files/documentos/guia_de_referencia_praticomapeamento-14-08-13.pdf>. Acesso em: 21 maio 2016.

MEISTER, Jeanne C. Educação Corporativa: a gestão do Capital Intelectual Através das Universidades Corporativas. São Paulo: Person Makron, 2005.

MELLO, José A. C.; SILVA, Sheila A. P. S. Competências do Gestor de Academias Esportivas. Motriz, Rio Claro, v.19 n.1, p.74-83, jan./mar. 2013.

MOSCOVICl, Fela. Renascença Organizacional. RJ. LTC - Editora Ltda, 1988.

MOURA, Ana L. N.; SOUZA, Bruno C. Gestão Estratégica de Pessoas na Administração Indireta do Setor Público Federal: na Prática, ainda um Discurso. Revista do Serviço Público, v. 67, n. 4, p. 575-602, 2016.

PANTOJA, Maria J. et al. Política Nacional de Desenvolvimento de Pessoal na Administração Pública Federal: uma Caracterização da Capacitação por Competências na Administração Pública Federal. In: Anais do V Congresso Conselho Nacional de Secretários de Estado da Administração de Gestão Pública, 2012.

PINHEIRO, Marcelo T.; SILVA, Monica A. R. Contribuições do escritório de Gerenciamento de Projetos Públicos na Gestão para Resultados. Revista do Serviço Público, v. 63, n. 2, p. 199-215, 2012.

RIBEIRO, Carla V. S.; MANCEBO, Deise. O servidor público no mundo do trabalho do século

XXI. Psicologia: Ciência e Profissão, v. 33, n. 1, p. 192-207, 2013.

SALES, Ulisses. (Coordenador). Administração Gerencial: uma Revolução na Área Pública. São Paulo: Ripress, 2010.

SAMPIERI, Roberto H.; COLLADO, Carlos F.; LÚCIO, Pilar B. Metodologia de la Investigación. 4. ed. México: Mc Graw-Hill, 2006.

SANTOS, Joaquim; CAETANO, Antonio; JESUÍNO, Jorge C. As competências Funcionais dos Líderes e a Eficácia das Equipas. Revista Portuguesa e Brasileira de Gestão, v. 11, n. 2-3, p. 95-106, 2012.

SÃO PAULO. Lei Municipal no 13.399 de 1o de agosto de 2002. Dispõe Sobre a Criação de Subprefeituras no Município de São Paulo, e dá Outras Providências. Disponível em: 


\section{Competências Do Nível De Comando De Um Órgão Público Municipal}

<http://www.prefeitura.sp.gov.br/cidade/upload/lei_13_399_1254940922.pdf>. Acesso em: 03 jun. 2017.

SIGOLLO, Walter; SOARES, Maria T. R. Os Avanços e Caminhos do Desenvolvimento de Pessoas na Área Pública. In: BOOG, G. G.; BOOG M. (Coordenadores) Manual de Treinamento e Desenvolvimento: Gestão e Estratégia. São Paulo: Pearson Education do Brasil, 2013.

SILVA, Benedito. Dicionário de Ciências Sociais. Rio de Janeiro: Editora da FGV, 1986.

SILVA, Francielle M.; MELLO, Simone P. T. A Implantação da Gestão por Competências: Práticas e Resistências no Setor Público. Revista Eletrônica de Administração e Turismo-ReAT, v. 2, n. 1, p. 110127, jan-jun. 2013.

SPENCER, John; PRUSS, Adrian. Gerenciando sua Equipe. São Paulo: Siciliano, 1994

VERGARA, Sylvia C. Projetos e Relatórios de Pesquisa em Administração. 15. ed. São Paulo: Atlas, 2014. VIEIRA, Sonia. Estatística Básica. São Paulo: Cengage Learning, 2013. 


\section{Capítulo 8}

\section{doi $10.37423 / 210403763$}

\section{ESTUDOS DE LIDERANÇA TRANSFORMACIONAL NO SETOR AUTOMOTIVO: UMA LACUNA PARA PESQUISAS}

Bruno Provazi

Andreia Maria Pedro Salgado

Jorge Muniz Junior

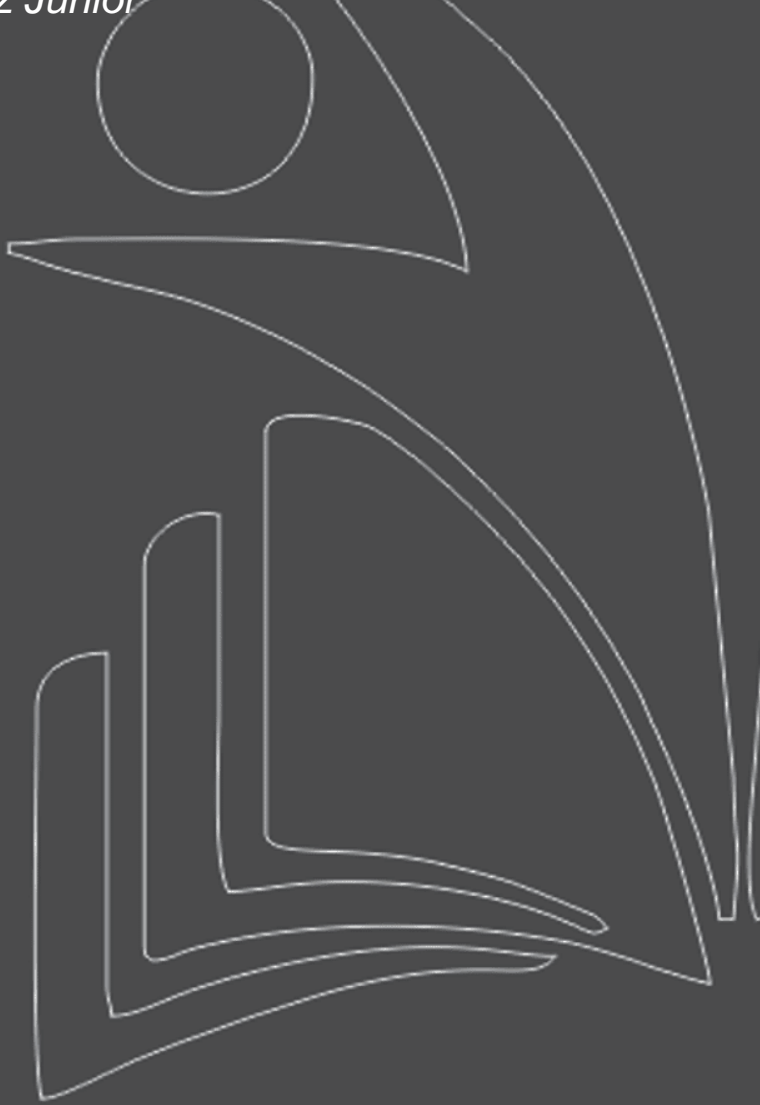

Universidade Estadual Paulista Júlio de Mesquita Filho, UNESP

Universidade Estadual Paulista Júlio de Mesquita Filho, UNESP

Universidade Estadua/ Paulista Júlio de Mesquita Filho, UNESP

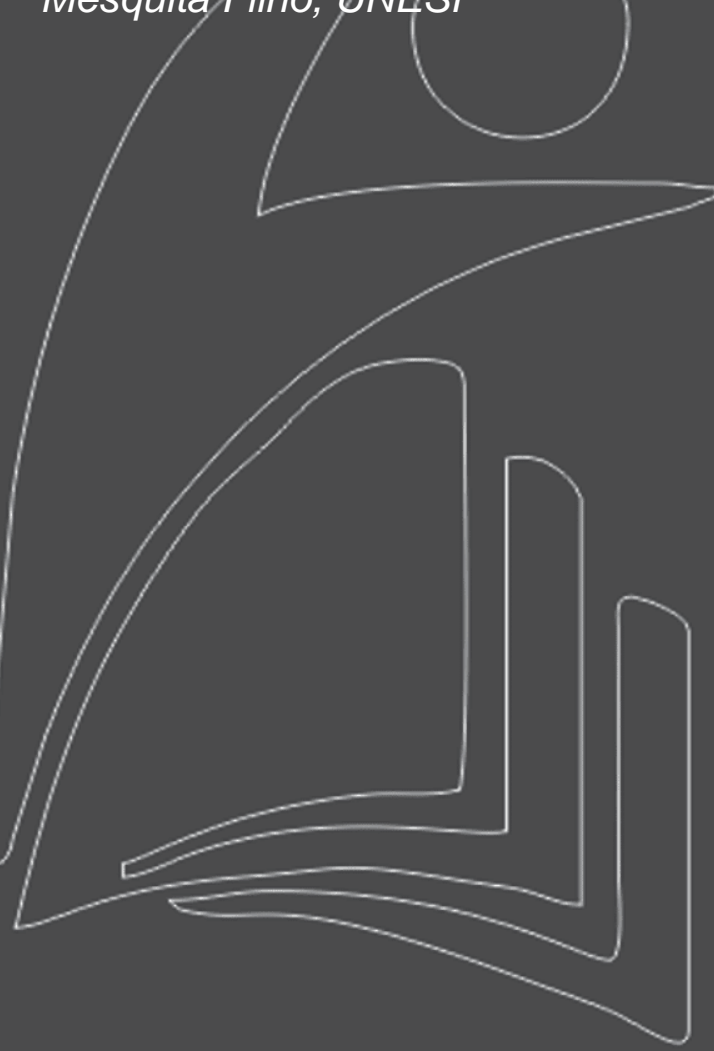


Resumo: O presente artigo investiga de forma sistemática a abordagem científica da teoria de Liderança de Bass e Avolio (1995) no contexto automotivo no Brasil. A ênfase nos conceitos de Liderança Transformacional e Transacional publicados, permiteem a compreensão da realidade da indústria automotiva brasileira neste tema. A natureza da pesquisa é qualitativa, com procedimento de pesquisa bibliográfica. A pesquisa constatou a existência de publicações significativas desta teoria, mas apresenta escassez de pesquisas relacionadas ao setor automobilístico. Identifica-se que o nível de gestão estratégico é mais pesquisado, e pouca abordagem do papel dos liderados neste setor e na relação da liderança.

Palavras-chave: Liderança, Transformacional, Automotivo. 


\section{INTRODUÇÃO}

A liderança tem como referência principal a habilidade de influenciar pessoas, gerando interação entre líder e seguidor, visando atingir um objetivo, promovendo transformações num determinado contexto. Segundo Balsanelli et al. (2006), a liderança tem como princípio o relacionamento interpessoal e os líderes influenciam pessoas para mudança, via processo comunicativo. Borgogni; Dello Russo; Latham (2011) reforçam que a liderança pode ser caracterizada como um processo social relacional, onde os papéis são de líderes e liderados. Nesta relação, o comportamento dos líderes exerce influência sobre o comportamento dos liderados, de forma individual, bem como do ambiente organizacional, incluindo os aspectos éticos, expectativas, interpretações e interações com os outros. Vergara (2007) contribuiu com a visão humanista e as relações entre líder e seguidores, reforçando que as pessoas às quais o líder lidera, têm valores, expectativas, motivações e histórias de vida diferentes umas das outras. Salienta-se que, na liderança, os motivos que inspiram uma pessoa pode não ser o mesmo que outra, assim, é necessário haver sensibilidade do líder para entender essa diferenciação e transformar motivações em ações. Este artigo busca realizar uma análise sobre a abordagem científica da teoria de Liderança de Bass e Avolio, que envolve os conceitos de Liderança Transformacional e Transacional no contexto automotivo mundial e nacional, por meio de análise de produções científicas publicadas em sites de buscas nacionais e internacionais. Assim, o tema liderança é um forte atrativo para pesquisa, tanto que nas últimas décadas, conquistou grande relevância na pesquisa científica. De 2008 a 2013, no Leadership Quartely, principal periódico específico sobre o tema foram publicados 368 artigos envolvendo vários estilos de liderança. Dentre estes artigos, se destacam os que abordam os estilos Transacional e Transformacional (TURANO; 2015).

Esta pesquisa apresenta características exploratórias e de natureza qualitativa, busca fazer uma análise sobre o estilo de liderança transformacional, a partir de uma investigação sistemática do acervo do Web of Science, Scopus e Capes. Salienta-se que os conceitos contingenciais, ou transacionais da liderança, estão vinculados à teoria de liderança transformacional, dispensando assim, buscas específicas deste conceito nas etapas desta pesquisa. A pesquisa seguiu as seguintes etapas, tendo como período limitante o ano 2000 até 2017, com a as seguintes combinações de palavras chave nas buscas:

- Liderança Transformacional;

- Liderança Transformacional e setor automotivo;

- Liderança Transformacional e setor automotivo no Brasil. 
Salienta-se que a principal contribuição deste artigo é analisar o panorama teórico sobre o tema liderança baseadas nos estilos transacional e transformacional dentro do contexto da indústria automotiva, permitindo uma compreensão sobre a realidade da indústria e a importância da liderança.

\section{LIDERANÇA TRANSACIONAL E TRANSFORMACIONAL}

Historicamente, a liderança, sempre assumiu papel importante nas organizações, seja no contexto militar, político, fabril e social se tornando, por esta diversidade de cenários de aplicação, foco para pesquisas (BASS, 2008). Muitas definições de liderança foram levantadas, mas até meados de 1970, nenhum conceito com amplitude plenamente aceita foi difundida (BURNS, 1978). O foco de estudos sobre liderança convergiu para a relação entre líder e seguidores, de forma mais individualizada, na década de 1970. A escola da nova liderança surgiu no final da década de 1980, emergindo a teoria da liderança carismática, voltando de certa forma há alguns princípios anteriores da liderança, no que a figura do líder como admirado pelos seguidores, ou seja, o líder inspirador (ANTONAKIS, 2012; GRINT, 2011). Burns (1978), em seu estudo seminal, desenvolveu a liderança Transformacional, que abordava esse enfoque de líder gerando inspiração e que tinha como seguidores, pessoas influenciadas pelo seu comportamento exemplar. Essa perspectiva de Burns foi vinculada aos conceitos de nova liderança de Bryman (2009) e de certa forma faz contraste ao estilo contingencial.

Após o trabalho de Burns, um campo vasto para pesquisa com essa temática de liderança foi criado e ampliado. Na década de 1980, Bernard Bass ganhou grande destaque ao associar os conceitos de Liderança Transformacional, com o meio empresarial. O conceito de líder inspirador para um meio competitivo e que busca resultados práticos. A liderança passou a ser medida pelos gestores, de forma a trabalharem para a evolução dos líderes. Bass e seus colaboradores adotam um enfoque mais pragmático, acrescentando à teoria de Burns sobre liderança Transformacional. Assim, buscam em seus estudos uma visão mais gerencialista à teoria de Burns (1975) sobre este tema, ou seja, uma visão humanista e ainda baseada em valores e moral do líder, mas com foco nos resultados e produtividade. 
Quadro 1 - Publicações com conceituação da teoria de liderança transformacional e transacional

\begin{tabular}{|c|c|c|c|}
\hline Titulo & Autor & Ano & Citaç̃oes \\
\hline Leadership: Good, better, best & Bass, B. & 1985 & 126 \\
\hline Transformational Leadership: Learning to Share the Vision & Bass, B. & 1990 & 487 \\
\hline $\begin{array}{c}\text { Transformational Leadership and Performance: } \text { A Longitudinal } \\
\text { Investigation }\end{array}$ & $\begin{array}{c}\text { Yammarino, F.; } \\
\text { Spangle, W.; Bass, } \\
\text { B. }\end{array}$ & 1993 & 138 \\
\hline Transformational Leadership: A Response to critiques & $\begin{array}{c}\text { Bass, B.; Avolio, } \\
\text { B. }\end{array}$ & 1993 & 326 \\
\hline $\begin{array}{c}\text { Transformational leadership redux } \\
\text { Individual consideration viewed at multiple levels of analysis: } \text { A } \\
\text { multi-level framework for examining the diffusion of } \\
\text { transformational leadership }\end{array}$ & $\begin{array}{c}\text { Avolio, B.; Bass, } \\
\text { B. }\end{array}$ & 1995 & 80 \\
\hline $\begin{array}{c}\text { Ethics, character, and authentic transformational leadership } \\
\text { behavior }\end{array}$ & $\begin{array}{c}\text { Bass, B.; } \\
\text { Steidlmeier, P. }\end{array}$ & 1995 & 471 \\
\hline $\begin{array}{c}\text { Re-examining the components of transformational and } \\
\text { transactional leadership using the Multifactor Leadership } \\
\text { Questionnaire }\end{array}$ & $\begin{array}{c}\text { Avolio, B.; Bass, } \\
\text { B.; Jung, D. }\end{array}$ & 1999 & 575 \\
\hline $\begin{array}{c}\text { The effect of authentic transformational leadership on follower and } \\
\text { group ethics }\end{array}$ & $\begin{array}{c}\text { Zhu, W.; Avolio, } \\
\text { B.; Riggio, R. }\end{array}$ & 2011 & 17 \\
\hline
\end{tabular}

Fonte: Web of Science, Scopus (2017)

No Quadro 1 observa-se as publicações dos autores desde 1985: Avolio; Bass (1995); Bass (1985, 1990, 1995); Bass; Steidlmeier (1999); Yammarino; Spangler; Bass (1993). Sendo que no Gráfico 1 percebe que as citações dos trabalhos de Bass e Avolio apresentam crescimento significativo a partir de 2009.

Gráfico 1 - Citações do trabalho de Bass e Avolio

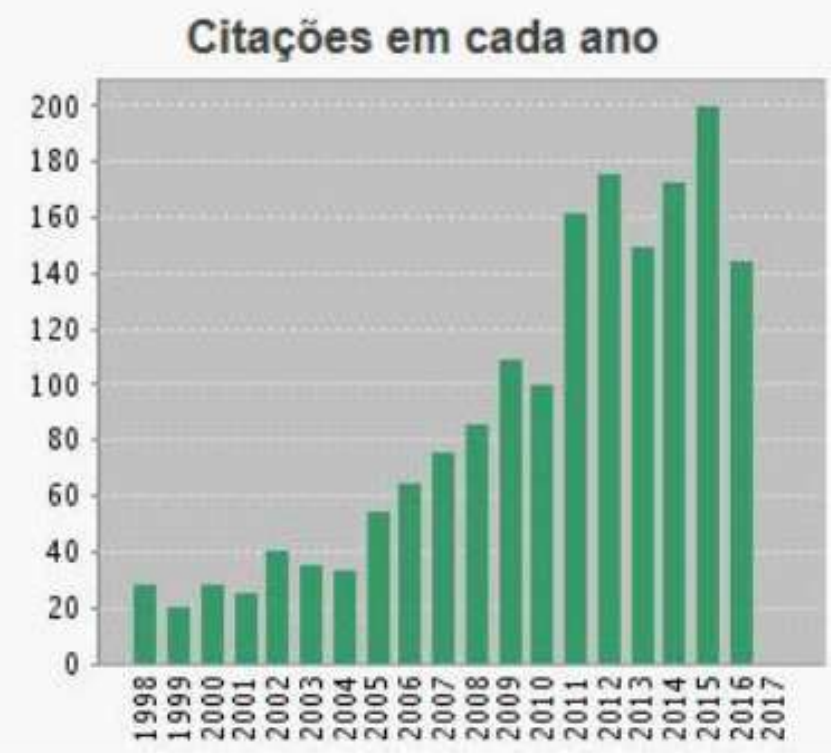

Fonte: site Web of Science (2017) 
Bass e Avolio, (2004) e Burns (1978), definem estes estilos de liderança transformacional e transacional (Figura 1) da seguinte forma:

- Liderança Transformacional: É um perfil que integra criatividade, persistência, energia, intuição e sensibilidade dos outros. É caracterizado pela capacidade de influencia e de inspiração para a equipe ao qual lidera. $O$ liderado segue o líder por confiar.

- Liderança Transacional: É um processo de troca social entre os liderados e líderes que envolvem excencialmente transações por recompensa. Ele monitora o desempenho de seus liderados.

Figura 1 - Liderança Transacional como pré-requisito junto com a Transformacional

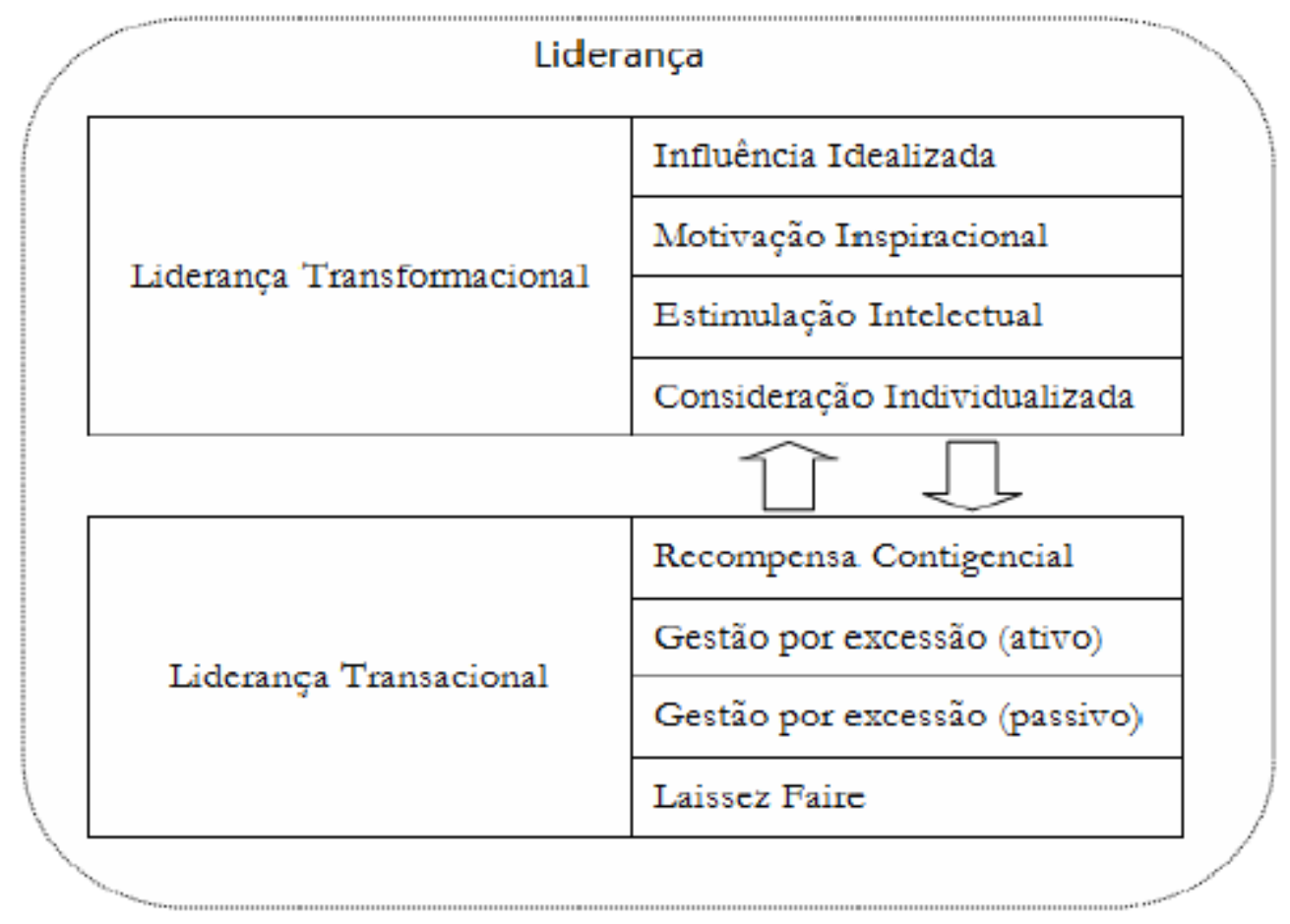

Fonte: Adaptado de Bass e Avolio (2004, p. 21)

As dimensões indicadas pela liderança transformacional possuem um aspecto de influência por inspiração e a responsabilidade do líder pelo desenvolvimento do liderado, conforme definição de Bass e Avolio (1995).

- Influencia Idealizada (II) - O líder neste perfil, mostra convicção, estimula a confiança, assume posição diante de situações difíceis, torna nítido seus valores mais fortes, reforça a importância dos objetivos e sobretudo aos valores éticos, de no qual as decisões devem partir. Líderes com este perfil são carismáticos e são admirados pelos seus funcionários. 
- Motivação Inspiracional (MI) - Neste ponto, o líder inspira e consegue construir junto dos seus liderados, uma visão em longo prazo, de como seria o futuro. Encoraja os seus, com otimismo, rumo ao que deve ser executado. Esta motivação cria em geral um ambiente favorável à mudança.

- Estimulação Intelectual (EI) - Novas ideias são uma constante neste líder. Não há problemas em mudar a perspectiva de se fazer as coisas.

- Consideração Individualizada (CI)- As necessidades de cada um são tratadas de forma individual, balizado por habilidades e aspirações. Tem a característica de saber ouvir e se expressar muito bem. Promove de forma constante o desenvolvimento de seus seguidores.

Na liderança Transacional são correlacionados os aspectos contingenciais, ou seja, baseados na recompensa e tarefa. São 3 as dimensões descritas por Bass e Avolio (1995).

- Recompensa contingencial (RC) - Aqui o conceito de recompensa é o principal traço. Os objetivos são alcançados por meio da promessa por recursos e acordos satisfatórios para todos. Assistência por reforço e elogia seguidores que conseguem atingir os resultados.

- Gestão por exceção (ativo)(GEa) - Este perfil de líder tem controle e monitoramento para detectar com antecedência possíveis problemas. Avalia desempenho dos liderados e toma ações para ajuste de curso em eventuais desvios.

- Gestão por exceção (passivo)(GEp) - Não toma ações antes que os problemas de fato se tornem sérios e trazidos ao seu conhecimento. Não gosta de mudanças.

Nesta teoria ainda existe uma parcela, chamada de Laissez-faire, que compõe o perfil de liderança proposto por Bass e Avolio ( 1995).

- "Laissez-Faire" (LF) - Evita assumir responsabilidades e sua presença é mínima. Quando necessário não está diante das situações. Não atende as necessidades dos seguidores e não compartilha suas opiniões e visões, sobre os rumos a serem seguidos.

Desta forma pode-se afirmar que os lideres transformacionais não substituem os Líderes Transacionais, mas aumentam os efeitos da liderança. 


\section{PANORAMA DA LIDERANÇA TRANSFORMACIONAL NO SETOR AUTOMOTIVO}

Com o foco em Liderança Transformacional, efetuou-se uma busca sistemática nos bancos de dados Scopus, Web of Science e Capes, buscando em títulos, resumos e tópicos, e limitando a pesquisa ao período do ano de 2000 até 2017. Obteve-se os resultados no Gráfico 2, onde é apresentado um elevado patamar dos artigos científicos entre 2012 e 2016.

Gráfico 2 - Evolução dos estudos sobre liderança transformacional no período de 2000 a 2017.

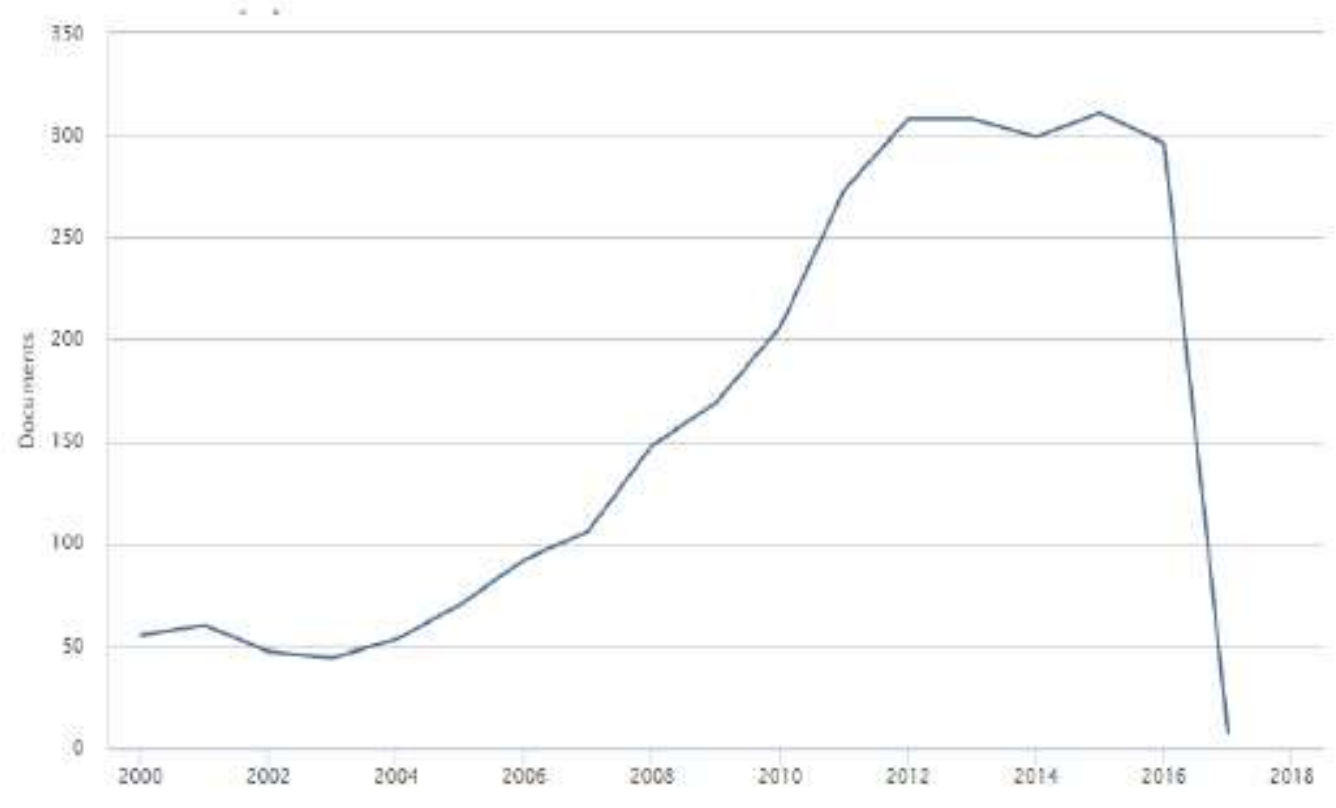

Fonte: Scopus, 2017

No gráfico 2, a evolução dos estudos no mundo em liderança transformacional pode ser constatada, tendo como principal país responsável pelos artigos, os EUA, o qual pode ser visualizado no gráfico 3 . 
Gráfico 3 - País responsável pela elaboração destes artigos no período de 2000 a 2017

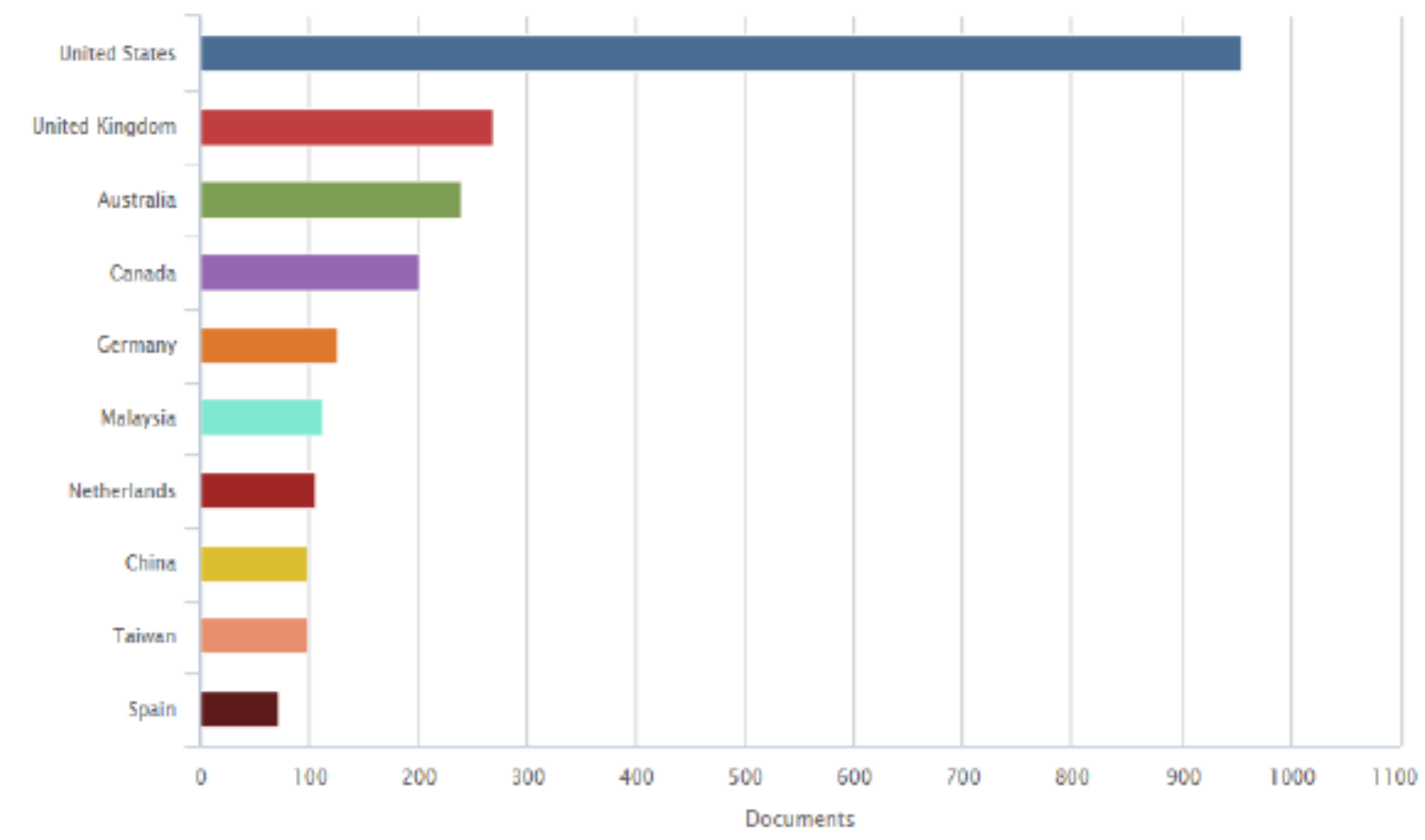

Fonte: Scopus, 2017

No gráfico 4, seguindo para a 20 etapa da pesquisa, realiza-se uma correlação utilizando os termos "leadership transformational e automotive", restringindo-se aos artigos que possuíssem em seu título, palavras chaves ou resumo, tais termos. Percebe-se grande participação da Alemanha na elaboração destes estudos.

Gráfico 4 - País responsável por estudo correlacionando liderança transformacional e setor automotivo

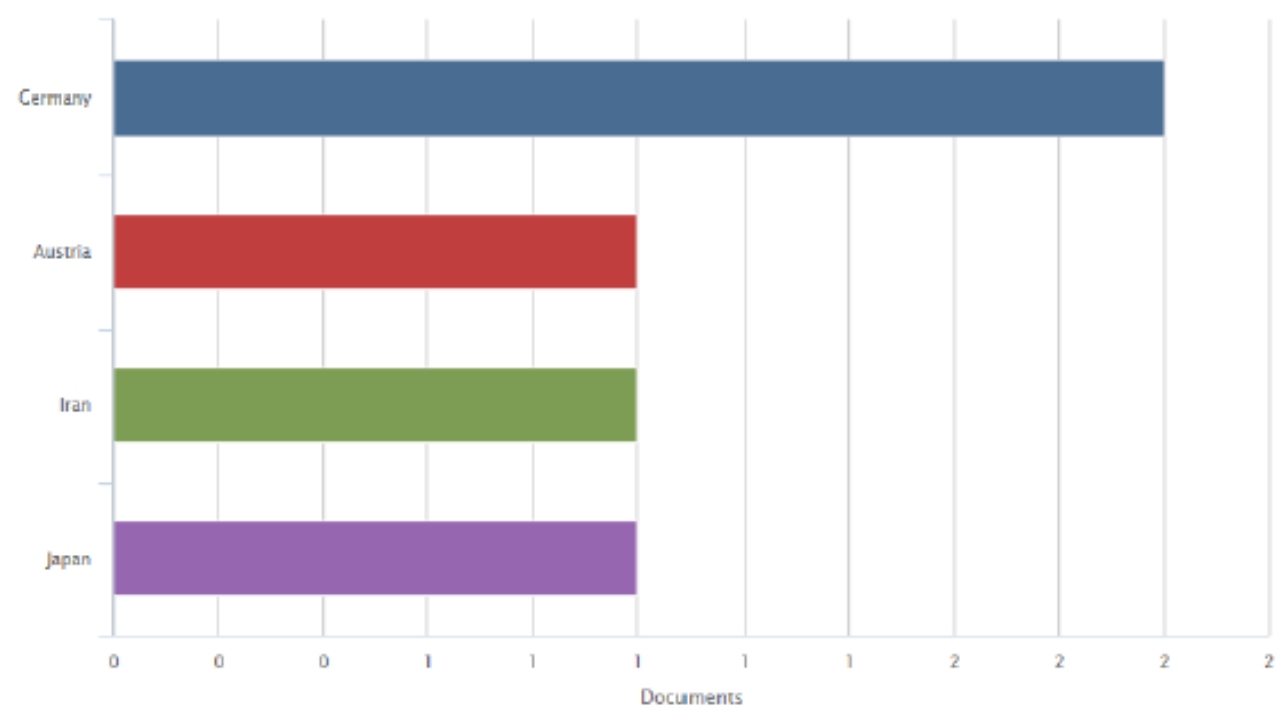

Fonte: Scopus, 2017 
Mesmo diante deste cenário mundial de pesquisas com enfoque na teoria transformacional, observase pouca abordagem em estudos científicos correlacionando este estilo de liderança com a indústria automotiva, principalmente no Brasil, e especificamente no setor de veículos comerciais, conforme Quadro 2. Esta correlação entre liderança transformacional e setor automotivo no Brasil, configura a 3o etapa da pesquisa.

Quadro 2 - Artigos sobre liderança transformacional no Brasil

\begin{tabular}{|c|c|c|c|}
\hline Título & Autor & Setor & Ano \\
\hline Liderança transformacional na enfermagem & Strapasson, M. & Enfermagem & 2008 \\
\hline $\begin{array}{l}\text { Uma aproximação entre liderança transformacional e teoria da } \\
\text { ação comunicativa }\end{array}$ & Vizeu, F. & Teórico & 2011 \\
\hline $\begin{array}{c}\text { Executivos brasileiros: na contramão do perfil deificado da } \\
\text { liderança transformacional }\end{array}$ & $\begin{array}{l}\text { Carvalho Neto, } \\
\text { A. }\end{array}$ & $\begin{array}{l}\text { Empresarial: } \\
\text { Executivos }\end{array}$ & 2012 \\
\hline $\begin{array}{l}\text { O efeito de valores pessoais nas atitudes perante estilos de } \\
\text { liderança }\end{array}$ & Porto, J. & Teórico & 2012 \\
\hline $\begin{array}{c}\text { Em busca de uma abordagem não atomizada para o exame } \\
\text { das relações entre liderança transformacional e } \\
\text { comprometimento organizacional }\end{array}$ & Maciel, C. & $\begin{array}{l}\text { Prestação de } \\
\text { Serviços }\end{array}$ & 2013 \\
\hline $\begin{array}{l}\text { Validação fatorial de escala de atitudes frente a estilos de } \\
\text { liderança }\end{array}$ & Fonseca, A. & Teórico & 2013 \\
\hline Cultura organizacional e liderança: uma relação possivel? & Barreto, L. & Restaurantes & 2013 \\
\hline $\begin{array}{l}\text { Estilo de liderança e desempenho criativo em equipes de } \\
\text { telejornalismo: um estudo em emissoras de TV cearenses }\end{array}$ & $\begin{array}{l}\text { Pereira S. } \\
\text { Roldan, V. }\end{array}$ & Telejornalismo & 2013 \\
\hline $\begin{array}{c}\text { Abordagem de liderança em ambientes multiculturais da } \\
\text { indústria da aviação }\end{array}$ & Brito Neto, J. & Aviação & 2014 \\
\hline Liderança: um retrato da produção cientifica brasileira. & Fonseca, A. & Teórico & 2015 \\
\hline
\end{tabular}

\begin{tabular}{|c|c|c|c|}
\hline $\begin{array}{c}\text { A relação entre liderança e cultura organizacional: um estudo } \\
\text { realizado em uma IES }\end{array}$ & Gonçalves, A. & Educação & 2015 \\
\hline $\begin{array}{c}\text { Estilo de liderança, controle gerencial e inovação: papel das } \\
\text { alavancas de controle }\end{array}$ & Da Cruz, A. & $\begin{array}{c}\text { Empresarial: } 20 \\
\text { setores distintos }\end{array}$ & 2015 \\
\hline $\begin{array}{c}\text { A relação entre o estilo de liderança e a resistência à mudança } \\
\text { dos indivíduos em um processo de fusão }\end{array}$ & Almada, L. & Empresarial & 2015 \\
\hline $\begin{array}{c}\text { Estilos de liderança e desempenho de equipes no setor público } \\
\text { Bias, M. } \\
\text { Conges, R. } \\
\text { bibliometrimento científico sobre liderança: uma analise }\end{array}$ & Setor Público do The Leadership Quarterly & 2015 \\
\hline
\end{tabular}

Fonte: Web of Science; Scopus, Capes, 2017.

De acordo com o Quadro 2, existem trabalhos científicos focados no estilo de liderança Transformacional no Brasil, mas pouca incidência no setor automotivo. Com base nos resultados da pesquisa, existe um elevado volume de trabalhos científicos no mundo com a abordagem da teoria da liderança transformacional, principalmente do ano de 2010 em diante, mostrando como esta teoria ganhou importância. O grande produtor destes trabalhos são os EUA, onde se observa o triplo de artigos se comparado ao segundo colocado, o Reino Unido, seguido por Austrália, Canadá e Alemanha. 
O Brasil por sua vez, não configura as dez primeiras posições deste ranking. Quando se observa os dados com foco no setor automotivo, a Alemanha assume a liderança em publicações com esta temática, mas o volume de trabalhos decresce de forma considerável. Enquanto a Alemanha produziu trabalhos sobre liderança transformacional em cerca de 120 artigos no período limitado, apenas 2 artigos, ou seja, 1,66\% são aplicadas ao setor automotivo. Seguido por Áustria, Irã e Japão com uma publicação cada. Estes dados soam interessantes quando se observa o papel do setor automotivo alemão no contexto mundial com grandes fabricantes e marcas consolidadas. Da mesma forma, o Japão, com um papel similar ao alemão neste mercado mundial de automotores, apresentou pouca participação científica com este enfoque de liderança transformacional. O mercado de automotores é competitivo e requer um elevado grau de inovação para se manter no negócio, haja vista a abertura de mercados e fábricas de montadoras alemãs, produzindo na América do Sul, do Japão, produzindo em outra cultura como a americana. Pelas definições de Bass e Avolio, e inicialmente de Burns (1978), a liderança transformacional está vinculada também a inovação e seria adequada a este meio competitivo.

Esta mesma avaliação pode-se entender sobre os EUA. Apesar de ser o grande produtor de artigos científicos sobre a teoria transformacional, sua participação com foco no setor automotivo não configura as cinco primeiras posições. O papel americano na produção de automotores tem grande importância e deveria estar mais vinculado a uma liderança com perfil de inovação e transformação. $\mathrm{Na}$ terceira etapa da pesquisa, onde se confronta liderança transformacional com o setor automotivo no Brasil, o cenário apresentado nos últimos dez anos é de inexistência de artigos científicos tendo este ambiente como objeto de estudo. Foram identificados muitos artigos sobre esta teoria de liderança, mas nenhum com foco no setor automotivo, estando de certa forma consonante com o panorama mundial. Baseado nos artigos estudados, o perfil das pesquisas no Brasil sobre liderança transformacional, está concentrado em trabalhos teóricos e no meio empresarial quando estratificados por setor, conforme Gráfico 5. 


\title{
Gráfico 5 - Artigos científicos no Brasil contextualizado por setor
}

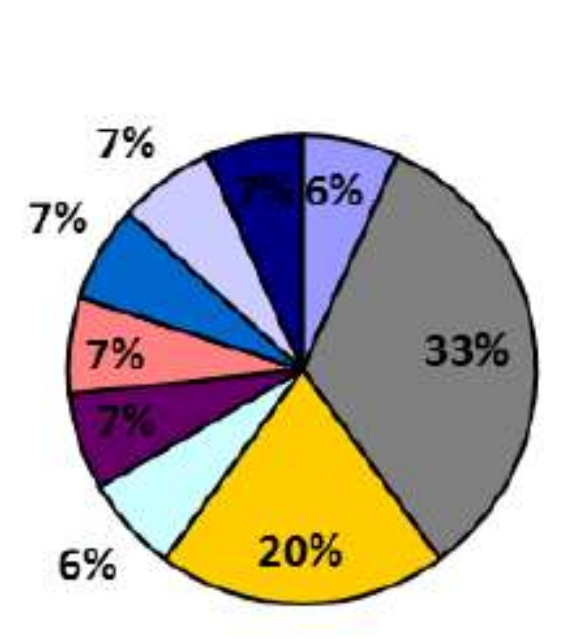

\author{
DEnfermagem \\ 口Teórico \\ DEmpresa rial \\ 口Prestaçào de Serviços \\ Drestaurantes \\ 口Telejornalismo \\ ロ Aviação \\ ロEducaçõo
}

- Setor Publico

Fonte: Scopus, 2017.

A estratificação dos artigos quanto aos aspectos de perfil de aplicação, obteve-se a subdivisão entre artigos: técnicos (29\%), teórico (35\%) e com foco no atendimento ao público (36\%), constata-se uma grande concentração de direcional destes estudos ao contexto de atendimento ao público, reforçando características da teoria transformacional de consideração individualizada, conforme Quadro 2.

E ainda a pesquisa constata que os estudos de liderança transformacional no Brasil estão vinculados principalmente à estudos teóricos e com foco no atendimento ao público. Também, se observado o Quadro 2, a produção científica no Brasil sobre esta teoria tem sua concentração por ano de publicação em 2015 com 33\% e 2013 com 26,6\%, o que demonstra um interesse recente pelo tema. 
Gráfico 6 - Artigos Científicos no Brasil por ano sobre liderança transformacional

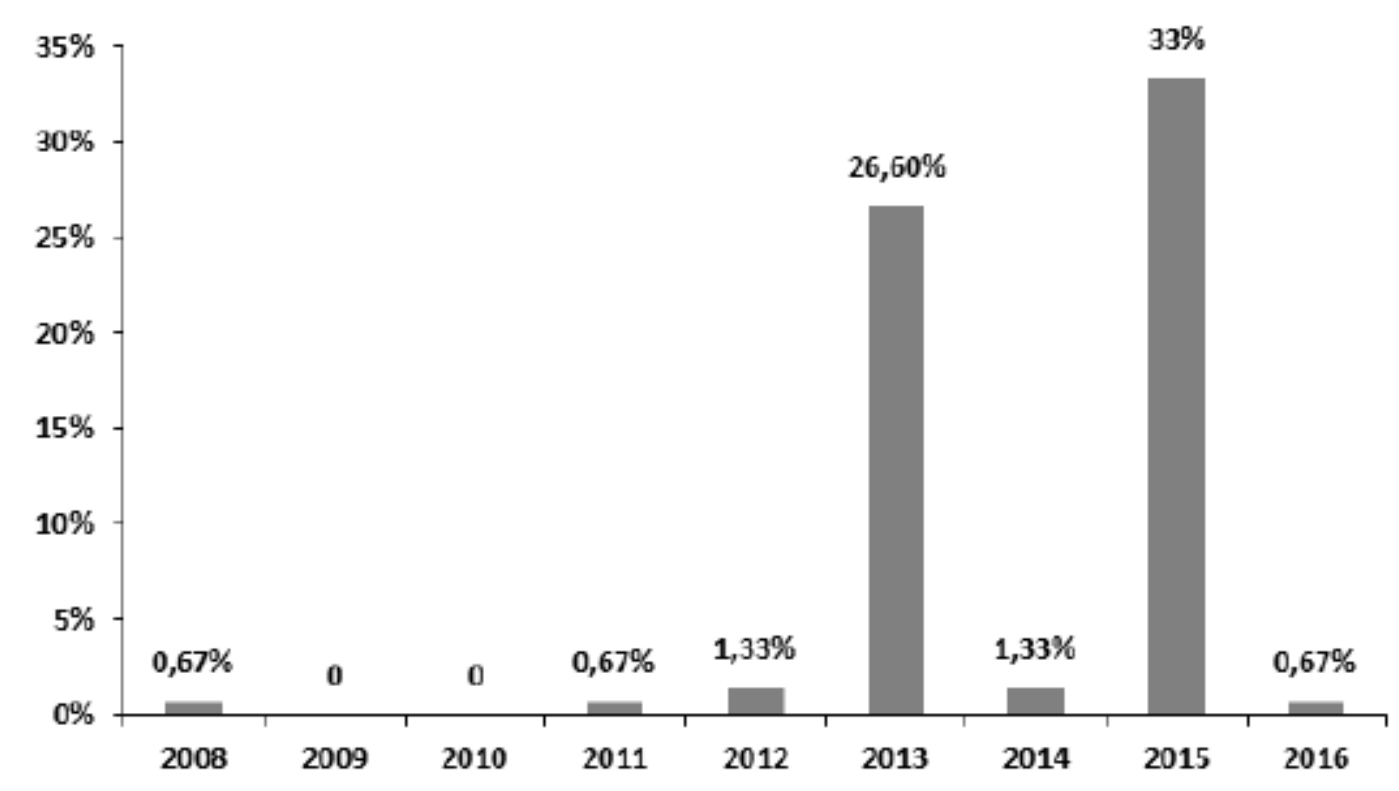

Fonte: Scopus, 2017.

Se observado os dados dos artigos publicados no Brasil (Gráficos 6), que não se enquadram na classificação de teóricos, e apresentam seu foco hierárquico na avaliação de liderança transformacional, identifica-se concentração no nível estratégico (70\% das publicações), ou seja, na alta gestão executiva e nenhuma relação com as expectativas dos liderados, 20\% de publicações para o nível tático e $10 \%$ para o operacional (Scopus, 2017).

\section{CONCLUSÕES}

Pode-se afirmar que existe um campo de pesquisa pouco explorado de forma global no que se refere à liderança transformacional no setor automotivo. Também é conclusivo que o Brasil, apesar do aumento na contribuição científica sobre a teoria da liderança transformacional e por consequência na liderança transacional, aplica os estudos em contexto teórico, ou seja, revisão de bibliográfica de publicações e quanto ao aspecto de perfil de aplicação mais focado, o atendimento ao público ganha destaque. Neste estudo, ficou evidente a concentração das pesquisas em nível estratégico de liderança, pouca vinculação com os níveis hierárquicos mais operacionais e nenhuma interação com os liderados, de forma a ter uma visão geral da organização. Recomenda-se, como trabalhos futuros, estudos no setor automotivo, baseado nas teorias transformacionais e transacionais de liderança, em todos os níveis da cadeia hierárquica, haja vista a identificação de características referentes à capacidade de inovação e facilidade para conduzir mudanças, necessárias numa organização. 


\section{REFERÊNCIAS}

ALMADA, Lívia, POLICARPO, Renata Veloso Santos. A Relação entre o Estilo de Liderança e a Resistência à Mudança dos Indivíduos em um Processo de Fusão, REGE - Revista da Gestão, Sabará, Vol. 23, p 10-19, jan/mar. 2016.

AVOLIO, Bruce; BASS, Bernard. Individual consideration viewed at multiple levels of analysis: A multilevel framework for examining the diffusion of transformational leadership. The Leadership Quarterly, Binghamton, v. 6, n. 2, p. 199-218, 1995.

BALSANELLI, Alexandre Pazzeto, CUNHA, Isabel Cristina Kowal Olm. Liderança no contexto da enfermagem. Revista da Escola de Enfermagem da USP, v. 40, n. 1, p. 117-122, 2006.

BARRETO, Leilianne. Cultura Organizacional e Liderança: Uma relação Possível? Revista de Administração, São Paulo, Vol. 48, p 34-52, jan/mar, 2013. BASS, Bernard. Leadership and Performance Beyond Expectations. New York: Free Press, 1985. 191 p.

BASS, Bernard. Leadership: Good, better, best. Organizational Dynamics, vol. 13 (3) p 26-40, mar, 1985.

BASS, Bernard. The Bass Handbook of Leadership. Ed. 1. New York: Free Press, 2008. 1296 p. BASS, Bernard. Transformational Leadership: Learning to Share the Vision. Organizational Dynamics, v. 18, n. 3, p. 19-31, 1990.

BASS, Bernard. Transformational leadership redux. Leadership Quarterly, v.6, p. 463-485, 1995. BASS, Bernard. STEIDLMEIER, Paul. Ethics, character, and authentic transformational leadership behavior. The Leadership Quarterly, v. 10, n. 2, p. 181-217, 1999.

BASS, Bernard. Transformational Leadership: Industry, military, and educational impact. Ed. 1. New York: Free Press, 1990. 208p. BASS, Bernard, AVOLIO, Bruce. Multifactor Leadership questionnaire: Manual and Sampler. California, Mind Garden: Academic Press, 2004.

BASS, Bernard, AVOLIO, Bruce. Transformational Leadership: A Response to critiques. San Diego, Academic Press, p. 49-80, 1993.

BERGAMINI, Cecília. Liderança: a administração do sentido. RAE - Revista de Administração de Empresas, v. 34, n. 3, p. 102-114, mai/jun, 1994.

BORGOGNI, Laura, DELLO RUSSO, Silvia, LATHAM, Gary. The Relationship of Employee Perceptions of the Immediate Supervisor and Top Management With Collective Efficacy. Journal of Leadership \& Organizational Studies, Baker, v. 18, p. 5-13, 2011.

BRITO NETO, José Félix de. Abordagem de Liderança em Ambientes Multiculturais da Indústria da Aviação, Aviation in Focus, Vol. 5, p 25-30, jan/jun, 2014.

BRYMAN, Alan. Liderança nas organizações, Handboock de estudos organizacionais: Ação e análise organizacionais. 3a ed., v. 3, São Paulo: Atlas, 2009, 257-281p.

BURNS, James Macgregor. Leadership. New York: Perenium, 1978. 
CALAÇA, Pedro Alessandro Freitas. A Liderança Transformacional por James McGregor Burns: Revisitando as Origens. Rio de Janeiro: UNIGRANRIO, 2014. 104 p. Dissertação (Mestrado) - Programa de Pós-Graduação em Administração, Universidade do Grande Rio, Rio de Janeiro, 2014.

CARVALHO NETO, Antônio. Executivos Brasileiros na Contramão do Perfil Deificado da Liderança transformacional, Revista de Ciência da Administração, Curitiba, V.14, N.32, p.35, nov, 2012.

CARVALHO, Rafaela Alexandra Soares. Estilo de Liderança Percebido e Interação Trabalho-Família: Qual Relação? Coimbra: UC/FPCE, 2012. 52 p. Dissertação (Mestrado) - Mestrado em Psicologia Faculdade de Psicologia e Ciências da Educação da Universidade de Coimbra, Coimbra, 2012.

DA CRUZ, Ana Paula Cápua. Estilos de Liderança, Controle Gerencial e Inovação: Papel das Alavancas de Controle, RAC - Revista de administração Contemporânea, Vol. 19, p 772, nov/dez, 2015.

DAY, David, ANTONAKIS, John. The Nature of Leadership, 2o edição, Thousand Oaks: Sage Publication, Inc., 2012. 3-543 p.

DIAS, M.; BORGES, R. Estilos de liderança e desempenho de equipes no setor público. READ. Rev. eletrôn. adm. Porto Alegre, vol.21, n.1, p.200-221, set, 2015.

DINH, Jessica, LORD, Robert, GARDNER, William, MEUSER, Jeremy, LIDEN, Robert, HU, Jinyu. Leadership theory and research in the new millennium: Current theoretical trends and changing perspectives. Leadership Quarterly, v. 25, n. 1, p. 36-62, fev, 2014.

FIEDLER, Fred. A theory of leadership effectiveness, Administrative Science Quarterly, Nova York. Vol. 13, No. 2, p. 344-348, 1968.

FONSECA, Ana Márcia de Oliveira. Liderança: um Retrato da Produção Científica Brasileira, RAC Revista de administração Contemporânea, Vol. 19, p 290, Mai/Jun, 2015.

FONSECA, Ana Márcia de Oliveira. PORTO, Juliana Barreiros. Validação fatorial de escala de atitudes frente a estilos de liderança, Avaliação Psicológica, Vol. 12 (2), p 157-166, Mai/Jun, 2013.

GARNER, John. Liderança: sucesso e influência a caminho da modernidade. Ed. 2, Rio de Janeiro: Record, 1990. 295 p.

GONÇALVES, Andressa. A Relação entre Liderança e Cultura Organizacional: Um estudo realizado em uma IES, Gepros: gestão de Produção, Operações e Sistemas, Vol. 10, p.85, abr/jun, 2015.

GRINT, Keith. A history of leadership, ed. 1, Londres: Sage Publication, Inc., 2011. 3-14p

KRAUSER, Donald. A força de um líder. ed. 1, São Paulo: Makron Books, 1999.

LEHMANN-WILLENBROCK, Nelan, MEINECKE, Annika, ROWOLD, Jens, KAUFFELD, Simone. How transformational leadership works during team interactions : A behavioral process analysis. The Leadership Quarterly, v. 26, n. 6, p. 1017-1033, 2015.

MACHADO, Ana Paula. Mercado de Caminhões deve Crescer 10\% Ano que vem. Autodata, 2016. Disponível em: <http://www.autodata.com.br/noticias/22605/mercado-de-caminhoes-deveracrescer-10-no-ano-que-vem.> Acesso em: 14 dez 2016. 
MACIEL, Cristiano de Oliveira, NASCIMENTO, Mauricio Reinert. Em Busca de uma Abordagem não Atomizada para o Exame das Relações entre Liderança Transformacional e Comprometimento Organizacional, Revista de Administração, Vol. 48, p 544-559, jul/ago/set, 2013.

PORTO, Juliana Barreiros. O Efeito de Valores Pessoais nas Atitudes Perante estilos de Liderança, Revista de Administração de Empresas Mackenzie, 2012 RAM, São Paulo, vol.13, no. 3, p 122-129, mai/jun, 2012

RAMALHEIRA, Pedro. O impacto da Cultura Portuguesa e da Proactividade na Liderança: Um estudo Exploratório. Lisboa: UAL, 2013.141 p. Dissertação (Mestrado) - Programa de Pós-Graduação de Mestrado em Planejamento e Gestão Estratégica - Universidade Autonoma de Lisboa, Lisboa, 2013.

ROLDAN, Vivianne, PEREIRA, Salas. Estilo de Liderança e Desempenho Criativo em Equipe de Telejornalismo: Um estudo em Emissoras de TV Cearense, RECADM, Vol. 12, p 355-353, nov, 2013.

STRAPASSON, Maria Rejane. Liderança Transformacional na Enfermagem, Revista Brasileira de Enfermagem, Lajeado, Vol.62(2), p 228-233, mar/abr, 2009.

TURANO, Lucas Martins, CAVAZOTTE, Flávia. Conhecimento Científico sobre Liderança: Uma Análise Bibliométrica do Acervo do The Leadership Quarterly, Revista Administração Contemporânea, Rio de Janeiro, v. 20, n. 4, p. 434-457, jul/ago, 2016.

VERGARA, Sylvia Constant. A liderança aprendida. GV Executiv, São Paulo, v.6, n.1, p. 61-65, jan/fev, 2007.

VIZEU, Fabio. Uma Aproximação entre Liderança Transformacional e Teoria da Ação Comunicativa, Revista de Administração de Empresas Mackenzie, São Paulo, Vol.12, nำ, p. 53-81, nov, 2011.

YAMMARINO, Francis, SPANGLER, William, BASS, Bernard. Transformational Leadership and Performance: A Longitudinal Investigation. Leadership Quarterly, Binghamton, v. 4, n. 1, p. 81-102, 1993.

ZACCARO, Stephen, RITTMAN, Andrea, MARKS, Michelle. Team leadership. Leadership Quarterly, Flórida, v. 12, p. 451-483, 2001.

ZHU, Weichun, AVOLIO, Bruce, RIGGIO, Ronald, SOSIK, John. The effect of authentic transformational leadership on follower and group ethics. Leadership Quarterly, v. 22, n. 5, p. 801-817, 2011. 


\section{Capítulo 9}

\section{doi) $10.37423 / 210403764$}

\section{CONCEITOS DE GESTÃO DE MARCA: COMPARATIVOS ENTRE AS VISÕES APRESENTADAS POR LINDSTROM, MESHER E WHEELER}

Arina Blum

Taís Vieira Pereira

Vanessa Neto Bischoff

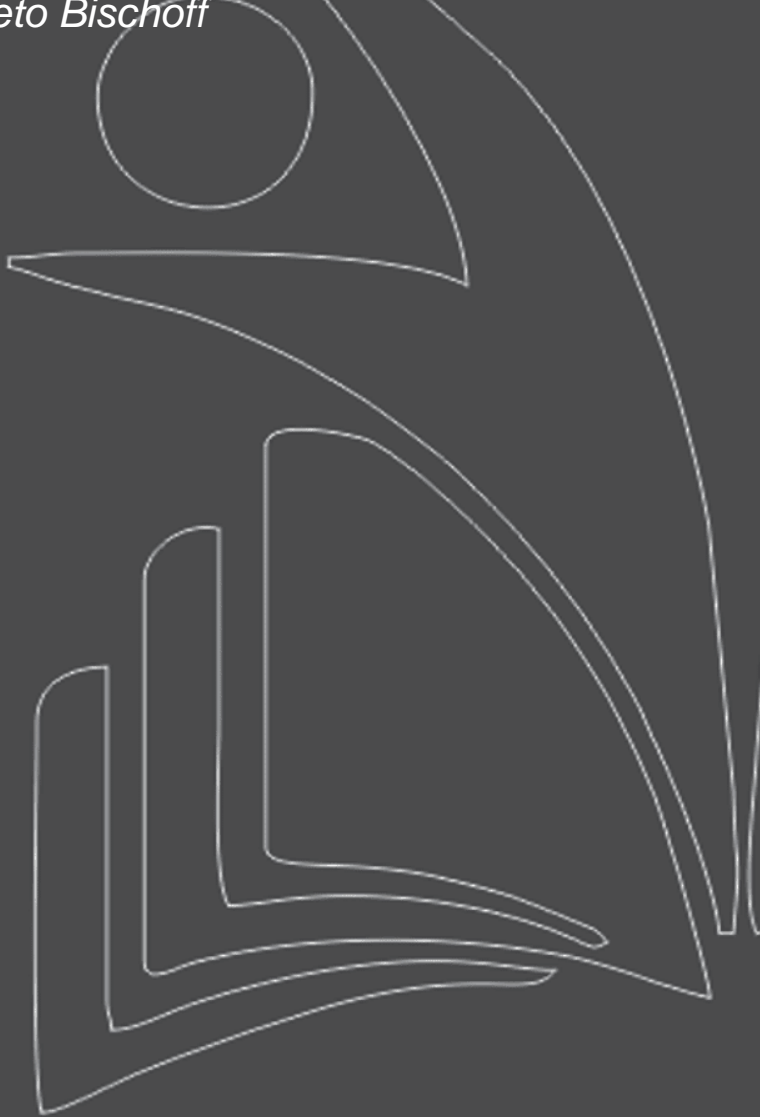

Centro Universitário de Brusque

Faculdades Integradas de, Taquara

Faculdade América Latina

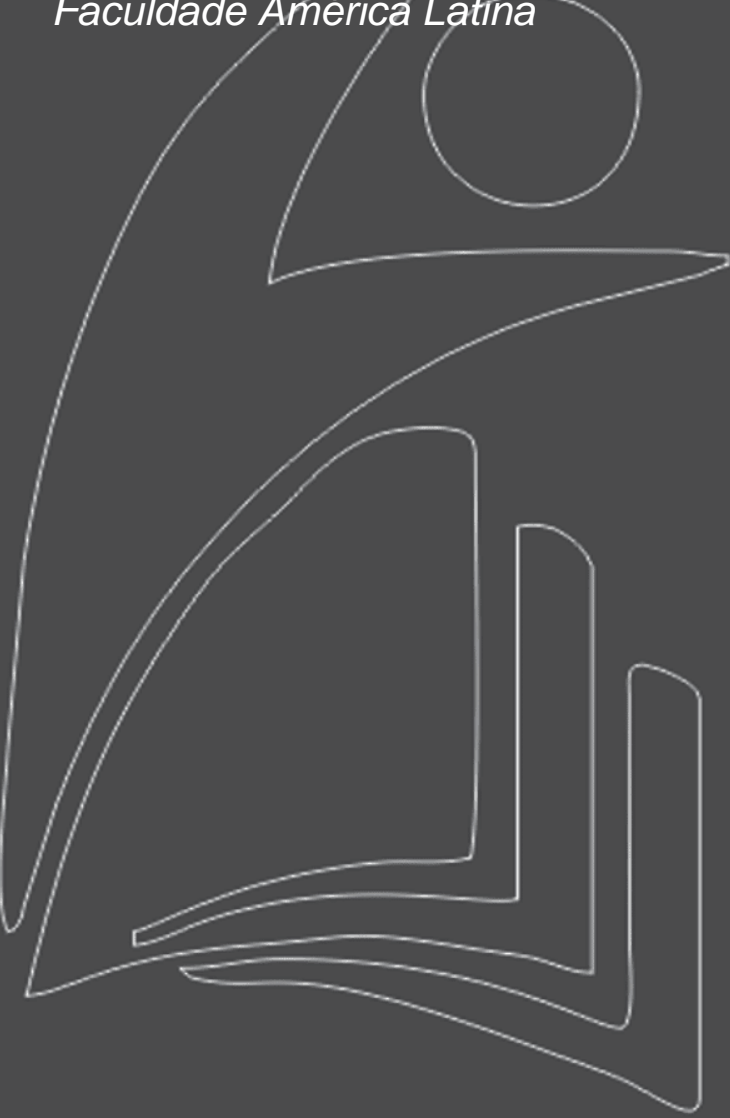


Resumo: Marca, ou brand, abarca fatores de propriedade somados à responsabilidade e aos atos de cuidado que recaem sobre ela. O termo brand deu origem ao chamado "branding" por justamente fazer menção à carga de direitos e deveres atribuídos a um dono. Por meio de uma pesquisa qualitativa de revisão bibliográfica nas áreas do design e do marketing, mais especificamente acerca do branding como gestão de marca, este artigo apresenta as visões de Lindstrom, Mesher e Wheeler sobre o tema, considerando a hipótese de que os três autores apresentam conceitos que se convergem, embora os seus escritos tenham focos diferentes. O objetivo do estudo aqui relatado é, a partir da relação entre as ideias afins dos três autores, extrair conceitos que constituam ideais no campo do branding. Os resultados indicam seis apontamentos que fazem a interação entre os autores analisados.

Palavras-chave: design, marketing, identidade, marca, gestão de marca. 


\section{INTRODUÇÃO}

Branding e marca são termos que se correlacionam. Para Strunck (2012), branding faz menção à carga de direitos e deveres atribuídos a um dono. A propriedade e toda a responsabilidade e os atos de cuidado que recaem sobre esta são fatores concernentes a uma marca ou brand. Silva (2002) afirma que a ideia de branding vem de uma evolução do marketing corporativo - o responsável por determinar o gerenciamento das marcas - e, muito mais do que um planejamento da marca, o branding se configura na relação de afetividade desta com o seu público. Cameira (2013) corrobora com essa ideia ao afirmar que a própria criação da marca - ideia que ultrapassa os meandros estritamente visuais - evoluiu para a direção da identidade corporativa e, mais recentemente, para o branding - a gestão da marca.

A partir do embasamento de que "na pesquisa qualitativa, o pesquisador utiliza os insights e as informações provenientes da literatura enquanto conhecimento sobre o contexto" (FLICK, 2009, p. 62), o presente artigo se baseia na hipótese de que três autores que apresentam enfoques distintos sobre gestão de marcas - Lindstrom (2007), Mesher (2011) e Wheeler (2008) - convergem quanto a alguns conceitos que explanam. Por meio de uma pesquisa de revisão bibliográfica, o objetivo deste artigo concentrou-se em confrontar seus textos com a intenção de extrair conceitos afins que constituam ideais no campo do branding.

A escolha desses autores deu-se pela abordagem que os mesmos fazem à gestão de marca, tendo, no entanto, diferentes focos: Lindstrom volta-se aos aspectos sensoriais da marca; Mesher expõe sobre aplicação da marca em ambientes comerciais; Wheeler, por sua vez, enfatiza a construção da identidade visual da marca. A busca proposital por enfoques diferenciados teve como objetivo conferir visões mais amplas quanto ao contexto de branding e, assim, promover discussões que contribuam para os estudos nesta área.

\section{BRANDING COMO GESTÃO DE MARCA}

Silva (2002, p.13) reuniu uma série conceitos sobre branding e a sua relação com a ideia de marca, entre eles: "Branding é um processo de construção de gerenciamento de marca" (Luciano Deos); "Branding é a ampliação da importância da marca como elemento diferenciador em um mercado em que a tecnologia não ocupa mais esse papel” (Ronald Kapaz); "Branding é uma forma de desenvolver uma construção de marca aplicada no pré-design e no pós-design" (Bill Martinez); "Branding é uma palavra que os clientes estão usando e o que a gente está procurando fazer entender [...] para poder 
atender às expectativas do cliente e do mercado" (Luiz Roberto Farina); "Branding é uma questão de vivência e afetividade para se desenvolver a fidelidade da marca pelo cliente" (Antônio Roberto Oliveira).

Nesse contexto, entende-se que a correlação entre branding e marca está na maneira como a segunda tem sido gerida pelos conceitos do primeiro. Para Cameira (2013) esta gestão é, na atualidade, marcada pelo aumento da complexidade do projeto. A ideia de complexidade e a maneira de lidar com ela é proposta também por Moraes (2010, p.65) como parte da atuação do designer no cenário contemporâneo, cabendo a este profissional a "capacidade permanente de atualização e de gestão da complexidade". O branding é, nesse sentido, uma maneira de gerenciar uma série de fatores próprios da marca no cenário da atualidade.

Mesher (2011) relata o surgimento do branding "por volta de 1880, quando começaram a aparecer logotipos nas embalagens dos alimentos, como sopa Campbell, a Coca Cola e o xarope Lyle's Golden Syrup"1 (MESHER, Ibid., p.14). A atuação da publicidade foi ampliada no final da década de 1940, quando a aplicação do branding deixou de ser apenas relacionada ao produto e passou a expressar também a atividade e a função da organização. Com isso, difundiu-se o termo "identidade de marca" no vocabulário corporativo.

Segundo a pesquisadora, foi na década de 1980 que o conceito de branding se consolidou graças à gradativa substituição da valorização do processo de produção pela estratégia de desenvolvimento da essência de marca. Uma desaceleração no mercado ocorreu na década seguinte. Nesse contexto, observou-se a sobrevivência e consolidação das marcas que mantiveram seus valores nas estratégias de marketing. Enquanto isso, o contrário aconteceu com as organizações que deixaram de investir em publicidade, tendo como consequência a "morte da marca", conforme descreve Mesher (Ibid.).

Para Lindstrom (2007), o tema marca é particularmente importante para as organizações nos dias atuais. Ao considerar a nova lógica do consumo - o consumidor mais consciente, o surgimento de novas tecnologias e a compra com ênfase na produção de sentido - faz-se necessário que a marca amplie suas funções e modos de abordagem. Além de representantes de produtos e serviços, ela se torna um recurso dotado de valor autônomo.

Compreender e transitar dentro do universo contemporâneo da comunicação comercial é uma necessidade das marcas atuais. Conforme Semprini (2006), é especialmente a partir dos anos 1980 que a comunicação passou a empreender uma transformação reforçada devido à comunicação de massa e à complexidade crescente da sociedade - algo que requereu o estabelecimento de novas 
formas de contato para conquistar o consumidor. A comunicação comercial começou exaltar valores imateriais e, nesse cenário, as marcas passaram a ser vistas como enunciadoras das organizações na concretização de projetos de sentido. Desde então, sua identidade se manifesta não somente nos produtos e serviços, mas também em níveis do sensível, pertencente ao mundo das experiências.

A marca contemporânea é dinâmica, evolutiva. À medida que vai sendo construída, se desconecta da materialidade do produto para produzir sentidos mais abrangentes. Para Desserti (2007), a marca assume a função de geradora de identidade, do produto e da organização, um suporte linguístico que se relaciona com os espaços sociais. Semprini (Ibid.) afirma que surge uma nova lógica de marca que a liberta da dimensão comercial e estende sua influência para o discurso social. Torna-se um modo de organização de valores mais eficaz e flexível que atinge esferas políticas e culturais. Para o pesquisador, essa ligação da marca com a configuração comunicacional a oportuniza um espaço central na sociedade contemporânea e nas organizações.

A fim de compreender o contexto de gestão de marca trazidos por Lindstrom (2007), Mesher (2011) e Wheeler (2008), o presente artigo segue oferecendo uma compilação dos escritos desses autores. Lindstrom é publicitário e consultor de marketing. Destaca-se pelos estudos sobre marcas sensoriais e pelas pesquisas em neuromarketing sobre porque as pessoas compram. Lynne Mesher possui formação em design (de móveis e produto) e atua na área de design de interiores nos setores de varejo e lazer para marcas internacionalmente conhecidas. É docente, pesquisadora e possui publicações nas áreas de ensino de interiores, processo de design, ambientes comerciais e ambientes experienciais. Alina Wheeler é designer, consultora e conferencista que trabalha junto a equipes de gerenciamento e criação em empresas. A essência das ideias propostas pelos autores são apresentadas nos itens 2.1, 2.2 e 2.3 baseando-se unicamente nos escritos em estudo: Lindstrom (2007), Mesher (2011) e Wheeler (2008), respectivamente.

\subsection{CONCEITOS POR LINDSTROM (2007)}

A cada ano, o consumidor é exposto a uma variedade excessiva de ofertas e marcas. Em meio a tantos apelos, cabe à publicidade e ao marketing encontrar formas relevantes de abordagem e relação. É neste contexto que Lindstrom (2007) introduz as marcas sensoriais, ou Brandsense. Partindo do pressuposto de que os indivíduos compreendem o mundo através dos sentidos, o pesquisador afirma que o diferencial destas marcas no mercado está em serem planejadas considerando dimensões 
sensoriais que estabelecem um vínculo emocional com consumidor. Elas oportunizam colocá-lo em contato com suas memórias, estimulando seu lado irracional no ato da compra.

Você lembra da compra de seu primeiro carro novo? O cheiro de carro novo era inconfundível. Muitas pessoas citam esse cheiro como um dos aspectos mais gratificantes da compra de um carro novo. $O$ cheiro é tão significativo quanto o brilho de sua carroceria (LINDSTROM, 2007, p. 25)

Segundo Lindstrom (Ibid.), ao explorar os sentidos humanos, as marcas se veiculam à memória dos consumidores, atingindo diretamente suas emoções. No que diz respeito ao olfato, por exemplo, o cheiro se conecta às lembranças. A audição relaciona-se ao som e este cria o ânimo. $\mathrm{O}$ tato oportuniza o contato, o toque, e se liga diretamente ao bem estar. No paladar está a importância do sabor, do prazer e, por assim dizer, do humor. A visão impacta, cria a primeira impressão e estabelece a diferenciação.

A marca sensorial comunica sua identidade nos pontos de contato com o consumidor através de imagens, cores, formatos, sons, texturas, formas de utilização dos produtos, atendimento, entre outras ações. Cada uma é desenvolvida com o intuito de fortalecer o posicionamento da marca, atuando sozinha ou integrada a outras estratégias. Lindstrom (Ibid.) orienta que, à medida que as organizações investem em um plano de gestão de suas marcas, torna-se igualmente relevante investir em um plano sensorial para elas.

O branding sensorial (LINDSTROM, Ibid., p. 116), como o próprio nome indica, compreende o planejamento e gestão de marcas sob o ponto de vista sensorial, com o objetivo de estabelecer um compromisso emocional com o consumidor. A criação de estratégias origina-se de uma profunda análise sobre a marca e leva em conta uma auditoria sensorial, a montagem da marca, a dramatização da marca, a assinatura da marca, a implementação e avaliação da marca sensorial.

A auditoria sensorial da marca consiste no levantamento de informações sobre seu posicionamento, seus consumidores e concorrentes. Também avalia a marca sob o ponto de vista sensorial identificando e monitorando pontos de contato sensoriais existentes. A montagem da marca consiste em dar atenção à sinergia sensorial da marca (LINDSTROM, 2007). Ou seja, seus pontos de contato devem ser planejados para funcionar em sintonia e, assim, fortalecer o efeito da comunicação.

O planejamento do branding sensorial também requer conhecer a personalidade da marca - sua dramatização. Segundo Lindstrom (Ibid.), consiste em identificar os sentimentos e emoções ligados à marca para então transformá-los em apelos sensoriais. A assinatura da marca, por sua vez, é sua 
“declaração exclusiva” (LINDSTROM, Ibid., p. 134), a personalidade que a diferencia a partir de estados de humor e de atitude.

A quinta etapa do branding sensorial diz respeito à implementação da marca propriamente dita e envolve pesquisas e desenvolvimento de ações dirigidas às dimensões sensoriais. Por fim, o branding sensorial propõe uma avaliação da marca, tarefa que envolve uma análise crítica das estratégias implementadas, considerando em que grau a marca sensorial alcançou o efeito desejado sem perder sua autenticidade.

A gestão de marcas sob o ponto de vista sensorial oportuniza altos níveis de fidelidade do consumidor em um contexto mercadológico saturado por apelos publicitários. Ao considerar a ampliação das marcas em arquiteturas cada vez mais complexas e desvinculadas dos produtos de origem, o branding sensorial auxilia na criação de uma plataforma única, calcada em um vínculo emocional capaz de transitar em diferentes mercados, consumidores e linhas de mercadorias. Conforme Lindstrom (Ibid.), os profissionais de marketing que reconhecerem o poder dos sentidos encontrarão novos meios para construir um vínculo duradouro com seus clientes baseado no prazer e na apreciação oportunizados pelas marcas sensoriais.

\subsection{CONCEITOS POR MESHER}

Mesher (2011) descreve o projeto de interiores comerciais como um processo complexo, que requer análise da marca e sua identidade na etapa inicial. As lojas são locais que devem atrair, entusiasmar e seduzir os consumidores através de uma experiência com a qual possam se identificar, complementa. Em vista disso, o pleno conhecimento da marca torna-se imprescindível para o brandscaping ${ }^{2}$. Tal projeto, que leva em conta o branding, também é caracterizado pela necessidade de constante atualização, para que os ambientes mantenham-se competitivos, seguindo os modismos e as aspirações de seu público.

Em “Diseño de espacios comerciales", Mesher (Ibid.) aborda os processos e estratégias projetuais de interiores comerciais, sendo o primeiro capítulo destinado a branding e identidade. A pesquisadora expõe sobre a relevância da transferência da marca ao espaço tridimensional. Nessa perspectiva, apresenta (i) o conceito e os princípios de branding, (ii) processo de desenvolvimento da marca e sua aplicação no ambiente e (iii) os mecanismos de promoção e consolidação de uma marca no mercado global. Uma síntese dessa seção é exposta a seguir. 
Branding, de acordo com a autora, é uma técnica utilizada para atrair um público específico com o intuito de vender produtos e serviços sob um determinado nome. "Uma marca pode ser um produto, uma pessoa ou um logotipo: qualquer coisa que se possa comprar ou vender, como uma ideia ou artefato, pode ser convertido numa marca"33 (MESHER, Ibid., p.12). Além disso, afirma que o branding é sustentado pelo consumismo e a necessidade humana de definir e expressar um estilo de vida através de suas compras. Por esse motivo, o branding está fundamentalmente relacionado à publicidade e ao marketing aplicados à aproximação das aspirações subconscientes dos consumidores.

Em contrapartida, nenhuma marca é atrativa a todos, pondera Mesher (Ibid.). Para que ocorra a identificação entre uma marca e o público ao qual é direcionada, há um trabalho de marketing e publicidade que inicia pela definição dessa marca através da análise dos valores da organização que representa. Esse processo consiste num profundo conhecimento do produto e de como dirigi-lo ao público adequado, além do estudo desses consumidores. Ao final desse processo, o espaço comercial deve ser projetado de forma a transmitir e enaltecer os valores da marca, com o intuito de favorecer a identificação e a relação entre ela e a mensagem, o produto e consumidor.

Para Mesher, "Toda imagem de marca se cria a partir da definição dos princípios fundamentais de seu significado"4 (MESHER, Ibid., p.15). Tais princípios consideram o produto e o contexto de inserção, ou seja, conhecer os concorrentes com o intuito de posicionar a marca. A partir desse estudo, os objetivos organizacionais são evidenciados e a estratégia de marca estabelecida. De acordo com a autora, a análise dos princípios de uma marca abarca: (i) a essência, que representa as principais características da organização, considerando a atividade e a natureza do trabalho; (ii) os valores, que requer o estudo dos princípios morais corporativos e a como são transmitidos na marca; (iii) a imagem, que expressa a essência e os valores organizacionais através de meios visuais, elemento de extrema relevância no desenvolvimento da marca; (iv) as grandes ideias, que revelam os objetivos da marca; (v) a geração de lucro; (vi) a atração de novos consumidores e (vii) a cultura, que envolve o questionamento sobre o mercado consumidor pretendido.

Mesher (Ibid.) explica que, geralmente, as organizações contratam consultores de marca para gerenciar o processo de desenvolvimento ou reinvenção de uma marca, pois isso exige conhecimentos específicos. Segundo a pesquisadora, esse processo inicia com investigação e análise da natureza da organização e de sua caracterização, ponderando sua posição atual. Para uma melhor definição do posicionamento da empresa no mercado, os principais concorrentes também podem ser analisados nessa fase. 
A etapa seguinte envolve os designers gráficos, que "contextualizam os diferentes significados implícitos na ideia central, e se questionam acerca da imagem e a sensação que transmite a marca" 5 (MESHER, Ibid., p.18). Para definição da imagem da marca, são elaborados painéis de inspiração (mood boards) e de estilo de vida (lifestyle boards). A partir disso, é possível determinar um estilo que fundamentará tanto o projeto de design gráfico, como o projeto design de interiores. Nesse momento, designers gráficos e de interiores trabalham de forma colaborativa.

As decisões do projeto gráfico envolvem a representação da marca na publicidade. Para tanto, é desenvolvido um manual de identidade corporativa (brand guidelines), que preconiza a coerência da comunicação visual, sua aplicação no ambiente comercial e nos acabamentos aplicados nesse espaço, esclarece Mesher (Ibid.). Dessa forma, a partir do manual de identidade corporativa, as aspirações do consumidor pretendido e a postura competitiva que se pretende adotar, o projeto de interiores é elaborado.

Painéis de inspiração apoiam a investigação visual necessária no processo projetual de brandscaping, complementa Mesher (Ibid.). Para viablizar a aplicação da marca num ambiente é essencial: (i) identificar a marca e suas cores, motivos, logotipos, sons e aromas associados; (ii) entender o produto e seus possíveis consumidores e (iii) analisar o estilo de vida das pessoas que poderiam utilizar essa marca, bem como, identificar o que esperam de uma experiência de compra no ambiente em projeto. Para dar continuidade ao projeto, são elaboradas simulações das ideias geradas através de storyboards (série de imagens organizadas em sequência para oferecer a pré-visualização de um projeto). Para implantar o projeto (roll out), a equipe de design desenvolve um manual para padronização das lojas em diferentes lugares.

Por fim, Mesher (Ibid.) apresenta os mecanismos de promoção e consolidação de uma marca no mercado global, classificados em: (i) lojas conceito (concept stores), onde novas ideias comerciais são testadas ou promovidas; (ii) lojas próprias (flagship stores), onde a marca é promovida em grandes zonas comerciais; (iii) lojas de estilo de vida (lifestyle stores), onde uma ampla gama de produtos de setores distintos é oferecida como forma de representação de um modo de vida representado pela marca e (iv) lojas ou instalações temporárias (pop-up), uma estrutura efêmera que permanece em determinado local por um período de tempo reduzido. E esclarece que tais estratégias são realizadas em locais relevantes, com o intuito de alcançar a maior parte dos consumidores possível, para depois o projeto ser reinterpretado em lojas menores. 


\subsection{CONCEITOS POR WHEELER (2008)}

Alina Wheeler (2008, p.12) define marca como "a promessa, a grande ideia e as expectativas que residem na mente de cada consumidor a respeito de um produto, de um serviço ou de uma empresa". A pesquisadora faz essa afirmação após explanar que a marca se encontra como elemento de competição pelo reconhecimento, sendo este não mais restrito ao terreno físico, mas evoluído para a concorrência do share of mind, ou seja, o espaço do reconhecimento pela mente do consumidor. Neste contexto, o presente artigo segue apresentando alguns dos conceitos expressos por Wheeler em "Design de identidade da marca", dando especial atenção às visões da autora com relação aos processos que envolvem a gestão de marcas e as iniciativas requeridas na construção de uma identidade de marca bem sucedida.

Por identidade, Wheeler compreende aquilo que é tangível e também aquilo que apela para os sentidos. Consiste na expressão visual e verbal de uma marca que pode ser vista, tocada, agarrada, ouvida, observada e movida. Quando é de fácil memorização e imediatamente reconhecível, a identidade viabiliza a conscientização e o reconhecimento da marca. Esta torna-se intrínseca na cultura de uma organização na medida em que é uma lembrança constante de seus valores fundamentais e de sua tradição.

Reforçando tal pensamento, Wheeler (Ibid., p. 19) cita as aspirações de identidade desenvolvidas pela estrategista de design da informação, Sylvia Harris, que pontua que a identidade é capaz de: "expressar que espécie de organização você é"; "garantir ao público que você é realmente aquilo que diz ser"; "conectar sua empresa a imagens e ideias"; "servir como fio condutor para construir patrimônio ao longo do tempo", "proporcionar consistência nos canais de comunicação".

Tornar "a compra mais fácil para o consumidor", fazer "com que, para a equipe de vendas, seja mais fácil vender" e permitir que seja "mais fácil a construção de brand equity" são razões para investir na identidade de marca, segundo Wheeler (Ibid., p.23). A compreensão por parte do consumidor sobre as vantagens e benefícios de uma marca garante mais respeito, sendo isso uma consequência da identidade, pois ela ajuda a gerenciar a percepção de uma organização e a diferencia-la de seus concorrentes.

A venda de uma imagem de marca estrategicamente pensada não somente funciona entre diferentes públicos, mas também, contribui para que a própria organização tenha ciência de seu potencial. Isso 
se dá também por meio do brand equity, ou seja, o valor da marca no que tange a sua reputação positiva, aquilo que está além do patrimônio físico de uma empresa, por exemplo.

O desafio dos estudos que envolvem o branding tem sido entender o que fazem algumas marcas se destacarem em meio a tantas outras. Wheeler defende que a excelência no design é um dos requisitos para tanto e que as melhores identidades são mais eficientes na impulsão da empresa através da marca. Para a autora, melhores identidades significam, entre outros quesitos, aquelas que visualmente seguem critérios funcionais adequados e características como audácia, memorização, adequação e reconhecimento imediato; conceitos que apresentam uma imagem clara e consistente para a empresa e comunicam a sua personalidade.

Wheeler (Ibid., p.25) também defende que a visão geral dos ideais de uma marca podem ser resumida em nove itens inter-relacionados: visão; significado; autenticidade; diferenciação; sustentabilidade; coerência; flexibilidade; comprometimento; valor. Isso constitui uma marca que é movida por uma visão estimulante; que significa um conjunto de valores positivos; que é autêntica e clara no que se refere ao mercado de atuação; que diferencia-se de seus concorrentes; que tem posição sustentável em termos de longevidade; que tem coerência nas experiências dos consumidores; que é flexível para mudanças voltadas ao crescimento futuro; que se compromete no cuidado com as diversas variáveis gerenciais; que pode ser medida em termos de valor agregado.

No que se refere à experiência das pessoas com a marca, Wheeler entende que cada oportunidade com o consumidor é um momento de realçar uma conexão emocional. Para a pesquisadora, a grande quantidade de opções de compra estão induzindo as marcas a verem no planejamento de experiências um meio para seduzir o público. Neste sentido, a eficaz estratégia de marca tem sido aquela que funciona, através de produtos e serviços, pela união de conceitos de comportamento, ações e comunicações adequados. Em suma, as melhores estratégias são aquelas que consistem em uma profunda compreensão das necessidades e percepções dos consumidores alinhando-se à ações de marketing em ressonância com os stakeholders.

\section{ANÁLISE COMPARATIVA}

Um aprofundamento nos escritos de Lindstrom (2007), Mesher (2011) e Wheeler (2008), demonstrou que os autores convergem em alguns pontos e que, mesmo com enfoques diferentes quanto à abordagem da temática - gestão de marca ou branding - conceitos similares podem ser reconhecidos em seus textos. Desconsiderando descrições que apontavam ações específicas - tais como exemplos, 
ferramentas ou maneiras de fazer algo - o estudo levantou seis pontos afins entre os conceitos apresentados pelos autores e que foram resumidos nas seis sentenças a seguir: (i) Linguagem organizada que faça sentido; (ii) Marca como vínculo emocional; (iii) Marca como meio de sobrevivência; (iv) Algum diferencial que atraia; (v) Meios que tangibilizem conceitos; (vi) Design e marketing como aliados.

A fim de compreender os pontos de convergência, as sentenças foram expressas em forma de quadro (Quadro 1), sendo que a coluna denominada "Conceitos convergentes" se refere às sentenças, ou seja, ao resultado da correlação entre os conceitos de gestão de marca ou branding trazidos pelos três autores.

Quadro 1 - Análise comparativa

\begin{tabular}{|c|c|c|c|}
\hline $\begin{array}{l}\text { CONCEITOS } \\
\text { CONVERGENTES }\end{array}$ & LINDSTROM (2007) & MESHER (2011) & WHEELER (2008) \\
\hline $\begin{array}{l}\text { Linguagem } \\
\text { organizada que } \\
\text { faça sentido }\end{array}$ & $\begin{array}{l}\text { As estratégias sensoriais } \\
\text { da marca devem ser } \\
\text { planejadas em sinergia e } \\
\text { considerando a "herança } \\
\text { da marca", isto é, sua } \\
\text { essência. }\end{array}$ & $\begin{array}{l}\text { O projeto de um ambiente } \\
\text { comercial é desenvolvido } \\
\text { em torno do conceito da } \\
\text { marca e dos produtos que } \\
\text { serão vendidos. A loja se } \\
\text { iguala aos valores e às } \\
\text { qualidades que a marca } \\
\text { aspira, com o objetivo de } \\
\text { destacar a relação } \\
\text { coerente entre o espaço e } \\
\text { a mensagem, reafirmando } \\
\text { o valor da marca. }\end{array}$ & $\begin{array}{l}\text { A mensagem é o mantra da } \\
\text { marca e funciona bem } \\
\text { quando destila a essência } \\
\text { do produto ou serviço. A } \\
\text { mensagem vem através da } \\
\text { linguagem que precisa ser } \\
\text { viva, direta, eloquente e } \\
\text { substanciosa. }\end{array}$ \\
\hline $\begin{array}{l}\text { Marca como } \\
\text { vínculo } \\
\text { emocional }\end{array}$ & $\begin{array}{l}\text { O branding sensorial } \\
\text { oportunizará um } \\
\text { compromisso emocional } \\
\text { com o consumidor } \\
\text { gerando níveis mais altos } \\
\text { de fidelidade por colocá- } \\
\text { los em contato com suas } \\
\text { memórias e o lado menos } \\
\text { racional no ato da } \\
\text { compra. }\end{array}$ & $\begin{array}{l}\text { O branding é sustentado } \\
\text { pelo consumismo e a } \\
\text { necessidade humana de } \\
\text { definir e expressar um } \\
\text { estilo de vida através de } \\
\text { suas compras. Seja para } \\
\text { alimentação, vestuário ou } \\
\text { lazer, comprar é uma } \\
\text { atividade cotidiana. Os } \\
\text { produtos e locais } \\
\text { escolhidos refletem o } \\
\text { estilo de vida, a cultura e } \\
\text { os interesses de uma } \\
\text { pessoa, que estabelece } \\
\text { um vínculo emocional } \\
\text { com o contexto comercial } \\
\text { no qual se sente a } \\
\text { vontade. }\end{array}$ & $\begin{array}{l}\text { Quando as pessoas se } \\
\text { apaixonam por uma } \\
\text { determinada marca são } \\
\text { fiéis a ela e acreditam na } \\
\text { sua superioridade e essa } \\
\text { fidelidade é construída em } \\
\text { cada ponto de contato da } \\
\text { empresa com o } \\
\text { consumidor, em momentos } \\
\text { onde a marca oportuniza } \\
\text { que se realcem conexões } \\
\text { emocionais. }\end{array}$ \\
\hline $\begin{array}{l}\text { Marca como } \\
\text { meio de } \\
\text { sobrevivência }\end{array}$ & $\begin{array}{l}\text { Marcas sensoriais se } \\
\text { diferenciam em um } \\
\text { contexto mercadológico } \\
\text { saturado por apelos } \\
\text { publicitários. No contexto }\end{array}$ & $\begin{array}{l}\text { A identificação das } \\
\text { pessoas com } \\
\text { determinadas marcas } \\
\text { fideliza o consumo, } \\
\text { independente do preço }\end{array}$ & $\begin{array}{l}\text { Marcas ineficazes debilitam } \\
\text { o negócio, enquanto a } \\
\text { diferenciação leva ao bom } \\
\text { posicionamento e se torna } \\
\text { determinante para }\end{array}$ \\
\hline
\end{tabular}




\begin{tabular}{|c|c|c|c|}
\hline & $\begin{array}{l}\text { de arquiteturas de marca } \\
\text { cada vez mais complexas } \\
\text { e desvinculadas dos } \\
\text { produtos de origem, o } \\
\text { branding sensorial auxilia } \\
\text { na criação de uma } \\
\text { plataforma única } \\
\text { (emocional) capaz de } \\
\text { transitar em diferentes } \\
\text { mercados, consumidores } \\
\text { e linhas de produto. }\end{array}$ & $\begin{array}{l}\text { dos produtos. As marcas } \\
\text { são identificadas e } \\
\text { vendidas ao público } \\
\text { através do marketing e da } \\
\text { publicidade. Uma } \\
\text { organização que deixara } \\
\text { de investir em publicidade } \\
\text { corre o risco de não } \\
\text { sobreviver no mercado. }\end{array}$ & $\begin{array}{l}\text { sobreviver em um meio } \\
\text { povoado de marcas. A } \\
\text { sobrevivência de uma } \\
\text { empresa está diretamente } \\
\text { relacionada ao } \\
\text { reconhecimento positivo } \\
\text { por parte do consumidor e } \\
\text { a gestão da marca é } \\
\text { determinante neste } \\
\text { contexto. }\end{array}$ \\
\hline $\begin{array}{l}\text { Algum } \\
\text { diferencial que } \\
\text { atraia }\end{array}$ & $\begin{array}{l}\text { O branding sensorial } \\
\text { diferencia-se pelas } \\
\text { estratégias sensoriais que } \\
\text { relaciona o consumidor a } \\
\text { uma experiência } \\
\text { emocional com a marca. }\end{array}$ & $\begin{array}{l}\text { As lojas conceito (concept } \\
\text { stores), lojas próprias } \\
\text { (flagship stores), lojas de } \\
\text { estilo de vida (lifestyle } \\
\text { stores) e as instalações } \\
\text { temporárias (pop-up) são } \\
\text { estratégias de promoção } \\
\text { e consolidação de uma } \\
\text { marca no mercado global } \\
\text { através do design de } \\
\text { interiores. }\end{array}$ & $\begin{array}{l}\text { A empresa precisa } \\
\text { diferenciar-se de seus } \\
\text { concorrentes para obter } \\
\text { uma fatia maior de } \\
\text { mercado. Esse diferencial } \\
\text { pode estar no estilo do } \\
\text { serviço oferecido pela } \\
\text { marca e no uso da } \\
\text { identidade para criar polos } \\
\text { de atração sensoriais que } \\
\text { captem e fixem } \\
\text { consumidores. }\end{array}$ \\
\hline $\begin{array}{l}\text { Meios que } \\
\text { tangibilizem } \\
\text { conceitos }\end{array}$ & $\begin{array}{l}\text { O branding sensorial deve } \\
\text { se fazer presente de } \\
\text { forma consistente e nos } \\
\text { pontos de contato com o } \\
\text { consumidor, como lojas, } \\
\text { embalagens, produtos, } \\
\text { peças e ações publicitárias }\end{array}$ & $\begin{array}{l}\text { O brandscaping preconiza } \\
\text { identificar as } \\
\text { características associadas } \\
\text { à imagem da marca e o } \\
\text { estilo de vida que ela } \\
\text { pretende transmitir na } \\
\text { elaboração do projeto de } \\
\text { interiores. Desse modo, } \\
\text { elementos de } \\
\text { comunicação visual, } \\
\text { iluminação, revestimentos } \\
\text { (cores, motivos e } \\
\text { texturas), música e } \\
\text { aromas tangibilizam a } \\
\text { marca no espaço. }\end{array}$ & $\begin{array}{l}\text { A identidade visual é um } \\
\text { dos fatores que ajudam a } \\
\text { impulsionar uma marca e } \\
\text { essa identidade se } \\
\text { tangibiliza na expressão } \\
\text { visual e em produtos e } \\
\text { serviços que demonstram } \\
\text { critérios funcionais como } \\
\text { reconhecimento imediato, } \\
\text { memorização, imagem } \\
\text { clara e consistente, } \\
\text { personalidade, entre } \\
\text { outros. }\end{array}$ \\
\hline $\begin{array}{l}\text { Design e } \\
\text { marketing } \\
\text { como aliados }\end{array}$ & $\begin{array}{l}\text { No branding sensorial o } \\
\text { marketing é um } \\
\text { importante aliado na } \\
\text { criação e implementação } \\
\text { de estratégias de } \\
\text { aproximação com o } \\
\text { consumidor através das } \\
\text { ferramentas de } \\
\text { promoção: publicidade, } \\
\text { relações públicas, venda } \\
\text { direta, entre outros. }\end{array}$ & $\begin{array}{l}\text { O branding está } \\
\text { essencialmente } \\
\text { relacionado à publicidade } \\
\text { e ao marketing aplicados } \\
\text { na interpretação das } \\
\text { aspirações subconscientes } \\
\text { dos consumidores. }\end{array}$ & $\begin{array}{l}\text { O marketing dirige a gestão } \\
\text { da marca no contexto da } \\
\text { cultura organizacional e } \\
\text { através de ações específicas } \\
\text { nas quais o design tem } \\
\text { papel fundamental de } \\
\text { articulação dos fatores que } \\
\text { ligam a marca ao seu } \\
\text { público. }\end{array}$ \\
\hline
\end{tabular}

Fonte: Elaborado pelas autoras com base na pesquisa realizada.

A sentença "linguagem organizada que faça sentido" se refere a um conjunto de estratégias a serem gerenciadas pela marca, sendo que essas devem remeter a sensações que toquem o público, ao mesmo tempo que reafirmam valores positivos. A essência da marca está, justamente, na 
comunicação que ela estabelece com os seus admiradores e esta ocorre por meio de uma linguagem bem estabelecida. Nesse sentido, falar de "marca como vínculo emocional" é também remeter ao canal de comunicação e às linguagens múltiplas. Essas, no entanto, em todos os aspectos intangíveis que a marca permite experienciar. O resultado é o estreitamento emocional da relação entre o público e todos os pontos de contato propiciados pela marca.

O branding é determinante para a gestão de um processo inserido em um contexto mercadológico saturado. Pensar na "marca como meio de sobrevivência" é estar ciente que transitar por diferentes mercados requer consciência e trabalho árduo, mas somente desta forma - e através de adequada gestão de marca - é possível sobressair-se. O público está em busca de "algum diferencial que atraia", não por falta de opção em termos de quantidade de produtos ou serviços a ele disponibilizados, mas porque muitas vezes há carência de atrativos sensoriais. O diferencial é, desta forma, a maneira de conquista em meio ao excesso no mercado, a forma de relacionar-se com o público através de produtos e serviços que promovam novidades, experiências positivas e emoções agradáveis.

O reconhecimento imediato, a memorização, imagem clara e consistente e personalidade são resultados de uma marca bem trabalhada e tais são perceptíveis através dos conceitos que produtos e serviços sensorialmente emitem. Buscar "meios que tangibilizem conceitos" é ter a ciência que os melhores produtos e serviços devem estar contidos de conceitos substanciosos que são alimentos por ele. Neste sentido, "design e marketing são aliados" na construção do elo entre o conceito, o produto e o serviço que estrutura a marca em si. Design e marketing não se tratam de áreas isoladas uma da outra, mas de campos complementares e interconectados.

\section{CONCLUSÃO}

As sentenças emitidas por meio das análises dos textos de Lindstrom (2007), Mesher (2011) e Wheeler (2008) confirmam a hipótese de que os três autores convergem quanto a alguns conceitos que apresentam, mesmo que seus enfoques em termos de aplicação sejam diferenciados. As ideias trazidas em seus trabalhos se correlacionam, sendo complementares e especialmente afins em seis pontos: (i) Linguagem organizada que faça sentido; (ii) Marca como vínculo emocional; (iii) Marca como meio de sobrevivência; (iv) Algum diferencial que atraia; (v) Meios que tangibilizem conceitos; (vi) Design e marketing como aliados.

A análise que resultou nos seis apontamentos ou sentenças relatados no presente estudo não somente permitiram a visualização das linhas convergentes entre os autores, mas mostraram 
maneiras particulares com que cada um deles entende o contexto da gestão da marca, ou seja, do branding. Se por um lado foi possível, através do objetivo proposto nessa pesquisa, confrontar seus textos com a intenção de extrair conceitos afins, por outro foi notável que as abordagens diversas, particularizadas nos textos de cada autor, podem ser complementares.

O estudo se concentrou em três publicações que descrevem proposições na área do branding e os escritos de Lindstrom (2007), Mesher (2011) e Wheeler (2008) foram resumidos a breves textos, tais quais relatados neste artigo. Esta síntese pode ser apontada como uma limitação da pesquisa, embora tal tenha sido necessária para que as análises se concretizassem a partir do confronto de conceitos pontuais na essência do texto de cada autor. Seguindo a linha desta pesquisa, como continuação em trabalhos futuros sugere-se o estudo de possíveis pontos de discordância entre os autores, assim como, a complementação a partir da análise de outras publicações de relevância na área. Ainda, por integrarem a esta pesquisa uma forma de reflexão aplicada, levantamentos de casos que exemplifiquem os conceitos teóricos trazidos pelos autores estudados seriam, também, ideia de continuação. 


\section{REFERÊNCIAS}

CAMEIRA, Sandra Ribeiro. O branding e a metodologia de sistemas de identidade visual. 2013. $428 \mathrm{f}$. Dissertação (Mestrado) - Curso de Design e Arquitetura, Departamento de Faculdade de Arquitetura e Urbanismo, Universidade de São Paulo, São Paulo, 2013. Disponível em: <http://www.teses.usp.br/teses/disponiveis/16/16134/tde-28012014-100230/en.php>. Acesso em: 01 maio 2014.

CELASCHI, Flaviano e DESERTI, Alessandro. Design e Innovazione: Strumenti e pratiche per la ricerca applicata. Roma: Carocci. 2007.

LINDSTROM, Martin. Brandsense: a marca multissensorial. Porto Alegre: Bookman, 2007.

MESHER, Lynne. Diseño de espacios comerciales. Barcelona GG, 2011.

FLICK, Uew. Introdução à pesquisa qualitativa. 3. ed. Porto Alegre: Artmed, 2009.

SEMPRINI, Andrea. A marca pós-moderna: poder e fragilidade da marca na sociedade contemporânea. São Paulo: Estação das Letras, 2006.

SILVA, Adriana Costa e. Branding \& Design: Identidade no varejo. Rio de Janeiro: Rio Books, 2002.

STRUNCK, G. Como criar identidades visuais para marcas de sucesso. Rio de Janeiro: Rio Books, 2012.

WHEELER, Alina. Design de identidade da marca: um guia completo para criação, construção e manutenção de marcas fortes. Porto Alegre: Bookman, 2008. 


\section{Capítulo 10}

\section{doi $10.37423 / 210403766$}

\section{BIM PARA A ANÁLISE DE DESEMPENHO TÉRMICO EM EDIFICAÇÕES DO PROGRAMA MINHA CASA MINHA VIDA}

Lais Guerle Tonso

Eduardo Sampaio Nardelli

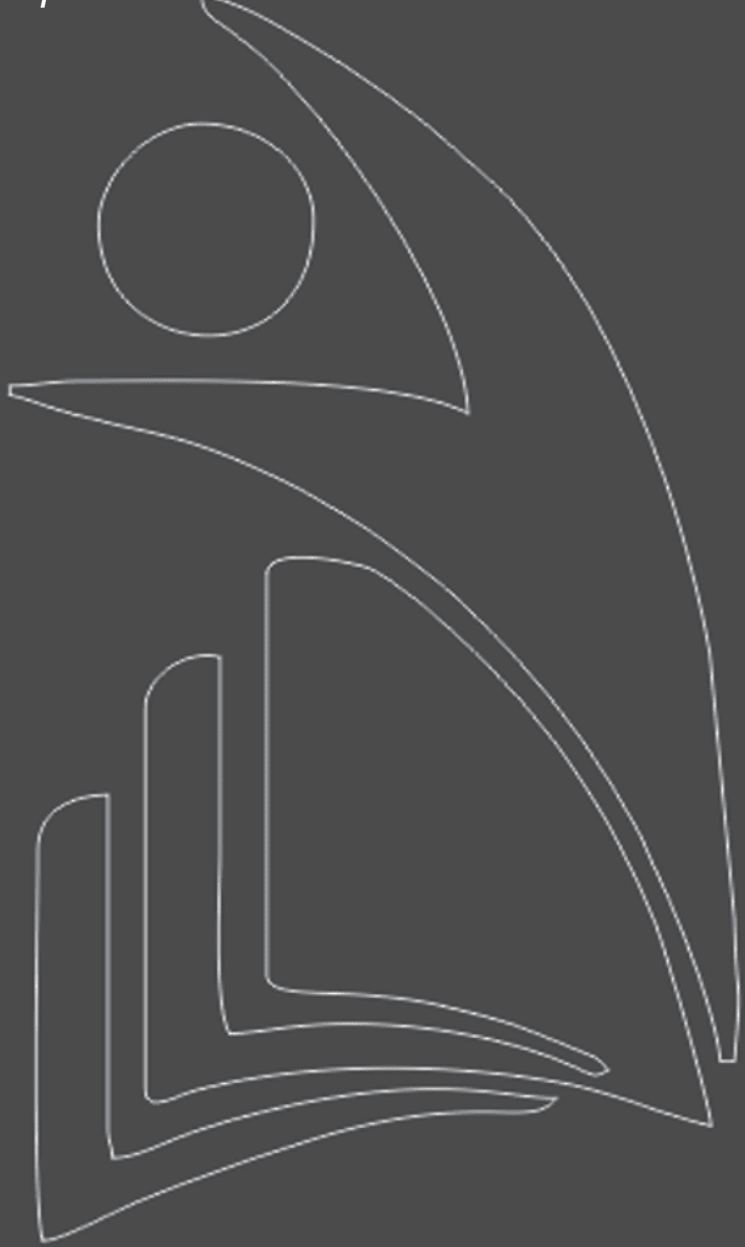

Universidade Presbiteriana Mackenzie

Universidade Presbiteriana Mackenzie

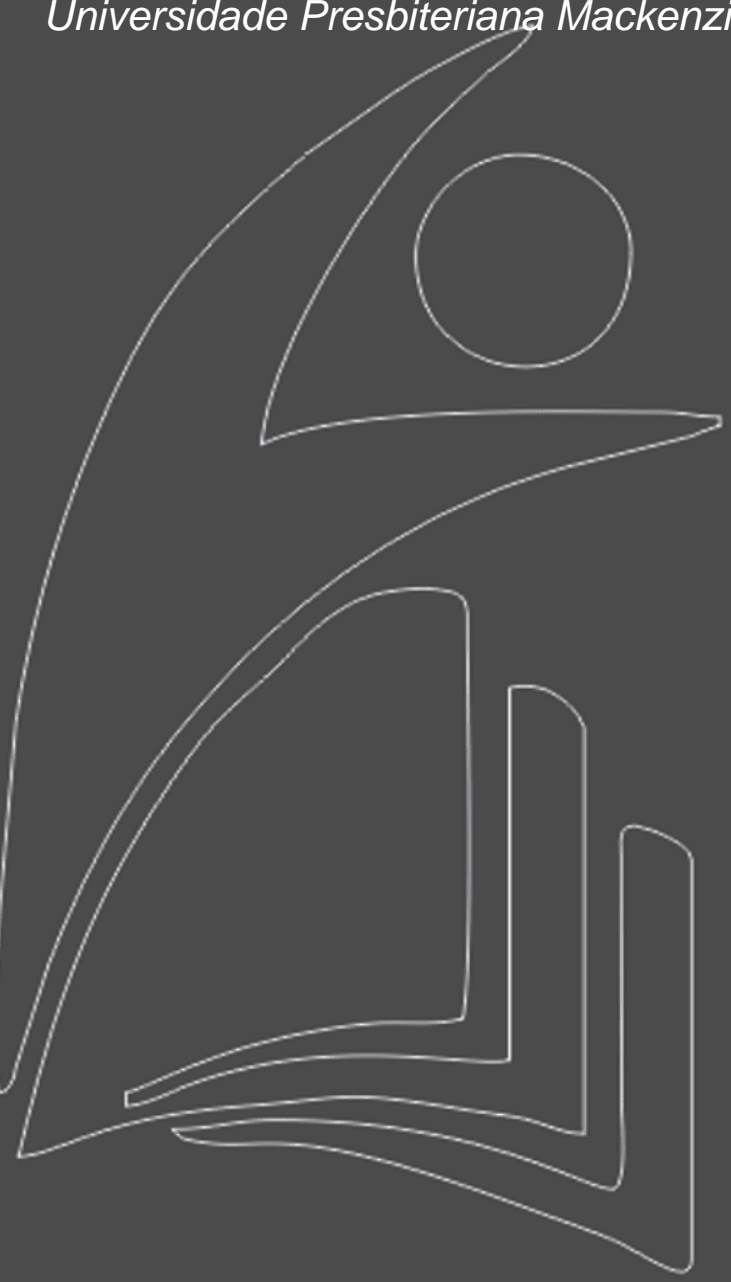


Abstract: The Minha Casa Minha Vida institutional housing program aims to build millions of residences in Brazilian cities. This situation decreases the building quality as the Federal Government, who founds the program, demands very low costs, so it is even more complicate to achieve quality enhancement. To solve this situation, many regulations have been instituted and, in 2013, ABNT published NBR 15575, a regulation regarding housing building performance, including aspects such as thermal, acoustic and maintenance performance. This paper aims to study thermal analysis section and the possibility to use BIM to achieve accurate data about thermal performance.

Keywords: BIM, Thermal Analysis, Norma de Desempenho, Minha Casa Minha Vida 


\section{INTRODUÇÃO}

\section{PROGRAMA MINHA CASA MINHA VIDA}

O Programa Minha Casa Minha Vida (PMCMV) foi criado em 2009 com a finalidade de subsidiar habitações para populações com rendimento bruto mensal de até $R \$ 1.600,00$ (US\$450,00) e facilitar a aquisição para aqueles com rendimento mensal bruto de $\mathrm{R} \$ 5.000,00$ (US\$1.300,00), a fim de mitigar o déficit habitacional no pais, que segundo o Ipea (2013), atingiu 8\% dos domicílios brasileiros, (cerca de 5.244.525 residências. Em 2015, o programa se encontra na segunda fase e pretende construir 2 milhões de moradias (Portal Brasil, 2014.).

Apesar do PMCMV ter reduzido o déficit habitacional e ter avaliação de 8,8 de satisfação entre os beneficiados (Nicacio, 2014), o programa prioriza a construção em larga escala em detrimento da qualidade do projeto arquitetônico. Pela necessidade de se construir um número grande de residências num curto período de tempo e a baixo custo, uma vez que o valor final da unidade habitacional é pré-fixado, a qualidade do empreendimento fica em segundo plano, já que depende de aspectos tanto legais quanto técnicos, tais como definições de parâmetros técnicos e executivos, de fornecedores e de custos envolvidos (Abyko \& França, 2013).

\section{ABNT NBR-15575 - DESEMPENHO DE EDIFICAÇÕES}

Desde 1998 existe o PBQP-H (Programa Brasileiro de Qualidade e Produtividade do Habitat) que procura aperfeiçoar o setor deu-se enfoque no critério de habitabilidade no quesito de desempenho térmico.

Para essa categoria de desempenho, a ABNT NBR 15.575-1 prevê dois tipos de análise: a análise simplificada (normativa), que deve atender aos parâmetros mínimos especificados pelas ABNT NBR 15575-4 (sistemas de vedações verticais internas e externas) e ABNT NBR 1575-5 (sistemas de coberturas) e a análise computacional. Casos onde a avaliação de transmitância térmica (a capacidade do material de conduzir mais ou menos energia térmica por uma área linear por um certo período de tempo) e capacidade térmica (quantidade de calor necessária para variar a temperatura em uma unidade) resultem em desempenhos inferiores às normas anteriores, deve-se partir para a análise térmica computacional, levando em consideração a edificação como um todo (ABNT, 2013).

O método para a simulação computacional recomenda o uso do software Energy Plus ou softwares que estejam de acordo com a ASHRAE Standard 140, a qual padroniza métodos para análise de 
eficiência energética, de tal forma a evitar incongruências entre diversos softwares para este fim, definindo uma série de procedimentos para o desenvolvimento de modelos para análises energéticas (ABNT, 2013; ASHRAE, 2001).

\section{BIM - BUILDING INFORMATION MODELLING}

Modelos desenvolvidos em BIM possuem características específicas que os diferem de uma produção 3D num software CAD. BIM produz modelos tridimensionais, onde a planta, o corte e a elevação fazem parte do mesmo todo, assim como tabelas de quantitativos e visualizações 3D. Em outras palavras, são diversas formas de visualizar a mesma informação. Além da questão visual, os modelos são compostos por componentes que possuam características como representação gráfica e atributos que os identificam juntamente com suas informações parametrizadas, de maneira que possam ser manipulados de modo inteligente, além de informações sobre o desempenho, necessários para análises e processos de trabalho. Por fim todas essas informações devem ser consistentes e não redundantes sobre cada parte de tais componentes (Eastman et al, 2011).

Com a possibilidade de parametrização, é possível facilitar a personalização de componentes, alterálos ou atualizar suas informações ao longo do desenvolvimento do projeto conforme a necessidade, aumentando assim a produtividade (Flório, 2007 apud Coelho \& Novaes, 2008).

Com o potencial do BIM e a busca constante por melhorias nos padrões de desenvolvimento de projetos na construção civil, em 2011 o Ministério do Desenvolvimento, Indústria e Comércio Exterior (MDIC), desenvolveu uma biblioteca de componentes em BIM, utilizando o software Revit Autodesk. A biblioteca, que é apresentada aos usuários como um template de projeto em Revit, conta com componentes de Estrutura, Vedação e Revestimento, Guarda-corpos e Corrimãos, Telhados, Peças Sanitárias e Caixilhos (Nardelli \& Oliveira, 2013). Atualmente esta biblioteca não possui informações relativas a desempenho dos materiais, e também não permite a customização dos componentes existentes, pois seus parâmetros estão travados.

\section{ANÁLISE DE EFICIÊNCIA TÉRMICA EM BIM}

Hännien, Karola e Laine (2007) apontam que a maior dificuldade em desenvolver análises térmicas é a quantidade de inputs a serem inseridos manualmente. Apesar de existirem diversos softwares muito precisos de análises térmicas, estes ainda não são difundidos na indústria da construção. Com isso, o BIM se presta a criar um banco de dados de informações térmicas mais eficientes e abrir a possibilidade de reutilizar as informações uma vez inseridas nos materiais dos componentes. Aksamija 
(2012) reforça esta situação, em que, apesar de existirem diversos softwares de análises térmicas, estes não são utilizados em larga escala pelos arquitetos, pois são programas muito complicados e não compatíveis com seus métodos e trabalho e projeto. Porém, a autora coloca que as análises térmicas desenvolvidas em BIM permitem um método de projeto onde este processo analítico está integrado com o desenvolvimento do projeto e pode acontecer desde estudos preliminares.

Análises de performance de edificações em BIM tem a vantagem de, além de não estarem baseadas em regras simplificadas, partirem de modelos detalhados e materiais exatos e várias possibilidades de soluções poderem ser analisadas de maneira mais eficiente (Aksamija, 2012).

Uma questão fundamental para que o BIM possa ser eficaz e eficiente é a interoperabilidade entre as aplicações utilizadas pelos envolvidos no projeto. Aksamija (2012) aponta que uma das grandes barreiras na utilização de BIM para análises térmicas é exatamente o compartilhamento e consistência de informações ao se exportar dados de um software para outro. De 9 softwares estudados (Green Building Studio, Energy 10, HEED, Design Builder, ECOTECT, aQUEST, IES VE, Energy Plus + SketchUp e Energy Plus), apenas 3 possuem compatibilidade com BIM.

\begin{tabular}{|l|c|c|c|c|}
\cline { 2 - 5 } \multicolumn{1}{l|}{} & Conceitual & Esquemática & $\begin{array}{l}\text { Desenvolvi- } \\
\text { mento }\end{array}$ & $\begin{array}{l}\text { Compatível } \\
\text { com BIM }\end{array}$ \\
\hline $\begin{array}{l}\text { Green } \\
\text { Building } \\
\text { Studio }\end{array}$ & $\mathrm{x}$ & $\mathrm{x}$ & & $\mathrm{x}$ \\
\hline Energy 10 & $\mathrm{x}$ & $\mathrm{x}$ & & \\
\hline HEED & $\mathrm{x}$ & $\mathrm{x}$ & & \\
\hline $\begin{array}{l}\text { Design } \\
\text { Builder }\end{array}$ & $\mathrm{x}$ & $\mathrm{x}$ & & \\
\hline ECOTECT & & $\mathrm{x}$ & $\mathrm{x}$ & $\mathrm{x}$ \\
\hline aQUEST & & $\mathrm{x}$ & $\mathrm{x}$ & \\
\hline IES VE & & $\mathrm{x}$ & $\mathrm{x}$ & $\mathrm{x}$ \\
\hline $\begin{array}{l}\text { Energy } \\
\text { Plus + } \\
\text { SketchUp }\end{array}$ & & $\mathrm{x}$ & $\mathrm{x}$ & \\
\hline $\begin{array}{l}\text { Energy } \\
\text { Plus }\end{array}$ & & $\mathrm{x}$ & $\mathrm{x}$ & \\
\hline
\end{tabular}

Tabela 1: Softwares de Análise Energética e Ambiental e sua relação com os estágios de design. Adaptado de Aksamija (2012).

Aksamija (2012), aponta que existem certas boas práticas no desenvolvimento de modelos para análise de desempenho de edificações. Para a análise térmica são necessários parâmetros de organização espacial, propriedades dos materiais e de superfícies sombreadas. Esta informação, que no BIM está hospedada como design, precisa ser exportada como analítica. Por exemplo, caso as plataformas utilizadas sejam Autodesk Revit e Autodesk Ecotect, a transferência de informações é 
realizada através do Green Building XML (gbXML), uma extensão de arquivo desenvolvida especialmente para este tipo de exportação. A estrutura deste arquivo é composta por:

- Spaces: paredes, pisos, tetos, superfícies sombreadas e

- janelas, onde as propriedades numéricas são transferidas com a finalidades analíticas. Spaces são componentes que carregam informações de localização dos objetos e parâmetros referentes a cargas térmicas. É importante ressaltar que rooms e spaces, ambos componentes do Revit, possuem finalidades diferentes: rooms concentram informações referentes aos espaços e suas ocupações, em contrapartida spaces são utilizados apenas para finalidades analíticas. O volume do ambiente e a definição de paredes internas e externas, é calculado pela ferramenta space através dos mesmos componentes limitantes dos rooms.

- Superfícies analíticas (Pisos, paredes e telhados) que devem estar relacionadas de maneira consistente entre si.

- Aberturas: Janelas e claraboias com informações relativas a espessura, transmitância térmica, transmitância visual e coeficiente de ganho de calor solar.

- Superfícies sombreadas, que são entendidas como superfícies que não delimitam spaces. Além do arquivo gbXML, é possível fazer a transferência de informações geométricas a partir de arquivos DXF.

Com isso, a informação criada no modelo em BIM é exatamente a mesma do arquivo gbXML a ser utilizado na análise térmica (Aksamija, 2012).

\section{METODOLOGIA}

BIM tem o potencial de melhorar a qualidade da informação além de auxiliar a tomada de decisão em diversos momentos críticos do projeto, no entanto ainda falta muito a ser explorado sobre o que é inserido e como essa informação é utilizada (Dowsett \& Harty, 2013). Esta pesquisa tem como objetivo explorar a potencialidade do BIM para executar a análise de eficiência térmica exigida pela ABNT NBR 15575, além de compreender não só questões referentes a modelagem em BIM com finalidades analíticas, mas também como a própria norma espera que estas análises sejam executadas.

Com esse objetivo, estudou-se sobre como a ABNT NBR 1575-1 apresenta a questão da análise térmica e como ela precisa ser desenvolvida. A partir desse entendimento, foi criado o modelo na aplicação Revit de um projeto existente do Minha Casa Minha Vida. 
A modelagem teve como base plantas e cortes em 2D fornecidos pelo escritório responsável pelo projeto. Para a definição dos materiais das paredes, pisos e tetos, utilizou- se como referência o memorial descritivo apresentado pela arquitetura ao órgão fomentador do PMCMV. O modelo foi criado com a biblioteca de componentes do MDIC, modelando apenas elementos específicos do projeto que não estavam disponíveis na biblioteca. Conforme foi sendo construído o modelo, foram sendo inseridas informações referentes a características físicas e térmicas dos materiais. Na aplicação utilizada, o Revit 2015, as informações térmicas vieram da biblioteca de assets disponíveis no software, por exemplo, uma determinada parede é composta por: Acabamento em gesso - tijolo cerâmico Acabamento em massa corrida fina, cada uma dessas camadas foi configurada com um determinado asset disponível no software - tijolo cerâmico é composto por brick - medium weight, que possui as seguintes características: condutibilidade térmica $-0,54 \mathrm{~W} /(\mathrm{mK})$, calor específico $0,84 \mathrm{~J}(\mathrm{~g} \stackrel{\circ}{ } \mathrm{C})$, densidade $1,55 \mathrm{~kg} / \mathrm{m}^{3}$ et., valores estes que não correspondem à realidade porque o intuito da pesquisa é apenas explorar a possibilidade de utilização do BIM. A partir desta composição de materiais, o próprio software calcula as mesmas características térmicas para a parede como um todo, e desta forma temos que o coeficiente de transmitância térmica desta parede é 2,6273, a resistência térmica é $0,3806\left(\mathrm{~m}^{2} \mathrm{k}\right) / \mathrm{W}$ e a massa térmica é $25,56 \mathrm{~kJ} / \mathrm{K}$ (ver figura 1 ).

Nos componentes de janelas, no entanto, não funcionam com base em assets de materiais. Neste caso, é preciso configurar apenas a constituição do vidro, que o software define como construção analítica do componente (ver figura 2).

Com isso, está sendo estudada a composição de modelos analíticos em BIM, como deve ser executado e quais informações são pertinentes. Ainda está em andamento o estudo de como devem ser configurados os dados para serem exportados para o arquivo gbXML. Ainda não foi escolhido o programa a ser desenvolvida a análise computacional prevista na ABNT NBR 15575-1 pois, além da escassa interoperabilidade entre os softwares, existe a barreira de falta de capacitação técnica, não apenas para manipular a aplicação, mas também como exportar e inserir as informações criadas em BIM. 


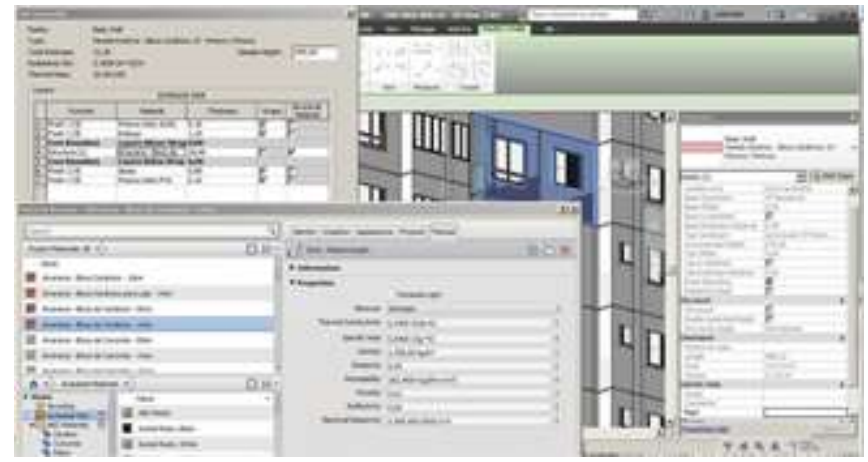

Figura 1: Exemplo de configuração do material Alvenaria - Bloco Cerâmico $14 \mathrm{~cm}$ utilizando as préconfigurações de asset Brick - Mediumweight. Autodesk Revit.

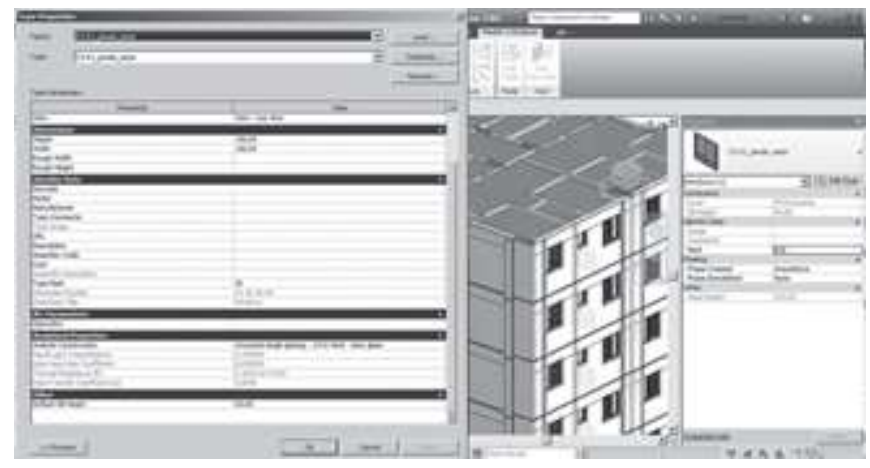

Figura 2: Exemplo de configuração de propriedades analíticas em janelas. Autodesk Revit.

\section{RESULTADOS}

O trabalho encontra-se em andamento e até o presente momento temos o modelo desenvolvido em BIM de um projeto do PMCMV, com informações relativas ao desempenho térmico dos materiais da edificação. Com este modelo, já é possível analisar as informações de acordo com o método simplificado especificado pela norma em estudo, porém intenciona-se ir além e criar uma análise mais aprofundada em softwares específicos para análises de desempenho.

É possível identificar que existem poucos trabalhos definindo metodologias de modelagem com finalidades de análise de desempenho, como aponta Dowsett \& Harty (2013). E além disso, é importante ressaltar o desalinhamento entre indústria e academia, não só na questão de análise térmica, mas também no uso e no desenvolvimento de BIM (Chaves et al, 2014). Com isso, o trabalho de entendimento de processos de exportação e importação de informações entre os softwares, para que se possa ter a análise mais completa e consistente, fica muito debilitado, resumindo-se muito a utilização da bibliografia existente no campo de engenharia de ar-condicionado e de sustentabilidade. Engenharia de ar- condicionado que, inclusive, tem interface com os próprios parâmetros, definições 
e termos utilizados pelos softwares BIM e a Sustentabilidade, define os processos de análise dos softwares de desempenho.

A versão do software utilizada nesta pesquisa, o Revit 2015, possui a ferramenta de análise energética na nuvem, o Green Building Studio, que recolhe as informações analíticas sobre o projeto e gera um relatório sobre o desempenho da edificação. No entanto, o relatório se restringe a informações relativas à sustentabilidade da edificação e não deixa claras as informações necessárias para a norma em estudo. Por outro lado, o próprio Revit fornece relatórios muito detalhados sobre questões relevantes a projetos de ar-condicionado e são relativamente complexos para poder avaliar se a edificação estudada está em conformidade com a ABNT NBR 15.

Apesar de vários autores apontarem o Ecotect como o mais indicado para análises de desempenho (Corbella, 2009; Aksamija 2012), o software não está mais disponível para download da versão educacional no website da Autodesk.

Com isso, estão em estudo tanto os relatórios fornecidos pelo Revit e pelo Green Building Studio, quanto a possibilidade de utilização da versão de demonstração do software Design Builder, que apesar da necessidade de reinserção de alguns parâmetros já inseridos no BIM (tais como localização e uso do edifício), a versão mais recente apresenta a possibilidade de importar o arquivo gbXML criado no Revit.

\section{DISCUSSÃO}

A ABNT NBR 15575-1 revela a crescente preocupação com a qualidade dos projetos de edifícios residenciais, não só esta norma exemplifica isso, como também todos os outros documentos normativos que são exigidos pelo PMCMV. Até o momento, o programa não exige o uso da norma de desempenho, porém tanto os dirigentes do programa quanto os clientes estão pressionando para a ABNT NBR 15575-1 seja mandatória nos projetos (Téchne, 2012; AsBEA, 2013; Caixa, 2014).

Considerando a potencialidade do BIM para diversas áreas do setor da construção civil, cada vez mais escritórios de arquitetura estão implementando este sistema de trabalho, a fim de oferecer projetos com mais informações com mais consistência e menos erros, além de poder fornecer novos serviços (Amorim et al, 2009). Esta pode ser uma ferramenta facilitadora para a implementação da norma de desempenho nos projetos dos escritórios. Por outro lado, é importante ressaltar os custos, não só do uso do BIM, o qual requer computadores muito potentes, mas também o custo em se adotar materiais 
e técnicas que se adequem à ABNT NBR 15575-1, principalmente no PMCMV, que hoje já sofre com problemas de custo e lucro para a empresas envolvidas (Amorim et al; 2009, Abyko \& França, 2013).

Apesar das questões apresentadas anteriormente, é interessante a possibilidade oferecida pelo BIM de criar, não só bibliotecas de famílias e componentes, como também bibliotecas de materiais que já possuem os parâmetros estabelecidos pela norma e, uma vez disponibilizados pelos fornecedores, é possível organizar tais dados e reutilizá-los sempre que for necessário, além de já incorporar na biblioteca de componentes BIM existente e disponibilizada pelo MDIC. Porém, como já foi ressaltado por diversos autores, é necessário que primeiramente os envolvidos no projeto tenham não só as ferramentas necessárias como base de dados climáticos e parâmetros mínimos, mas também, base de dados sobre os materiais e componentes do projeto que contenham as informações necessárias para a análise.

Por outro lado, é importante mencionar que, os métodos de análise apresentados pelo conjunto de normas NBR 15575- 1, NBR 15575-4 e NBR 15575-5 estão sendo amplamente criticados, não só pela generalidade apresentada em seus textos como também nos métodos apresentados, ambos simplificado e computacional. Ghisi et al (2014) defende que o método computacional exigido pela norma não contempla todos os parâmetros necessários para uma análise acurada no software Energy Plus. Já o método simplificado, também é questionado por Chvatal (2014) pois a norma não apresenta corretamente o impacto dos parâmetros de transmitância térmica e da absortância gerando não só classificações de desempenho equivocadas como também divergentes da análise computacional mais detalhada.

Com isso, é possível concluir que a criação da ABNT NBR 15575-1 - Edificações habitacionais é um avanço no desenvolvimento do setor da construção civil e necessita de constantes revisões, e o trabalho acadêmico é um grande fomentador de discussões sobre o tema (Chvatal, 2014).

As possibilidades do uso de BIM para a aplicação da norma de desempenho são claras e reais, mas ainda falta muito para que o conhecimento sobre análise térmica esteja difundido no mercado e possa ser incorporado nos processos de trabalho dos escritórios. Também é importante ressaltar que, uma vez que a utilização da norma seja mandatória para os empreendimentos do PMCMV, os envolvidos (tanto projetistas quanto fornecedores) deverão atender e o BIM pode ser um facilitador dessa nova demanda da indústria. 


\section{REFERÊNCIAS}

Abyko, A. K., \& França, M. S. (2013). Minha Casa Minha Vida: uma avaliação preliminar. 13o Conferência Internacional da Lares. São Paulo. Fonte:

http://www.lares.org.br/Anais2013/artigos/895- 1041-1-SP.pdf

Aksamija, A. (2012). BIM-Based Building Performance Analysis: Evaluation and Simulation of Design Decisions. ACEEE Summer Study on Energy Efficiency in Buildings. Fonte: http://aceee.org/ files/proceedings/2012/start.htm

Amorim,S.R.,Lyrio,A.d.,\&Souza,L.L.(novembrode2009).Impactos do uso do BIM em escritórios de arquitetura: oportunidades no mercado imobiliário. Gestão \& Tecnologia de Projetos, 4, pp. 26-53. doi:10.4237/gtp.v4i2.100

AsBEA, A. B. (13 de março de 2013). "Minha Casa, Minha Vida" vai exigir aplicação da Norma de Desempenho 15575. Fonte: AsBEA: http://www.asbea.org.br/escritorios-arquitetura/noticias/minhacasa-minha-vida-vai-exigir-aplicacao-da-norma-de-279262-1.asp ASHRAE - American Society of Heatinh, Refrigerationg and Air- Conditioning Enginers. (26 de junho de 2004). Standard Method of Test for the Evaluation of Building Energy Analysus Computer Programs. ASHRAE Standard 140. Atlanta, Nebraska, Estados Unidos. Fonte: https://www.ashrae.org/File\%20Library/docLib/ Public/2004715124811_347.pdf

Associação Brasileira de Normas Técnicas - ABNT. (19 de fevereiro de 2013). ABNT NBR 15575-1. Edificações habitacionais

- Desempenho Parte 1: Requisitos gerais. Rio de Janeiro, Rio de Janeiro, Brasil.

Associação Brasileira de Normas Técnicas - ABNT. (s.d.). ABNT NBR 15575-5. Edificações habitacionais - Desempenho Parte 5: Requisitos para sistemas de coberturas. Rio de Janeiro, Rio de Janeiro, Brasil. Autodesk. (s.d.). About Spaces. Fonte: Autodesk Revit 2015 Help:

http://help.autodesk.com/view/RVT/2015/ENU/?guid=GUID-B876A6F6-4091-40CA-ADCDAA5D0EFC5EE3

Brasil, P. (06 de abril de 2014). Infraestrutura. Fonte: Portal Brasil:

http://www.brasil.gov.br/infraestrutura/2014/04/entenda-como- funciona-o-minha-casa-minha-vida

Caixa. (27 de março de 2014). Cumprimento de normas técnicas são desafio no Minha Casa Minha Vida. Fonte: Agência Caixa de Notícias: http://www20.caixa.gov.br/Paginas/Noticias/Noticia/ Default.aspx?newsID=517

CBIC. (14 de abril de 2010). Mais qualidade nas obras do Minha Casa, Minha Vida e do PAC. Fonte: CBIC: http://www.cbic.org.br/ informativos/cbic-hoje/cbic-hoje-edicao-extra?page=show Chvatal, $\mathrm{K}$. M. (dezembro de 2014). A avaliação do procedimento simplificado da NBR 15575 para determinação do nível de desempenho térmico de habitações. Ambiente Construído, 14(4), pp. 119-134. Fonte: http://www.scielo.br/pdf/ac/v14n4/a09v14n4. pdf 
Coelho, S. S., \& Novaes, C. C. (2008). Modelagem de Informações para Construção (BIM) e ambientes colaborativos para gestão de projetos na construção civil. Pelotas, Rio Grande do Sul, Brasil.

Corbella, O., \& Yannas, S. (2009). Em busca de uma Arquitetura Sustentável para os Trópicos (2e ed.). Rio de Janeiro: Revan.

Dowsett, M. R., \& Harty, C. F. (2013). Evaluating the benefits of BIM for sustainable design - a review. Reading, Reino Unido.

Eastman, C., Teicholz, P., Sacks, R., \& Liston, K. (2011). BIM Handbook: a guide to building information modeling for owners, managers, designers, engineers and constructors (2 ed.). Nova Jersey: John Willey \& Sons.

Ghisi, E., Mazzaferro, L., Melo, A., Silva, A. S., \& Sorgato, M. J.

(dezembrode2014).IncertezadométododesimulaçãodaNBR15575- 1 para avaliação do desempenho térmico de habitações. Ambiente Construídos, 14(4), pp. 103-117. Fonte: http://www.scielo.br/scielo. php?script=sci_isoref\&pid=S1678-86212014000400008\&lng=en\& $\operatorname{tng}=p t$

Instituto de Pesquisa Econômica Aplicada - IPEA. (novembro de 2013). Estimativa do Déficit Habitacional brasileiro (PNAD 2007- 2012). Fonte:

http://www.ipea.gov.br/portal/images/stories/PDFs/ nota_tecnica/131125_notatecnicadirur05.pdf

InstitutodePesquisaEconômicaAplicada-IPEA.(11denovembrode 2013). Estudo aponta redução no défict habitacional no país. Fonte: Ipea: http://www.ipea.gov.br/portal/index.php?option=com_ content $\&$ view=article\&id=20656

Laine, T., Hänninen, R., \& Karola , A. (2007). Benefits of BIM in the Thermal Performance Management. Helsinki, Finlândia. Fonte: http://www.aivc.org/sites/default/files/p785_final.pdf

Nardelli, E. S., \& Oliveira, J. T. (2013). BIM e o Desempenho no Programa Minha Casa Minha Vida. SIGraDI - Sociedad Iberoamericana de Gráfica Digital, (pp. 312-316). Valparaíso. Fonte: http://cumincades.scix.net/data/works/att/sigradi2013_370. content.pdf

Nicacio, A. (23 de maio de 2014). IPEA. Fonte: Desafios do Desenvolvimento:

http://www.ipea.gov.br/desafios/index.php?option=com_content\&view=article\&id=3027:catid=28\& Itemid=23

Téchne. (março de 2013). Desempenho revisado. Téchne. Fonte:

Téchne:http://techne.pini.com.br/engenharia-civil/192/desempenho-revisado-publicada-emfevereiro-nova-norma-de- desempenho-288027-1.aspx 


\section{Capítulo 11}

\section{doi $10.37423 / 210403768$}

\section{SEMANAS ACADÊMICAS COMO POSSIBILIDADES DE EFETIVAÇÃO DO TRÂNSITO DISCIPLINAR: UMA EXPERIÊNCIA NA ESCOLA DE BELAS ARTES DA PUCPR}

Luciane Hilu

Rita de Cássia Veiga Marriott

Patricia Lupion Torres

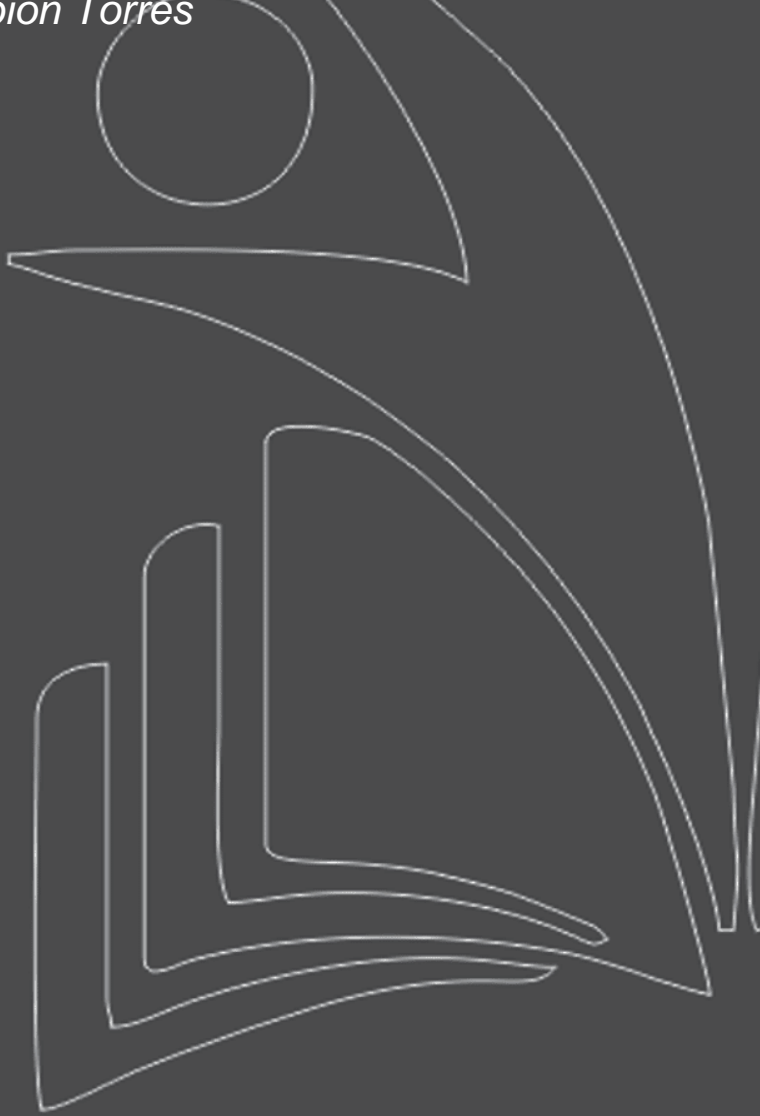

Pontifícia Universidade Católica do Paraná

Universidade Tecnológica,Federal do Paraná

Pontifícia Universidade Católica do Paraná 
Resumo: Com o objetivo de promover o sentido de complexidade e reintegração (ou abolição) disciplinar, neste estudo de caso pesquisamos como as formas de intercâmbio disciplinar, como a multidisciplinaridade, a pluridisciplinaridade, a interdisciplinaridade, a transdisciplinariedade e a metadisciplinaridade (ZABALA, 2002) foram estimuladas pelas Semanas Acadêmicas propostas pela Escola de Belas Artes da PUCPR (Pontifícia Universidade Católica do Paraná) e como este intercâmbio disciplinar foi apreendido e vivenciado pelos alunos. Participantes voluntários, alunos de todos os períodos dos cursos de Design Digital, Design Gráfico, Design de Produto, Design de Moda e Arquitetura e Urbanismo responderam a um questionário de avaliação online após os eventos a respeito da sua percepção quanto à efetivação do intercâmbio disciplinar promovido pelas Semanas Acadêmicas de seus cursos, Curso de Design (Charneira) e de Curso de Arquitetura e Design (Sincronicidade). Foram analisadas quali-quantitativamente perguntas sobre a interação de sua Semana Acadêmica com as outras áreas de estudo, a contribuição deste evento no desenvolvimento holístico e global dos participantes, a articulação dos saberes acadêmicos e não acadêmicos, bem como quais atividades, dentre oficinas, palestras e mesas-redondas, mais proporcionaram a transdisciplinariedade na Escola e minimizaram a fragmentação dos saberes. Os resultados revelaram que a forma de intercâmbio mais reconhecida é a Interdisciplinaridade, mas apontam, ainda que de forma inconsciente e não sistematizada, uma leve tendência à promoção da transdisciplinaridade, indicando que as Semanas Acadêmicas têm o potencial de promover o rompimento dos paradigmas tradicionais de ensino. 


\section{INTRODUÇÃO}

O repensar das práticas educacionais em espaços formais educativos baseia-se na ideia de que "um bom sistema educativo é aquele que se manifesta sensível às diferentes demandas sociais e às exigências de um mundo em constante evolução" (ZABALA, 2002, pag. 20), o que implica na movimentação contínua dos saberes propostos, na direção oposta da fragmentação do saber, de vertente propedêutica.

Este repensar está sustentado por uma tomada de consciência da mudança do paradigma científico e, por conseguinte, educacional, que supera o paradigma cartesiano adotado ainda em grande parte das escolas. Segundo Morin (2000), o modelo cartesiano não consegue mais tratar dos problemas fundamentais e globais atuais, sendo necessário um novo modelo que tenha como proposta a exploração da inteligência geral. Para o autor, quanto mais poderosa é a inteligência geral, maior é a capacidade do indivíduo de tratar de problemas da atualidade.

Refletida na educação, esta ideia vem dando suporte à implementação de uma educação que busca favorecer a aptidão natural da mente para formulações e resoluções de problemas essenciais, rejeitando a disjunção entre as humanidades e as ciências, e a superespecialização das ciências fragmentadas.

Para dar conta dos problemas cada vez mais multidisciplinares, transversais, multidimensionais, transacionais, globais e planetários, Morin (2000) propõe o novo paradigma, no qual o indivíduo deve se perceber e conceber a construção do conhecimento integralmente nos aspectos inerentes ao Contexto, ao Global, ao Multidimensional e ao Complexo. Para tal, deve-se ter em vista que para dar conta do Contexto é necessário situar as informações e os dados em seu contexto para que adquiram sentido; para contemplar o Global é essencial pensar na relação do todo com as partes também, pois não se conhece o todo sem conhecer as partes; com relação ao Multidimensional, é preciso compreender que as unidades são complexas e multidimensionais; e com relação ao Complexo, é necessário enfrentar a complexidade pelo conhecimento pertinente, devendo-se buscar a união entre a unidade e a multiplicidade.

Por esta perspectiva, os espaços educativos devem refletir sobre a importância da educação para o desenvolvimento integral da pessoa em todas as suas dimensões: social, interpessoal, pessoal e profissional, independentemente do papel profissional que desenvolverá na sociedade, de modo a capacitá-la a responder às demandas que a sociedade apresentará. Devem promover uma atuação 
para que o ensino não exacerbe a supervalorização da disciplina que inibe a construção do ser e do saber global, ao mesmo tempo em que privilegie o diálogo entre a teoria e a prática, que se perdeu ao longo das vertentes educacionais anteriores. É necessário conectar o ensino com o contexto do aluno, à sua realidade, para que se proceda à aprendizagem significativa devolvendo ao aluno o elo entre o conhecimento científico e o conhecimento cotidiano.

Frente a este desafio, questionam-se os modelos acadêmicos atuais tradicionais de organização curricular por disciplinas e buscam-se propostas para a implementação de uma abordagem holística e global necessária para responder a esta configuração social. Neste questionamento, o aluno passa a ser o centro do processo educativo, e não o conteúdo em si, que, embora fundamental, passa a não ter prioridade. Isto demanda o estabelecimento de novos processos de ensino que tratem os conteúdos não mais de forma fragmentada, disciplinar, estanque e isolada, mas de forma integral e indissociável dos aspectos dimensionais do aluno (sociais, interpessoais, pessoais e profissionais).

Devido à grande dificuldade dos espaços educativos em proceder à educação para este novo paradigma surgiu uma demanda específica de pesquisa com o intuito de levantar quais propostas educacionais estão permitindo a nova integração dos saberes, minimizando a sua fragmentação e restaurando o conhecimento como um elemento holístico. Buscou-se compreender, dentro de um nicho educacional específico, quais ações são realizadas na tentativa de reverter a fragmentação e desconexão dos saberes, bem como se estas ações alcançaram sucesso, seja consciente ou inconscientemente.

O nicho escolhido para proceder a este estudo de caso foram as ações da atual Escola de Belas Artes da PUCPR (Pontifícia Universidade Católica do Paraná), no momento da pesquisa denominada Escola de Arquitetura e Design, que buscaram promover o sentido de complexidade e reintegração (ou abolição) disciplinar. Analisou-se também como estas ações foram apreendidas e vivenciadas conscientemente pelos alunos como catalizadoras de um intercâmbio disciplinar.

\section{DESENVOLVIMENTO}

\subsection{FORMAS DE INTERCÂMBIO DISCIPLINAR}

Pensar a mudança de paradigma educacional para que atenda às necessidades atuais advindas da complexidade tem instigado a alguns autores a buscar a compreensão das relações possíveis entre as disciplinas de forma a repensar seus possíveis intercâmbios. Entre os autores, temos Zabala (2002, p.39), que aponta as relações possíveis como: multidisciplinaridade, pluridisciplinaridade, 
interdisciplinaridade, metadisciplinaridade e transdisciplinaridade. Para Zabala (2002, p. 32, 33 e 34), a multidisciplinaridade é a forma de intercâmbio mais tradicional. Nela, a organização dos conteúdos das disciplinas ocorre independentemente uma das outras e seu significado pode ser compreendido pela palavra Somativa. Segundo o autor, a pluridisciplinaridade é compreendida como sendo as relações complementares entre disciplinas mais ou menos afins, atrelando à ela a palavra Contiguidade. Com relação à interdisciplinaridade, o autor a entende como o reencontro e a cooperação entre duas ou mais disciplinas, cada qual com seus próprios esquemas conceituais, maneiras de definir os problemas e seus métodos de pesquisa, promovendo em alguns momentos um novo corpo disciplinar, com significado personificado na palavra Interação. Compreende a transdisciplinaridade como o contato e a cooperação entre disciplinas de tal magnitude que ambas acabam por adotar um mesmo conjunto de conceitos fundamentais ou elementos de métodos de pesquisa, ou seja, o mesmo paradigma. É onde ocorre o máximo grau de relações entre disciplinas, promovendo uma integração global dentro de um sistema totalizador, buscando explicar a realidade sem fragmentações. A palavra chave da transdisciplinaridade é a Unificação. Já a metadisciplinaridade, representada pela palavra Libertação, é o prescindir das disciplinas, eliminando o conceito de relações entre elas e se focando no ponto de vista ou perspectiva sobre qualquer situação ou objeto. Seria esta a forma mais adequada de conhecer a realidade complexa, global e holística.

Esta classificação serviu de base para proceder à pesquisa sobre a percepção do trânsito disciplinar nas ações da Escola de Belas Artes, estudo de caso deste artigo.

\subsection{A ESCOLA DE BELAS ARTES (ARQUITETURA E DESIGN)}

A Escola de Belas Artes é uma unidade acadêmica criada em 2020 a partir da junção de duas escolas da PUCPR: Escola de Arquitetura e Design e Escola de Comunicação e Artes. O foco deste estudo se deu no âmbito da extinta Escola de Arquitetura e Design, escola esta criada em 2012 na estrutura da Pontifícia Universidade Católica do Paraná - PUCPR, em uma perspectiva de atualização e inovação do seu Projeto Pedagógico Institucional (PPI). Já no momento de sua criação, em 2021, e que foi sendo cada vez mais reforçado vide a reformulação em 2020, a Escola em questão tinha com pressuposto se constituir em uma Unidade Acadêmica que congregasse cursos nos quais existisse uma pré-disposição para trocas, interações, trabalhos em conjunto, e outras ações de natureza mais holística, devido à natureza compartilhada de suas áreas de atuação. Assim, um dos principais objetivos da criação das escolas foi a possibilidade de integração entre os cursos que definem o contorno de uma área 
específica do conhecimento. Nesta conformação, as integrações são possibilitadas nos diferentes níveis, seja vertical e horizontal, com atividades de pesquisa, ensino e extensão.

Na época deste estudo, faziam parte da Escola de Arquitetura e Design os cursos de graduação de Arquitetura e Urbanismo e de Design (Produto, Gráfico, Moda, Digital), o Programa de Pós-Graduação stricto sensu em Gestão Urbana e os cursos de pós-graduação lato sensu. Atualmente, fazem parte da Escola de Belas Artes os cursos: Arquitetura e Urbanismo, Design, Comunicação (Publicidade e Propaganda, Relações Públicas e Jornalismo), Cinema e Artes (Música, Dança, Artes Visuais e Teatro)

Para dar suporte à ideia de integração trazida pela organização da Universidade em Escolas, e em atendimento às exigências dos órgãos oficiais de regulamentação da educação (MEC), os documentos oficiais norteadores da Escola em questão, como o PPI (Projeto Pedagógico Institucional), o PPE (projeto Pedagógico da Escola) e os PPCs dos cursos (Projetos Pedagógicos de Curso) previam ações de integração e de promoção da construção do ser global nos seus mais variados níveis, incluindo também movimentos para promoção de trânsitos disciplinares. Por meio deles, entendeu-se a interdisciplinaridade como ponto fundamental para o desenvolvimento de um indivíduo em consonância com a contemporaneidade. Segundo o PPI $(2012$, p.14) da PUCPR,

o conceito de Escola na universidade refere-se a um trabalho centrado numa construção humana coletiva, que persegue um projeto comum, por meio do qual as ações e objetivos dos agentes adquirem sentido. Pressupõe, portanto, o empenho em construir comunidade acadêmica, cuja preocupação central é o aperfeiçoamento da aprendizagem intelectual docente e discente. Assim, o sentido de pertencimento se explicita no conceito de comunidade como "um estado de espírito dinâmico e envolvente que traduz certa maneira de ser e conviver.

Segundo o Plano Pedagógico da EArqD (2013, p.12), o PPE:

A Escola de Arquitetura e Design tem por objetivo central o aperfeiçoamento da aprendizagem intelectual de seus docentes e discentes, o que é almejado por meio da organização de conteúdos integrados e atividades interdisciplinares. Dessa forma, busca-se uma integração horizontal, com o relacionamento e aproveitamento dos cursos de mesmo nível entre si, e uma integração vertical, compreendida como a relação obtida pela integração de seus diversos cursos em nível de Graduação, Educação Continuada/ PósGraduação Lato Sensu, e Pós-Graduação Stricto Sensu.

Tendo por base estes conceitos, ações interdisciplinares e sinergias foram adotadas para que fosse valorizado um processo de ensino e aprendizagem que permitisse aos discentes a construção do sujeito inserido no mundo complexo, sem esquecer-se do desenvolvimento de competências necessárias aos profissionais da área. As competências almejadas foram aquelas voltadas à criatividade (fantasia e concretude), à inovação, ao empreendedorismo, às técnicas e à tecnologia, à 
ação social, ao experimentalismo, ao planejamento e à gestão, mas também à multiculturalidade, à transdisciplinaridade, ao pensamento sistêmico e ao humanismo.

O Projeto Pedagógico da Escola de Arquitetura e Design visa a integração de ações que buscam o debate crítico, a construção coletiva e a consolidação da sua identidade, a partir da sinergia dos cursos de graduação que a compõem, na pesquisa e na extensão, pautadas pelas atuais políticas de fomento existente, com foco no aprendizado intelectual discente e docente, onde a prática do compartilhamento de princípios semelhantes e da co-criação possam interagir a favor da superação de conflitos. (NIGRO, 2013)

Os projetos que a nortearam a Escola, consideraram, pois, a integração de ações como ponto central. Para efetivação desta proposta, além de uma integração curricular com oferta de disciplinas comuns buscando pesquisas e projetos interdisciplinares, a Escola promoveu o desenvolvimento de Projetos Integradores e de Eventos que buscaram a inter-relação entre os conhecimentos propostos no intuito de formar um indivíduo holístico em sua área de saber. Alguns dos projetos desenvolvidos neste âmbito foram o Projeto Integrado de Arquitetura e Design e o Projeto Integrado de Temas Contemporâneos. Com relação aos eventos, a escola promoveu a Semana Acadêmica Integrada da Escola de Arquitetura e Design - Sincronicidade e a Semana Acadêmica de Design - Charneira (continua ocorrendo até os dias atuais). Estas ações buscaram em seu cerne promover os preceitos estabelecidos nos projetos pedagógicos, em específico o de construir um ser humano apto a atuar em uma sociedade complexa dentro do conceito da transdisciplinariedade. Porém, entre a ideia da proposta e a real eficácia da mesma ainda residiam questionamentos: as ações realizadas estavam realmente promovendo a construção do ser humano global? As ações eram percebidas como de trânsito disciplinar?

Para iniciar uma discussão sobre estes aspectos selecionou-se para um Estudo de Caso a análise dos eventos da Escola, em específico das Semanas Acadêmicas ofertadas, no intuito de verificar se elas conseguiam - ou não - promover estes conceitos. Além disto, buscou-se verificar se estes conceitos eram apreendidos e vivenciados conscientemente pelos alunos e professores nestes eventos.

\subsection{SEMANAS ACADÊMICAS}

As Semanas acadêmicas são eventos estudantis comumentemente realizados no ensino superior, que tem por objetivo promover atividades de caráter científico, técnico ou cultural, com a participação conjunta dos corpos docente, discente e técnico, integrando ensino, pesquisa e extensão com a comunidade. Os itens que merecem destaques na realização das Semanas Acadêmicas são a diversidade de temas abordados pertinentes aos cursos que a promovem e a participação de 
professores e profissionais atuantes e reconhecidos nacional e internacionalmente, que desenvolvem palestras, participam de debates e ministram oficinas. A valorização dos profissionais egressos da universidade também é comum nas Semanas Acadêmicas, trazendo suas experiências profissionais, expectativas e desafios enfrentados, funcionando como um sinalizador de possibilidades aos alunos que ainda estão na universidade e contribuindo para a consolidação e fortalecimento de uma cultura do design e da arquitetura baseada nas transdisciplinaridade.

Em consonância com o conceito da transdisciplinaridade, a Escola analisada teve como mote principal a integração traduzida na palavra da Sincronicidade que foi tomada como sendo relativa a acontecimentos que se relacionam de forma não casual, ou seja, por uma relação de significados. A sustentação conceitual por meio deste termo permitiu a construção de uma gama diversa de ações em prol do trânsito disciplinar, podendo ocorrer por meio de dois ou mais eventos que coincidam de maneira significativa para uma pessoa ou grupo de pessoas, aos quais este significado sugere um padrão uma sincronia.

\begin{abstract}
A desejada sincronicidade é a busca de uma harmonia gestionável, da macro escala à micro escala, do ambiente externo ao ambiente interno, de uma escola, de um curso, de uma disciplina, de uma turma, de um professor, de um aluno, de um colaborador, no seu isolamento e no todo que rege este sistema aberto e dinâmico que é a Escola de Arquitetura e Design, orientado por seus princípios próprios, alinhados aos princípios institucionais, fundamentado por valores. (NIGRO, p.18)
\end{abstract}

Tomando por base este conceito, a Semana Acadêmica Integrada da Escola, denominada Sincronicidade, realizada no âmbito desta pesquisa, era organizada e desenvolvida de forma integrada pelos acadêmicos (docentes e discentes) dos cursos de Arquitetura e Design sob a orientação dos seus professores e coordenações. A integração entre professores e alunos, na elaboração da programação, ocorria por meio dos Centros Acadêmicos de Arquitetura e Urbanismo (CAU) e de Design (CAD). Esta Semana acadêmica deixou de existir adquirindo novos contornos em outras ações de interação, principalmente ações desenvolvidas em laboratórios interdisciplinares (Escritório Modelo Integrado, Laboratório de Cidade, entre outros)

Além da Sincronicidade, especificamente aos cursos de design, ocorre até os dias de hoje, a Charneira - Semana Acadêmica de Design, um evento que tem o objetivo de promover a troca de informações entre a comunidade acadêmica e profissional do Design. A Charneira atinge, além dos alunos e professores da PUCPR, estudantes e professores de Design de outras IES (Instituições de Ensino Superior) e profissionais de mercado, tendo como objetivo a promoção da discussão, a troca de informações e a criação de novas ideias sobre as diversas expressões do Design. O evento conta com 
aproximadamente 800 participantes por edição, entre estudantes, professores e profissionais renomados da área de todo o Brasil.

\subsection{PESQUISA}

Na pesquisa realizada buscou-se verificar se as ações realizadas no âmbito das Semanas Acadêmicas da escola, na tentativa de reverter a fragmentação e desconexão dos saberes, tiveram sucesso. Para tal explorou-se a problemática de como as formas de intercâmbio disciplinar (multidisciplinaridade, pluridisciplinaridade, interdisciplinaridade, transdisciplinariedade e metadisciplinaridade) estavam sendo percebidas e apreendidas pelos alunos.

Por meio de uma pesquisa quantitativa, participantes voluntários, alunos de todos os períodos dos cursos de Design Digital, Design Gráfico, Design de Produto, Design de Moda e Arquitetura e Urbanismo, responderam a um questionário objetivo no formato online, com o intuito de levantar sua percepção quanto à efetivação do intercâmbio disciplinar promovido pelas Semanas Acadêmicas de seus cursos, em específico a do Curso de Design (Charneira) e da Escola de Arquitetura e Design (Sincronicidade), realizadas respectivamente em outubro e setembro de 2013.

O questionário versou acerca dos níveis e tipos de intercâmbios percebidos pelos alunos, acerca da expansão dos conhecimentos e ampliação dos saberes ligados à complexidade do mundo atual, acerca dos tipos de atividades - em quais se percebeu melhor a transdisciplinaridade - e, por fim, disponibilizaram palavras-chave relacionadas aos níveis de intercâmbio para que o aluno indicasse a que melhor descrevia a experiência obtida.

O questionário dividiu-se e duas partes: uma relacionada à Charneira, aplicada somente aos alunos de Design, e a segunda, com as mesmas questões, relacionada à Sincronicidade, aplicada aos alunos de Design e Arquitetura.

Questão 1 foi com relação ao período que os respondentes estavam cursando. Do total de 43 alunos respondentes, a maioria encontrava-se no 2 ㅇ período do curso (15 respondentes), seguido do 6으 período (11 respondentes) e do 4ำ período (9 respondentes), provindos dos cursos: Design Digital (11 respondentes), Design Gráfico (10 respondentes), Design de Produto (9 respondentes), Arquitetura e Urbanismo (7 respondentes), e Design de Moda (6 respondentes). 


\subsection{RESPOSTAS RELATIVAS À SEMANA ACADÊMICA DE DESIGN - CHARNEIRA}

Questão 2 - Com relação à Charneira, questionou-se que tipo de intercâmbio disciplinar teria sido o mais evidente, solicitando que os alunos enumerassem em ordem crescente (de 1 ao 5) as seguintes: Multidisciplinaridade - onde não existe nenhum tipo de relação entre os conteúdos apresentados com os do curso; Pluridisciplinaridade - onde existiram relações complementares entre disciplinas mais ou menos afins; Interdisciplinaridade - onde acontece o reencontro e a cooperação entre duas ou mais disciplinas; Transdisciplinaridade - onde ocorre o máximo grau de relações entre disciplinas, promovendo uma integração global dentro de um sistema totalizador, buscando explicar a realidade sem fragmentações; Metadisciplinaridade - onde desligou-se das disciplinas, eliminando o conceito de relações entre elas e se focando no ponto de vista ou perspectiva da realidade

Constatou-se que das respostas totais (43 respondentes) somente 4 delas foram numeradas corretamente pelos participantes e consequentemente consideradas válidas. Nas outras respostas houve repetição de números de níveis, invalidando as respostas dadas. No cômpito geral verificou-se que a Pluridisciplinaridade foi a opção mais apontada como resultante das semanas acadêmicas. Os alunos justificaram as respostas. Seguem algumas relevantes:

[...] a maioria dos eventos tinham algum conteúdo interessante para o meu curso, o que trouxe a grande oportunidade de conhecer mais do que eu esperava e também, obter um conhecimento a mais.

[...] proporcionar um mundo de conhecimento e experiência que são de vidas de profissionais e alunos para alunos iniciantes e os já veteranos, é bem pouco por que é pouco tempo pra passar muita coisa, mas o suficiente que me ajudou um pouco a abrir a cabeça e ver o que é esse mundo de arquitetura e design, que ele existe e é bem mais presente do que se imagina.

Questão 3 - Tratou de levantar a percepção acerca da efetividade da semana acadêmica Charneira, em uma análise de graus que iam de 1 (sim) a 5 (não), com relação: 1. à interação com outras áreas do conhecimento; 2. contribuição com o desenvolvimento holístico e global; e 3. oportunidades de articulação tanto dos saberes acadêmicos (como os conceituais, metodológicos, conteudísticos) quanto de saberes não acadêmicos (como a corresponsabilidade, autonomia, cidadania). Na análise das respostas verificou-se que as três concepções básicas do intercâmbio entre as disciplinas foi efetivada, sendo que a maioria respondeu sim, no primeiro grau para as três questões. As justificativas mais relevantes dadas a esta questão estão descritas a seguir:

A interação com outras áreas do conhecimento se mostram claras quando observado o panorama geral do programa, muitas escolhas extremamente distintas e que chegaram a causar dúvida na hora da escolha de palestras que concorriam no mesmo horário. Quanto ao desenvolvimento holístico, penso 
em partes que coube ao aluno fazer ligações desse tipo, das palestras com assuntos correlacionados.

A charneira contribuiu muito para meu conhecimento e desenvolvimento pessoal por causa da grande interação com os outros cursos que trouxe muitas experiências novas.

Questão 4 - Buscou-se levantar quais atividades da Charneira mais proporcionaram a transdisciplinaridade da Escola, minimizando a fragmentação dos saberes. Verificou-se que na percepção de 17 alunos de design, as palestras tiveram este maior papel.

Questão 5 - Questionou-se que palavra o aluno achava que definia melhor a CHARNEIRA, tendo em vista os pares sinônimos: soma / multidisciplinaridade; contiguidade / pluridisciplinaridade; interação/interdisciplinaridade; unificação / transdisciplinaridade; libertação / metadisciplinaridade. Verificou-se que $64 \%$ dos respondentes (23 alunos) perceberam como Interação, relacionada à interdisciplinaridade, a palavra que melhor define a Charneira.

\subsection{RESPOSTAS RELATIVAS À SEMANA ACADÊMICA DA ESCOLA DE ARQUITETURA E DESIGN - SINCRONICIDADE}

O questionário sobre a Sincronicidade foi aplicado a alunos de todos os cursos da Escola, tendo as mesmas questões do questionário específico para os alunos de Design. Seguem-se os resultados.

Questão 2 - Relativamente a qual tipo de intercâmbio disciplinar que teria sido o mais evidente, verificou-se também que das respostas totais, somente 4 das respostas foram numeradas corretamente pelos respondentes. Da análise das respostas válidas, os alunos tiveram a percepção de que a Metadisciplinaridade foi a que mais foi significativa na Sincronicidade. Em segundo lugar encontra-se a Interdisciplinaridade, em terceiro, a Transdisciplinaridade e em último lugar a Multidisciplinaridade. Os alunos justificaram as respostas. Segue uma fala:

A Sincronicidade promoveu oportunidades em relação ao conhecimento, pelos conteúdos abordados e em relação a uma melhora pessoal e agregadora, pelos valores éticos e morais incentivados por organizadores e palestrantes.

Questão 3 - Relativa à percepção acerca da efetividade da semana acadêmica Sincronicidade, pôde-se ver que a opinião dos participantes ficou mais dividida entre os níveis de resposta. Quanto a interação com outras áreas do conhecimento, o mesmo número de respondentes (12 participantes), que equivale a $28 \%$, optou pelos níveis 1 e 3 enquanto que 21\% (9 participantes) selecionaram o nível 5; com relação ao desenvolvimento holístico e global, para 13 respondentes (30\%) a seleção foi nível 3 seguidos de $23 \%$ no nível 2 (10 alunos), 21\% no nível 1 (9 participantes) e 19\% (8 alunos) no nível 5; e 
no que diz respeito às oportunidades de articulação dos saberes acadêmicos e não acadêmicos prevaleceram os níveis 1 e 2, com $23 \%$ dos respondentes (10 alunos) selecionando cada um dos níveis 1 e 2 e 21\% (9 alunos) optando pelo nível 5. Nesta resposta identifica-se um maior equilíbrio de percepção das atividades, podendo ser atribuída à um equilíbrio maior entre as atividades propostas na Semana Acadêmica, que procurou atender a todos os aspectos previstos nos Projetos pedagógicos.

Questão 4 - Relativa a quais atividades da Sincronicidade mais proporcionaram a transdisciplinaridade da Escola, verificou-se que na percepção dos alunos, as palestras tiveram este maior papel. Os alunos justificaram suas respostas. Seguem 2 delas:

Observei com mais clareza a mistura dos cursos, nas palestras, que se mostraram mais direcionadas, um dos cursos sempre se mostrava mais presente do que o outro.

Isso se justifica pelo acúmulo de conhecimento e a agregação de novas ideias.

Questão 5 - Com relação à palavra que o aluno achava que definia melhor a Sincronicidade, a maioria dos alunos (16 deles) perceberam a Interação, relacionada à interdisciplinaridade, a palavra que melhor a definiu.

\section{CONCLUSÃO}

Neste trabalho, apresentamos o resultado de uma pesquisa feita com participantes das Semanas Acadêmicas dos cursos de Design (Charneira) e de Arquitetura e Design (Sincronicidade) da Escola de Arquitetura e Design da PUCPR. O objetivo da pesquisa foi diagnosticar "se" e "que" forma de intercâmbio disciplinar (multidisciplinaridade, pluridisciplinaridade, interdisciplinaridade, transdisciplinariedade e metadisciplinaridade) foi promovida pela Escola nestes eventos e se os participantes perceberam este intercâmbio.

Pelas respostas dadas ao questionário, pode-se observar que apesar de ter havido uma leve tendência a categorizar a Semana Charneira como pluridisciplinar e a Semana Sincronicidade como metadisciplinar, os 43 respondentes, na sua maioria, acreditam que as Semanas Acadêmicas foram um evento Interdisciplinar (67\% e $37 \%$ respectivamente) com a palavra-chave mais votada sendo definida como Interação. Este intercâmbio disciplinar ocorreu na maioria das vezes nas palestras (47\% e $65 \%$ ) do que nas mesas-redondas e workshops, contrariamente ao que poderia se esperar, pois as palestras tendem a ser eventos mais centrados no palestrista (um para todos) do que, por exemplo, nas mesas-redondas onde há uma maior discussão de pontos de vistas diferentes e complementares 
(alguns para todos), e nos workshops que tendem a trazer atividades mais práticas e de interação entre os participantes (todos para todos).

Somando-se a ideia de interdisciplinaridade, em ambos os eventos os participantes acreditaram que houve grande interação com as outras áreas do conhecimento ( $86 \%$ na Charneira somando-se nível 1 [ótimo] e 2 [bom], e 56\% na Sincronicidade somando-se o percentual destes dois níveis). Eles também expressaram ter havido muitas oportunidades de articulação dos saberes acadêmicos e não acadêmicos (72\% nos níveis 1 e 2 para Charneira e $46 \%$ entre os mesmos níveis para a Sincronicidade). Entretanto, com relação à contribuição com o desenvolvimento holístico e global, os respondentes se aperceberam muito mais deste aspecto na Semana Charneira onde a maioria (39\%) selecionou o nível 1 (ótimo) do que os participantes da Semana Sincronicidade, onde a maioria (30\%) optou pelo nível 3 (neutro).

Os resultados desta pesquisa preliminar corroboram com a proposta sustentada pelo PPI da Escola, que entende a interdisciplinaridade como ponto fundamental para o desenvolvimento de um indivíduo. Entretanto, busca-se galgar um nível mais alto de cooperação entre as disciplinas, onde haja inicialmente uma integração global como a proposta pela transdisciplinaridade para então atingir ao nível mais alto que é o da metadisciplinaridade, onde se eliminam os conceitos e compreende-se a realidade como uma relação complexa, global e holística.

Já nesta pesquisa, alguns dos dados apontam levemente para a transdisciplinaridade nas Semanas Acadêmicas Charneira e Sincronicidade, onde a palavra unificação foi a terceira mais votada (11\% e $21 \%$ respectivamente). Isto pode indicar que alguns participantes puderam possivelmente apreender este nível de intercâmbio disciplinar, o que nos deixou otimistas para continuar desenvolvendo trabalhos que buscassem explicar a realidade com menos fragmentações e onde houvesse uma "unificação semântica e operativa das acepções através e além das disciplinas" (SOMMERMAN \& SANTOS, 2009, pag. 62, art 4ㅇ.). Acredita-se, pois, que as Semanas Acadêmicas tenham o potencial de promover este rompimento com os paradigmas mais tradicionais de ensino e sugere-se que pesquisas como esta continuem a ser feitas para poder diagnosticar como este intercâmbio disciplinar está se desenvolvendo para promover os mais altos níveis de cooperação e interação da realidade nestes eventos. 


\section{REFERÊNCIAS}

JULIATTO, C. I. Parceiros educadores: estudantes, professores, colaboradores e dirigentes. Curitiba: Champagnat, 2007, p.

MORIN, Edgar. Os princípios do conhecimento pertinente. In: Os sete saberes necessários à educação do futuro. São Paulo: Cortez, 2000.

NIGRO, Carlos Domingos. Fórum de Desenvolvimento da Escola de Arquitetura e Design da PUCPR. Curitiba: Monografia de especialização em Gestão e Liderança Universitária, PUCPR, 2013.

PUCPR. Projeto Pedagógico Institucional. Curitiba: PUCPR, 2013.

PUCPR. Projeto Pedagógico da Escola de Arquitetura e Design. Curitiba: PUCPR, 2013.

PUCPR. Projeto Pedagógico do Curso de Arquitetura e Urbanismo. Curitiba: PUCPR, 2013.

SOMMERMAN, Américo e SANTOS, AKIKO. Complexidade e Transdisciplinaridade: em busca da totalidade perdida. Porto Alegre: Sulina, 2009.

TARDIF, M.; LESSARD, C. O trabalho docente: elementos para uma teoria da docência como profissão de interações humanas. Tradução de João Batista Kreuch. Petrópolis: Vozes, 2007.

ZABALA, Anton. Enfoque globalizador e pensamento complexo. Porto Alegre: Artmed, 2002. 


\section{Capítulo 12}

doi $10.37423 / 210403769$

\section{ID-THINK: FACILITADOR DA VISUALIZAÇÃO DOS CONHECIMENTOS DA EMPRESA}

ANA PAULA PERFETTO DEMARCHI

Cleuza Bittencourt Ribas Fornasier

Elingth Simoné Rosales Marquina

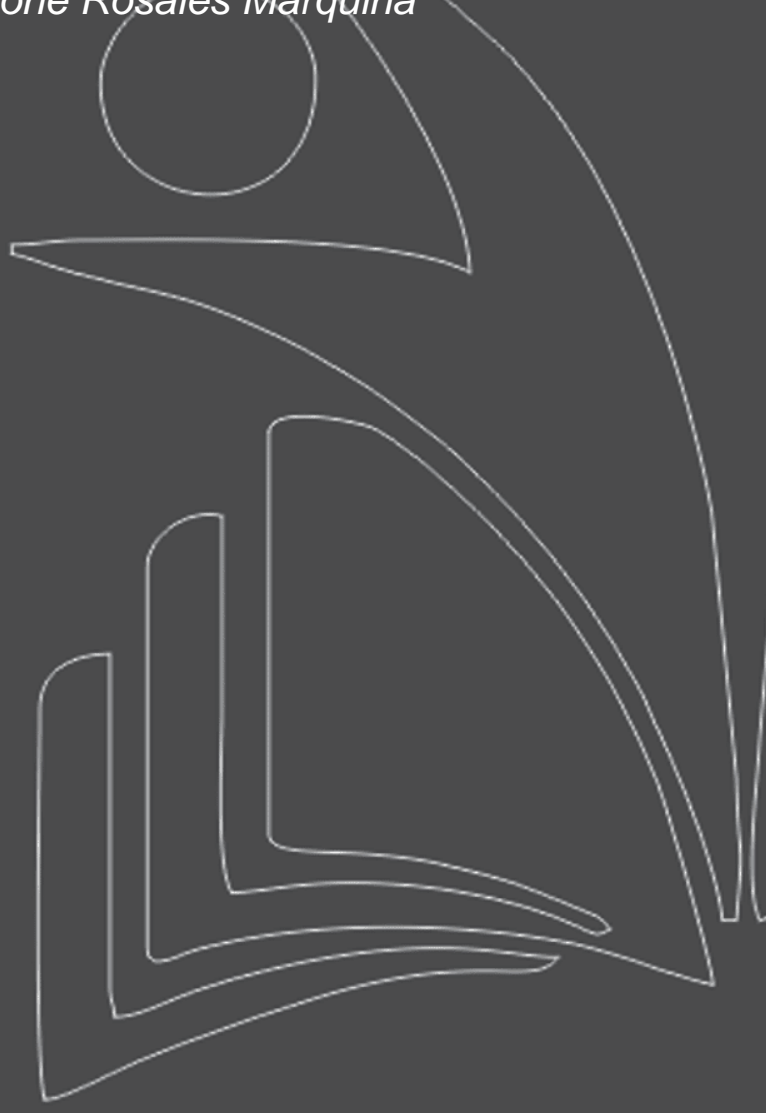

Universidade Estadual de Londrina

Universidade Estadual de Londrina

Pontificia Universidad daveriana de Cali

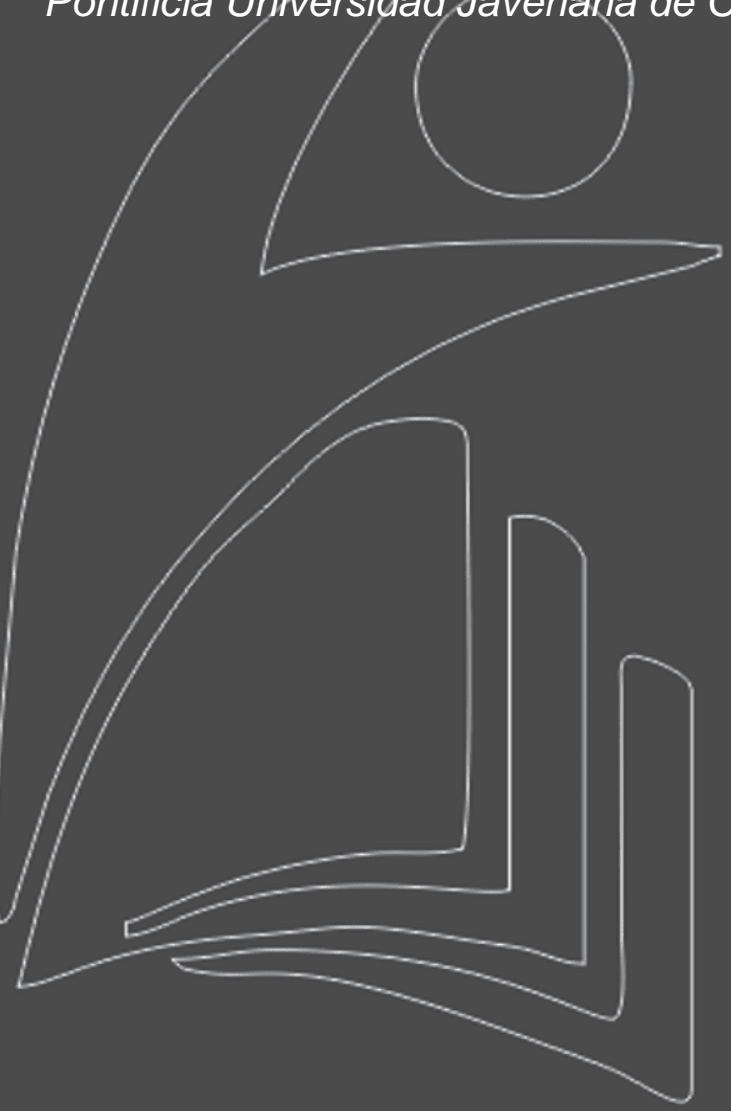


Resumo: Este artigo relata o projeto desenvolvido na Universidade Politécnica de Valencia em conjunto com a Universidade Estadual de Londrina, o qual resultou em um produto que pretende facilitar o desenvolvimento da gestão do conhecimento e sua visibilidade a partir dos objetivos a serem perseguidos, por meio da transmissão de informações e conhecimentos e da transformação destas em ações e novos conhecimentos. Para tanto, utilizou-se dos conceitos do design thinking e das habilidades inerentes aos design thinkers, desenvolveu-se uma interface que auxilia a integração dos conhecimentos de todos os envolvidos na gestão da organização.

Palavras-chave: Modelo sistêmico, Gestão do conhecimento, Design Thinking. 


\section{INTRODUÇÃO}

Esta pesquisa promove mudanças organizacionais pela inserção da Gestão do Conhecimento, que preserva as características da organização, a lógica de produção, o respeito à diversidade cultural, e também coopera para que haja a inserção do produto na lógica empresarial por meio do entendimento mercadológico, gerenciadas pelos design thinkers.

O design thinker traduz observações em insigths e insights em produtos e serviços. Não só os designers podem ser design thinkers, mas aqueles que têm as mesmas experiências e habilidades integrativas e holísticas do design thinker, (nas organizações, nas sociedades e na vida). Sabe-se que o acúmulo de experiências durante a vida possibilita aguçar a sensibilidade e habilidades.

O design thinker extrai conhecimentos (tácito, cultural, objetivo e explícito) das organizações (Demarchi, Fornasier, Martins, 2013), codifica-os e gera conhecimento organizacional para produzir o conhecimento objetivo, agregando valor aos produtos e contribuindo para torná-los mais competitivos. Porém, os novos conhecimentos são criados a partir do conhecimento subjetivo que avalia as informações e conhecimentos a que os sujeitos são expostos. Por isto, que a informação só se torna conhecimento, pelo pensamento reflexivo, que é a forma analítica de extrair sentido das informações.

Este artigo descreve um produto desenvolvido por este grupo de pesquisadores, que permite visualizar o plano de empresa sobre um suporte material, a partir da representação gráfica dos vários conhecimentos atribuídos a organização.

O produto facilita a visualização do seguimento contínuo dos objetivos da empresa, auxilia a visualização do problema de maneira global, por meio de um processo gráfico que garante retroalimentações tanto nas estruturas disponíveis, quanto nos recursos humanos e materiais, assim como facilita a visualização das ações e fluxos de informações correspondentes as decisões necessárias para a produção de produtos e serviços. O produto demonstra também quais são as habilidades e as atitudes de design thinker que o gestor deve ter em cada etapa, o que facilita a aplicação da gestão do conhecimento na organização.

O produto utiliza os conceitos do Modelo Sistêmico de Hernandis (2003) agregado de conceitos proposto na Gestão Estratégica Integradora de Design Aprimorado (GelDa) de Demarchi, Fornasier e Martins (2013), sendo estes modelos baseados na gestão do conhecimento. 


\section{GESTÃO DO CONHECIMENTO}

O modelo GelDa (Demarchi, Fornasier e Martins, 2013), adota a segunda fase da gestão do conhecimento considerando o modelo de Mark W. McElroy (apud Firestone e McElroy, 2003), construído pelo trabalho conjunto com o Knowledge Management Consortium International (KMCl) que vê a primeira fase como centrada na produção (oferta) do conhecimento, que presumia que os conhecimentos valiosos já existem. Esta primeira fase, para os autores, é centrada no trabalho de Nonaka e Takeuchi (1997), que considerava o conhecimento como externalizado e a disposição para ser processado pela informação.

No entanto, Firestone e McElroy (2003) consideram a segunda fase da gestão do conhecimento, como surgida na metade da década de 90 , focada na oferta do conhecimento, no compartilhamento e também na demanda do conhecimento, ou seja, na produção do conhecimento em resposta à demanda induzida por um problema. Este foco combina a produção com a integração do conhecimento, sendo esta a característica básica da definição da Segunda Geração da Gestão do Conhecimento (SGGC) ou a Nova Gestão do Conhecimento (NGC).

De acordo com os autores um importante aspecto da NGC é o reconhecimento de que organizações são permeadas de um fenômeno do sistema adaptativo complexo. Nesse contexto, a gestão do conhecimento baseia-se na utilização deste sistema para a adaptação organizacional, que possibilita e reforça a auto-organização e processa o conhecimento para atingir uma acelerada inovação sustentável. Lembrando que o modelo de McElroy (2003, p. 5), apresenta o conhecimento como algo produzido por "sistemas sociais humanos, que fazemos isso por meio de processos individuais e por compartilhamento que regularmente acontece entre os seres humanos".

O produto, a que se refere este artigo, adota a NGC, e consequentemente visa a interdependência da produção e da integração do conhecimento, apesar de neste momento, o produto apresenta somente a produção do conhecimento, mas será ampliado.

O Modelo Sistêmico (Hernandis, 2003) é um aparato que gestiona dados, informação e conhecimento. Convêm reforçar que basicamente os dados são provenientes quando ocorre a definição dos componentes do sistema exterior por meio das variáveis de entrada. Neste ponto é oportuno destacar a importância da abordagem sistêmica para potencializar a compreensão integral do processo de gestão do conhecimento. Como assinala Cross (2011), a perspectiva é contextual e, portanto, não só a análise da estrutura como também a qualidade do sistema estudado e suas interações, aspectos que 
são essenciais para este projeto. Portanto, a gestão de dados, informação e conhecimentos articulamse com conceitos fundamentais associados a noção de análise sistêmica como a proposta por Joel de Rosnay (1979), que "[...]consiste em definir os limites do sistema a modelar; em identificar os elementos importantes e os tipos de interações entre estes elementos; depois, em determinar os enlaces que os integraram em um todo organizado" (p.85).

A contribuição proposta do Modelo Sistêmico será justamente no processo de extração do conhecimento, assim o modelo trabalha com dados, informações e conhecimentos, considerando os conhecimentos explicitados (objetivo e explícito) e conhecimentos não explicitáveis (conhecimento tácito e cultural) estudados por Demarchi, Fornasier e Martins (2010).

O conhecimento objetivo é o conteúdo lógico de nossas teorias, conjecturas e suposições explicitados em procedimentos aparentes nos produtos, tecnologia, arte, arquitetura, linguagem escrita e falada, mitos, rituais e histórias, enfim são os fenômenos que alguém vê, ouve e sente, quando depara-se com um novo grupo, ou com uma cultura não familiar. O conhecimento explícito está na linguagem formal, em afirmações gramaticais, expressões matemáticas, especificações, e manuais sendo transmitido, formal e facilmente entre os sujeitos.

O conhecimento tácito é compartilhado a partir de exemplos ou demonstrações, quando se trata da experiência "do fazer" é difícil de ser verbalizado ou explicitado, pois é o conhecimento pessoal incorporado à experiência individual e envolve fatores intangíveis como as crenças pessoais, perspectivas e sistemas de valores. Muitas vezes pode ser somente compartilhado por meio de discurso como: analogias, metáforas e compartilhamento de histórias. Apesar de o conhecimento tácito ter característica pessoal, as organizações possuem conhecimento tácito em torno de práticas que a tornam diferentes entre si.

Conhecimento cultural está expresso nas crenças, normas e pressupostos usados para dar valor e importância a novos conhecimentos e informações, não é codificado, mas divulgado por vínculos e relacionamentos que ligam um grupo, e que por meio da linguagem constrói-se o sistema que articula com outros sujeitos. As crenças são sustentadas como verdades, porque são construídas por determinadas referências da realidade a partir de aceitações anteriores formuladas pelo grupo.

À medida que estes conhecimentos são explicitados, vão sendo anexados ao produto proposto a partir de dois tabuleiros, que facilitam a visualização da externalização do conhecimento. Demarchi, Fornasier e Martins (2010) a definem como a ação de extrair os conhecimentos explícitos e culturais do ambiente, que se articulam com as necessidades latentes do sujeito (conhecimento subjetivo), pois 
ao compartilhar um conhecimento, o sujeito adquire outro conhecimento, ou muda as crenças e valores enraizados.

A partir da relação dos cinco conhecimentos pode-se produzir um novo conhecimento. Observa-se que três dos conhecimentos apresentados anteriormente não podem ser explicitados. 0 conhecimento tácito e o conhecimento cultural podem ser compartilhados, mas não externalizados; e o conhecimento subjetivo não é nem explicitado, nem compartilhado, é somente alterado quando ocorrem as relações de sociabilidade, o que justifica a dificuldade em extrair os conhecimentos, e coloca em xeque o entendimento de Nonaka e Takeuchi (1997) de que o conhecimento está pronto para ser trabalhado.

Para poder utilizar os conhecimentos durante o processo de design, deve ocorrer o processo de aprendizagem. Aprende-se por meio de um processo que inclui o conhecimento investigado, associando-o ao saber como fazer algo, e ao saber que este algo é feito desta ou daquela maneira, ou seja, da teoria e da prática, numa ação sistêmica. Este ciclo ocorre durante a conversão do conhecimento, pois o designer precisa aprender para poder sintetizá-lo e convertê-lo em outra linguagem.

Para produzir um novo conhecimento é necessário fazer a sua extração e conversão pela interação dos cinco conhecimentos articulados em quatro possíveis modos de conversão que são a essência do Processo de Produção do Conhecimento.

A Externalização é conseguida pelo compartilhamento de experiências. Esta fase é muito importante para o designer, e provavelmente a que ele tem maior dificuldade, pois necessita tirar das pessoas o que sabem e querem que seja importante para o trabalho, considerando que nem elas mesmas sabem que sabem, ou o que querem, "ajudar as pessoas a articularem as novas necessidades que eles podem nem saber que têm" (Brown, 2009, 40) é um desafio que pode ser solucionado utilizando as habilidades dos design thinkers. O designer é ajudado por algumas ferramentas, como ir ao campo observar o comportamento das pessoas enquanto elas agem, o que proporciona pistas valiosas sobre uma lista de necessidades insatisfeitas.

Na Explicitação o pesquisador normalmente incentiva a socialização a partir de metáfora e/ou analogia, importantes para a criação de uma rede conceitual, como também: contação de histórias (storytelling- metáforas para externalizar conceitos e transmitir ideias ou eventos); e o pensamento visual (visual thinking - para explicitar conceitos). Após, sintetiza as observações que serão agrupadas 
e a partir delas formularão outros conhecimentos, por meio da redução do conhecimento, a primeira do Processo de Produção do Conhecimento.

Na Experimentação compartilha-se o conhecimento explícito, por meio das habilidades criativas e experimentais. Desmembram-se as ideias surgidas e se operacionalizam as visões explicitadas conseguidas pelas pesquisas qualitativas, quantitativas, e na construção de protótipos. Eles são utilizados como modelo, como uma representação física ou matemática de um objeto, ou pode ser ainda "qualquer coisa tangível que nos deixe explorar uma ideia, avaliá-la e levá-la adiante" (Brown, 2009, p.92). Portanto, a experimentação é o processo de sistematização de conceitos em um sistema de conhecimento.

A Estratégia é o processo de redução progressiva para chegar a uma alternativa de aplicação estratégica formada pelo conhecimento explicitado. Está relacionada ao "aprender fazendo", já que "para que o conhecimento tácito torne-se explícito, é necessária a verbalização e diagramação do conhecimento sob a forma de documentos, manuais ou histórias orais"(Nonaka e Takeuchi, 1997, p.78)

O modelo proposto é um modelo de explicitação de conhecimentos adquiridos do sistema exterior e que entram no modelo por meio de variáveis de entrada. No entanto, essas variáveis também contêm conhecimentos não explicitados, sendo necessária a realização da extração do conhecimento em uma etapa anterior que se materializa no modelo proposto no primeiro tabuleiro que orienta o pesquisador a colocar em prática os conceitos de design thinking, assim como as habilidades inerentes ao design thinker, principalmente a habilidade de visual thinking.

\section{DESIGN THINKING}

O Design Thinking, apesar de ser considerado novo, ele sempre esteve presente, é uma nova maneira de pensar e utilizar o processo de design, mesmo que a nível inconsciente. llipinar et all (2008) dizem que o design thinking é um processo criativo baseado na construção de ideias, que elimina o medo de falhar por não haver julgamento, por isto encoraja a máxima absorção e participação dos indivíduos no processo de resolução de problemas. Roger Martin, citado pelos autores, vê o design thinking como fonte de vantagem competitiva e consideram-o como fator essencial para as organizações obterem inovação.

Dyer, Gregersen e Christensen (2011) concordam que a inovação revolucionária (disruptiva) é desencadeada pela habilidade que os inovadores possuem de ligar ideias (pensamento associativo), 
no entanto, os inovadores não só pensam de maneira diferente, mas também agem de forma diferente. Alguns observam o mundo com uma intensidade maior que os indivíduos comuns, outros criam network formando um grupo colaborativo, enquanto outros se engajam em ações experimentais. Eles afirmam que a inovação e a criatividade não são só habilidades cognitivas, são uma questão de comportamento. A partir disto, os autores criaram um modelo que demonstra o DNA de pessoas inovadoras para gerar ideias inovadoras, demonstrado na figura 1 abaixo.

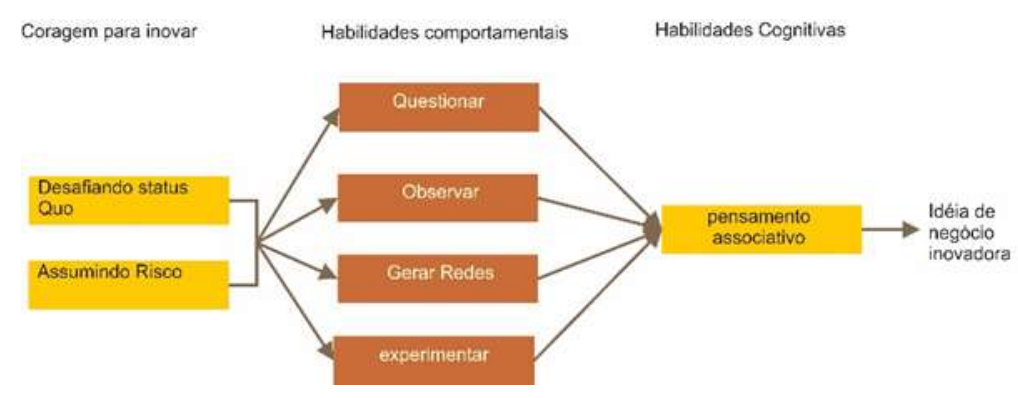

Fig1: Modelo de DNA de Inovadores

Fonte: Adaptado de Dyer, Gregersen e Christensen (2011, p.27)

Observou-se que as habilidades comportamentais, e cognitivas dos inovadores são as mesmas dos design thinkers. Para Brown (2009), o design thinking inicia com as habilidades que os designers aprenderam no decorrer do tempo; como a de alinhar as necessidades dos seres humanos com o recurso tecnológico disponível na organização, na intuição, na habilidade de reconhecer padrões, construir ideias que tenham significado tanto emocional quanto funcional, na habilidade de questionar o entorno e ser empático, e a habilidade de expressar de outra maneira que não em palavras ou símbolos, mas desenhando.

Ao que parece o processo de design é difícil de conduzir por processos mentais puramente internos, o designer precisa interagir com uma representação externa por isto que Cross (2011, p.12) diz: “O ato de desenhar parece clarear meus pensamentos", já que há um limite cognitivo para a quantidade de complexidade que pode ser manipulada no cérebro. Esboçar fornece um depósito temporário e externo para ideias tentadas, e essa externalização suporta o diálogo que o designer tem entre o problema e a solução, sendo a principal habilidade do designer.

O processo de desenho é tanto um processo de crítica, como meio de materialização, imaginação, ou descoberta de algo que não pode ser construído na sua mente, e também como um meio de comunicação com os outros. De acordo com Cross (2011) nesses casos, o design torna-se não somente um processo pessoal e cognitivo, mas um processo partilhado e social. Esse processo leva a outra habilidade, que, segundo Brown (2009), é a de trabalhar de forma interdisciplinar e de criar redes. 
De acordo com Schon (apud Cross, 2011, p.23), o design procede como "uma conversação reflexiva da situação" um processo interativo baseado em apresentar um quadro do problema e explorar as implicações a partir de 'movimentos' que investigam as decorrentes possibilidades de solução. Esses movimentos envolvem todos da equipe interdisciplinar.

Portanto, o design thinker observa o ordinário e grava as suas observações e ideias visualmente; ele tem em si a habilidade de expressar suas ideias visualmente. A cultura do design thinking encoraja a criação do protótipo, que não deixa de ser uma maneira de pensar visualmente, pois o protótipo é uma maneira de validar ideias finais, sendo também parte do processo de criação. Brown (2009, p.231) relata que os protótipos precisam ser testáveis, mas não necessariamente físicos, podem ser "storyboards, cenários, filmes, e até um improviso teatral".

Praticantes do design thinking competentes sabem mais do que conseguem dizer, porque é um tipo de saber-na-prática, sendo que a maioria são conhecimentos tácitos. Brown (2009) identificou um processo cognitivo de reflexão-em-ação que é um quadro experimental no qual o design thinker encontra uma maneira de ver a problemática a partir da realização de protótipos, como a inteligência que guia o comportamento 'intuitivo' em contextos práticos que fazem pensar-e-agir.

As técnicas de design como: esboçar, construir protótipos, fazer maquetes, cenários, etc., habilitam o designer a fazer um "inquérito da futura situação de uso". Estas técnicas fazem parte do mundo da cognição, e fornecem ao designer um conjunto de "estratégias situadas". Gedenryd (apud Cross, 2011, p.27) argumenta que a visão cognitiva como puramente racional e uma atividade 'intra-mental' (unicamente dentro da mente) é errônea, mas a reconhece como uma atividade prática e interativa. $\mathrm{O}$ ato de design é uma atividade intensa de cognição, que possui a necessidade de manter períodos de atividade intensa de intuição, intercaladas com períodos de contemplação mais reflexiva, usualmente fora do ambiente normal de trabalho.

Para Lockwood (2009) os atributos do design thinking são: habilidade de criar o futuro em vez de reagir à condição presente; ser colaborativo; ser empático; ser um visual thinker; integrativo; criativo; e trabalhar com a diferenciação. Para ser designer e líder requer-se "habilidade de imaginar 'o que ainda não existe' para criar novo significado ou novas realidades, para encontrar direção, operar com intenção e propósito, e operar em um mundo praticamente mudando a complexidade e informação". O quadro abaixo gera a relação de semelhanças entre as habilidades e atributos do design thinker com o DNA de inovadores. 
Tab. 1: Comparação entre as habilidades e atitudes do design thinker com o DNA do inovador

\begin{tabular}{|c|c|c|c|}
\hline $\begin{array}{l}\text { Habiticlades o atitudes do } \\
\text { dasigan Thinkar }\end{array}$ & $\begin{array}{l}\text { Habilidades comportamentals } \\
\text { do lnovador }\end{array}$ & $\begin{array}{l}\text { Habillidades Cognilivas } \\
\text { do inovador }\end{array}$ & Coragem de inovar \\
\hline Observaçáo empática & $\begin{array}{l}\text { Observaçăo } \\
\text { Questionar }\end{array}$ & & \\
\hline $\begin{array}{l}\text { Colaborativa } \\
\text { Integrativo }\end{array}$ & Criar rede & & \\
\hline Gerar prototipos & Experimental & & \\
\hline $\begin{array}{l}\text { Criativo } \\
\text { Visual thinkers }\end{array}$ & & Pensamento associativo & \\
\hline Trabalhar com a diferenciaça & & & Desafiar o Status Quo \\
\hline $\begin{array}{l}\text { Visåo do futuro } \\
\text { Assumir risco }\end{array}$ & & & Assumir risco \\
\hline
\end{tabular}

Chesbrough (2012) diz que a inovação não é invenção, mas é a invenção implantada e levada ao mercado. A inovação revolucionária (disruptiva) é aquela que altera as práticas sociais (modo de viver, aprender e trabalhar). Como visto acima na Tabela 1, as habilidades do design thinker auxiliam a implantação da inovação revolucionária (disruptiva), que é essencial para a sobrevivência das organizações.

O produto aqui demonstrado foi desenvolvido no intuito de potencializar o uso destas habilidades. $\mathrm{O}$ ID-Think define maneiras de processar conhecimentos não explicitáveis por meio da sua habilidade de visual thinking, representando a maneira de pensar dos designers, com objetivo de tornar visíveis os conhecimentos para transformá-los em produtos e processos de sucesso.

\section{METODOLOGIA}

Tanto Hernadis (2003) quanto Demarchi, Fornasier, e Martins (2013) desenvolveram modelos conceituais baseados na gestão do conhecimento. A justaposição dos dois conceitos com a aplicação dos conceitos de design thinking possibilitou o desenvolvimento deste produto.

No primeiro momento foi necessário o aprendizado por parte do grupo de como funcionava os dois modelos e dos conceitos de design thinking. Depois foram realizadas sessões de contações de histórias por ambas as partes para que ocorressem os aprendizados dos novos conceitos, para depois por meio de brainstorming possibilitar a geração dos tabuleiros do jogo e do modo de utilização. Por último, realizaram-se os protótipos para que fossem aplicados em empresas pilotos e assim realizados os devidos ajustes. O trabalho caracterizou-se como um trabalho de cocriação, no qual toda a equipe participou das diferentes etapas de realização. 


\section{IDTHINK: UM JOGO EMPRESARIAL}

ID-Think foi o nome dado ao produto que é caracterizado como um jogo empresarial, tendo como objetivo auxiliar o processo de criação e planejamento de empresas, assim como para a análise, descrição, e detecção de problemas, para posterior correção de desvios de gestão empresarial.

Durante a modelagem do produto devem participar diretores, gestores, design thinkers, e pessoas diretamente envolvidas com a área ou empresa em questão. O processo é de cocriação, o que significa que todos deverão determinar os problemas da empresa/área planificando e determinando ações corretivas futuras, para que a empresa se adapte ao entorno e evolua. Como todo processo deve haver um líder, alguém com habilidades propícias para ajudar a realizar a externalização dos conhecimentos e que dirija as ações de preenchimento do modelo.

O produto constitui-se de dois tabuleiros. O primeiro tabuleiro é o Sistema Exterior, o segundo tabuleiro é o Sistema de Empresa e abaixo do último existe uma faixa mais estreita, aonde serão colocados os objetivos já cumpridos, denominada de Faixa de Objetivos Cumpridos. Lembrando que o produto auxilia no processo de criação e planejamento de empresas a partir das definições dos objetivos em cada um dos níveis empresarial e a partir deles define-se quem realizará o que, de que maneira, com o que e quando será realizado e o mesmo processo ocorre para ser validado.

Os dois tabuleiros possuem quadros específicos que facilitam a localização das ações a serem realizadas. A modelagem é induzida pela disposição destes quadros que serão preenchidos com os materiais incluídos na maleta do jogo, como post its, marcadores, e fichas específicas com imagens ou com conceitos escritos.

O tabuleiro completo deve ficar pendurado a partir dos dois orifícios superiores. Ele possui indicação numérica de um (1) a vinte e seis (26), que indicam a ordem correta de preenchimento, por mais que tenham dificuldade sugerimos que não pulem nenhuma das etapas, isto só dificultará o entendimento.

O sistema em estudo é a organização, mesmo que o estudo abranja apenas parte dela. O primeiro espaço a ser preenchido no tabuleiro é o nome e a atividade que a empresa realiza, passando depois para o sistema exterior. O sistema exterior é a realidade externa que rodeia a empresa, e por sua vez levanta um problema de design.

O Sistema Exterior é onde se copila toda a informação relativa ao entorno da empresa e se analisa mediante diversas ferramentas de transcendência da informação, gerando uma síntese mediante 


\section{ID-THINK: Facilitador Da Visualização Dos Conhecimentos Da Empresa}

conceitos base, fotografias ou representações gráficas que constituem a informação fundamental da realidade da empresa (figura 2).

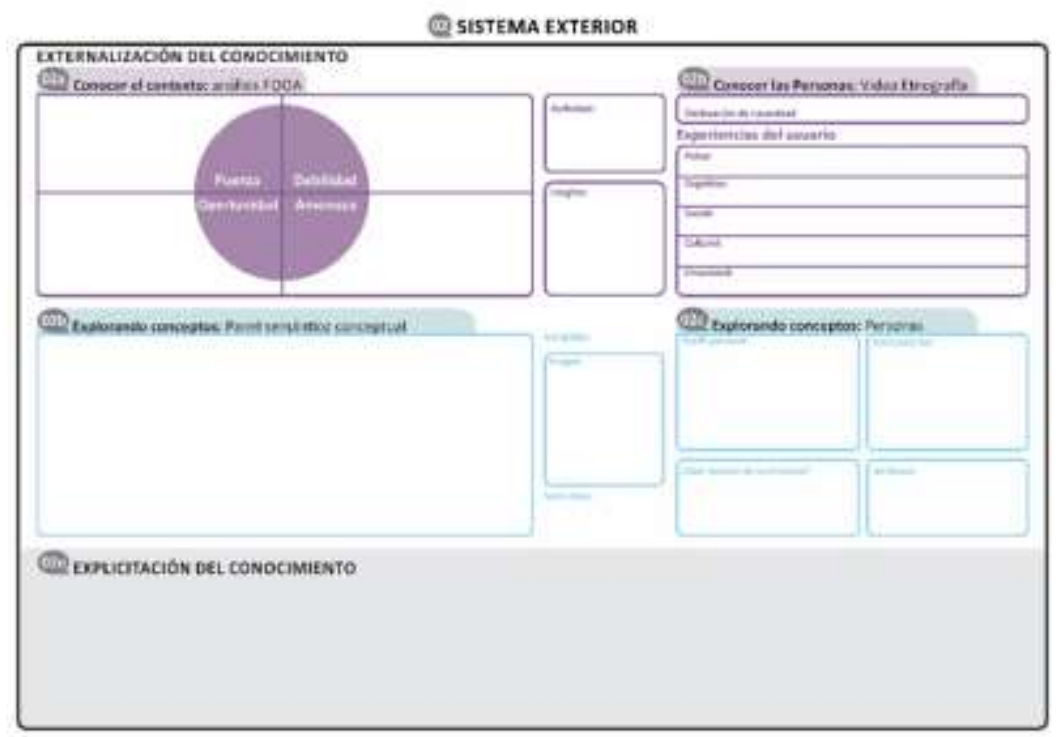

Fig 2: Tabuleiro Sistema Exterior

O Sistema Exterior alimenta o Sistema em Estudo com dados, informações e conhecimentos, Ortuño e Navarro (2000) definiram-no como sendo a caracterização do sistema aonde se localizará a atenção do pesquisador. Por isto que o segundo tabuleiro é constituído pelo subsistema de empresa. A organização, é formada por subsistema físico e pelos níveis de gerência que demonstram a ordem de prioridade, portanto, de preenchimento do sistema, de cima para baixo, começando pelos objetivos do nível de mutação.

A maneira lógica de preencher o Sistema em Estudo é do nível macro para o micro, sempre inicia pelo nível de Mutação, no qual o conselho administrativo, ou seja, os agentes responsáveis pela organização atuam diretamente, definem o conceito organizacional, e após determinam os objetivos de Mutação.(fig 2) 


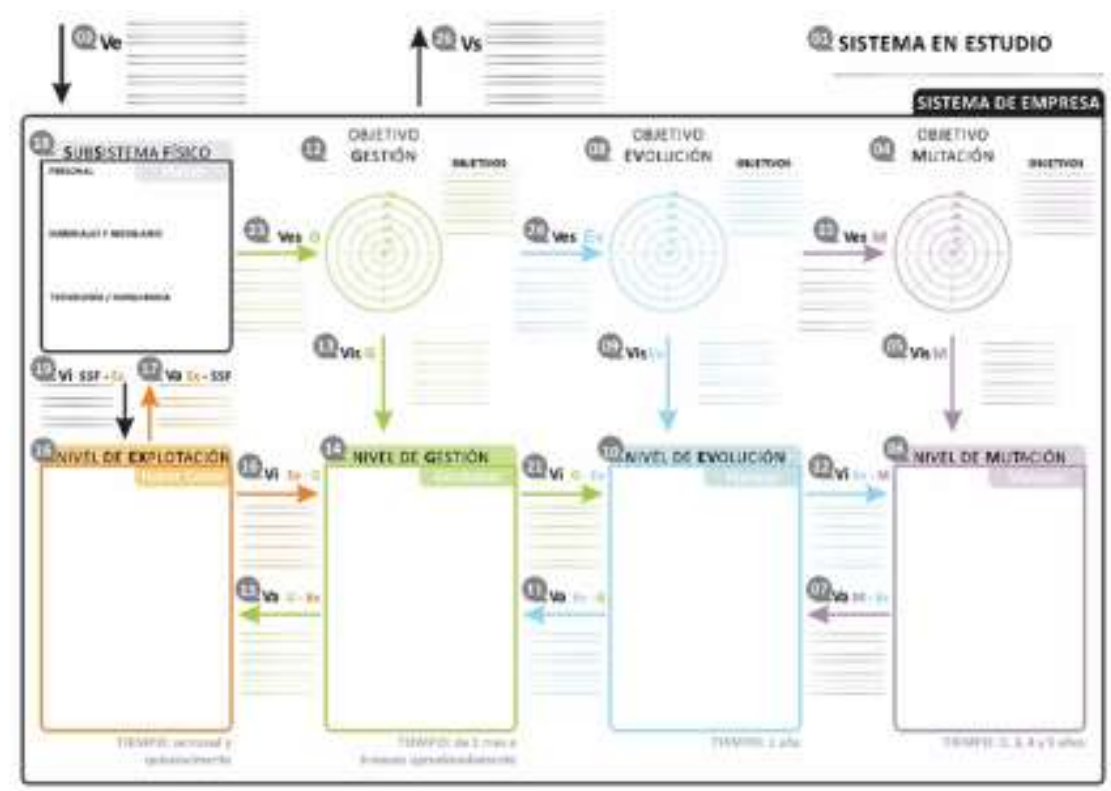

Fig 3: Tabuleiro Sistema de Empresa

O modelo de empresa é caracterizado como um Modelo de Formulacão por Objetivos que permite analisar os ciclos de retroalimentação da informação de um sistema, com objetivo de representar graficamente seus recursos humanos e materiais, e pode avaliar sua participação nos objetivos selecionados e determinar a correta definição e funcionamento dos subsistemas que participam no cumprimento destes objetivos. Assim mesmo, pode-se visualizar o grau de eficiência dos meios utilizados em função dos resultados obtidos.

O produto é utilizado para a análise, descrição, e detecção de problemas, assim como para o processo posterior de correção de desvios. Neste sentido, uma vez preenchido os tabuleiros serão possíveis estabelecer feedbacks reguladores do sistema.

Os resultados dos procedimentos são colocados na representação gráfica do cumprimento dos objetivos, que segue o formato de um diagrama polar e é utilizado para a avaliação da estabilidade de um sistema de feedback, o nível da porcentagem de cumprimento do objetivo, varia de 0 a 100 pontos, iniciando em zero no centro do círculo, limitados a cada duas dezenas por linhas pontilhadas.

Para cada objetivo cumprido é colocado um ponto no gráfico em uma das linhas pontilhadas. A cor do ponto deve seguir a cores dos objetivos de cada nível e cada objetivo será representado em uma linha. A ligação dos pontos coloridos desenhará um gráfico que será o resultado estimado do grau de cumprimento dos objetivos.

Pode-se realizar a análise comparativa da evolução mensal dos objetivos, para isso utiliza-se a Faixa de Objetivos Cumpridos que se localiza abaixo do Sistema em Estudo. Sobre esta faixa transfere-se o 
Diagrama Circular que é a representação gráfica do cumprimento dos objetivos de cada mês para uma posterior visualização e análise comparativa do cumprimento dos objetivos de gestão podendo ser a cada mês, ou bimestral como demonstrado na figura 4 abaixo.

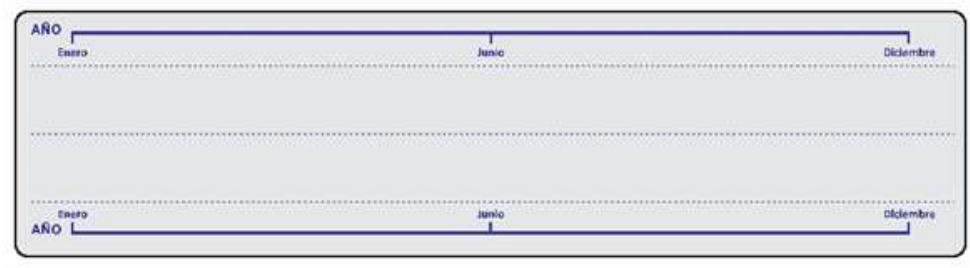

Fig 4: Faixa de Objetivos Cumpridos

\section{CONCLUSÃO}

O produto desenvolvido permite representar o problema de maneira global, permite visualizar pelo processo gráfico os pontos de retroalimentação de informação tanto dos recursos humanos e materiais, quanto das ações e fluxos de informações correspondentes às decisões necessárias para a produção de produtos e processos.

Também permite observar a evolução do entorno e sua influência na empresa para auxiliar nas ações corretoras.

A identificação de conceitos e sua representação gráfica posicionada por meio dos tabuleiros preenchidos utilizando os post its, imagens, entre outros facilita a tomada de decisões e a observação do funcionamento global da empresa focando os indicadores que se julgam apropriados.

Pelo exposto, o produto ID-Think é um depósito temporário e externo para ideias tentadas, com o qual o indivíduo precisa interagir, e essa externalização suporta o diálogo necessário que o indivíduo deve ter entre o problema e a solução, o que minimiza o estresse cognitivo ao tratar com quantidade e complexidade de conhecimentos a serem processados internamente.

Considerando que o grande diferencial de uma organização na atualidade é o conhecimento que esta possui e como gerencia este conhecimento, o produto ID-Think sendo um jogo de gestão do conhecimento, enfatiza as habilidades e atitudes do design thinker, as quais são similares as habilidades cognitivas e comportamentais do inovador, este auxilia na implementação da inovação revolucionária (disruptiva) a qual é essencial para a sobrevivência nas organizações em uma sociedade complexa. 


\section{REFERÊNCIAS}

BROWN, Tim. Change by design: how design thinking transforms organizations and inspires innovation. New York: HarperCollins, 2009.

CHESBROUGH, H. (2012). Inovação aberta: como criar e lucrar com a tecnologia. Porto Alegre: Bookman.

CROSS, Nigel, (2007). Designerly ways of knowing. Boston: Birkhauser verlag AG

DEMARCHI, Ana Paula, FORNASIER, Cleuza Bittencourt Ribas, MARTINS, Rosane Fonseca de Freitas. Design thinking no processo de gestão de design: um estudo de caso na agricultura familiar. Paper presented at the $9^{\circ}$ Congresso Brasileiro de Pesquisa e Desenvolvimento em Design. São Paulo, Brasil: October 10-14, 2010.

DEMARCHI, Ana Paula, FORNASIER, Cleuza Bittencourt Ribas, MARTINS, Rosane Fonseca de Freitas. Strategic Integrator Design Management model enhanced. Paper presented at the 3rd int. Conf. on integration of design, engineering \& management for innovation. Porto, Portugal: Setembro, 2013.

DEOS, Luciano, e MONTEIRO, V. Protifólio Brasil: Gad’design. São Paulo: J.J. Carol, 2004.

DYER, Jeff, GREGERSEN, Hal, e CHRISTENSEN, Cleyton. The innovator's DNA: Mastering the five skills of disruptive innovators. Havard: Havard Bussiness Review Press, 2011.

FIRESTONE, Joseph M. e McELROY, Mark . Key Issues in new knowledge management. Burlington: Butterworth-Heinemann, 2003.

GROS, Begoña, De la cibernética clásica a la cibercultura: herramientas conceptuales desde donde mirar el mundo cambiante. Universidad de Barcelona, España, 2001. [En línea] Available at: http://campus.usal.es/ teoriaeducacion/rev_numero_02/n2_art_gros.htm [Último acceso: 03 diciembre 2013].

HERNANDIS, Bernabé. Desarrollo de uma metodologia sistêmica para el diseño de produtos industrials. Tesis Doctoral no publicada, Valencia, Universidad Politécnica de Valencia, 2003.

ILIPINAR, Gursel et all. Design thinking in postmodern organization. In: International DMI education conference, anais... France, April 2008.

LOCKWOOD, Thomas, (2009). Design thinking: Integrating innovation, customer experience, and brand value. New York: Allworth Press.

McELROY, Mark W. The New Knowledge Management: complexity, learning and sustainable innovation. Burlington: Butterworth-Heinemann, 2003

NONAKA, Ikugiro, e TAKEUSHI, Hirotaka. Criação de conhecimento na empresa. R J: Campus, 1997. 


\section{AGRADECIMENTOS}

Gostaríamos de agradecer à Universidade Estadual de Londrina a oportunidade de estarmos desenvolvendo essa pesquisa, disponibilizando tempo e local para tanto e a Capes que oferece apoio científico e financeiro a este projeto. 


\section{Capítulo 13}

\section{doi $10.37423 / 210403773$}

\section{A EXPERIÊNCIA DO USUÁRIO NO PROCESSO EVOLUTIVO DO DESIGN}

Renato do Nascimento Oliveira

Carlos Dias Limeira

José Guilherme Santa Rosa

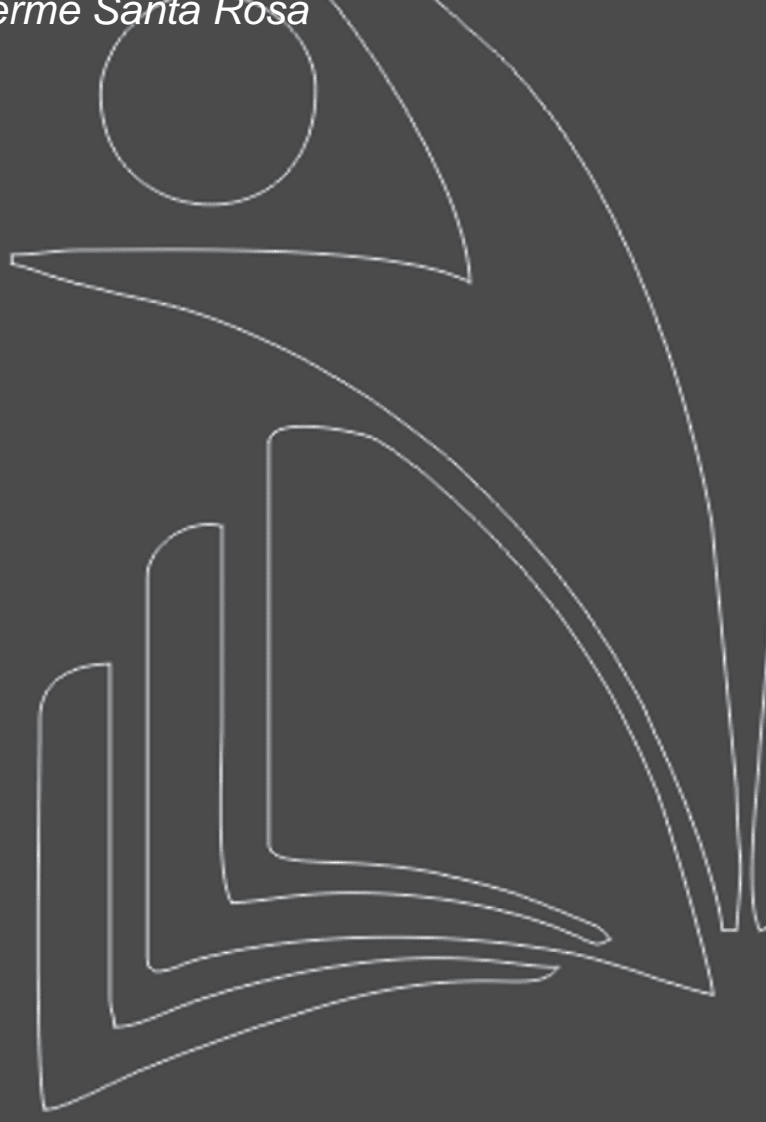

Universidade Federal do Rio Grande do Norte

Universidade Federal do Bio Grande do Norte

Universidade Federal do Río Grande do Norte 


\section{A Experiência Do Usuário No Processo Evolutivo Do Design}

Resumo: As transformações sociais, econômicas e tecnológicas ocorridas na passagem da era industrial à pós-industrial, acabaram por redefinir o foco de intervenção do design, que passa dos produtos para as experiências dos usuários, visando atender as suas necessidades e inserindo-os como sujeitos ativos no processo de design. A partir de um levantamento bibliográfico interdisciplinar, o presente trabalho aborda como a experência do usuário passou a ser contemplada dentro do processo evolutivo do design. Concluiu-se que a experiência do usuário, assim como o conceito de design são processos mutáveis, frutos da evolução de filosofias projetuais, tecnologias, e contextos sócioeconômicos, em que seus significados são construídos tanto pelos designers que pensam a solução quanto pelos usuários que a experienciam.

Palavras-chave: Design, Experiência do Usuário, Design Emocional 


\section{A Experiência Do Usuário No Processo Evolutivo Do Design}

\section{INTRODUÇÃO}

Do perído industrial até a atualidade o design passou por diferentes momentos acompanhados por sucessivas transformações no cenário socio-econômico e tecnológico que ocasionaram constantes redefinições conceituais e a expansão do seu foco de intervenção. O curso dessas transformações é marcado por reformulações nos modelos organizacionais da indústria, pelo advento das novas tecnologias, e a busca por competitividade de mercado, que impulsionaram sucessivas mudanças de estágios econômicos em que, no contexto atual, denominado por Pine e Gilmore (1998) como "economia da experiência", ocorre um forte estímulo ao desenvolvimento de pesquisas na área do design, por meio do emprego de teorias e métodos projetuais, como o Design Emocional (Emotional Design), e o Design para experiência (Experience Design), com foco em conhecer e atender às necessidades de um usuário mais interessado em viver experiências, do que propriamente na aquisição de produtos.

\section{DESIGN, SOCIEDADE E ECONOMIA}

Durante a primeira metade do século XX, segundo Cardoso (2008), houve a predominância de uma tendência essencialmente funcionalista no design, popularizando o mote "a forma segue a função" que buscava priorizar a visão utilitária dos artefatos na relação usuário-produto, em que a estética dava suporte a tal diretriz. Neste período, a área do design assumiu uma posição mais centralizadora, levando os designers a projetarem de forma indutiva e descontextualizada de cenários de uso individuais, sendo influenciados por um contexto de desenvolvimento tecnológico incipiente marcado pela ausência de pesquisas com os usuários.

Ainda para Cardoso (2008), é possível perceber mesmo em transição, a partir do início da década de 1930, um ganho de importância do valor simbólico dos produtos que culminou para o advento da prática do styling, estratégia mercadológica praticada pela indústria visando impulsionar a venda dos produtos a partir de sua aparência, em um contexto marcado pela restruturação econômica após a quebra da bolsa de valores americana de 1929. O styling ficou marcado como uma filosofia que se opunha ao funcionalismo, atraindo o consumidor pela estética dos produtos, que muitas vezes tentavam disfarçar limitações e ausências de ganhos funcionais para os usuários, e contribuiu para a popularização do design como recurso estético.

A partir dos anos 1960, com o desenvolvimento tecnológico e de pesquisas de marketing realizadas com consumidores, começa a haver um esforço generalizado das empresas em desenvolver produtos 


\section{A Experiência Do Usuário No Processo Evolutivo Do Design}

mais adaptados às necessidades e desejos individuais dos usuários, que tornam-se cada vez mais exigentes. Nesse cenário, segundo Freire (2009), ocorrem tentativas mais consistentes em integrar os usuários ao processo de design com o emprego de técnicas qualitativas, como a pesquisa etnográfica e grupos motivacionais. Como resultado, houve uma oferta cada vez maior de produtos diversificados que visavam atender diferentes usuários e contextos de uso específicos.

No âmbito sócio-econômico, a crescente valorização simbólica dos produtos demarca o início de um período de homogeneização das características estruturais do produto como diferencial mercadológico, configurando o surgimento de um cenário no qual os serviços emergem como nova prática competitiva. Para Pine e Gilmore (1998), assim como os produtos, os serviços também acabam por ingressar em um mesmo processo homogeneizador, que culmina em um novo estágio econômico, denominado pelos supracitados autores de "economia da experiência". Nesse cenário, a oferta da experiência surge como um novo diferencial mercadológico, fazendo surgir investimentos no design centrado nas experiências dos usuários, e diferindo assim dos estágios anteriores que focavam primordialmente a aquisição dos produtos pelos usuários.

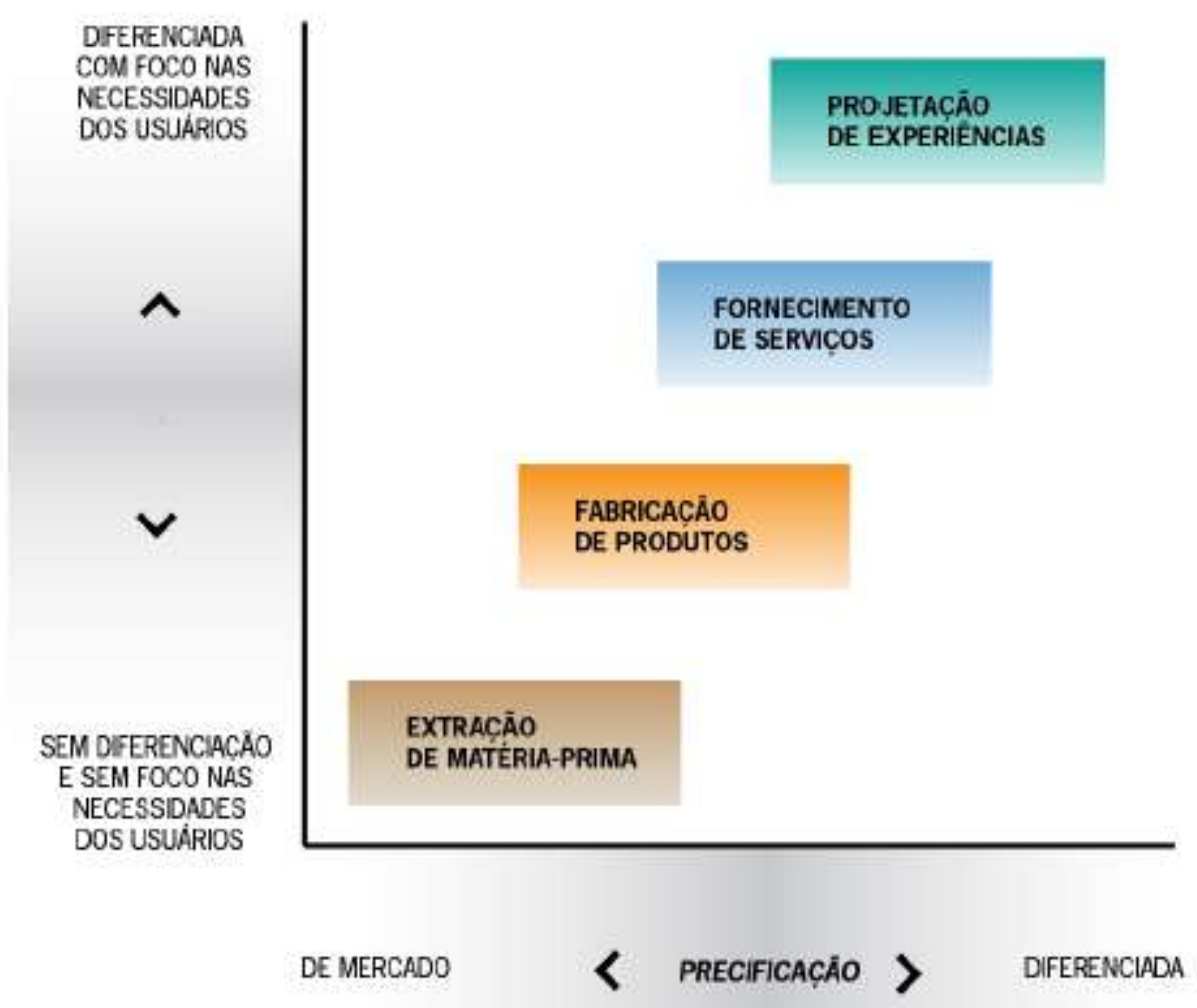

Figura 1 - Progressão do valor econômico na era pós-industrial.

Fonte: Adaptado de Pine e Gilmore (1998). 


\section{A Experiência Do Usuário No Processo Evolutivo Do Design}

A mudança de cenário econômico (Figura 1), denominada por Pine e Gilmore (1998) de "Progresssão do Valor Econômico", levou as empresas a adotarem uma nova postura, partindo de um cenário no qual a centralidade estava na oferta de produtos e serviços comoditizados caracterizado por um baixo nível de competitividade de mercado (em que o único diferencial seria o preço) e sem foco nas necessidades dos usuários consumidores, para um novo cenário fundamentado na projetação de experiências como estratégia mercadológica para a geração e aumento do diferencial competitivo com foco nas necessidades dos usuários.

Esses acontecimentos de ordem social, econômica e tecnológica estão relacionados com a mudança da visão de mundo e dos padrões comportamentais dos indivíduos, caracterizando um sujeito pósmoderno orientado a um ethos mais teatral, do brincar/jogar (RIFKIN, 2001), que busca experiências estimulantes para satisfazer os seus sonhos, influenciando e sendo influenciado pelo mundo que o cerca e pelo impacto das experiências materiais e afetivas que ajudam por criar sua própria identidade. Nesse novo estágio em que as necessidades subjetivas dos usuários tornam-se essenciais, observa-se, também, uma mudança de foco no papel dos designers, que além de criadores de formas e significados, buscam transformar sonhos em realidade, atuando como verdadeiros viabilizadores de experiências.

Com o intuito de contemplar as novas práticas de mercado, assim como as novas exigências e preocupações do sujeito pós-moderno, pesquisas com usuários no design surgem com o intuito de melhor compreender a experiência subjetiva e afetiva da relação usuário-produto. Toneto e Costa (2001) apontam que a partir dos anos 1990, passa a ocorrer uma investigação científica das emoções e a sua influência no comportamento dos usuários, possibilitando o surgimento de produtos mais adaptados às necessidades e desejos dos mesmos.

\section{A EXPERIÊNCIA DO USUÁRIO}

A experiência permeia a vida humana em todos os aspectos, em que para Dewey (1980), constitui-se fruto da interação de pessoas com o contexto em que vivem. Nesse sentido, o fenômeno da experiência sempre existiu, e segundo Ferreira (2011), está intimamente ligado aos cinco sentidos humanos, que por sua vez, interagem com a cognição do sujeito em atividades cotidanas.

No âmbito do design, para Mclellan (2000), o foco nas experiências começa a figurar de forma mais contundente em projetos realizados a partir dos anos 1990, com a emergência da "economia da experiência". Nos períodos anteriores, as abordagens refletiam produtos ou serviços primordialmente 


\section{A Experiência Do Usuário No Processo Evolutivo Do Design}

voltados para as suas características estruturais (forma e função) como por exemplo os relógios, que durante muito tempo, para Cardoso (2012) foram tratados como objetos limitados a sua função de uso, sendo hoje convertidos em elementos de moda customizados que tentam satisfazer os desejos individuais dos consumidores, revelando assim uma preocupação sobre experiência de uso e respostas emocionais dos usuários tão determinantes quanto a preocupação com materiais e processos de fabricação.

Para Hartson e Pardha (2012) a experiência do usuário (user experience) é a totalidade do efeito ou efeitos sentidos internamente por um usuário como resultado da interação com um dado ambiente ou contexto de uso. Além dos fatores internos humanos, de acordo com Unger e Chandler (2009), a experiência do usuário é influenciada por outros elementos externos como as pessoas e objetos que um individuo podem interagir através dos seus sentidos, bem como as atividades realizadas nesse contexto.

Em nossa experiência com produtos podemos satisfazer algumas necessidades físicas e psíquicas, sendo que as interações oriundas dessa relação homem-produto, para Hekkert (2007), podem acontecer em diversos níveis:

- Interação instrumental - em que o indivíduo interage com um produto para realizar uma tarefa específica (ex.: utilizar o controle remoto da televisão para verificar a programação);

- Interação não-instrumental - em que o indivíduo manipula o produto sem fins práticos (ex.: admirar a textura ao acariciar um sofá);

- Interação não-física - em que o indivíduo pensa sobre o produto, lembrando experiências passadas ou antecipando futuras experiências (ex.: imaginar como o novo sistema de computador funciona).

Assim, para Desmet e Hekkert (2007) a experiência do usuário com produtos pode ser entendida não como uma propriedade do produto (passível de manipulação pelo designer) mas sim como o resultado da interação do usuário com o mesmo, abrangendo além da interação instrumental ligada a facilidade de uso (usabilidade), percepções, reflexões e sentimentos na relação entre usuário e artefato. Como exposto na Figura 2, o usuário estabelece uma relação com o objeto da interação antes mesmo do contato físico, por meio expectativas e anseios, seguido pelo momento da interação e pela reflexão pós- uso. 


\section{A Experiência Do Usuário No Processo Evolutivo Do Design}

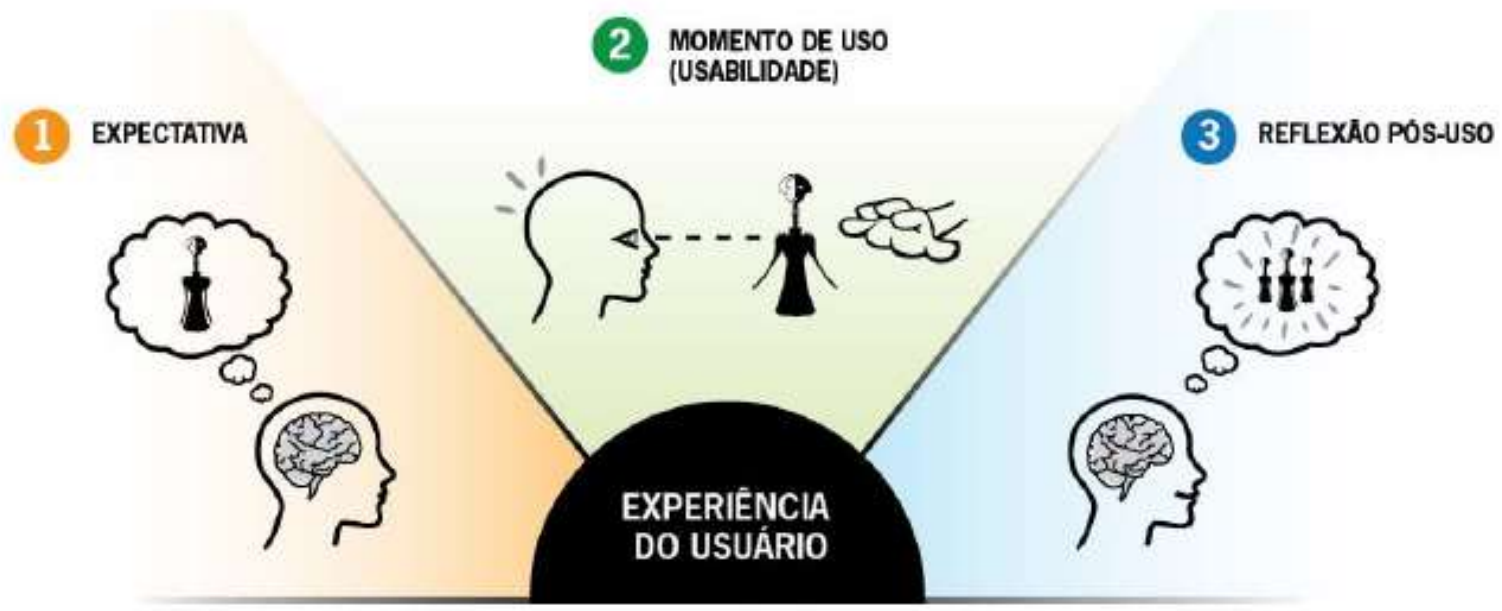

Figura 2 - Etapas da experiência do usuário.

Fonte: Autores da pesquisa realizada.

Podemos observar que enquanto a experiência do usuário se estende a todos os momentos da interação e se relaciona, fundamentalmente, com aspectos subjetivos da complexidade humana, a usabilidade, em termos funcionais-humanos (SANTA ROSA e MORAES, 2008) ocorre no momento da interação, e atende primordialmente a aspectos práticos e objetivos, correspondentes a eficácia, eficiência e facilidade de uso, e uma vez que esses aspectos são atendidos, a usabilidade favorece a experiência do usuário e colabora para proporcionar agradabilidade e a satisfação durante a interação. Portanto, no desenvolvimento de produtos interativos, como aponta Preece, Rogers e Sharp (2005) deve-se contemplar metas de usabilidade (objetivas) e metas decorrentes da experiência do usuário (subjetivas) com o intuito de projetar, significativamente, para a experiência do usuário.

\section{PROJETANDO PARA A EXPERIÊNCIA DO USUÁRIO}

Projetar produtos interativos usáveis, segundo Preece, Rogers e Sharp (2005) requer que seja levado em conta por quem serão utilizados e o seu contexto de uso. Outra preocupação importante consiste em entender o tipo de atividade que as pessoas realizam quando estão interagindo com os produtos.

Desse modo, em um projeto para a experiência do usuário, é preciso considerar um conjunto de elementos: para quem vamos projetar (é necessário conhecer especificidades correspondentes ao usuário que irá participar da experiência); o que será projetado como objeto da experiência (se é um produto, um serviço, uma interface, ou uma nova tecnologia); o objetivo da interação (como por exemplo, criar uma experiência de interação imersiva por meio de uma interface atraente e fácil de operar); onde a experiência ocorrerá (seu contexto específico de uso, seja este físico, social, 


\section{A Experiência Do Usuário No Processo Evolutivo Do Design}

tecnológico, etc.); e quando a experiência ocorrerá (considerando que, de acordo com aspectos cognitivos e emocionais do usuário, a experiência pode iniciar antes mesmo da interação).

Dada complexidade das relações entre os fatores humanos e contextos que compõem uma experiência, bem como suas características intrínsecas, pesquisas desenvolvidas no campo do Design Emocional (Emotional Design), sub-área recente do design, buscam compreender a experiência subjetiva na relação humano-produto e assim projetar com foco nas emoções.

A preocupação central do design, segundo Bonsiepe (2012), está justamente na otimização da relação usuário e produto, contribuindo para o processo de desenvolvimento do produto de forma integrada, em que, a aparência do produto não deve ser interpretada de forma especial como algo agregado, mas sim conformada com a estrutura da solução. Dese modo, por meio da aparência, o designer busca imprimir personalidade ao produto, estimulando as emoções e o comportamentos dos usuários.

Embora não sejam previsíveis nem controláveis por parte do designer, as emoções podem ser estudadas a fim de conhecer o seu impacto no comportamento dos usuários. Sendo assim, é importante esclarecer um aspecto essencial para uma compreensão do projeto de design de interação: não é possível projetar emoções em um produto. Portanto, não se pode "projetar a experiência do usuário", mas sim "projetar para a experiência do usuário".

Projetos com foco nas emoções humanas já vinham sendo desenvolvidos anteriormente na área do design porém sem a devida comprovação científica dos reais impactos causados pelos produtos em sua relação com usuários, o que acabou levando os projetistas, a trabalharem de forma arbitrária ou indutiva na tentativa de criar produtos que causassem determinadas sensações nas pessoas. $O$ estudo das emoções no design, de caráter interdisciplinar, surge portanto com o propósito de fornercer suporte aos projetos de design com foco nas experiências dos usuários, contando com contribuições de áreas como a ergonomia, a psicologia e a antropologia.

Nesse sentido torna-se esssencial envolver os usuários no desenvolvimento do projeto, com a possibilidade de investigar de forma mais direta e aprofundada a interação deste produto com pessoas por meio de testes e demais instrumentos de coleta de dados.

Durante a experiência subjetiva com o produto, as emoções dos usuários são evocadas pelos atributos ali encontrados, em que, de acordo com Norman (2008), estímulos contribuidores para o bem-estar de um usuário tendem a despertar emoções prazerosas, enquanto que aqueles considerados ameaçadores ou prejudiciais despertam emoções ruins. 


\section{A Experiência Do Usuário No Processo Evolutivo Do Design}

De acordo com Mccarthy e Wright (2000), o Design para a experiência (Experience Design), como objeto de estudo e área projetual, pode ser melhor compreendido quando analisados de forma integrada, em que necessidades humanas estão interrelacionadas com fatores tecnológicos, estéticos, organizacionais e ambientais, influenciando um ao outro, atendendo a certo nível de organização e compartilhando finalidades em comum. Para os supracitados autores, a experiência está nas relações entre as partes e deve ser entendida como um todo, abrangendo os contextos sócio-cultural e o imediato da utilização.

\section{CONCLUSÃO}

O Design evolui em consonância com as transformações que ocorrem na sociedade, e com as consequentes mudanças de percepções, comportamentos e necessidades das pessoas. Essas transformações em escala global não tem afetado a indústria de maneira homogênea, e configura um novo cenário competitivo em expansão fundamentado na projetação para as experiências dos indivíduos.

Isso exige das organizações uma readequação de seus valores e sua identidade, e na forma como se comunicam com seus clientes, levando os designers a projetarem soluções integradas, que além de contemplar as necessidades físicas e psíquicas dos usuários, possam transformar sonhos em realidade através de experiências memoráveis.

Assim, conclui-se que o conceito de design pode ser entendido como fruto/resultado do seu tempo, consequência de filosofias e contextos, que vai muito além da aplicação de princípios funcionais e estéticos, abrangendo de forma mais ampla o favorecimento de verdadeiras experiências que integrem pessoas, objetos e ambientes. 


\section{A Experiência Do Usuário No Processo Evolutivo Do Design}

\section{REFERÊNCIAS}

BONSIEPE, Gui. Design como prática de projeto. São Paulo: Blucher, 2012. CARDOSO, Rafael. Uma introdução a história do design. São Paulo: Blucher, 2008.

. Design para um mundo complexo. São Paulo: Cosac Naify, 2012.

DESMET, Pieter; HEKKERT, Paul. Framework of Product Experience. Internacional Journal of Design, vol. 1, n. 1, mar, 2007.

DEWEY, John. Experiência e Natureza; Lógica: a teoria da investigação; A arte como experiência; Vida e educação; Teoria da Vida moral. São Paulo: Abril Cultura, 1980.

FERREIRA, Nicholas Gabriel M. L. O papel da experiência na filosofia de Jonh Dewey. (2011). Filogênese, São Paulo, vol. 4, n.ㅇ 2, p. 147-156, 2011.

FREIRE, Karine. Reflexões sobre o conceito de design de experiências. Strategic Design Research Journal, n.2 (1), p. 37-44, jan-jun, 2009.

HARTSON, Rex; PARDHA, Pyla S. The Ux Book. Process and guidelines for ensuring a quality user experience. Waltham: Elsevier, 2012.

HEKKERT, Paul. Design Aesthetics: Principles of Pleasure in Product Design. Psychology Science, vol. 48, n. 48, p. 157-172, 2006.

MCLELLAN, Hilary. Experience Design. Cyberpsycology \& Behavior, vol. 3, n.o 1, p. 59-69, 2000.

MCCARTHY, John; WRIGHT, Peter. Technology as Experience. Cambridge, MA: MIT Press, 2004.

NORMAN, Donald Arthur. Design emocional: por que adoramos (ou detestamos) os objetos do dia-adia. Rio de Janeiro: Rocco, 2008.

PINE, B. Joseph; GILMORE, James H. Welcome To The Experience Economy, Harvard Business School Review. 1998.

PREECE, Jeniffer; ROGERS, Yvonne; SHARP, Helen. Design de interação: além da interação homemcomputador. Porto Alegre: Bookman, 2005.

RIFKIN, Jeremy. A era do acesso. São Paulo: Makron Books, 2001.

SANTA-ROSA, José Guilherme; MORAES, Anamaria de. Avaliação e projeto no design de interfaces. Teresópolis, RJ: 2AB, 2012.

TONETTO, Leandro; COSTA, Filipe. Design Emocional: conceitos, abordagens e perspectivas de pesquisa. In Startegic Design Research Journal, 4 (3): 132-140 Setptember- December 2011.

UNGER, Russ; CHANDLER, Carolyn. O Guia para projetar UX. A experiência do usuário (UX) para projetistas de conteúdo digital, aplicações e web sites. Rio de Janeiro: Alta Books, 2009. 


\section{Capítulo 14}

\section{doi $10.37423 / 210403774$}

\section{A PRESENÇA FEMININA NOS CURSOS DE ENGENHARIA: UM ESTUDO QUANTITATIVO E QUALITATIVO}

Joseline Melo Corrêa

Elen Priscila de Souza Lobato

Flávia de Cássia Martins Ribeiro

Isabelle da S. de Lima

Wellington da Silva Fonseca

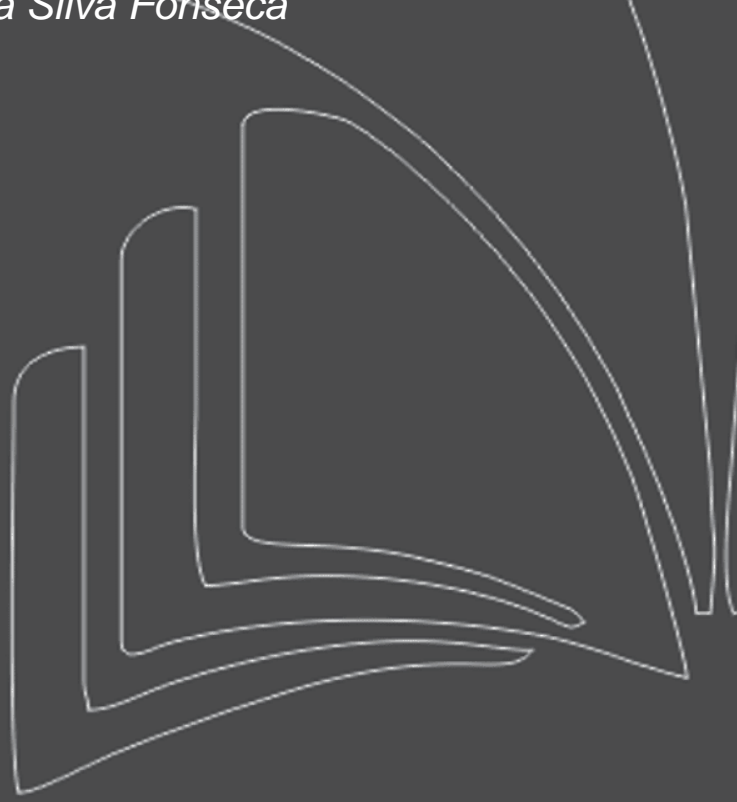

Universidade Federal do Pará

Universidade Federal do Pará

Universidade Federal do Pará

Universidade/Federal do Pará

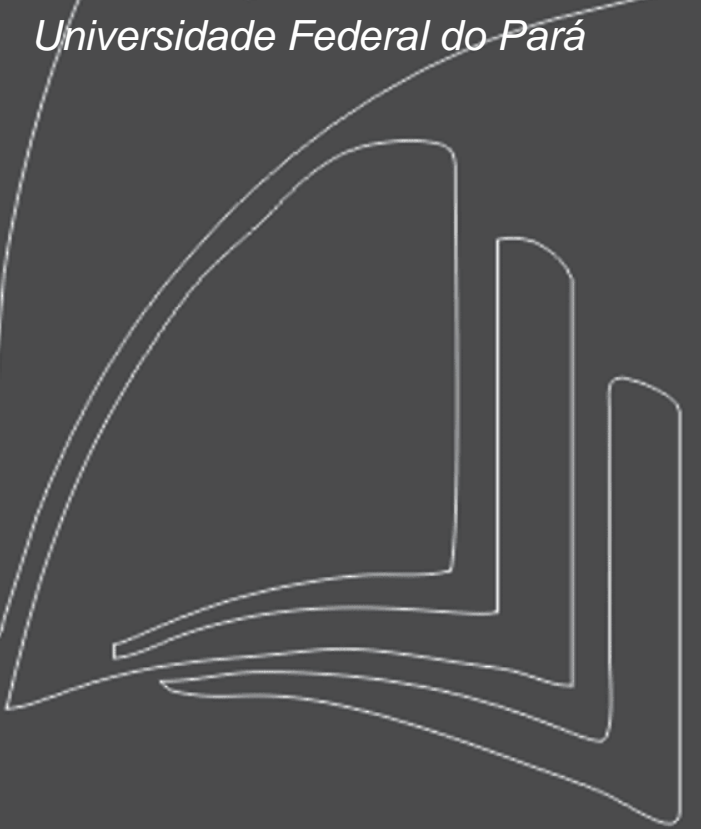


Resumo: Por todo o mundo, a desigualdade de gênero está presente na história da educação, onde as mulheres são recorrentemente excluídas ou têm sua participação pouco valorizada. No presente, este cenário tem sofrido mudanças, a presença feminina se mostra majoritária nas Instituições de Ensino Superior (IES), entretanto não há uma igual distribuição e representatividade destas mulheres em cursos de ciências exatas e engenharias. Dados mostram que o ingresso de alunas nas áreas de engenharia vem crescendo ano após ano, mas de forma lenta e gradual. Portanto, é necessário definir estratégias de desenvolvimento no campo educacional para estimular a presença feminina em cursos superiores na área de engenharias. Com esse objetivo, surgiu o projeto "Mulheres na Ciência e Engenharia: Conquistando espaço na área tecnológica" do Laboratório de Engenhocas na Universidade Federal do Pará. O projeto busca promover palestras, encontros, oficinas, visitas técnicas, entre outras atividades que possam mostrar o dia-a-dia de uma aluna desta área. Este artigo busca contribuir para a discussão, a partir de uma análise teórica e quantitativa a entrada de mulheres nos cursos de Engenharia do Instituto de Tecnologia (ITEC) da UFPA, no período de 2005 a 2018.

Palavras-chave: Mulheres. Mulheres na Engenharia. Mulheres no Ensino Superior. 


\section{INTRODUÇÃO}

A quarta revolução industrial que está acontecendo no recente cenário, irá evidenciar ainda mais a desigualdade de gênero existente no mercado de trabalho. Segundo o relatório "O futuro do trabalho", do Fórum Econômico Mundial, os novos cargos irão exigir trabalhadores com habilidades de projetar, construir e trabalhar juntamente com sistemas tecnológicos, ou seja, áreas que são predominantemente masculinas, tendo em vista que os homens ainda dominam as engenharias, ciência da computação e a matemática (SCHWAB, 2016).

Contrapondo a predominância masculina nessas áreas, o terceiro objetivo do milênio visa promover a igualdade entre os sexos e a autonomia das mulheres, superando as diferenças entre os gêneros e promovendo oportunidades para as mulheres ocuparem papéis cada vez mais ativos na sociedade.

Visando a promoção da igualdade, buscamos contribuir com a difusão de informações para reflexões e debates a fim de mostrar de forma quantitativa a situação do ingresso feminino nos cursos de engenharia do ITEC.

\section{MULHERES NA ENGENHARIA}

O percentual de acesso ao ensino superior no Brasil, tanto público como privado, é em sua maioria por mulheres, de acordo com dados do INEP de 2016, 57,2\% eram mulheres. Entretanto, quando se entra em detalhes nota-se discrepâncias em relação à distribuição por áreas do conhecimento. No campo da, matemática, engenharia, produção e construção a participação feminina é de apenas 3\% (IBGE, 2010).

Evidenciando este fato, veremos nos dados analisados que o número de meninas que ingressam nos cursos de engenharia da UFPA é baixo, e é ainda menor o número das que se formam. Por isso, é preciso que haja estímulo e apoio não só para o ingresso, mas também durante a graduação, para que essas alunas continuem e possam concluir seus cursos com êxito.

\subsection{INGRESSANTES}

Como já mencionado, as mulheres estão em maior número na educação superior. Entretanto, quando se observa por área do conhecimento há um baixo índice de ingresso de mulheres nas áreas das ciências, tecnologias e engenharias o que provoca um acesso desigual a profissões que possuem melhores benefícios em relação a prestígio social e remuneração. A tabela abaixo mostra dados do censo da educação superior de 2013 com relação à área geral do conhecimento e o sexo. Constata-se 
uma participação feminina de apenas 31\% nas áreas de engenharia, produção e construção e ciências, matemática e computação.

Tabela 1 - Matrículas total e percentual por área geral do conhecimento e sexo.

\begin{tabular}{c|c|c|c}
\hline $\begin{array}{c}\text { Área Geral do } \\
\text { Conhecimento }\end{array}$ & Total & Feminino\% & Masculino\% \\
\hline Total geral & 7.305 .977 & 57,2 & 42,8 \\
\hline Agricultura e Veterinária & 178.413 & 45,5 & 54,5 \\
\hline $\begin{array}{c}\text { Ciências Sociais, } \\
\text { Negócios e Direito }\end{array}$ & 2.958 .690 & 57,0 & 43,0 \\
\hline $\begin{array}{c}\text { Ciências, Matemática e } \\
\text { Computação }\end{array}$ & 441.406 & 31,0 & 69,0 \\
\hline Educação & 1.371 .767 & 72,7 & 27,3 \\
\hline $\begin{array}{c}\text { Engenharia, Produção e } \\
\text { Construção }\end{array}$ & 1.017 .328 & 31,5 & 68,5 \\
\hline Humanidades e Artes & 163.090 & 55,8 & 23,5 \\
\hline $\begin{array}{c}\text { Saúde e Bem-Estar } \\
\text { social }\end{array}$ & 984.769 & 76,5 & 39,3 \\
\hline Serviços & 166.767 & 60,7 & 54,1 \\
\hline Não corresponde a ABI & 23.747 & 45,9 & \\
\hline
\end{tabular}

Fonte: Censo da Educação Superior - Inep/Deed (INEP,2015, p. 25)

\subsection{CONCLUINTES}

No cenário nacional o número de mulheres concluintes do ensino superior tem se aproximado do número de concluintes homens. É possível fazer a análise dos dados do Inep que correspondem aos anos de 2009 a 2012. Desse modo podemos perceber um equilíbrio de gênero dos concluintes na Educação superior a nível Nacional.

Por outro lado, a partir dos dados obtidos pelo Centro de Registro e Indicadores Acadêmicos (CIAC) na UFPA, podemos observar que a quantidade de mulheres que ingressaram é menor do que a quantidade de ingressantes homens. Esse número difere apenas no curso de engenharia de alimentos, onde o número de mulheres que ingressaram nesse período foi muito superior ao de homens e consequentemente teve o maior número de concluintes em um curso de Engenharia na UFPA. 
Figura 1 - Concluintes Institutos Federais X Gênero 2009-2012.

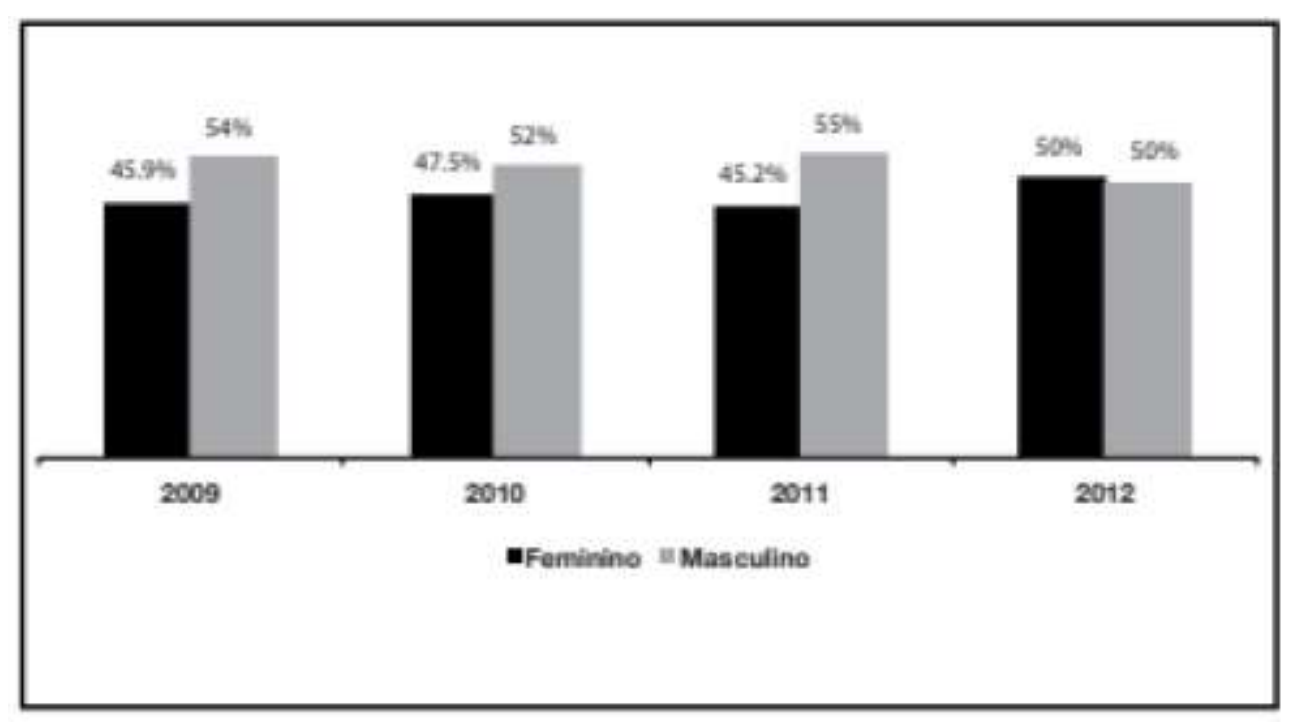

Fonte: Inep/Censo da Educação Superior

\section{PROCEDIMENTO METODOLÓGICOS}

Buscando contribuir com a discussão sobre o atual cenário da presença feminina nos cursos de engenharia da UFPA, foram solicitados dados quantitativos juntamente ao CIAC, órgão da UFPA, responsável pelo monitoramento do quantitativo de discentes matriculados, ingressantes, evadidos e diplomados. E também, foi aplicado um questionário às calouras de engenharias da UFPA, que participaram do evento de recepção do projeto "Mulheres na Ciência e Engenharia: conquistando espaço na área tecnológica", e foram realizadas entrevistas com alunas dos cursos de engenharia da computação da Universidade e do curso de física do Instituto Federal, como forma de análise qualitativa.

\section{ANÁLISE E RESULTADOS}

\subsection{ANÁLISE QUANTITATIVA}

Os dados a seguir são do período de 2005 a 2018, referentes à quantidade de alunos que ingressaram nos cursos de engenharia na Universidade e as que se formaram nos respectivos cursos, também é feita uma separação por turnos, manhã (M), tarde (T) e noite (N). 
Figura 1 - Ingressantes dos cursos de Engenharia/UFPA

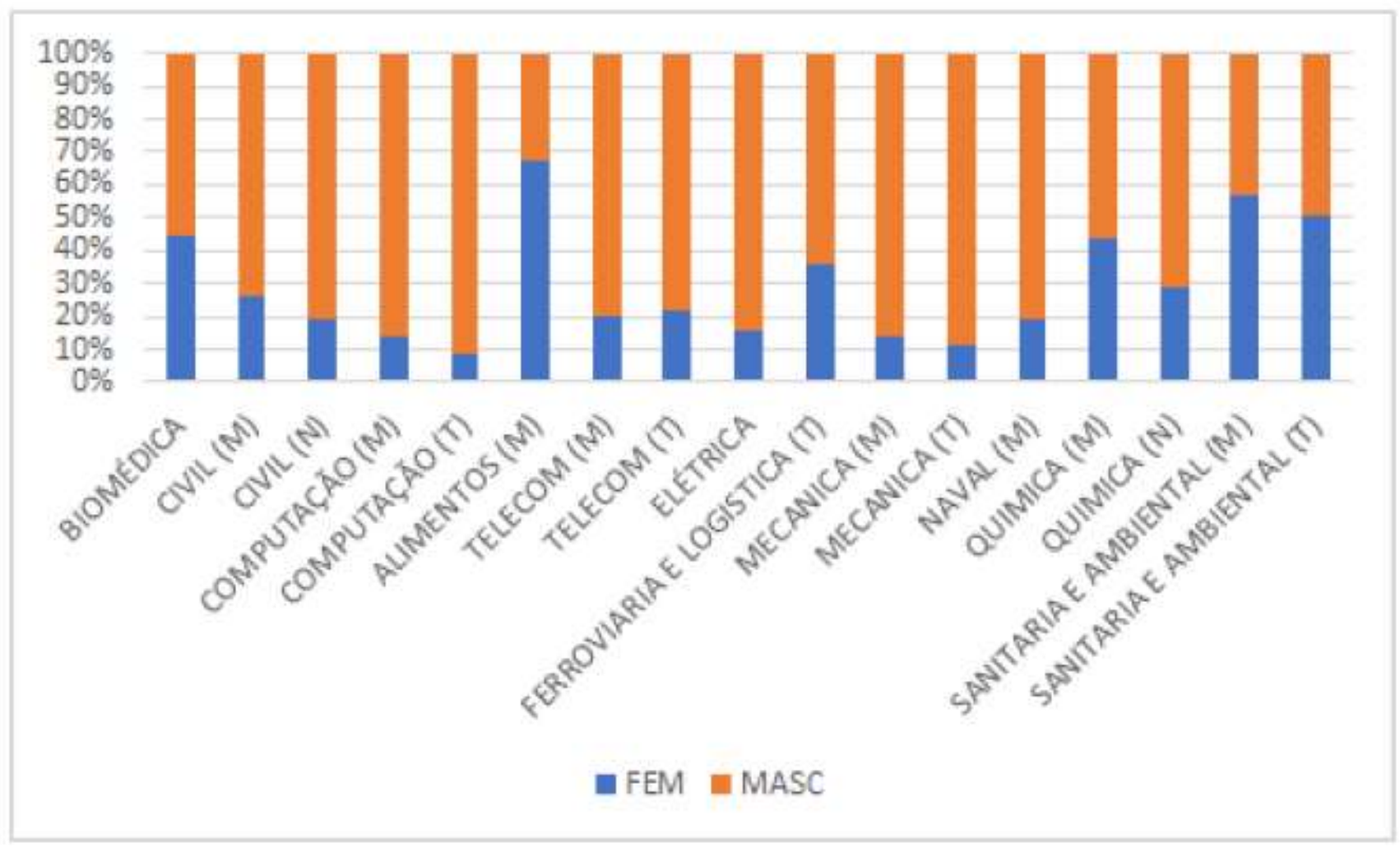

Fonte: CIAC

Ao analisar o gráfico acima percebe-se que a quantidade de mulheres que entram nas engenharias é inferior se comparado com a quantidade de homens. O curso de engenharia da computação, turno tarde, por exemplo, apresenta uma taxa de $8,65 \%$ de mulheres contra $91,35 \%$ de homens. Engenharia Mecânica, turno tarde, apresenta $11,54 \%$ de mulheres ingressantes e $88,56 \%$ de homens. Tais cursos apresentam as menores taxas de participação feminina de 2005 até 2018 . O curso de Engenharia de Alimentos, turno manhã, é o único que apresenta um maior percentual de mulheres matriculadas (66,98\%). Tais dados revelam que, apesar da Engenharia ser uma área dominada por homens, ela também conta com participação feminina, e o quadro de predomínio masculino está sendo revertido, mesmo que lentamente.

No gráfico abaixo, é apresentado os concluintes das Engenharias da UFPA, divididos por curso e turno. 
Figura 2: Formandos dos cursos de Engenharia/UFPA

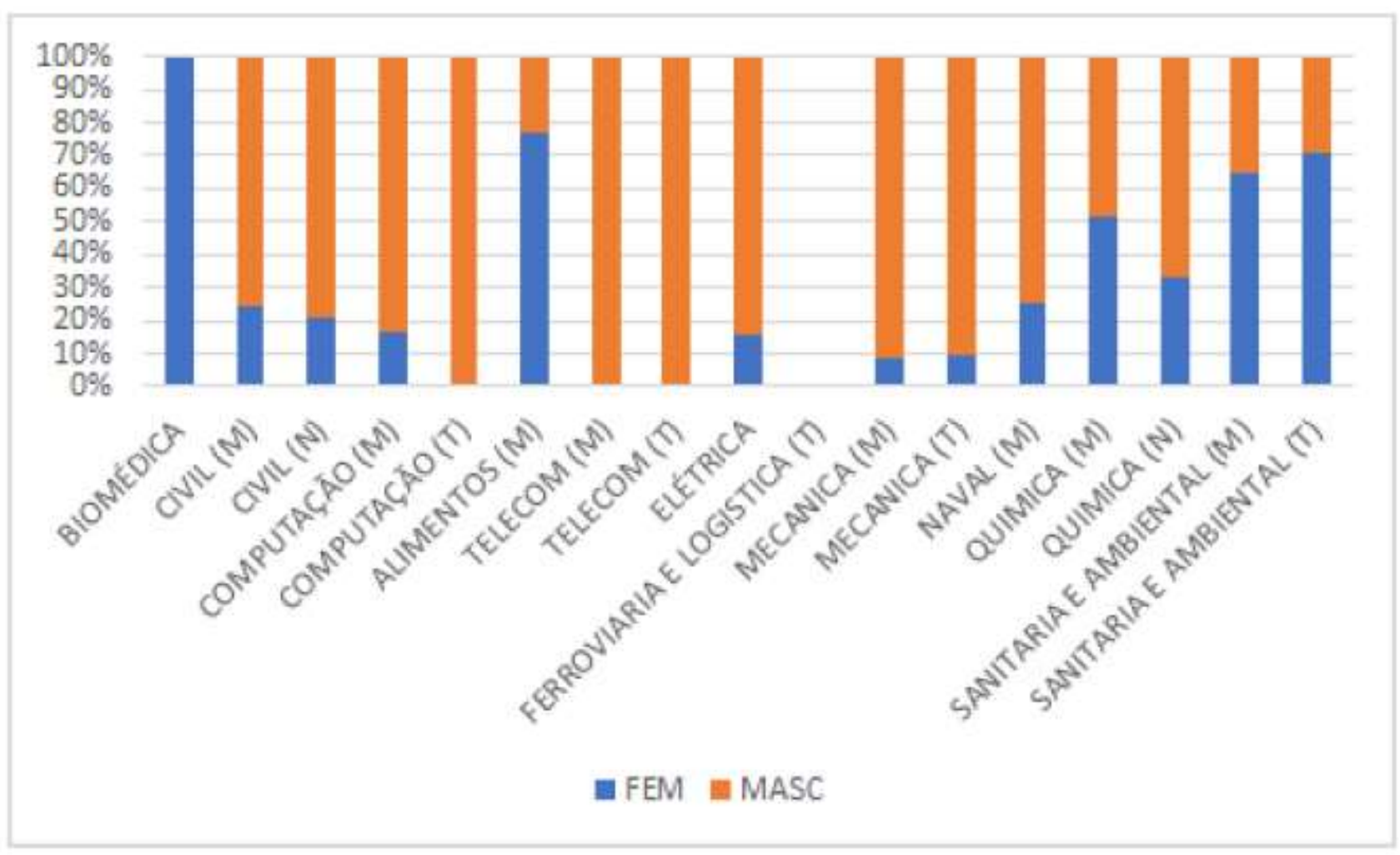

Fonte: $\mathrm{CIAC}$

Imediatamente percebe-se que a taxa de mulheres que se formam é maior que as dos homens em diversos cursos, como Engenharia de Alimentos, turno manhã, com 77,12\% de mulheres formadas. Além disso, há também Engenharia Biomédica, onde formaram-se apenas mulheres. Não obstante, apesar dos dados positivos, o número de mulheres que se formam comparados com as que entram, ainda é pequeno. Engenharia Biomédica, por exemplo, ainda que tenham se formado só mulheres, a taxa comparada às ingressantes é baixíssima: $0,85 \%$ das mulheres que entraram se formaram. Além de que, ainda se encontram engenharias com baixos índices de mulheres formadas: Engenharia mecânica, de ambos os turnos, apresentam mais de $90 \%$ de homens formados. Também há cursos em que nenhuma mulher se forma: Engenharia de Telecomunicações, ambos os turnos, é o exemplo.

Os cursos onde não há colunas plotadas são cursos em que o CIAC não forneceu informações sobre os formandos.

\subsection{ANÁLISE QUALITATIVA}

\section{Questionário}


Esse ano o projeto "Mulheres na Ciência e Engenharia" promoveu um evento para a recepção das calouras dos cursos de engenharia, aprovadas no processo seletivo da UFPA 2018. Durante o evento foi aplicado um questionário impresso para as participantes, o mesmo era composto por 5 perguntas, que deveriam ser respondidas de forma descritiva. No total, 14 meninas participaram, todas foram aprovadas em um dos seguintes cursos de engenharia: biomédica, civil, computação, elétrica, mecânica e telecomunicações. O questionário era composto das seguintes perguntas e obteve, em síntese, as seguintes respostas:

\section{O que incentivou você a optar pelo curso de engenharia?}

A maioria respondeu que gosta e tem afinidade pela área de exatas e tecnologia.

\section{Você tem incentivo da sua família para cursar engenharia?}

Das 14 meninas, apenas uma não tem o incentivo da família para ingressar ao curso de Engenharia.

\section{Você considerava a área de exatas masculina?}

Algumas não consideram, apenas acham que precisa de mais incentivo para que o gênero feminino tenha interesse e perca algumas mistificações; outras acham que sim, é uma área masculina, mas que as mulheres vêm conquistando o seu espaço.

4. O que elas consideram importante fazer para incentivar as mulheres a escolherem os cursos de exatas e afins?

Para a maioria é importante realizar projetos como este para a divulgação das mulheres nas exatas; realizar palestras falando da área, juntamente com outras mulheres já engenheiras; mostrar a importância da participação feminina nas escolas, principalmente ensino médio e cursinho; abrir as portas das universidades para visitação; e uma delas disse que é primordial fazer com que as mulheres se sintam acolhidas nesse cenário.

\section{E em uma escala de 0 a 10, qual a importância da mulher nos cursos de exatas?}

Todas responderam que 10 .

Além das 14 garotas, um menino também respondeu ao questionário e ele ressalta que apesar da sociedade considerar a engenharia uma área masculina, a área é para todos que tiverem interesse, independentemente de gênero e estimou com nota 10 a importância da presença feminina.

A partir desse questionário é possível subentender que as meninas que possuem uma habilidade com os números e gostam de tecnologia, optam, sim, por algum curso de engenharia e a maioria conta com 
o apoio da família. Percebemos também que, metade das meninas que estão cursando engenharia, ainda acham que é um curso tido como masculino. E todas consideraram a importância da mulher nos cursos de exatas com a nota máxima de 10.

\section{Entrevistas}

Foram realizadas entrevistas com algumas alunas que tiveram a oportunidade de conhecer o projeto. Seus verdadeiros nomes serão substituídos por codinomes de flores, como forma de preservar suas identidades. Margarida, em entrevista dada especialmente para o projeto, ao ser perguntada sobre como conheceu o projeto e qual a importância do mesmo na escolha do seu curso disse:

"Conheci o Projeto Mulheres na Engenharia através do comitê científico na
escola pública onde eu estudava (2016/2017), tendo como mediador o
laboratório de Engenhocas. O Projeto me ajudou a escolher os cursos que
desejava e apoiou meu interesse pela área de exatas. Optei em minha inscrição
na UFPA no Curso de Engenharia da Computação, mas infelizmente o resultado
não foi positivo, pois não consegui ingressar. Porém, havia optado pelo curso de
física no IFPA, onde eu passei nesse ano (2018) e estou cursando. Foi
fundamental as palestras que tive no projeto, pois pude ver com exemplos reais
como seria estar em um curso de exatas." (Margarida) Outro caso especial, são das alunas de graduação, Rosa e Orquídea, que foram convidadas para palestrar no evento de lançamento do projeto, em 2017, falando sobre seus cursos. Elas gostaram tanto da causa, que desde então, tornaram-se voluntárias e entraram para o laboratório responsável pelo desenvolvimento do projeto, onde agora participam de várias outras atividades. Orquídea destaca que sua participação no projeto foi imprescindível para que a mesma continuasse a graduação, pois se sentiu mais incentivada e motivada:

"Conhecer o projeto Mulheres na Engenharia foi uma das melhores coisas que me aconteceu durante a graduação. Graças ao projeto, me senti mais incentivada e motivada a continuar no curso, além de aprender coisas novas e viver experiências incríveis que não seriam possíveis se eu estivesse apenas na sala de aula. " (Orquídea)

As análises realizadas durante a produção do artigo nos mostraram uma perspectiva abrangente sobre o cenário da participação feminina nos cursos de engenharia da UFPA. Frisamos que ainda há a necessidade de buscarmos uma visão mais detalhada deste cenário através da expansão da pesquisa em outras variáveis relativas à família, renda, sistema de ingresso, entre diversas outras que atingem homens e mulheres de formas diferentes na sociedade, com graduandas da Universidade. 


\section{CONSIDERAÇÕES FINAIS}

A partir dos dados obtidos através do CIAC, após o estudo quantitativo podemos apresentar a situação da presença feminina nos cursos de engenharia do ITEC, que é pequena e não uniforme, de forma que em certos casos, como o de engenharia de alimentos, a presença de mulheres é maior do que a de homens, e em outros como o de engenharia de telecomunicações não houve a formação de nenhuma mulher. Desde 2017, ano do lançamento do projeto na UFPA no campus de Belém, o mesmo ganhou força e reconhecimento dentro e fora da universidade. Contando com o apoio, de professoras e professores da academia. Uma das professoras apoiadoras do projeto, destaca a importância da criação de uma rede de apoio entre as alunas, para o fortalecimento da presença feminina nos cursos de engenharia, rede esta que tem crescido mediante a divulgação do projeto e a cada novo evento promovido pelo mesmo. Tais eventos são ansiosamente aguardados, tanto pelas alunas do ensino médio, quanto pelas graduandas em engenharia, pois o mesmo é visto como mais um momento de troca de experiências, busca de inspiração, e criação de novos vínculos através do "networking" propiciado pelo encontro.

Com a produção deste estudo, buscamos despertar o interesse para a situação ao qual o instituto alvo se encontra e promover a discussão da participação feminina em um meio acadêmico que ainda é tido como masculino, e também contribuir para uma sociedade onde a diferença de gênero não seja fator de desigualdade em nenhuma esfera da vida.

\section{AGRADECIMENTOS}

Os autores agradecem o professor orientador pelo incentivo e apoio. Agradecemos, a Universidade Federal do Pará, a Pró-reitora de Extensão (PROEX), ao Centro de Registros e indicadores acadêmicos (CIAC) e as escolas da Rede Pública por abrirem as portas para divulgação do projeto. Agradecemos também, os laboratórios LCADE e LSE e aos nossos colegas de graduação que nos ajudaram nas palestras e na revisão bibliográfica. 


\section{REFERÊNCIAS}

Livros:

SCHWAB, Klaus. A quarta revolução industrial. 1a edição, São Paulo: EDIPRO, 2016.

Monografias, dissertações e teses:

NASCIMENTO, Jaqueline Dourado do. Mulheres nos cursos de engenharia da UFBA: Um estudo sobre o acesso e desempenho. 2017. 269 f. Tese (Doutorado) - Faculdade de Educação, Universidade Federal da Bahia, Salvador, 2017.

Publicações periódicas consideradas em parte (suplementos, fascículos, números especiais:

A MULHER NO ENSINO SUPERIOR DISTRIBUIÇÃO E REPRESENTATIVIDADE. Cadernos do GEA: Andreia Barreto. Rio de Janeiro. n. 6, jul. - dez, 2014.

Internet:

Mulheres são maioria na educação superior. Disponível em: http://portal.inep.gov.br/artigo//asset_publisher/B4AQV9zFY7Bv/content/mulheres-sao-maioria-na-educacao-superiorbrasileira/21206. Acesso em: 10 mai. 2018.

INEP/MEC. Dados sobre o censo da educação superior. Disponível em:

http://portal.inep.gov.br/web/censo-da-educacao-superior. Acesso em: 04 mai. 2018.

Dados e softwares abertos:

SIGAA - CIAC: Número de estudantes que ingressam na graduação (ITEC), por curso e gênero no período de 2005 a 2018, na Universidade Federal do Pará. Disponível através de solicitação ao CIAC UFPA. mai. 2018. 


\section{Capítulo 15}

\section{doi $10.37423 / 210403777$}

\section{DO DESENHO DE CRIANÇA À ILUSTRAÇÃO DO LIVRO INFANTIL}

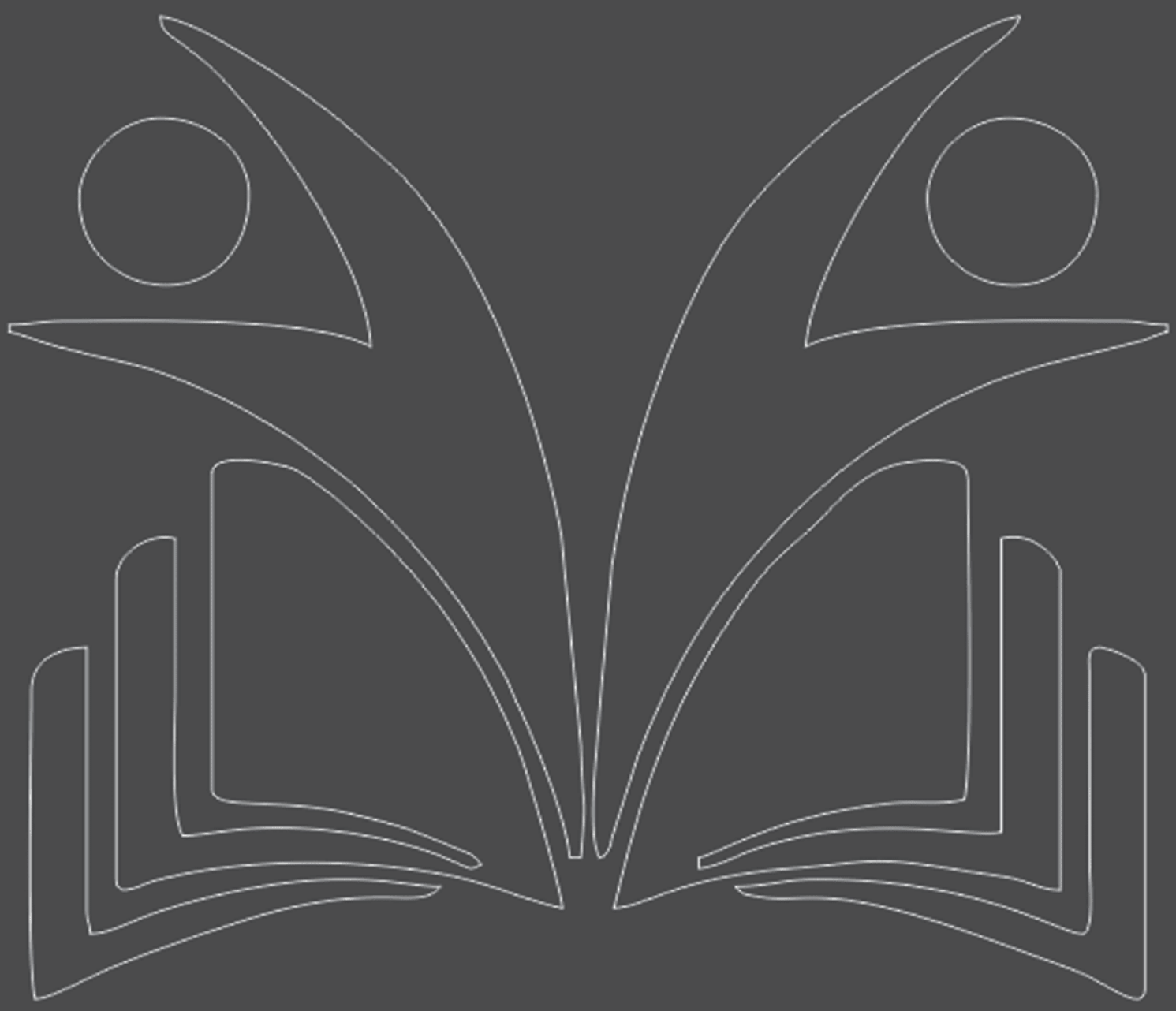




\section{Do Desenho De Criança À llustração Do Livro Infantil.}

Resumo: A proposta deste artigo é estabelecer relações entre as gêneses do desenho feito por crianças e da ilustração feita para crianças, partindo de um esquema descritivo da morfologia e do processo criativo do desenho infantil e, através deste referencial teórico, tentar expor uma análise de aspectos estéticos de cada um desses tipos de imagem. O trabalho descreve as etapas da maturação e aspectos morfológicos da mudança da linguagem visual (ícone gráfico) pela linguagem verbal escrita (símbolo gráfico); aponta afinidades ontológicas e relações cíclicas de influência entre o desenho infantil e a ilustração de livros infantis; e estabelece relações poéticas sublinhando a importância da memória no processo criativo das duas formas de expressão gráfica.

Palavras-Chave: Desenho de criança, ilustração de livros, análise estética, processo criativo. 


\section{Do Desenho De Criança À llustração Do Livro Infantil.}

\section{INTRODUÇÃO}

O presente artigo busca relacionar os desenhos infantis e as ilustrações da literatura infantil e juvenil, e tem como pano de fundo a pesquisa de mestrado concluída em 2004 (ALENCAR, 2004) e a pesquisa de doutorado iniciada em março de 2014, ambas pela PUC-Rio, que versavam sobre os dois objetos deste estudo respectivamente. Alguns conceitos resultantes dessas pesquisas permeiam este artigo como referência para uma abordagem comparativa entre processos e a busca de afinidades poéticas entre os dois tipos de imagem.

As bases teóricas utilizadas foram os estudos do desenvolvimento da criança de Jean Piaget (1968) os estudos sobre desenho infantil de Bernard Darras (1996), noções sobre o imaginário de Gilbert Durand (1994) e conceitos sobre imagens em Vilém Flusser (1985, 2007). As poéticas de Gaston Bachelard (2008, 2009) fundamentam a busca por relações entre esses dois tipos de imagens. Assim, esta abordagem se baseia no conhecimento empírico ${ }^{1}$ e nos conceitos sobre a imagem elaborados por esses autores, mas é movida principalmente pelos "devaneios voltados para infância." (BACHELARD, 2009. p. 93). O objetivo central é descrever os aspectos de uma relação cíclica de caráter estético e comunicativo para averiguar interseções poéticas entre essas duas vertentes da linguagem do desenho.

O trabalho parte de uma apresentação do problema e da metodologia relacionada aos autores utilizados como referencial teórico e três blocos de desenvolvimento. O primeiro bloco consiste na apresentação de alguns fundamentos da psicogênese do desenho infantil relacionados aos sinais gráficos decorrentes das fases de desenvolvimento da criança que nos permitem assim reconhecer semelhanças entre os processos criativos da imagem gráfica. O segundo bloco descreve o momento onde algumas crianças deixam de desenhar enquanto outras 'escolhem' preservar a linguagem do desenho, buscando apontar também as origens ontológicas das imagens da literatura relacionadas à infância. O terceiro bloco aborda o aspecto poético e a relação cíclica entre os dois tipos de imagem tomando o tema pelo seu aspecto mais subjetivo onde o ilustrador é movido pela memória em busca de identificação com seu público.

\section{DESENVOLVIMENTO}

O problema deste estudo está relacionado à distinção entre os conceitos de imagem artesanal $e$ imagem técnica (FLUSSER, 2002. p. 14). Ou seja, o desenho de criança é imagem essencialmente artesanal, enquanto a ilustração de livros infantis, mesmo quando é produzida artesanalmente, se 


\section{Do Desenho De Criança À llustração Do Livro Infantil.}

torna imagem técnica no processo de editoração, decorrendo daí diferenças morfológicas, teleológicas e mercadológicas entre as duas categorias.

Por outro lado, essas imagens têm como ponto em comum a criança, seja como autora no caso dos desenhos, seja como público no caso das ilustrações. Nesse sentido, este artigo busca responder o seguinte problema: Que tipo de relações estéticas e genealógicas podem existir entre essas imagens e como se manifestam apesar das diferenças apontadas?

A metodologia de análise utilizada nos estudos anteriores se baseava na abordagem fenomenológica das imagens. O primeiro estudo estava relacionado ao desenho como fruto de uma transposição e seus aspectos criativos, narrativos e mnemônicos, tomando a criança como sujeito da atividade de desenhar e "ilustrar" histórias. O trabalho de campo consistia na coleta de narrativas orais de pessoas idosas e o reconto dessas histórias para alunos de escolas municipais do Rio de Janeiro, com orientação e suporte material para que esses alunos com idades entre 6 e 10 desenhassem algo sobre a história contada, resultando na produção e posterior análise de cerca 450 desenhos. 0 objetivo era observar a transposição de linguagens e as variações de três aspectos desses desenhos: (1) a memória da narrativa oral; (2) o processo criativo; e (3) o potencial narrativo dos desenhos infantis.

O segundo é uma pesquisa de doutorado iniciada em 2014 que abrange as imagens bibliográficas voltadas para a infância e o projeto teve como base a monografia científica especializada realizada em 2008 através de uma bolsa de residência concedida pela Internationale Jugendbibliothek München $I J B^{2}$. O tema abordado foi A narrativa visual nos livros sem texto, seus aspectos históricos e estéticos. A pesquisa teve como objetivo a análise da morfológica dos livros de imagem.

\subsection{GÊNESE E DESENVOLVIMENTO DO DESENHO INFANTIL}

Assim, o principal ponto em comum entre os objetos deste estudo é a criança, tomada no primeiro estudo como autora e no segundo estudo como público. Essa diferença de posições da criança em relação às imagens deste estudo sugere uma circularidade dessas representações em torno do mesmo imaginário, ou seja, um compartilhamento do imaginário, entendido aqui como representações do pensamento tanto na criação quanto na fruição.

Gilbert Durand afirma que "Todo pensamento humano é uma representação, isto é, passa por articulações simbólicas" ${ }^{3}$. Mas é ao se referir ao que ele chama de 'imaginário da ciência' que ele introduz a dualidade como possibilidade de estudo das imagens, afirmando que, "todo 'objeto' 


\section{Do Desenho De Criança À llustração Do Livro Infantil.}

imaginário é constitutivamente 'dilemático' (Claude Levi-strauss) ou 'anfibológico' (isto é, 'ambíguo' ao compartilhar com seu oposto uma qualidade comum)."4

Durand atribui a Gaston Bachelard a origem dessa possível coerência entre plurais no estudo do imaginário e a possibilidade de diálogo entre imagens aparentemente contraditórias ou polarizantes. Este trabalho se vale da abordagem fenomenológica das poéticas bachelardianas para se referir às 'imagens bibliográficas' e às 'imagens iniciais' em busca de relações processuais e poéticas.

De imediato, vale diferenciar e ressaltar dois aspectos interdependentes do que podemos compreender como o conceito de imagem. Existe, uma imagem mental que tende a ser parte ou um estágio do desenho, e outra que é uma imagem configurada no espaço bidimensional do papel, uma tela de pintura ou a superfície plana de um computador. Quando se fala da imagem como ilustração de textos ou das ideias que cercam o processo criativo do ilustrador, a diferença entre ambos os conceitos tende a aumentar, embora a intimidade entre eles se faça inextrincável. Explico: um texto a ser ilustrado necessariamente suscita imagens mentais que vão se configurando, através de esboços ou rascunhos, tentativas que levam a novas imagens - e esse é o ponto em comum com o desenho de uma criança: a imaginação contínua, o ato de imaginar e formular imagens mentalmente sem dissociálas da ação desenho. É essa concomitância entre o traço e o pensamento que permite ao desenho ser um modo de conceber, quanto construir e expressar ideias.

Para se entender a psicogênese do desenho infantil, é preciso ter em conta que ele está na origem da ilustração ou qualquer outra expressão estética que possui o desenho como base. O desenho é uma expressão cultural que traz em si determinados aspectos epigenéticos, ou seja, carrega informações a respeito de sua gênese, do modo e da própria ação de representar o mundo real ou psíquicoimaginário de cada criança ou artista já adulto. O desenho liga-se diretamente ao desenvolvimento psicomotor do sujeito, desde muito cedo, e Gilbert Durand afirma que a lenta maturação do cérebro permite ao meio social desempenhar um papel importante nos processos desse aprendizado. Ele sustenta que "a articulação simbólica somente se manifesta por volta dos quatro ou cinco anos. A formação anatômica do cérebro humano se encerra por volta dos sete anos, e as reações encefalográficas se normalizam aos vinte anos". ${ }^{5}$

Resumidamente, a similitude entre os desenhos e o desenvolvimento cerebral torna-se evidente pela fala da criança que os fez. Uma criança pequena desenha e, ao fim, nomeia as figuras e dá título ao desenho. A criança um pouco mais velha dá nome a seu desenho quando já está quase pronto e, mais adiante, saberá de antemão o que deseja desenhar. 


\section{Do Desenho De Criança À Ilustração Do Livro Infantil.}

Logo nos primeiros estágios, o desenho vem acompanhado da fala egocêntrica da criança. Tal qual reconheceu Jean Piaget, o desenho é parte de uma expressão polifônica e não poderia ser visto separadamente, como uma simples expressão gráfica; o desenho infantil integra uma rede particular de descrições, onomatopeias, expressões faciais e gestos. Por isso, devemos evitar a tradicional dissociação entre vetores linguísticos, gestuais e gráficos, porque não estamos face a obras estáticas e fechadas, mas em meio a um conjunto comunicacional bastante dinâmico. Assegura o estudioso suíço: “Um desenho, cortado da 'polifonia' de seu meio gestual, postural, oral, verbal e social, é só um vestígio de um conjunto comunicacional coordenado". 6

Outro fator importante é o aspecto social do desenho. Isto pode ser observado no modo cooperativo de sua produção quando existe um grupo de crianças, como acontece na sala de aula e no ambiente familiar. Nesses momentos, são naturais as constantes colaborações, imitações, trocas, modificações de certos elementos do desenho, das cores, dos ícones, etc.. O que passa a contar é o aspecto das trocas plurimídias: a força comunicativa do desenho. Entre seus colegas, amigos, irmãos, o desenho para a criança é a possibilidade de um jogo comunicativo que se estabelece através de imagens mais ou menos convencionais, desenhos que seguem um padrão de representação adequado a um determinado modelo. Exemplo praticamente universal são as casas com telhados triangulares e chaminé, porta e janela, ou o sol na forma de um círculo e uma sequência de linhas ao redor representando raios.

Com estas primeiras fases do desenvolvimento infantil, o grafismo já busca uma forma de entendimento nas organizações icônicas. Inicialmente, reconhecemos os ícones de gesto, aqueles riscos ou traços que às vezes se manifestam antes de um ano de idade. São modulações de segmentos, circunvoluções de linhas que levam à emergência dos ícones de ritmo. Combinando os traços e controle do ritmo, chega-se às formas regulares nos experimentos da criança com lápis, crayon ou canetas hidrográficas sobre o papel. Em seguida, ela passa a explorar os chamados ícones de ações, derivados e complementares aos jogos que se desenvolveram com os materiais de desenho sobre a folha. Um caminhão de bombeiros, um avião ou um animal mesmo que imaginário deixam rastros atrás de si que organizados como ícones de ação, muito análogos àqueles traços que indicam movimento nas histórias em quadrinhos.

Desta maneira, a exploração de semelhanças e analogias com o mundo guiará a criança na direção das imagens de objetos e figuras. Avidamente, a sociedade espera, encoraja e felicita este evento. Paralelamente, a denominação verbal se impõe no mosaico plurimídia dos desenhos, assumindo um 


\section{Do Desenho De Criança À llustração Do Livro Infantil.}

papel identificador e orientando o reconhecimento dos atributos pertinentes às imagens de objetos e figuras.

Desde os sete até os dez anos, a criança está apta a fazer do desenho uma prática complexa, resultante do percurso de fases anteriores. Ela já sabe desenhar, é mestra do seu sistema de representação e revela, em última análise, um prazer em compartilhar seu domínio comunicativo e estético. 0 repertório visual e a articulação do discurso gráfico fazem com que o conceito de "novato" seja um tanto inadequado a criança nessa etapa. Ela se encontra no ápice do desenvolvimento de seu potencial criativo! Certamente, a maior parte dos adultos não desenhará tanto, nem com tanta frequência, muito menos irá se desenvolver, como nessa fase da criança.

Porém, nesse momento, tornam-se mais nítidas duas influências que polarizam as intenções do ato de desenhar. De um lado, temos o aspecto genérico que imprime às formas originais uma inclinação mais comunicativa e, de outro, o aspecto singular, que acabará por moldar o traço e a caligrafia da criança como uma representação única. Este é o ponto alto do desenvolvimento do desenho infantil e assinala uma mudança radical na representação gráfica. É quando a evolução do traço tende a se estabilizar para a maioria dos indivíduos.

Bem próximas aos dez anos, as crianças sentem grande atração por desenhos com características realistas. Os estudos demonstram que justamente nesse período uma grande maioria deixa de desenhar, interrompendo o desenvolvimento de sua capacidade de expressão e representação gráfica. Isso ocorre porque, como afirma Beth Edwards, "a aptidão para o desenho não é vital para a sobrevivência na cultura em que vivemos, como são a fala e a leitura" ${ }^{7}$ É comum muitas crianças deixarem de desenhar nesse momento, enquanto muitos adultos permaneçam neste estágio, ou seja, desenhando como crianças. Existe uma conceituação dos desenhos (ícones gráficos) que progressivamente são substituídos pela palavra escrita (símbolos gráficos).

Importante ressaltar: os primeiros traços de uma criança parecem resultar unicamente de sua ação, e não de uma intenção, sendo produzidos a partir da motricidade física e da imitação de gestos, para adquirirem pouco a pouco algum significado. Os significados da imagem emergem de níveis mais complexos de elaboração, à medida que a criança passou a nomear personagens, lugares, ações. A própria sucessão dessas representações impõe narratividade às imagens e, com o tempo, vai sendo estabelecida uma sincronia entre o desenho gráfico e a verbalização da imagem. Conforme o domínio é adquirido, a criança que desenha permite-se anunciar o que pretende fazer; esse estágio coincide com as necessidades de maior desenvolvimento verbal, quando as intenções e o gosto por desenhos 


\section{Do Desenho De Criança À Ilustração Do Livro Infantil.}

'realistas' tendem a superar suas habilidades. Podemos afirmar, por fim, que a atividade estética da criança conseguirá atravessar essa fase e sobreviver na vida adulta, quando a singularidade de seus desenhos for valorizada frente à generalidade representada pelas palavras.

Não restam dúvidas: a tendência em privilegiar a expressão verbal aponta para nossa necessidade de comunicação. No entanto, para as novas gerações em um mundo informatizado, as interfaces digitais interativas mostram que a imagem guarda ampla potência comunicativa - e que os adultos, sobretudo designers, professores, ilustradores, escritores, mediadores de leitura reencontram o desenho na parte mais essencial das novas modalidades de comunicação.

\subsection{AS IMAGENS DA INFÂNCIA E AS IMAGENS DA LITERATURA}

A criança tem um mundo próprio, bem diferente de nós adultos. Elas, assim como os idosos, não estão inseridas nas necessidades produtivas da sociedade e, de alguma maneira, são representantes de uma relação complementar entre imaginação e memória. Bachelard afirma que essa é uma relação indissolúvel e "a tripla ligação imaginação, memória e poesia deverá (...) ajudar-nos a situar, no reino dos valores, esse fenômeno humano que é uma infância solitária, uma infância cósmica" 8 Torna-se importante ressaltar que os desenhos colaborativos, feitos entre colegas em suas trocas plurimídias, já não existem na fase posterior aos dez anos. A atividade do desenho tende a ser uma construção solitária: a criança e suas primeiras obras precisam sobreviver ao vazio e à falta de interlocutores, encontrar significado em si próprias. O mundo interno precisa se impor ao externo, pois mesmo se alimentando das imagens do mundo visível ao campo da percepção, o desenho nasce de uma necessidade que abre mão da interação e da comunicação em função de um prazer expressivo e estético.

Ora, a memória da infância traz consigo diferenças em relação ao nosso mundo real. Como diz Bachelar: "Lembramo-nos enquanto sonhamos, sonhamos enquanto nos lembramos". O mundo do devaneio da infância é grande, maior que o mundo oferecido ao devaneio nas fases da adolescência e idade adulta. Gulliver, Alice, Narizinho, muitas são as imagens miniaturizadas ou imagens de miniaturas que enfatizam imensidades, desde Charles Perrault, os Irmãos Grimm, Andersen e todas as decorrências na literatura infantil contemporânea.

Em sua Poética do espaço, Bachelard aborda a relação inevitável que existe entre as imagens da infância e as imagens da literatura, ao afirmar que "o conto é a imagem que raciocina" e nos fazendo lembrar o que parece ser a narrativa ancestral desse conceito de miniatura - a história de O Pequeno 


\title{
Do Desenho De Criança À llustração Do Livro Infantil.
}

Polegar. $\mathrm{O}$ autor é bastante categórico ao atribuir a esse personagem o poder de revelar uma imagem primordial: "A simples pequenez vai facilitar todas as façanhas" ${ }^{9}$. Tal conto é encontrado em diferentes culturas e Gaston Paris afirma que aí está "o fundo primitivo de sua história, a marca que se encontra em todos os povos; já as outras histórias que Ihe são atribuídas, criadas pela fantasia que esse serzinho divertido estimula, costumam diferir entre os vários povos". ${ }^{10}$ Deste modo, parece de fato ser um ancestral das aventuras de $A$ Chave do Tamanho, de Monteiro Lobato ${ }^{11}$.

E Bachelard, no mesmo capítulo, apresenta ainda um trecho onde Hermann Hesse se apropria dessa imagem - que é a miniatura - para criar uma fascinante imagem poética:

\begin{abstract}
"Um prisioneiro pintou na parede de sua cela uma paisagem, um trenzinho entrando num túnel. Quando seus carcereiros vieram procurá-lo, ele pediu 'gentilmente que esperassem um momento para que pudesse entrar no trenzinho do meu quadro, a fim de lá verificar alguma coisa. Como de hábito, eles se puseram a rir, pois me consideravam um fraco de espírito. Eu me fiz pequenininho. Entrei em meu quadro, embarquei no trenzinho que se pôs em movimento e desapareceu na escuridão do pequeno túnel. Por instantes, podia-se ver ainda um pouco de fumaça em flocos que saía pelo buraco redondo. Depois essa fumaça se dissipou e com ela o quadro e com o quadro a minha pessoa"12.
\end{abstract}

\subsection{Quando o ilustrador lembra-se criança}

As primeiras imagens dos livros ilustrados para crianças encontram-se na origem do desenho da criança que, por algum motivo, se preserva em alguns sujeitos. Pode-se afirmar que ilustradores da literatura infantil e juvenil são levados pela expressão do desenho que se ramifica em diferentes vertentes, estruturando-se como linguagem em suas gradações mais utilitárias ou mais artísticas.

Essa linguagem, quando se manifesta nos livros ilustrados, traz uma visualidade que tem origens diversas, mas podemos estabelecer dois marcos principais: primeiramente, o imaginário das fábulas e contos de fadas e, posteriormente, o humor e a poesia nonsense que se apresenta na literatura para crianças, mais conscientemente, a partir dos livros Alice no país das maravilhas (1865) e Alice através do espelho (1871), escritos por Lewis Carroll e ilustrados por John Tenniel. A qualidade das imagens de Tenniel vai contribuir significativamente para estabelecer seu aspecto autoral tendo em vista da extensa lista de citações dessa obra na infinita galeria de permutações, apropriações, recriações, paródias e variações de Alice publicadas até hoje.

No mundo contemporâneo, superpovoado de objetos, as imagens funcionam como signos de informação e sedução, atraindo o observador e dando forma aos conteúdos subjacentes. A ilustração é uma espécie do que Vilém Flusser chama de "pensamento imagético" e dependem de pontos de 


\section{Do Desenho De Criança À llustração Do Livro Infantil.}

vista predeterminados, baseados em convenções técnicas e mercadológicas. Por essas características, as imagens dos livros tendem a resignificar imagens do mundo para as crianças, ressaltando um aspecto narrativo da imagem, uma inversão da sua natureza tradicionalmente descritiva. $\mathrm{O}$ autor afirma que "As imagens da mídia imagética são mais ricas e as mensagens da mídia conceitual (verbal) são mais nítidas." 13

A exemplo de John Tenniel ao colaborar com o segundo livro de Lewis Carroll, (1871), vemos já uma troca entre a narrativa e ilustração para o desenvolvimento da história. Ao entrar no espelho, Alice se depara com um mundo invertido, e essa fantasia cria vida quando o leitor se depara com as ilustrações. As inúmeras descrições de Carroll do ambiente encontrado por Alice são alimentadas e enriquecidas de detalhes nos desenhos. Porém, as imagens originais de Tenniel oferecem muitas vezes novas camadas de significado em inversões e relações formais internas que, embora possam parecer erros ou contradizer o substrato verbal aos olhos de alguns, na verdade, se tornaram parte de um aspecto crucial da estética do livro ilustrado, pertinente ao espaço/tempo.

Perry Nodelman em Words about Pictures: The Narrative Art of Children's Picture Books aponta para dois tipos de ironia da relação entre palavras e imagens no livro ilustrado devido às diferenças inerentes entre a narração verbal e a representação pictórica: “A primeira é a distância entre a objetividade relativa das imagens e a subjetividade relativa das palavras; a segunda é a distância entre o movimento temporal das histórias e a eternidade fixada geralmente nas imagens." ${ }^{14}$ Essa ironia, referida por Nodelman se estabelece pelo jogo entre narração e descrição onde imagens e textos se relacionam cambiando suas características tradicionais para ampliar as possibilidades poéticas do objeto livro.

Assim, a característica da linguagem visual do livro ilustrado para crianças se estabelece a partir do conjunto de imagens que vêm da memória articulada pelo sujeito ilustrador em relação ao texto. A arte de ilustrar se diferencia da linguagem da pintura, uma vez que as imagens se inclinam mais facilmente às verbalizações mentais constituídas pela tendência humana para dar significado àquilo que vemos por meio de uma sequência de imagens. As ilustrações podem se apresentar como uma narrativa independente em nossos livros ilustrados e nos chamados livros de imagem. É o que se costuma descrever como narrativa visual, presente em um ou outro tipo de publicação, e tal função narrativa que a ilustração pode desempenhar já aparece anteriormente nos desenhos de crianças. Desde as garatujas, nos sucedâneos e jogos lúdicos, a "fala egocêntrica" já descrevia cenas e 


\section{Do Desenho De Criança À llustração Do Livro Infantil.}

acontecimentos imaginários. Este instrumento do pensamento - a palavra - é indissociável da expressão gráfica.

Assim, para se compreender a linguagem visual nos livros de literatura infantil e toda sua pluralidade de significados, pode-se igualmente observar o desenvolvimento do grafismo infantil a partir da genealogia do ilustrador. Mesmo adulto, o ilustrador vai até a gênese do seu desenvolvimento como artista e busca lá a comunicabilidade com seu público. Essa possibilidade se dá graças a inextricável relação entre imaginação e memória. Será preciso deixar-se levar para um mundo interno, um mundo de infância, lembrar-se criança.

Bachelard afirma, "Quando na solidão, sonhando mais longamente, vamos para longe do presente reviver os tempos da primeira vida, vários rostos de criança vêm ao nosso encontro". Algumas ilustrações de livros contêm esses devaneios de memória, revelando como realmente os processos verbais e visuais se manifestam numa relação complementaridade, através do diálogo entre interior e exterior. As imagens são, enfim, espacialidades que vêm da memória, enquanto textos são temporalidades imaginativas capazes de deflagrar imagens, tudo de forma cíclica.

Casas, árvores, pássaros, rostos em diversidade: desenhos de criança são únicos quando se permite que ela se expresse livremente.

Desenhos ensinados, ao contrário, são desenhos mortos e ensinar uma criança dos quatro aos nove anos a desenhar é matar a essência de sua expressão, restringindo esse canal comunicativo ao substituir a criatividade pela repetição. Escolas onde se ensinam a desenhar tendem a conduzir os alunos a um processo precoce de generalização, o que se pode notar quando ocorre uma grande semelhança entre os desenhos de diferentes sujeitos de um grupo, seja no modo de configuração ou mesmo no posicionamento de elementos no papel. São desenhos predominantemente comunicativos que nos proporcionam um entendimento imediato, traçados com clareza de formas e com intensidades semelhantes de linhas e cor. Esse direcionamento os torna um tanto previsíveis e, em sua maioria, apresentam poucas soluções criativas.

Opostamente, seria oportuno citar o memorável caso descrito por Luquet (1927) de um garoto belga de três anos e meio chamado Victor que "desenhou no ventre do convidado para o jantar em família, as batatas que ele havia ingerido e representou os botões do sobretudo do visitante que tanto o haviam impressionado contornando toda a figura, num resultado de forte apelo visual". ${ }^{15}$ 


\section{Do Desenho De Criança À llustração Do Livro Infantil.}

A ilustração para a criança pretende a mesma aventura do grafismo da criança, pois ambos, cada um ao seu modo, são imagens da infância. Assim como lembrança de rever um lugar ou ouvir uma música não nos traz o mesmo sentimento da primeira vez, a ilustração também perde muito de seu passado, de sua essência infantil. A memória de um prazer é um sentimento do aprendizado, uma revivescência. Por isso, somos às vezes tomados pela nostalgia das primeiras imagens, sem conseguimos ter de volta o frescor daquele momento.

Contudo, neste caso é pertinente apontar a dupla face da experiência estética que muitas outras categorias de imagem podem proporcionar. Esse artigo se refere à ilustração como parte do design e dos livros ilustrados, onde, por um lado é necessário que o sujeito se valha da imaginação em busca de novas sensações estéticas e que o permita lidar com o novo; por outro lado, é a memória que proporciona reviver um momento e o imaginário onde se encontram as matrizes da criação de cada autor. Mas existe também outra dimensão da memória que é a História. Ela se torna crucial para a compreensão de como o campo de conhecimento humano estabeleceu suas bases ao longo do tempo, servindo direta ou indiretamente como forma de legitimação e formação de uma linguagem visual específica nas ilustrações de livros. Este é um conhecimento fundamental para a edição dos livros para crianças.

\section{CONCLUSÃO}

Seria difícil encontrar nas ilustrações de livros infantis as marcas de memória ou imaginação que as formularam. Nada pode determinar com clareza essa temporalidade fugidia ou uma causalidade para a forma que essas representações assumem. Nenhuma projeção ou lembrança explícita as explica, a não ser sua referência imediata ao texto que a que ela se refere.

A esse respeito, Gaston Bachelard, em sua fenomenologia das imagens, contradiz o lugar comum ao sugerir que "a imaginação é anterior à memória"16. Não há dúvida que os espaços habitados, observados, percorridos se diferenciam daqueles narrados, descritos, contados. Inconscientemente ou não, parece que a primeira imaginação é iniciada na vivência enquanto a memória passaria reconstruir essas imagens mentais pelo potencial afetivo das marcas dessas vivências no sujeito. Por esse ponto de vista, a palavra, elemento disparador de imagens para o ilustrador de livros, dialoga mais com a memória e as imagens mentais do leitor, e consequentemente do ilustrador, do que o mundo presente que o rodeia. A ilustração de literatura infantil não representa o mundo, mas constrói metáforas ou a ressignificação das imagens a partir da memória. 


\section{Do Desenho De Criança À llustração Do Livro Infantil.}

Talvez, por ter ainda uma vivência limitada de passado, o mundo presente toca a criança mais diretamente. Bachelard afirma que ao desenhar a casa, a criança irá revelar o sonho mais profundo em que ela deseja abrigar sua felicidade e que as marcas dessa felicidade são visíveis no desenho, pois "toda grande imagem simples revela um estado de alma". A casa, mesmo reproduzida em seu aspecto exterior, fala de uma intimidade, ou seja: "Quando a criança é feliz a fumaça brinca delicadamente acima do telhado. Se a criança é infeliz, a casa traz a marca das angústias do desenhista". ${ }^{17}$

Por esse ponto de vista, podemos concluir que as possíveis marcas da infância sobre a ilustração seriam o próprio ato de desenhar. Não há mais registros dessa felicidade na "caligrafia" que o gesto espontâneo deixa a mostra, nem na forma dos objetos ou em um detalhe significativo como uma porta aberta por onde se pode entrar, conhecer, decifrar. A ilustração pretende imitar superficialmente esse estado de espontaneidade, o ilustrador quer dar um corpo concreto a uma frase, quando o faz com competência, transforma sua impressão em uma metáfora visual ou refaz o caminho que o texto descreve com novos significados. Já no desenho de criança encontramos o mundo sem disfarces, o mundo como imagem, obra da imaginação absoluta onde a criança extrai todo o seu ser da imaginação.

O ilustrador de livros coleciona desde sempre as imagens da infância, essas imagens moldaram seu traço, seu mundo interno é povoado de memórias e ele as revive a cada texto no potencial imaginativo que ficou guardado dessa fase de sua vida.

O desenho de criança e o desenho para criança se encontram na memória. 


\section{Do Desenho De Criança À Ilustração Do Livro Infantil.}

\section{REFERÊNCIAS}

ALENCAR, J. Salmo Dansa de - O começo é o fim pelo avesso: a transposição da narrativa oral para o desenho infantil. 95 f. Dissertação (mestrado) - Departamento de Artes e Design - Pontifícia Universidade Católica do Rio de Janeiro. RJ, 2004.

9,16,17BACHELARD, Gaston - Poética do espaço. São Paulo: Martins Fontes, 2008.

9,10 - Poética do devaneio. São Paulo: Martins Fontes, 2009.

CARROLL, Lewis - Alice: edição comentada. Rio de Janeiro: Jorge Zahar Ed., 2002.

DARRAS, Bernard - Au commencement était l'image. Du dessin de l'enfant à la communication de l'adulte. Paris: ESF éditeur, 1996.

${ }^{15}$ DUARTE, Maria Lúcia Batezat - Sobre o sentido das representações gráficas infantis. São Paulo: Unicamp, Anais ANPAP. 1999.

3,4,5DURAND, Gilbert - O imaginário. Rio de Janeiro: Difel, 1994

7EDWARDS, Beth - Desenhando com o lado direito do cérebro. Rio de Janeiro: Ediouro. 2000.

FLUSSER, Vilém - Filosofia da Caixa Preta. Rio de Janeiro: Relume Dumara, 2002

13 Naify, 2007. - Mundo Codificado - Por uma filosofia do design e da comunicação. São Paulo: Cosac

${ }^{12}$ HESSE, Hermann. Revista Fontaine, Paris: n.57, P.725

LINDEN, Sophie Van der - Para ler o livro ilustrado. São Paulo, Cosac Naify, 2011.

${ }^{11}$ LOBATO, Monteiro. A chave do tamanho. São Paulo: Brasiliense, 1997.

LUQUET, George-Henri. (1927) - O desenho infantil. Porto: Ed. Minho, 1969. MUNARI, Bruno - Livros para crianças. In: MUNARI, Bruno. A arte como ofício. Lisboa: Presença, 1987.

14 NODELMAN, Perry. Words about Pictures: The Narrative Art of Children's Picture Books. Apud: LINDEN, Sophie Van der. Para ler o livro ilustrado. São Paulo, Cosac Naify, 2011. P. 165.

${ }^{6}$ PIAGET, Jean.; INHELDER, B. - A psicologia da criança. Rio de Janeiro. São Paulo: Difel, 1968.

SCHWARCZ, Joseph. H. - The Ways of the Illustrator. Chicago: American Library Association. 1982. 


\section{Do Desenho De Criança À llustração Do Livro Infantil.}

\section{NOTAS}

Nota 1

O autor se refere aqui ao citado trabalho de campo de sua referida pesquisa de mestrado e também à sua atuação por mais de 20 anos como autor e ilustrador de livros infantis e juvenis, com mais de 80 livros publicados.

\section{Nota 2}

Internationale Jugendbibliothek München - IJB tem o maior acervo de livros infantis e juvenis do mundo e concede anualmente até 10 bolsas para residências de 3 meses para especialistas e autores de literatura infantil. A pesquisa resultou em uma lista cronológica de 613 livros (aproveitada pela biblioteca) além de 170 resenhas e fotos das principais publicações entre 1823 e 1999. 


\section{Capítulo 16}

doi $10.37423 / 210403778$

\section{SELECIONANDO MEMBROS DE UMA EQUIPE DE PROJETO POR MEIO DE UM MÉTODO MULTICRITÉRIO DE APOIO À DECISÃO}

Glauco Barbosa da Silva

Helder Gomes Costa

Phelipe Medeiros da Rocha

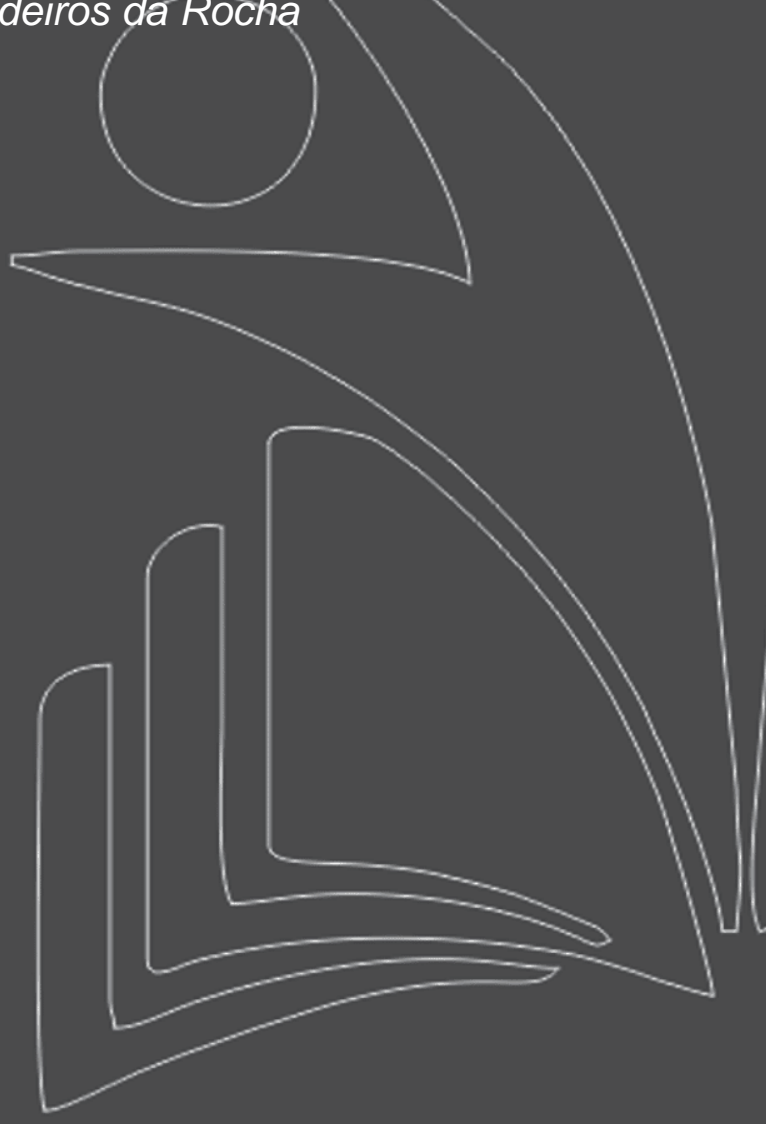

Universidade Federal Fluminense

Universidade Federal Fluminense

Universidade Federal Fluminense

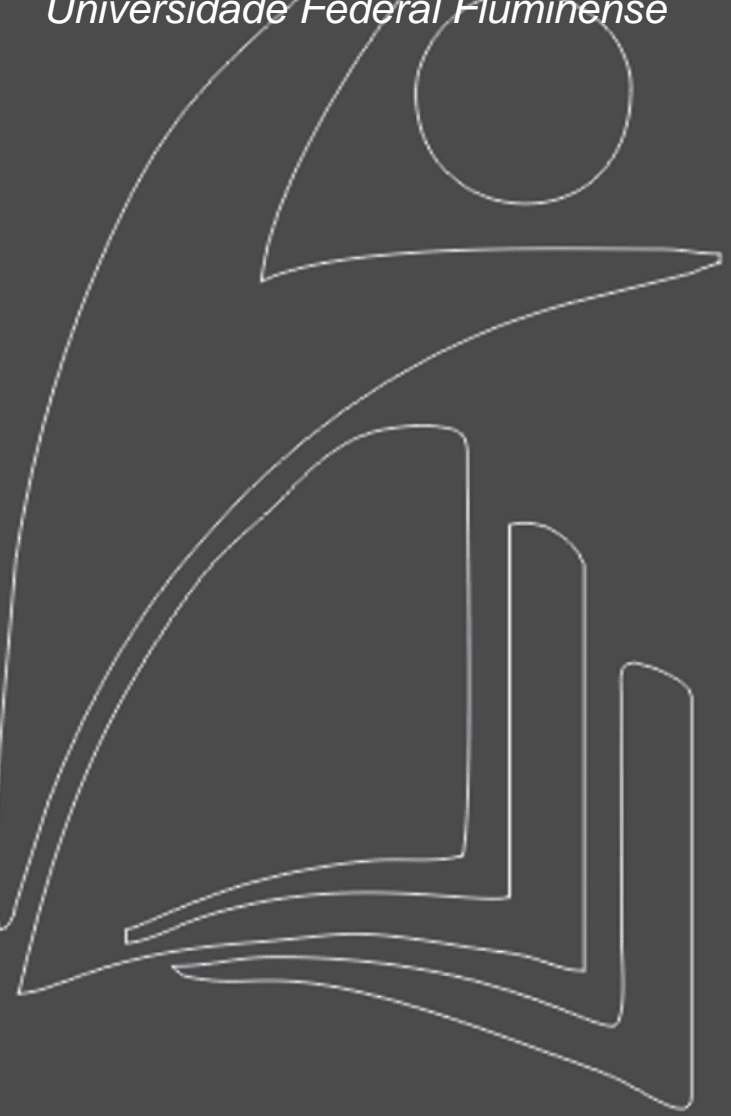


Resumo: O presente trabalho tem por objetivo propor soluções para um problema de seleção múltipla por meio de uma análise experimental multicritério baseada no Multiplex Electionis Methodus (MEM). Para isso, desenvolve-se um problema prático de seleção de uma dupla de programadores para um projeto de desenvolvimento de software utilizando o MEM e, em seguida, apresentam-se os resultados alcançados confrontando-os com os métodos De Borda e TOPSIS.

Palavras-Chave. MCDA. Multicritério. Gerenciamento de Projetos.

ADM - Apoio a Decisão Multicritério; AD\&GP - PO na Administração \& Gestão da Produção 


\section{INTRODUÇÃO}

Um fenômeno vivenciado pelas empresas, em especial as fábricas de software, têm sido a crescente complexidade dos projetos, aliada à redução dos ciclos de vida de produtos e serviços. Para Heizer e Render(2001), tal mudança origina-se da consciência do valor estratégico da competição baseada no tempo e da necessidade de melhoria contínua da qualidade. Desta maneira, a gestão de projetos transformou-se numa questão estratégica, essencial para a sobrevivência de qualquer organização no mercado.

No contexto do gerenciamento de projetos, o processo decisório para a formação de equipes envolve características difíceis de serem mensuradas, envolvendo muitos aspectos subjetivos que aumentam a complexidade do processo, exigindo a utilização de instrumentos mais eficientes, eficazes e flexíveis para tomada de decisão de uma maneira simples.

Alencar e Almeida(2008) afirmam que, na prática, a seleção de equipes é um problema complexo de apoio a decisão multicritério. Al-Reshaid e Kartam(2005); Al-Harbi(2001); Alencar e Almeida(2010); e Kelemenis, Ergazakis e Askounis(2011) abordaram o problema para a seleção de empresas e profissionais para a participação em projetos com métodos multicritérios.

Face às peculiaridades de um projeto de desenvolvimento de software, o processo de seleção de pessoal para essa atividade requer atenção especial no que tange a sinergia da equipe, isto é, alternativas que se complementam muitas vezes são mais interessantes que alternativas que se sobrepõem. A formação de equipes em projetos de software constitui-se um problema de seleção múltipla, que procura escolher mais de uma alternativa, no mesmo problema decisório, partindo da hipótese que as melhores alternativas em uma ordenação não compõem necessariamente o melhor conjunto de alternativas para o problema em questão. Hora(2013) propõe o método Multiplex Electionis Methodus (MEM), como solução para o problema de escolha múltipla partindo da modelagem tradicional dos problemas decisórios.

Os métodos multicritérios buscam em um espaço de alternativas possíveis uma solução para melhor atender as restrições e critérios associados ao problema proposto. Na seleção de pessoal para a composição de equipes em projetos de software a Análise Multicritério apresenta-se como potencial candidata no auxílio à tomada de decisão.

O presente trabalho tem por objetivo propor soluções para o problema de seleção múltipla por meio de uma análise experimental multicritério baseada no Multiplex Electionis Methodus (MEM). Para 
isso, desenvolve-se um problema prático de seleção de uma dupla de programadores para um projeto de desenvolvimento de software utilizando o MEM e, em seguida, apresentam-se os resultados alcançados confrontando-os com os métodos De Borda e TOPSIS.

\section{METODOLOGIA MULTICRITÉRIO DE AUXÍLIO À TOMADA DE DECISÃO}

Roy(1996) define o Apoio à Decisão Multicritério (AMD) como uma tentativa de prover respostas para questões levantadas pelos atores envolvidos no processo decisório por meio de um modelo claramente especificado. Para Lootsma(1999), é um ramo crescente da Pesquisa Operacional, com foco na concepção de ferramentas matemáticas e computacionais para apoiar a avaliação subjetiva de um número finito de alternativas em um numero finito de critérios de desempenho por um único tomador de decisão ou por um grupo

A tomada de decisão é o processo de seleção de um caminho dentre todas as alternativas disponíveis. Na maioria dos problemas, a multiplicidade de critérios para julgar as alternativas é generalizada. Sendo assim, para muitos desses problemas, o decisor deseja atingir mais de um objetivo na escolha do curso de ação, desde que satisfaçam as restrições ditadas pelo ambiente, processos e recursos.

Para Costa(2002), uma importante característica das metodologias AMD é a capacidade de reconhecer a subjetividade inerente aos problemas de decisão e utilizarem o julgamento de valor como forma de tratá-la cientificamente.

Em geral, a análise multicritério constitui-se de duas etapas:

- Avaliação de desempenho das alternativas à luz dos critérios; e

- Avaliação da importância dos critérios à luz do foco principal ou do objetivo geral.

Existem vantagens e desvantagens associadas à adoção de um método de AMD, por isso, um julgamento criterioso para escolher a técnica mais adequada para uma aplicação específica faz-se necessário. A seleção do método irá influenciar nos resultados, já que nem sempre diferentes métodos aplicáveis a um problema conduzirão às mesmas conclusões.

Algumas formas de categorizar os métodos multicritério são:

- métodos de ponderação;

- métodos ordinais;

- métodos baseados em funções de utilidade; 
- métodos de relações de superação; e

- métodos baseados na distância a uma alternativa ideal.

Dentre as mais conhecidas metodologias na literatura, citam-se: método de Análise Hierárquica (Analytic Hierarchic Process, AHP); Os métodos da Família ELECTRE (ELimination Et Choice TRadusàint la rEalitè); O método PROMETHEE; e MacBeth.

Recentemente proposto, o método Multiplex Electionis Methodus (MEM) é descrito a seguir.

\section{MULTIPLEX ELECTIONIS METHODUS (MEM)}

O Multiplex Electionis Methodus(MEM) é um método de auxílio a decisão multicritério proposto por Hora(2013), que busca solucionar a problemática de escolha de um conjunto que melhor se completa para atender com maior eficiência aos critérios propostos, independente da posição ordenada das alternativas.

A execução do método é composta por cinco etapas:

1. Elaborar a matriz Ai,j de pagamentos:

- aij contém a avaliação $g$ da alternativa $i$ a luz do critério $j$, mostrando o desempenho de cada alternativa diante dos critérios;

2. Elaborar a matriz Cj,j' de critérios complementares:

- Matriz quadrada de ordem $j$, que relaciona os critérios segundo uma escala que quantifica influências paritárias;

3. Elaborar um vetor Wj de pesos de cada critério;

4. Estabelecer o valor do tau $(\tau)$ de corte:

- Considerando a subjetividade/imprecisão dos julgamentos, o elemento $\tau$ busca ajustar o limiar de aceitação ou rejeição do conjunto de alternativas; e

5. Calcular a matriz B:

- A nova matriz de pagamentos, que traz as combinações das alternativas, tomadas $n$ a $n$ em suas linhas, e a combinação dos critérios, tomados dois a dois, e multiplicados entre si. 


\section{SELEÇÃO DE COMPONENTES DE UM PROJETO DE SOFTWARE (PS)}

Os projetos de desenvolvimento de software (PS) estão sujeitos, todo o tempo, a fatos que podem de alguma forma impactar seus objetivos, processos ou produtos. Estes fatos podem causar efeitos adversos e em muitos casos catastróficos ao projeto. São comuns relatos de PS com taxas relativamente altas de atrasos, com custos que ultrapassaram as estimativas, cuja implementação não correspondeu ao que foi solicitado ou que foram abortados antes da sua conclusão. Segundo Boehm(1991), entre 15 e 35\% de todos os PS incorrem em cancelamento ou erros de orçamento e/ou de agenda e/ou qualidade.

Relatos de experiência dos PS mostraram que muitos dos problemas poderiam ter sido evitados ou fortemente reduzidos se tivessem identificados e solucionados os elementos de maior risco. Dentre os elementos de maior risco para um PS sobressai-se o fator humano, ou seja, a equipe técnica envolvida, que, na grande maioria dos casos, representa o maior capital investido.

Nesse contexto, o recrutamento e seleção do pessoal envolvido são determinantes para o sucesso do projeto. Portanto, a utilização de métodos de Apoio à Decisão Multicritério apresentam-se como relevante instrumento para o processo decisório da seleção do pessoal.

Considerando a criticidade do processo de formação da equipe de um projeto e visando reduzir os riscos, conforme recomendado pela comunidade de software, é comum a composição de duplas de programadores. Caracteriza-se, desta forma, como um processo de seleção múltipla, ou seja, um processo em que mais de uma alternativa deve ser escolhida. Sendo assim, partindo da hipótese que uma solução composta com as melhores alternativas em uma ordenação não é necessariamente o melhor conjunto de alternativas para a solução do problema, na seção seguinte são descritos os passos da aplicação do método MEM aos dados de um PS real, no qual busca-se a seleção de uma equipe de programadores composta de um programador mais experiente (sênior) e um menos experiente (júnior), à luz dos critérios descritos a seguir segundo a visão do gerente do projeto(decisor).

\section{APLICAÇÃO DO MÉTODO MEM}

Durante o processo de seleção para as duas vagas para um projeto de software foram captados seis currículos, que foram considerados participantes do processo. As condições de contorno estabelecidas foram: a distância da residência do candidato ao local do trabalho e a pretensão salarial, condições eliminatórias. Dentre os participantes, dois candidatos não atenderam os limites e foram excluídos do processo por não representarem alternativas viáveis para o problema. 
Os dados computados foram obtidos a partir de entrevistas realizadas com candidatos préselecionados por meio de análise dos currículos dentre as seis alternativas iniciais, que foram avaliados a luz dos seguintes critérios:

C1 - Avaliação Global: representa o desempenho do candidato em relação às perguntas realizadas durante a entrevista;

C2 - Apresentação Pessoal: considera a necessidade de possíveis interações presencias da equipe com os clientes;

C3 - Experiência Profissional: representa a participação em projetos similares e conhecimentos desejáveis à condução do projeto; e

C4 - Potencial de Crescimento: representa a capacidade de aprendizado e interesse em ampliação dos conhecimentos afins.

Em cada critério os candidatos foram avaliados pelo gerente do projeto(decisor) com graus que variavam numa escala de zero até cinco. Para atender ao requisito da seleção de dois programadores com nível de experiências diferentes, as etapas que compõe o MEM foram desenvolvidas, como a seguir.

\section{Elaboração da Matriz de Pagamentos (A)}

A matriz $\boldsymbol{A}$ é uma matriz onde cada elemento aij representa o desempenho da alternativa Ai no critério Cj.

Tabela 1 - Matriz de Pagamentos

\begin{tabular}{|c|c|c|c|c|}
\hline & \multicolumn{4}{|c|}{ Critérios } \\
\hline Alternativas & $\mathrm{C} 1$ & $\mathrm{C} 2$ & $\mathrm{C} 3$ & $\mathrm{C} 4$ \\
\hline $\mathrm{A} 1$ & 3.50 & 3.00 & 5.00 & 4.00 \\
\hline $\mathrm{A} 2$ & 2.50 & 3.00 & 5.00 & 3.00 \\
\hline $\mathrm{A} 3$ & 2.50 & 4.00 & 5.00 & 4.00 \\
\hline $\mathrm{A} 4$ & 3.50 & 3.60 & 2.00 & 5.00 \\
\hline
\end{tabular}

\section{Elaboração da Matriz de Critérios Complementares (C)}

A matriz $C$ é uma matriz quadrada de ordem j, que contém o grau de complementaridade de um critério $j$ em relação a outro critério $n$. 
$\mathrm{Na}$ busca da complementaridade, quanto mais os critérios forem divergentes, mais eles complementam o perfil de uma escolha múltipla. Uma característica da matriz C é não possuir valores na diagonal principal, isto é, não é possível haver relacionamento de um critério com ele próprio.

Hora(2013) sugere que a escala para atribuição dos graus de complementaridade sejam:

- Os critérios se relacionam muito pouco, tem escassos temas em comum, e não há nenhuma dependência => Forte complementação (entre 0,6 e 1,0);

- Os critérios têm relacionamento mediano, existindo alguns temas em comum => Complementação moderada (entre 0,4 e 0,6, inclusos); e

- Os critérios têm grande relacionamento, vários temas em comum e há dependência entre eles $=>$ Pouca complementação (entre 0,1 e 0,4).

Observando os graus de complementaridade sugeridos, para o problema de seleção abordado, na tabela 2 são consolidados os relacionamentos entre os critérios

Tabela 2 - Matriz de Critérios Complementares

\begin{tabular}{|c|c|c|c|c|}
\hline & $\mathrm{C} 1$ & $\mathrm{C} 2$ & $\mathrm{C} 3$ & $\mathrm{C} 4$ \\
\hline $\mathrm{C} 1$ & - & 1.0 & 1.0 & 1.0 \\
\hline $\mathrm{C} 2$ & 0.5 & - & 1.0 & 1.0 \\
\hline $\mathrm{C} 3$ & 0.2 & 0.5 & - & 0.5 \\
\hline $\mathrm{C} 4$ & 0.3 & 1.0 & 0.5 & - \\
\hline
\end{tabular}

\section{Elaboração do Vetor de Pesos (W)}

O vetor peso tem uma relevante importância na escolha das alternativas. No entendimento do decisor, em termos de importância, os critérios podem ser ordenados:

$$
\mathrm{C}_{1}>\mathrm{C}_{3}>=\mathrm{C} 4>\mathrm{C}_{2}
$$

Sendo assim, de maneira arbitrária, foram previamente atribuídos valores aos critérios para a formação do vetor peso apresentados na tabela 3.

Tabela 3 - Vetor de Pesos

\begin{tabular}{|l|c|c|c|c|}
\hline Vetor de Pesos & C1 & C2 & C3 & C4 \\
\hline $\mathrm{W}$ & 0.455 & 0.091 & 0.2275 & 0.2275 \\
\hline
\end{tabular}


Para a definição do tau de corte $(\tau)$, consideram-se as avaliações da alternativa à luz do critério; pesos dos critérios; e índice de complementaridade. Considerando os valores presentes na tabela 4, a média dos valores é 0.63 , que foi estabelecido como tau de corte( $\tau)$.

\section{Elaboração da Matriz B}

A matriz B' representa uma nova matriz de pagamentos, que traz as combinações das alternativas, tomadas $\underline{n}$ a $\underline{n}$ em suas linhas, e a combinação dos critérios, tomados dois a dois, e multiplicados entre si. (HORA, 2013)

Os elementos de B' são calculados a partir de:

$$
b_{l m}^{\prime}=\frac{\sum_{i} \sum_{j} a_{i j}^{\prime}}{n^{2}} \cdot \frac{\sum_{j} w_{j}}{n} \cdot c^{\prime}, \forall i \in L, \forall j \in M
$$

Onde a'ij são os elementos da Matriz A, wj os elementos do vetor de pesos W e c' é a média dos índices de complementaridade entre critérios recuperados a partir dos elementos da Matriz C de complementaridade entre critérios.

Para o problema em curso, onde se deseja escolher duas alternativas $(n=2)$, tem-se:

Tabela 4 - Matriz B'

\begin{tabular}{|c|c|c|c|c|c|c|}
\hline & $\mathrm{C} 1-\mathrm{C} 2$ & $\mathrm{C} 1-\mathrm{C} 3$ & $\mathrm{C} 1-\mathrm{C} 4$ & $\mathrm{C} 2-\mathrm{C} 3$ & $\mathrm{C} 2-\mathrm{C} 4$ & $\mathrm{C} 3-\mathrm{C} 4$ \\
\hline $\mathrm{A} 1$-A2 & 0,6143 & 0,8190 & 0,7209 & 0,4778 & 0,5176 & 0,4834 \\
\hline $\mathrm{A} 1$-A3 & 0,6654 & 0,8190 & 0,7763 & 0,5076 & 0,5972 & 0,5119 \\
\hline $\mathrm{A} 1$-A4 & 0,6962 & 0,6910 & 0,8873 & 0,6609 & 0,6211 & 0,4408 \\
\hline $\mathrm{A} 2$-A3 & 0,6143 & 0,7678 & 0,6654 & 0,5076 & 0,5574 & 0,4834 \\
\hline $\mathrm{A} 2$-A4 & 0,6450 & 0,6398 & 0,7763 & 0,3912 & 0,5813 & 0,4123 \\
\hline $\mathrm{A} 3$-A4 & 0,6962 & 0,6398 & 0,8318 & 0,4210 & 0,6609 & 0,4408 \\
\hline
\end{tabular}

Para $\boldsymbol{\tau}=0.63$ definido e observando a regra a seguir:

$$
b_{l m}=\left\{\begin{array}{l}
1 \rightarrow b_{l m}^{\prime} \geq \tau \\
0 \rightarrow b_{l m}^{\prime}<\tau
\end{array}\right.
$$

A matriz B fica definida como: 
Tabela 5 - Matriz B

\begin{tabular}{|c|c|c|c|c|c|c|}
\hline & $\mathrm{C} 1-\mathrm{C} 2$ & $\mathrm{C} 1-\mathrm{C} 3$ & $\mathrm{C} 1-\mathrm{C} 4$ & $\mathrm{C} 2-\mathrm{C} 3$ & $\mathrm{C} 2-\mathrm{C} 4$ & $\mathrm{C} 3-\mathrm{C} 4$ \\
\hline $\mathrm{A} 1$-A2 & 0 & 1 & 1 & 0 & 0 & 0 \\
\hline $\mathrm{A} 1-\mathrm{A} 3$ & 1 & 1 & 1 & 0 & 0 & 0 \\
\hline $\mathrm{A} 1$-A4 & 1 & 1 & 1 & 1 & 1 & 0 \\
\hline $\mathrm{A} 2-\mathrm{A} 3$ & 0 & 1 & 1 & 0 & 0 & 0 \\
\hline $\mathrm{A} 2-\mathrm{A} 4$ & 1 & 1 & 1 & 0 & 0 & 0 \\
\hline $\mathrm{A} 3$-A4 & 1 & 1 & 1 & 0 & 1 & 0 \\
\hline
\end{tabular}

A partir da tabela 5, é possível observar o desempenho dos seis conjuntos (duplas) candidatas para solução do problema, que são representadas pelo $\mathrm{N}$ - número de vezes que o conjunto superou o tau de corte $(\tau)$ e do percentual de desempenho (PD) - critérios combinados que superam o tau de corte ( $\tau)$ dividido pelo total de critérios combinados (6).

Tabela 6- Desempenho dos conjuntos de alternativas que superam o valor de tau de corte.

\begin{tabular}{|c|c|c|}
\hline $\begin{array}{c}\text { Conjunto de } \\
\text { alternativas }\end{array}$ & $\mathrm{N}$ & $\mathrm{PD}$ \\
\hline $\mathrm{A} 1$-A4 & 5 & $83,33 \%$ \\
\hline $\mathrm{A} 3$-A4 & 4 & $66,67 \%$ \\
\hline $\mathrm{A} 1$-A3 & 3 & $50,00 \%$ \\
\hline $\mathrm{A} 2$-A4 & 3 & $50,00 \%$ \\
\hline $\mathrm{A} 1$-A2 & 2 & $33,33 \%$ \\
\hline $\mathrm{A} 2$-A3 & 2 & $33,33 \%$ \\
\hline
\end{tabular}

O resultado apresentado na tabela 6 sugere que o conjunto de alternativas formado por A1-A4 representam a melhor opção de escolha para os critérios considerados e a interação entre eles. Considera-se que os conjuntos que superam em pelo menos $50 \%$ o tau de corte são boas opções ao decisor e não devem ser descartadas.

Para que os resultados alcançados pelo MEM possam ser avaliados, na seção seguinte são apresentadas duas soluções para o mesmo problema por meio de dois métodos amplamente conhecidos.

\section{AVALIAÇÃO DOS RESULTADOS}

O problema proposto foi analisado pelos métodos De Borda e TOPSIS de modo a possibilitar uma comparação dos resultados.

\section{Aplicação do Método De Borda}

O método De Borda foi proposto no período da Revolução Francesa para a realização de votações em sistemas multidecisor. Dada as suas características, simplicidade e robustez, foi adaptado para 
problemas multicritério. Considerando que o método é amplamente conhecido, para aqueles que desejarem ampliar o conhecimento, Costa(2014) descreve e detalha as etapas do método.

Numa ordenação simples, utilizando o método De Borda, obtemos a tabela 7 a partir dos dados constantes da tabela 1 e do vetor de pesos (tabela 3).

Para o uso do método De Borda, em cada critério foram ordenadas as alternativas de acordo com as preferências. O número de Ordem Global é calculado multiplicando-se as pontuações de cada critério pelo peso do critério.

Tabela 7 - Ordenação das alternativas considerando a ponderação de critérios.

\begin{tabular}{|c|c|c|c|c|c|c|}
\hline Alternativas & $\mathrm{C} 1$ & $\mathrm{C} 2$ & $\mathrm{C} 3$ & $\mathrm{C} 4$ & $\begin{array}{c}\text { Número de } \\
\text { Ordem Global } \\
\text { C1.W1+C2.W2+C3.W3+C4.W4 }\end{array}$ & $\begin{array}{c}\text { Ordenação } \\
\text { final }\end{array}$ \\
\hline $\mathrm{A} 1$ & 4 & 2 & 4 & 3 & 3,69 & $1^{\circ}$ \\
\hline $\mathrm{A} 2$ & 2 & 2 & 4 & 1 & 2,53 & $4^{\circ}$ \\
\hline $\mathrm{A} 3$ & 2 & 4 & 4 & 3 & 2,97 & $2^{\circ}$ \\
\hline $\mathrm{A} 4$ & 4 & 3 & 1 & 4 & 2,93 & $3^{\circ}$ \\
\hline
\end{tabular}

\section{Aplicação do Método Technique for Order Preference by Similarity to Ideal Solution (TOPSIS)}

O TOPSIS é um método de Apoio à Decisão Multicritério que propicia a ordenação de alternativas por similaridade à Solução Ideal Positiva (PIS - Positive Ideal Solution) e dissimilaridade à Solução Ideal Negativa (NIS - Negative Ideal Solution), medidas por meio de distâncias, geralmente, euclidiana.

A execução do método é composta por 6 etapas: Construção da Matriz de Decisão (A); Normalização da Matriz de Decisão (An); Cálculo da Matriz Ponderada; Determinação da PIS(S+) e NIS(S-); Cálculo das distâncias de cada alternativa para PIS(S+) e NIS(S-); e Cálculo da Similaridade (Ci).

Para o problema em análise, a Matriz A é coincidente com a tabela 1; após a normalização, tem-se An.(tabela 8)

Tabela 8 - Matriz de Pagamentos Normalizada (An).

\begin{tabular}{|c|c|c|c|c|}
\hline Alternativas & C1 & C2 & C3 & C4 \\
\hline A1 & 0,292 & 0,221 & 0,294 & 0,250 \\
\hline A2 & 0,208 & 0,221 & 0,294 & 0,188 \\
\hline A3 & 0,208 & 0,294 & 0,294 & 0,250 \\
\hline A4 & 0,292 & 0,265 & 0,118 & 0,313 \\
\hline
\end{tabular}

A partir do vetor de pesos (tabela 3), calcula-se a Matriz Ponderada (tabela 9). 
Tabela 9 - Matriz de Ponderada (An).

\begin{tabular}{|c|c|c|c|c|}
\hline Alternativas & C1 & C2 & C3 & C4 \\
\hline A1 & 0,133 & 0,020 & 0,067 & 0,057 \\
\hline A2 & 0,095 & 0,020 & 0,067 & 0,043 \\
\hline A3 & 0,095 & 0,027 & 0,067 & 0,057 \\
\hline A4 & 0,133 & 0,024 & 0,028 & 0,071 \\
\hline
\end{tabular}

Tabela 10 - Determinação da PIS(S+) e NIS(S-)

\begin{tabular}{|c|c|c|c|c|}
\hline & C1 & C2 & C3 & C4 \\
\hline S+ & 0,133 & 0,027 & 0,067 & 0,071 \\
\hline S- & 0,095 & 0,020 & 0,027 & 0,043 \\
\hline
\end{tabular}

Tabela 11 - Cálculo das distâncias de cada alternativa para PIS(S+)

\begin{tabular}{|c|c|c|c|c|c|}
\hline $\begin{array}{l}\text { Cálculo das } \\
\text { distâncias } \\
\text { para S+ }\end{array}$ & \multicolumn{4}{|l|}{} & D+ \\
\hline A1 & 0,000000 & 0,000045 & 0,000000 & 0,000202 & 0,0157116 \\
\hline A2 & 0,001435 & 0,000045 & 0,000000 & 0,000809 & 0,0478349 \\
\hline A3 & 0,001435 & 0,000000 & 0,000000 & 0,000202 & 0,0404596 \\
\hline A4 & 0,000000 & 0,000007 & 0,001612 & 0,000000 & 0,040236 \\
\hline
\end{tabular}

Tabela 11 - Cálculo das distâncias de cada alternativa para NIS(S-)

\begin{tabular}{|c|c|c|c|c|c|}
\hline $\begin{array}{l}\text { Cálculo das } \\
\text { distâncias } \\
\text { para S- }\end{array}$ & & & & & D- \\
\hline $\mathrm{A} 1$ & 0,001435 & 0,000000 & 0,001612 & 0,000202 & 0,0569979 \\
\hline $\mathrm{A} 2$ & 0,000000 & 0,000000 & 0,001612 & 0,000000 & 0,0401471 \\
\hline $\mathrm{A} 3$ & 0,000000 & 0,000045 & 0,001612 & 0,000202 & 0,043112 \\
\hline A4 & 0,001435 & 0,000016 & 0,000000 & 0,000809 & 0,047535 \\
\hline
\end{tabular}

A similaridade é dada por:

$$
C_{i}=\frac{d^{-}}{d^{+}+d^{-}}
$$

\begin{tabular}{|c|c|}
\hline \multicolumn{2}{|c|}{ Similaridade } \\
\hline A1 & 0,784 \\
\hline A2 & 0,456 \\
\hline A3 & 0,516 \\
\hline A4 & 0,542 \\
\hline
\end{tabular}


A partir das similaridades obtidas, as alternativas foram ordenadas em: A1, A4, A3 e A2. Considerando a ordenação obtida pelo método TOPSIS, o conjunto das alternativas escolhidas é composto por A1 e A4.

\section{CONSIDERAÇÕES FINAIS}

$\mathrm{Na}$ busca por uma solução para o problema de seleção múltipla foi conduzido uma análise experimental multicritério utilizando o método MEM. O resultado alcançado por meio do método MEM, em uma análise experimental, refletiu o resultado do processo decisório ocorrido na prática. A aplicação do método apresenta-se como potencial instrumento de apoio ao processo decisório, visto que atendeu satisfatoriamente ao requisito estabelecido para a seleção da equipe, complementaridade

Uma análise de sensibilidade para os valores do o tau $(\tau)$ de corte foi realizada, tendo sido constatado que o valor médio adotado permitiu uma maior discriminação dos conjuntos candidatos.

Numa escolha dupla baseada em ordenação simples, pode-se verificar que há uma forte indicação pela seleção da alternativa $A 1$, que apresentou um desempenho superior as demais. Pode-se dizer que a alternativa $\mathrm{A} 1$ representa o melhor candidato Entretanto, devido à característica compensatória dos métodos de ordenação simples, as demais alternativas apresentaram desempenhos muito próximos, o que em geral dificultam a decisão e não reduz o risco da seleção de conjuntos que apresentam grande similaridade entre si.

A solução para a escolha dupla apresentada pelo método De Borda, alternativas (A1 e A3) diferiu das soluções propostas pelos outros métodos.

Por fim, os resultados apresentados pelo MEM apontam que a melhor opção de dupla não são as duas melhores colocadas na ordenação simples (alternativas com maior similaridade/substitutas). Mas, aquelas que juntas representam o melhor conjunto (alternativas complementares), dados os critérios e condições estabelecidos no contexto do problema.

Para trabalhos futuros, considerando a importância do vetor de pesos para a seleção, na definição do vetor, conforme proposto por Costa e de Seixas Correa(2010), sugere-se a utilização do método de Análise Hierárquica (Analytic Hierarchic Process, AHP), uma vez que o AHP permite medir o grau de consistência dos julgamentos. 


\section{REFERÊNCIAS}

Al-Harbi, K. M. A.-S. Application of the AHP in project management. International Journal of Project Management, v. 19, n. 1, p. 19-27, 2001. ISSN 0263-7863. Disponível em: < http://www.sciencedirect.com/science/article/pii/S0263786399000381 >.

Al-Reshaid, K. e Kartam, N. Design-build pre-qualification and tendering approach for public projects. International Journal of Project Management, v. 23, n. 4, p. 309-320, 2005. ISSN 0263-7863.

Alencar, L. H. e Almeida, A. T. d. Multicriteria decision group model for the selection of suppliers. Pesquisa Operacional, v. 28, p. 321-337, 2008. ISSN 0101-7438. Disponível em: < http://www.scielo.br/scielo.php?script=sci_arttext\&pid=S0101-74382008000200009\&nrm=iso >.

Alencar, L. H. e Almeida, A. T. d. A model for selecting project team members using multicriteria group decision making. Pesquisa Operacional, v. 30, p. 221-236, 2010. ISSN 0101-7438. Disponível em: < http://www.scielo.br/scielo.php?script=sci_arttext\&pid=S0101-74382010000100011\&nrm=iso >.

Boehm, B. W. Software risk management: Principles and practices. IEEE Software, v. 8, n. 1, p. 32-41, 1991.Disponível em:

<http://www.scopus.com/inward/record.url?eid=2-s2.0

0025791156\&partnerID=40\&md5=b077948553e98532caee0f82a89aef77 >.

Costa, H. G. Introdução ao Método de Análise Hierárquica: Análise Multicritério no Auxílio à Decisão. Niterói, 2002.

Costa, H. G. Sistemas de Votação pelo Método De Borda. Relatórios de Pesquisa de Engenharia de Produção B, v. 1, p. 1-10, 2014.

Costa, H. G. e de Seixas Correa, P. Construction Of an AHP - Based Model to Catch Criteria Weights in Post-Occupancy Evaluation. International Journal of the Analytic Hierarchy Process, v. 2, n. 1, 2010. ISSN 1936-6744.

Heizer, J. H. e Render, B. Administração de operações: bens e serviços. LTC, 2001.

Hora, H. R. M. d. Método de Escolha Múltipla: uma proposta multicritério para seleção em conjunto de mais de uma alternativa. 2013. 119 (Doutorado). Programa de Pós-Graduação em Engenharia de Produção, Universidade Federal Fluminense, Niterói.

Kelemenis, A., Ergazakis, K. e Askounis, D. Support managers' selection using an extension of fuzzy TOPSIS. Expert Systems with Applications, v. 38, n. 3, p. 2774-2782, 2011. ISSN 0957-4174. Disponível em: <http://www.sciencedirect.com/science/article/pii/S095741741000864X >.

Lootsma, F. A. (1999). Introduction Multi-Criteria Decision Analysis via Ratio and Difference Judgement.

Roy, B. Multicriteria Methodology for Decision Aiding. Springer, 1996. 


\section{Capítulo 17}

doi $10.37423 / 210403821$

\section{COMUNICAÇAO UBIQUA E PRODUÇAO DE PRESENCBA: O PENSAMENTO DA ARTE NOS METODOS DE PROJETO NO DESENVOLVIMENTO DE INTERFACES GRAFICAS}

Claudia Teixeira Marinho

Lara Silva Lima

Vitor Alencar Araripe Cordeiro

Ravi Passos

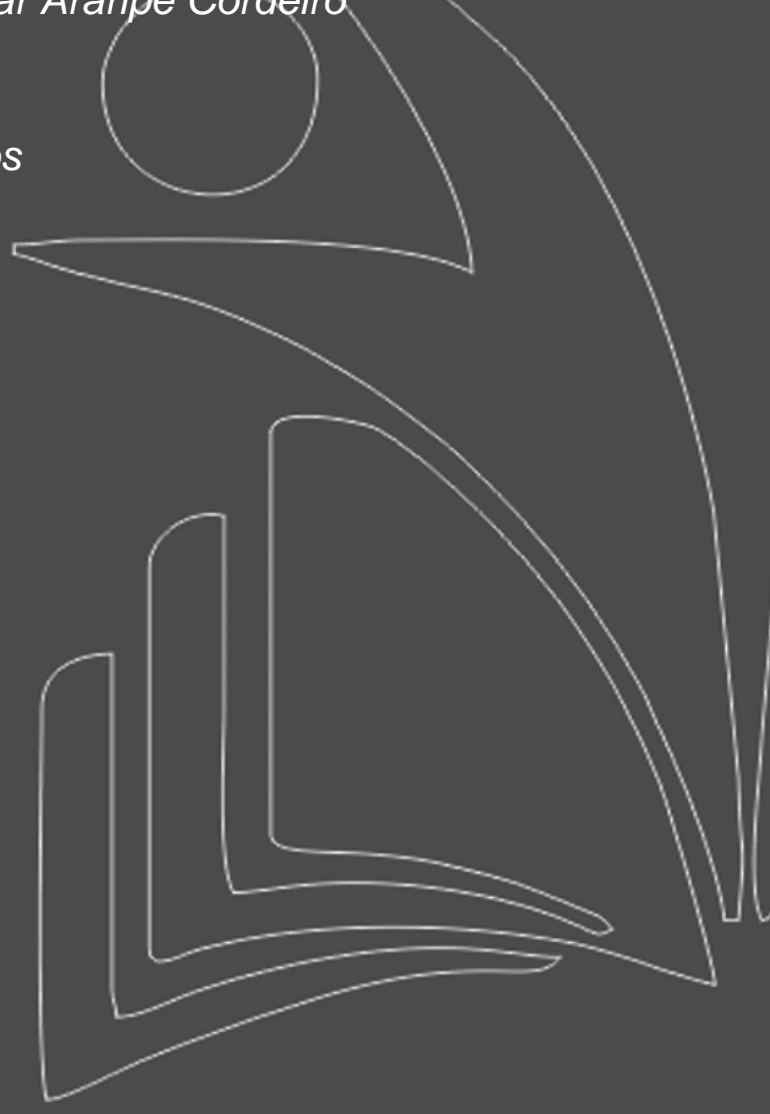

Universidade Federal do Ceará

Universidade Federal do Geará

Universidade Federal do Ceará

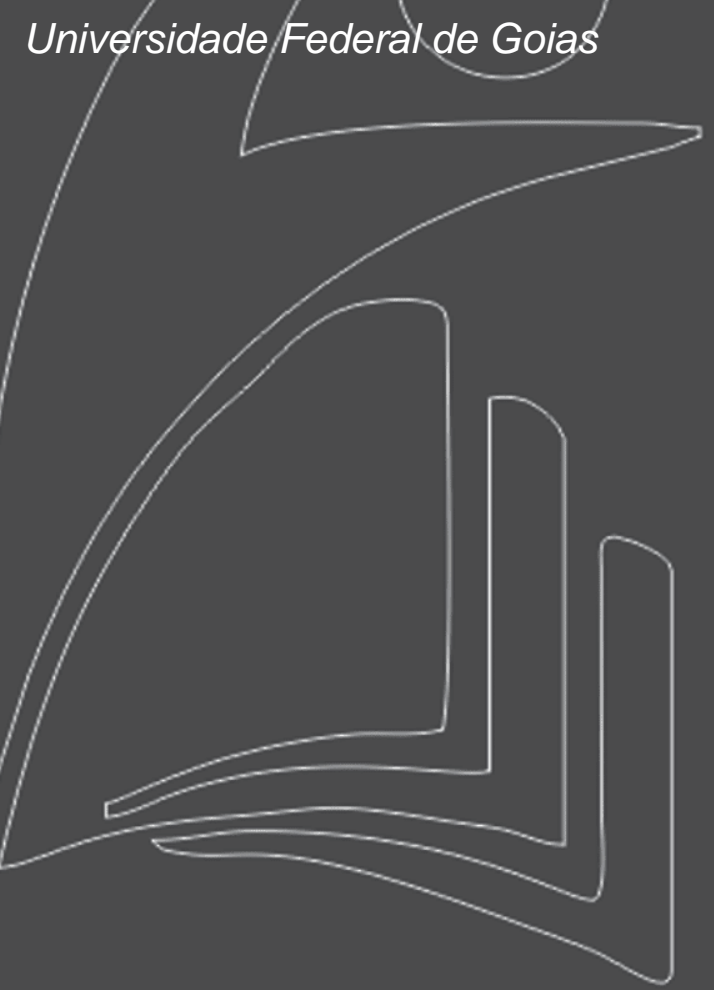


Resumo: As questões apresentadas neste artigo se fundamentam em discussões realizadas pela equipe de professores e alunos do curso de Design da Universidade Federal do Ceará durante o desenvolvimento de um sistema de comunicação para a cidade de Fortaleza. Conta-se com as possibilidades oferecidas pelas tecnologias digitais e de redes para a criação de sistemas de comunicação-sinalização, como legado da Copa 2014, a partir do uso dos recursos da realidade aumentada (RA). Tem como propósito explorar - em termos conceituais - uma tensão interpretativa que as tecnologias digitais podem promover nas formas de perceber e vivenciar os espaços urbanos, bem como - em termos de projeto - o desenvolvimento de interfaces gráficas que articulem uma noção de comunicação potencializada pelos mecanismos de trocas promovidos pela computação ubíqua a partir da articulação dos conceitos de estética da comunicação - tendo em vista o conceito de sublime tecnológico - e o pressuposto de uma cultura da presença , para refletir sobre métodos de projeto tendo em vista o pensamento da arte.

Palavras-chave: método, projeto, interface, realidade aumentada. 


\section{INTRODUÇÃO}

Os dispositivos móveis são hoje artefatos dotados de recursos que possibilitam a conexão entre espaços físicos e virtuais, promovendo assim, formas de comunicação que têm remodelado os potenciais perceptivos dos indivíduos - seja pela proposição de novas visualidades ou pela promoção de novas formas de articulação dos espaços.

Considerando este contexto, e considerando uma discussão inerente ao projeto "Fortaleza, Copa do Mundo 2014: avaliação de infraestrutura e proposição de melhorias para grandes eventos esportivos", a ser melhor detalhado seguir, entende- se que para o designer, sujeito envolvido neste processo, no que tange o pensar a comunicação em territórios híbridos, devem ser elaboradas estratégias projetivas que contemplem, mais do que a aplicação de princípios lógicos definidos pelo método de projeto empregado, a elaboração de percursos investigativos que possibilitem uma ampliação problematização - das questões do projeto.

Considerando os fundamentos de projeto voltados para a resolução de problemas complexos, como descrito por Moares (2010), relacionados ao projeto de pesquisa supracitado, determinou-se uma formatação e prospecção teórica que servisse de guia durante o processo projetual para definir, ao invés de uma resposta única, um campo de possibilidades de diferentes decisões de projeto.

Durante o desenvolvimento de um aplicativo voltado para o turismo em Fortaleza - que corporifica um sistema de comunicação ubíqua composto por um aplicativo (APP) e um sistema de sinalização constituído por um conjunto de placas que utilizam tecnologia da Realidade Aumentada (RA) - foram formuladas questões de pesquisa, algumas das quais constituem o escopo deste artigo e que versam sobre as aproximações entre os pensamentos da arte e do design; no que se refere aos novos processos de comunicação promovidos pelas tecnologias digitais, objetivando a formulação de métodos de projeto.

Para a criação de algumas das interfaces gráficas do APP, não se mostrou suficiente apenas processar e classificar os conteúdos para definir os parâmetros de organização dos elementos visuais, como indicado nos procedimento clássicos de desenvolvimento de taxonomias. Tal situação se deu por conta da necessidade de compreensão das potencialidades técnicas/tecnológicas em uso para o planejamento de uma visualidade coerente com uma concepção de design como estratégia investigativa integrada. 
Projetos de cunho artístico, como realizados pelo grupo Re+Public1 (ver figura 1), que fazem uso da realidade aumentada e transmídia para repensar o espaço e a arte de rua, serviram de mote para busca de fundamentos, e do pensamento da arte e suas estratégias comunicativas, para assim, pensar um conjunto de interfaces para o APP em desenvolvimento, que são dedicadas apresentação de informações sobre pontos de cultura da cidade de Fortaleza.
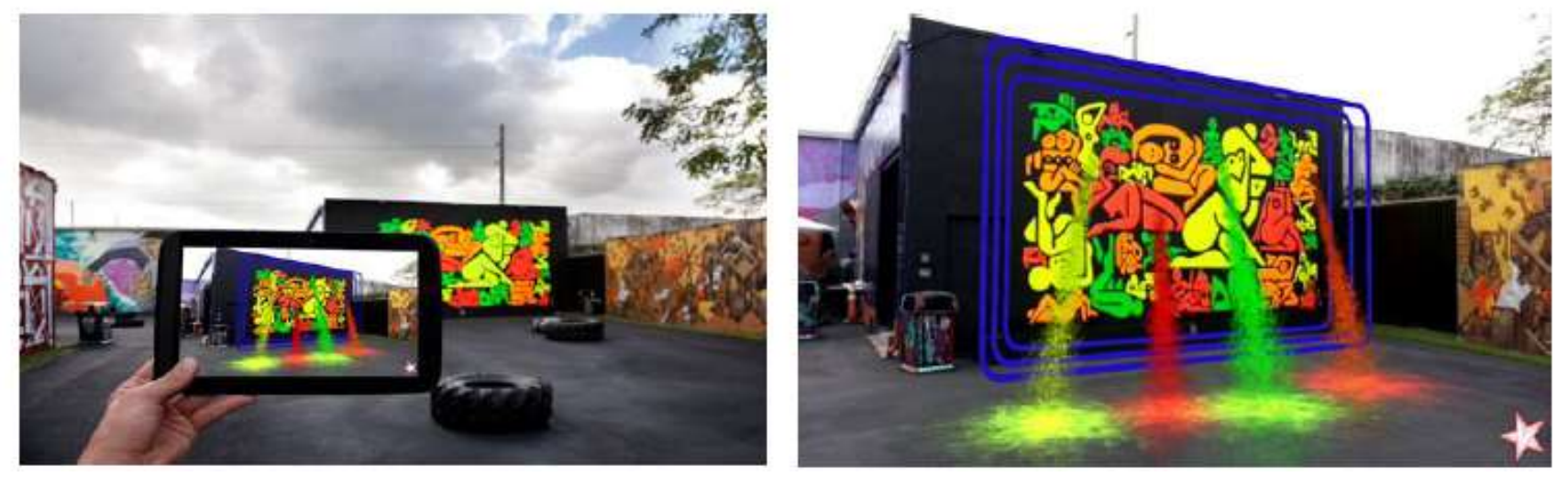

Figura 1 - Mural artístico de Ryan McGuinness animado pelo grupo Re+Public no evento Art Basel de Miami em dezembro de 2012.

Delimitou-se como significativa nesta etapa do projeto a ampliação da compreensão sobre as relações entre comunicação e tecnologia, com o objetivo de se investir em reflexões sobre os processos de projeto, e tendo-se em vista a elaboração de iniciativas que possibilitassem abordagens de métodos voltados para a produção de novas experiências nos espaços da cidade; a partir da articulação de repertório particular de projeto.

A definição de design como, "as ações de conceber, programar, projetar e realizar comunicações visuais, produzidas em geral por emissor industriais e destinadas a transmitir mensagens específicas para um grupo determinado, como definição do design." (Frascara, 1990, p. 19 ), não é suficiente ao contexto do projeto, na medida em que não contempla o potencial usuário do APP em desenvolvimento, identificado como aquele que participa ativamente dos processos comunicativos, que interpreta ativamente o conteúdo midiático, bem como está disposto a experimentar novas experiências do espaço e visualidades. Esta consideração se embasam em análises empíricas de interações em interfaces diversas, tais como games, vídeos interativos, comunicação em rede e as formas de troca operadas nas comunidades virtuais.

Avançando com o construto conceitual e a reflexão proposta, recorre-se aos conceitos, i) produção de experiência - emprestada do pensamento de Gumbrecht (2010) - e ii) estética da comunicação, como 
descrita por Costa (1993), para ampliar os fundamentos do projeto utilizado como objeto da pesquisa, em direção a uma abordagem dos processos de comunicação urbana pelo viés de reflexões sobre uma materialidade das informações digitais - capaz de criar presença - e as vivências estéticas possibilitadas pelas tecnologias.

Grumbrecht (2010) e Costa (1993) trazem como contribuição um questionamento sobre o predomínio contemporâneo da cultura do significado ou da interpretação, para pautar o pensamento gráfico quando aplicado às mídias digitais, de modo a não reduzir como função da linguagem gráficas, quando aplicada no desenvolvimento de interfaces para aplicativos móveis, à mera função de transmitir informação.

Enquanto Gumbrecht (2010), privilegia a materialidade da mensagem, sua integração aos contextos e os efeitos de sua presença, tendo em vista "um corpo capaz de forma de leitura que o perpassa e que antecede à interpretação"(p. 26). Costa (1993) , propõe pensar as novas tecnologias não como próteses do corpo humano, à maneira de Macluhan, e sim como funções separadas, como instrumentos dotados de uma lógica própria com a qual é necessário interagir para poder utilizá-los, trazendo a tona as funções dos artefatos trazidas por Löbach (2001).

Identifica-se durante as pesquisas que os argumentos dos designers envolvidos no desenvolvimento de interfaces gráficas para mídias digitais, são similares aos empregados pelos designers gráficos nas décadas entre 1920 e 1950; um período em que se pensou que o design, para ser design, deveria seguir um conjunto de regras, realizando as exigências de uma cultura voltada para a funcionalidade (CARDOSO, 2012), a clareza, a objetividade, a usabilidade. Como aplicado no design corporativo.

Diante desta reflexão, mostra-se oportuno e desafiador a processo de design, no contexto de emergência de novas tecnologias de comunicação - como o RA - definir modos de apropriação de saberes e estratégias de outras áreas do conhecimento que lidam com imagem e tecnologia - como no caso das artes, o cinema, o vídeo, a fotografia - logicamente sem o prejuízo dos requisitos fundamentais do projeto desenvolvido - como forma de realizar a vocação interdisciplinar do design em vista às demandas problemas contemporâneos.

A partir desta observação, realiza-se uma série de apontamentos sobre as novas possibilidades do design gráfico frente os desafios das mídias suportadas por dispositivos. Alguns destes, partilham-se neste artigo para propor caminhos para repensar as concepções de projeto que reduzem as ações do design ao cumprimento de um princípio de regras como garantia de uma boa prática de projeto e comunicação eficaz, para pensar métodos de trabalho que contemplem a hibridização de conceitos e 
de ações. Tal posicionamento encaminha para uma direção distinta dos resquícios na fé dos ideais progressistas do design - como previsto pelo pensamento moderno - que parecem sobreviver ainda hoje nos argumentos de projeto.

\section{DESENVOLVIMENTO}

A seguir apresentam-se descrições e detalhamentos sobre o projeto desenvolvido e utilizado como contexto da presente discussão.

\subsection{DESCRIÇÃO DO PROJETO}

O projeto, "Fortaleza, Copa do Mundo 2014: avaliação de infraestrutura e proposição de melhorias para grandes eventos esportivos", é uma encomenda feita ao Centro de Tecnologia da Universidade Federal do Ceará, pelo Ministério dos Esportes com o financiamento do CNPq, para a prospecção de oportunidades de desenvolvimento dos legados da Copa 2014.

Nesta perspectiva, foi apresentado pelo Curso de Design da UFC o desenvolvimento de um sistema de comunicação endereçado para a promoção do turismo na cidade de Fortaleza; a partir da criação de um aplicativo "guia da cidade" para dispositivos móveis (smartphones e tablets), conjuntamente à elaboração de um projeto de sinalização para pedestres que servisse de complemento para o aplicativo de modo integrado e interdependente (figura 2).

A partir da abordagem metodológica empregada pelo Design da Informação, associada às possibilidades oferecidas pela tecnologia de RA (Realidade Aumentada), propôs-se a criação de um sistema ubíquo de sinalização voltado para a definição de mapas que possibilitassem associações entre atores e espaços urbanos a fim de se permitir a visualização de informações sobre a cidade em formas diversas de linguagens; sobretudo aquelas não previstas no repertório gráfico visual normalmente utilizados nos projetos de sinalização urbana. 


\section{TURISMO E DISPOSITIVOS MÓVEIS}
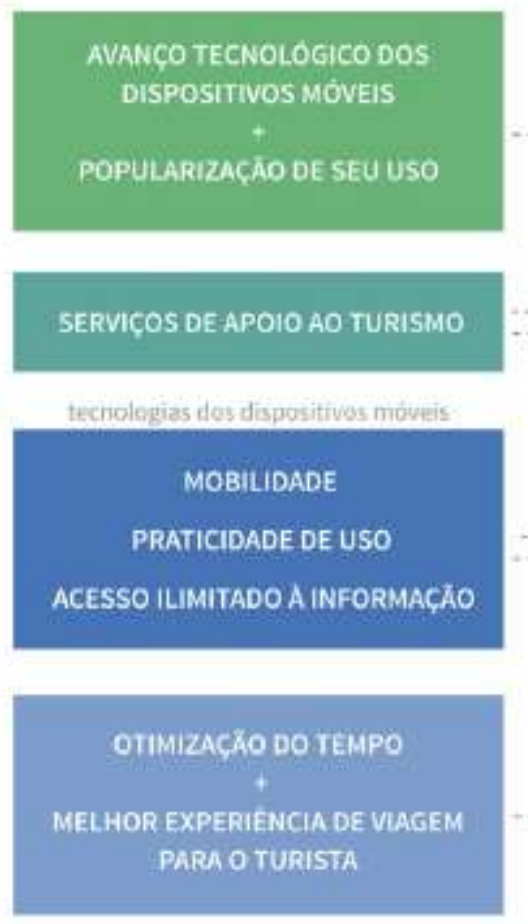

\footnotetext{
O Turismo é um dos maiores setores que movimentam a economia da nossa cidade e cresce a cada ano.
}

\section{O PROJETO}

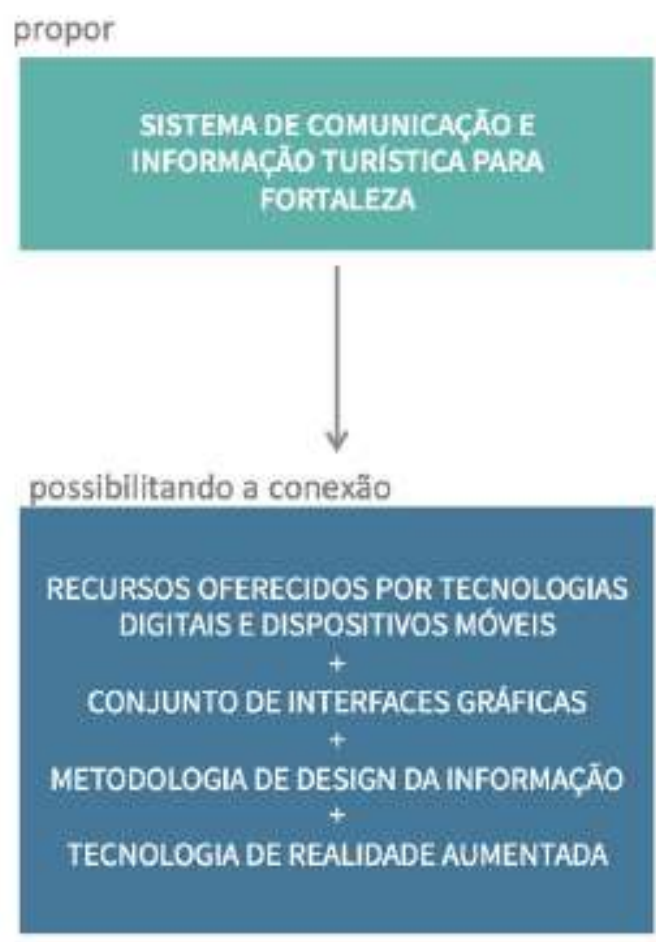

Figura 2 - Esquema das relações e influências entre turismo e tecnologia para dispositivos móveis; e as áreas que o projeto possibilita estudar.

A realidade aumentada ( $R A)$, pode ser definida como um sistema de mídias que proporciona a ampliação da visão que temos da realidade, por meio da sobreposição de informações e objetos virtuais no ambiente real. Os dispositivos empregados podem ser óculos, webcams, monitores e dispositivos móveis, como smartphones e tablet. São muitas os recursos oferecidos pela RA, para a gestão e gerenciamento de projetos de informação urbana, sobretudo para a criação de instrumentos que possibilitem a aquisição, troca e manipulação de conteúdos, voltados à saúde, à segurança, ao turismo, dentre outros. Observa-se que as possibilidades oferecidas pela RA, quando vinculadas ás dinâmicas do cotidiano, então ligadas aos serviços públicos e culturais, privilegiadas, sobretudo pelo uso de dispositivos móveis.

Para o desenvolvimento do APP foram aplicadas dois padrões: reconhecimento de imagem e orientação por GPS (Global Positioning System), para a apresentação, de conteúdos de mapas e apresentação de pontos de cultura e históricos da cidade, sendo o segundo para oferecer serviços de hotéis, restaurantes, rotas turísticas. 
Em um primeiro momento, as questões formuladas para o desenvolvimento do projeto, contemplaram as demandas aferidas nos estudos sobre o tema, tendo em vista uma eficácia de comunicação. Neste momento, o foco do projeto estava no acesso às informações de serviços oferecidos pela cidade. Este tipo de questão, para o grupo que é iniciante na área, foi resolvido por uma pesquisa bibliográfica direcionada.

Como resultado houve a compilação de princípios que fundamentaram a definição de tipografia, iconografia, paleta de cores e os sistemas de grid mais apropriados à realização dos objetivos do projeto.

Em uma etapa seguinte, foi definida como demanda do projeto a exploração das potencialidades dos meios e tecnologias empregados. Tendo em vista a afirmação de Tori (2009, p. 18), quando fala sobre a necessidade de o designer ter pleno domínio sobre os recursos oferecidos pela tecnologia e, principalmente, das limitações e requisitos que a acompanham, sobretudo quando chamar a atenção para o fato de que um designer gráfico, mesmo que bem sucedido, "não será necessariamente bem sucedido se tentar aplicar métodos e conceitos de mídia impressa, sem as devidas adaptações, em projetos de mídia digital interativa".

No caso específico da Realidade Aumentada, tema abordado pelo autor, possuiria peculiaridades e limitações bem diferentes das mídias digitais "convencionais". O autor sugere que uma ponte entre o pensamento do design gráfico e aquele direcionado para a construção de interfaces gráficas para mídias digitais - seja construída pelo viés do design da informação - uma subárea do design - no sentido de dominar as técnicas e conceitos que fundamentam essa nova tecnologia, sobretudo entender suas limitações e conhecer suas possibilidades.

Ainda, segundo Tori (2005), a RA é uma tecnologia que exige uma combinação precisa, harmoniosa e complexa de materiais físicos, digitais e humanos, elevando-se assim a ordem de grandeza dos conhecimentos envolvidos e das dificuldades a ser enfrentadas pelo designer. E coloca que um projeto de RA, deve atender aos seguintes requisitos:

- Integrar elementos virtuais, gerados por tecnologia computacional, a um ambiente real (ou integrar elementos reais a ambientes virtuais);

- Ser interativo e responder em tempo real;

- Prover registro, em três dimensões, entre elementos reais e virtuais (ou seja, as posições espaciais dos elementos virtuais devem ser bem definida e consistentes com o ambiente real). 


\subsection{FUNDAMENTOS DO PROJETO}

Para cumprir os requisitos do projeto, aplicou-se estratégias do design de interfaces gráficas e da interação como alicerces e ferramentas norteadoras no desenvolvimento da aplicação. Foram ainda definimos como demanda do projeto estratégias investigativas que possibilitassem a descrição de métodos que potencializassem a tecnologia empregada, para a proposição de novas visualidades.

\subsubsection{DESIGN DE INTERFACES GRÁFICAS E A METODOLOGIA APLICADA}

O design de interfaces gráficas é um instrumento que colabora no processo de comunicação, uma vez que planeja o modo de interação entre usuário em máquina - o mundo real e o virtual - e tem como objetivo reduzir a complexidade cognitiva e produzir clareza na transmissão das informações. Esse resultado não é adquirido trabalhando somente o aspecto visual, mas também se estendendo a outros canais de percepção, como o tátil, entre outros, utilizados por interfaces ditas "naturais". Assim o design da interação é usado como apoio para gerar um produto mais adequado e equilibrado, baseando-se na usabilidade e na interação usuário-interface, e tornar a experiência do usuário mais prazerosa.

Existe algumas maneiras de iniciar um projeto de interfaces gráficas, havendo uma dependência relativa ao tema abordado, aos recursos disponíveis e ao método de trabalho intrínseco ao designer. A abordagem metodológica empregada para o planejamento e o desenvolvimento de interfaces no projeto em questão iniciou-se com uma investigação sobre o tema, examinando seu conceito, suas regras e suas ferramentas, e buscando referências visuais. Com isso, pôde-se identificar as etapas do processo de criação e os componentes de uma interface.

O passo seguinte, foi elaborar uma pesquisa de referências sobre turismo ubíquo aplicado ao design de interfaces para dispositivos móveis e analisar as questões que envolvem o tema. A partir dessa análise e do estudo das possibilidades oferecidas pelo design de interfaces gráficas, criou-se uma lista de requisitos - um programa de necessidades - onde todos os itens da aplicação foram definidos. Finalizado esse procedimento, o material estava preparado para gerar um fluxo de navegação, onde estipularam-se as conexões e interações entre os elementos e seus conteúdos.

O conceito da identidade visual foi fundamental na necessidade firmar uma referência regional ao produto, utilizando cores e tipografias que fizessem alusão às paisagens e à produção de artesanato na cidade. Para gerar essa identidade, foram articulados dois conceitos de design, o Flat Design e o Skeumorfismo (ver figura 3). 


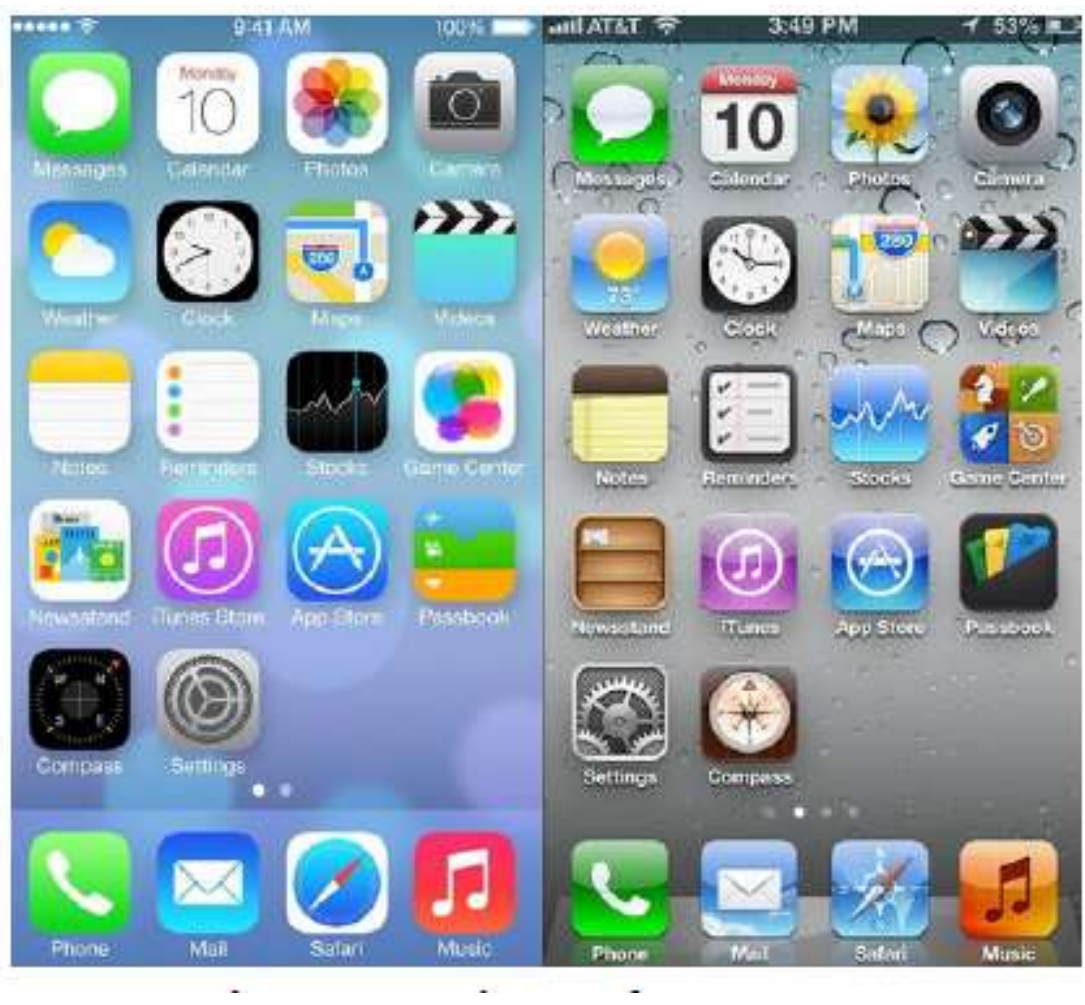

Figura 3 - Flat Design x Skeumorfismo

Recentemente, muitos debates sobre esses dois conceitos vem ocorrendo, e com isso, vem à tona o valor que agregou-se ao design de interfaces ao longo de sua evolução, as diferenças entre os dois estilos e seus elementos visuais, e a qualidade de design que cada um oferece. Um caminho sugerido pelo debate ao projeto em questão seria trabalhar os dois conceitos acoplados, pois entendeu-se que no contexto poderiam ser complementares, onde características negativas de um conceito poderiam ser substituídas por características positivas do outro.

O termo Flat Design tem sido utilizado para se referir a um estilo gráfico que trata de uma estética simplificada e minimalista, com pouco elementos, que abandona o uso do aspecto tridimensional nos elementos - gradientes, texturas e sombras - para dar lugar ao uso de vetores e cores chapadas, além de generosos espaços brancos para "respiro visual". Sua grande vantagem é sua implementação técnica e sua adaptação aos diferentes tipos de resolução de tela, mas pode ser de difícil compreensão para usuários que estão acostumados a responder a certo de tipo de visualidade.

Já o Skeumorfismo é um terno utilizado para tratar de um estilo gráfico com elementos que simulam/representam objetos reais da natureza a partir de cores, sombras, texturas, etc.. Sua vantagem é o fácil reconhecimento dos elementos visuais e suas ações pelos usuários, fazendo uso direto do conceito de metáfora de interação. Seu problema é que está defasado, pois não acompanhou bem a evolução da tecnologia. 
Levando em consideração esse debate entre esses dois conceitos de design de interfaces com uma marca leve, criou-se uma identidade visual adequada ao proposto do projeto e de características que possibilitam alta pregnância, onde os elementos são simples e de fácil reconhecimento e interação.

O processo de escolha da tipografia e da iconografia, durante toda a fase de concepção do layout geral, demandou grande parte do tempo, pois esses dois elementos possuem grande influência no resultado final do produto.

Paralelo a esse processo de desenvolvimento da identidade visual, foram geradas diversas alternativas de interfaces que foram estudadas com a implementação em mockups (ver figura 4). Em seguida, após seleção da alternativa que supre a lista de requisitos, foi implementado um protótipo final para validação do modelo funcional.
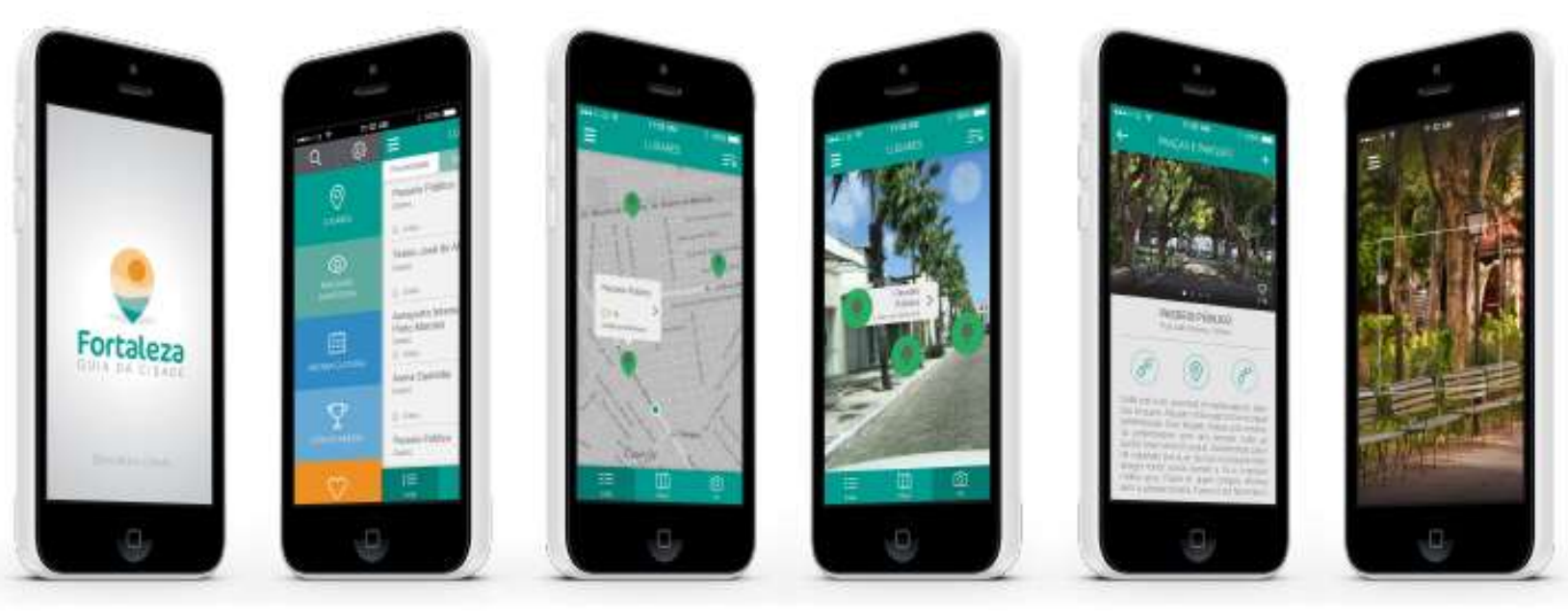

Figura 4 - Mockups da aplicação

\subsubsection{O PENSAMENTO DA ARTE}

Para o desenvolvimento das interfaces gráficas voltadas para a apresentação dos pontos de cultura de Fortaleza, elegeu-se uma concepção de projeto que privilegiasse uma compreensão do fazer do designer como potencial para traduzir o mundo pela perspectiva da projetabilidade; aquela que ao invés de aplicar ações previamente descritas, articulasse formas de apropriações de conhecimentos produzidos pela arte. No aso específico, que estivessem pautadas em estratégias de investigação tendo como critérios o desenvolvimento planejado, criativo e sistemáticos de visualizações de processos - para a proposição de visualidades que promovessem interação entre informações e as ações dos diferentes autores implicados na constituição de modelos de comunicação proposto a partir das tecnologias ubíquas, como possibilitada pela tecnologia empregada. 
É oportuno à trazer discussão as reflexões trazidas por Schneider (2011), que ao relacionar as noções de pesquisa e design, estabelece uma distinção entre pesquisa sobre design e pesquisa por meio do design:

- a pesquisa sobre design seria uma disciplina científica entre outras disciplinas científicas; teria como objeto, por exemplo, a história do design, a estética ou a teoria do design, na qual se reflete a essência do design ou de seus métodos.

- a pesquisa através do design seria a disciplina de projeto ou desenvolvimento, para obter novos conhecimentos, sendo que o seu objeto seria descrito a partir perspectiva da reconhecibilidade de códigos visuais devidamente relacionados.

A pesquisa sobre design, segundo o autor, envolveria, por exemplo, projetos de pesquisa da percepção e da estética, na área de metodologia, aperfeiçoamento de metodologia do design, da gestão dos processos de projeção, da padronização de métodos. Sendo que a atividade de pesquisa através do design, como um método específico de abordagem do mundo que gera um conhecimento imagético novo sobre esse mundo (SCHNEIDER, 2010, p. 276) seria uma disciplina de projeto ou desenvolvimento.

Ao definir como requisito do projeto, a proposição de visualidades que traduzissem as temporalidades e acontecimentos dos lugares - para produzir as interfaces gráficas do APP - para a integralização de dinâmicas comunicativas operadas pela arte e pelo design, em espaços híbridos, mostrou-se importante relacionar os temos estética e comunicação. As noções de estética da comunicação e produção de presença, como descritos, respectivamente por Costa (1999) e Gumbrecht (2010), serviram de subsídios para encaminhas as discussões.

Uma compreensão sobre os processos da arte - como estratégia de comunicação e proposição de novos conceitos (SALLES, 2010,) - vinculada ao reconhecimento de mecanismos - como articulados pelo design - para definir novos métodos de projeto, pareceu necessário para rever os conceitos clássicos da comunicação - articulados a partir do alinhamento das rubricas emissor, mensagem, receptor. Primeiro para estabelecer parâmetros para rever as noções de interação, funcionalidade e usabilidade - como aplicados na primeira fase do projeto, e segundo, para tencionar os pressupostos do sentido e da interpretação como propósitos e fundamentos do projeto gráfico.

O modelo de comunicação transmissiva - para a qual, seria a principal função do designer, a interpretação, a organização e a apresentação visual da mensagem - não pareceu contemplar os 
potenciais perceptivos do potencial usuário do nosso APP; descrito como um sujeito acostumado com as visualidade e dinâmicas comunicativas proporcionadas pelos games, o cinema e o vídeo e disposto a apreender mensagens pelo viés da experiência.

No campo do design a noção de experiência tem sido aplicada para o desenvolvimento de modalidades de projetos voltadas para a proposição de formas de interatividade que envolvam as ações do usuário como quesito de projetos de ambientes, objetos ou sistemas de informação; sobretudo para definir estratégias de marketing. Aplicada no contexto do projeto em questão, a noção de experiência é acionada como possibilidade de pensar o design como meio para produzir visualidades que promovam a sensação (ou ilusão) de que mundos do passado podem tornar-se tangíveis em espaços concretos, a partir da sobreposição de imagens digitais - como camadas de imaginários - nos espaços concretos; tendo em vista as possibilidades oferecidas pela RA.

Recorre-se a um pensamento da arte, que em termos históricos, foi articulado pelos artistas-designers das vanguardas históricas - como feito futurismo e o dadaísmo

- ao investimento em novas poéticas - modos de fazer - para refletir sobre o papel das tecnologias na proposição de novas visualidades (COUCHOT, 2003). Pensamento este que atualizado em termos de projeto no contemporâneo, traduziu-se como um investimento em novas visualidades, para refletir sobre o papel das tecnologias para a criação de novos modos de fazer projeto.

Neste sentido, o sublime foi um termo abordado por pela quipe do projeto para pensar a tecnologia no escopo do projeto, para pensar visualidades que produzissem novas experiências do espaço que não estivessem veiculadas ao pressuposto da interpretação, mas da produção de presença. Articulado por Costa (1995, p. 27) - a partir da expressão sublime tecnológico, é descrito pelo autor como parâmetro para compreender a estética da comunicação - "um campo de investigação ampliado à exploração e à definição dos fenômenos estéticos ligados às tecnologias comunicacionais e delas derivados".

Não cabe no escopo deste artigo buscar uma definição precisa sobre o termo, conta-se, portanto com a definição oferecida pelo autor, quando, a partir dos argumentos de Derrida, afirma que o sentimento de sublime se realizaria no horizonte da pequenez ou no absolutamente grande. Ou seja, seria ele gerado "por uma crise do simbólico, provocada por aquilo que não pode ser dito e não pode ser colocado em forma" (COSTA, 1995, p. 21). 
Em termos, o autor afirma que conceito de sublime, ao invés de restrito às investigações sobre as manifestações artísticas deve se vincular ás discussões sobre tecnologia. Na medida em que o sublime, como definido pelo campo da estético e no plano da produção artístico, foi mal entendido, pois ao se articular estritamente a partir da noção de belo, "nunca teve verdadeiramente a possibilidade de objetivar-se (de fazer-se objeto) e de manifestar-se". (COSTA, 1995, p. 19). No entanto, segundo ele, seria pelo viés das técnicas e tecnologias que o sublime poderia se manifestar.

Como justificativa, o autor ainda apresenta que "as novas tecnologias da comunicação também enquanto capazes de integrar as possibilidades abertas pela informática, parecem-nos um verdadeiro e próprio evento antropológico, capaz de reconfigurar radicalmente a vida do homem e a sua experiência estética". (Costa, 1995, p. 27)

Tais argumentos estão inseridos nas discussões sobre uma concepção de arte como forma de comunicação, e prevê como parâmetro para a formalização de discursos gráficos voltados para a exploração de novas tecnologias, a formalização de uma linguagem que prevê parâmetros estéticos que não reivindicam o belo mas a experiência do sublime - como potencializado pelos os sistemas de comunicação digital; ao promover novas formas de experiência com a informação; antes que possibilidades de leitura.

O conceito "produção de presença", como descrita por Gumbrecht (2010, p. 39), por este viés, tornase subsídios para afirmar uma materialidade das imagens digitais, sobretudo se considerado, como afirma o autor, que "qualquer forma de comunicação implica na produção de presença". Trata-se de um conceito que possibilita refletir sobre processos de projeto que estejam vinculados às formas de comunicação que se fundamentam no reconhecimento de eventos e de processos os quais se inicia ou se intensifica pelo impacto dos objetos 'presentes' sobre corpos humanos - as percepções

Fica evidente, que a ideia de objeto transcende a dimensão física do artefato e privilegia, sobretudo a linguagem e a tecnologia, como possibilidade para rever as missões do designer gráfico, ao pensar interfaces para dispositivos móveis.

Ao inferir como produto dos discurso gráfico a produção de presença, mostra- se um desejo da imediatez da comunicação, para questionar a eficácia da comunicação, em contraposição às possibilidades de leituras que uma abordagem crítica das tecnologias pode gerar.

Para Gumbrecht (2010), produção de presença - descrita pela relação do conceito de produção, como forma de "trazer adiante" (do latim producere) um objeto no espaço, traz a possibilidade de identificar 
oportunidade de experiências tecnológicas, que se mostrem o sublime, tendo em vista uma compreensão dos processos comunicativos, como caminho que possibilita rever, como desdobramentos do design, forma de investigar saberes correlatos, para propor novas formas de "traduzir" e descrever as relações nos espaços cotidianos.

\section{CONSIDERAÇÕES FINAIS}

Identificar potencias investigativos do projeto que possibilitem uma aproximação do design com outras áreas do conhecimento, direcionou ações - reflexões, que no caso, estavam vinculadas à possibilidades de comunicação instauradas pelas tecnologias comunicacionais, para pensar metodologias de projeto, em uma situação na qual as noções de sublime e presença podem se tronar argumentos do projeto de design.

Ainda que esta reflexão esteja vinculada com a exploração da tecnologia da Realidade Aumentada RA, para a criação de interfaces gráficas para um sistema que se articula entre espaços virtuais e concretos, articula-se a possibilidade de se estabelecer este mesmo pensamento em outras dimensões fronteiriças nas quais o pensamento de design pode se instalar.

O exercício de convocar autores que abordam a comunicação e a arte - no contextos das tecnologias digitais, para articular o pensamento do design gráfico, significa enfrentar questionamentos sobre metodologia de projeto. Isso significa investir em ações que levaram à formulação de conceitos que possibilitaram para a a equipe do projeto - constituída por designer gráficos, arquitetos e programadores, alinhar um pensamento de projeto que investe no repertório poéticos de um determinado usuário.

Dado o tempo de desenvolvimento do projeto de interfaces gráficas para dispositivos móveis, e por isso a impossibilidade de rever de forma crítica a literatura relacionada ao tema. Optou-se por caminhos flexíveis e não previstos, no entanto, pertinentes e relacionados aos conhecimentos disponibilizados pela equipe.

Assim sendo, justifica-se a opção por explorar a sublimidade da imagem digital e a construção da presença, na medida em que - diante de um desafio não previsto - identificou-se uma oportunidade para refletir as práticas projetivas, bem como uma oportunidade para prever que a função do designer é criar mais uma camada de significação sobre o mundo.

Antes de contrapor as noções de autoria e de mediação, como fundamento para definir as ações de projeto, optou-se por pensar sobre isso, de modo a reconhecer que cabe ao designer hoje se apropriar 
de conceitos, que advindos de outras áreas de conhecimento, possibilitem a ele reconhecer que as relações entre projeto, estética e função não são necessariamente tranquilas, mas devem ser estabelecidas.

Não se fala sobre conflitos de pensamentos, mas, antes disso, sobre a necessidade de investir em uma concepção de projeto que esteja implicada com o pensamento da arte, para tornar atual um pensamento que integre as tecnologia, as potencias comunicativas das artes e a história - como relato e genealogia - para revelar, pelo viés de um pensamento de projeto que elege a estética e a comunicação como fundamentos para explorar as novas tecnologias. 


\section{REFERÊNCIAS}

COUCHOT, Edmond. A tecnologia na arte. Porto Alegre: Editora da UFRGS, 2003. COSTA, Mario. 0 sublime tecnológico. São Paulo: Experimento, 1995.

FRASCARA, Jorge. Diseño gráfico y comunicacion. Buenos Aires: Ediciones Infinito, 1999.

GUMBRECHT, H.U. Produção de presença. Rio de Janeiro: Contraponto, 2010. HOOBER, S., \& BERKMAN, E. Designing Mobile Interfaces. O’Reilly Media, Inc., California, 2012.

KOUNAVIS, C., \& KASIMATI, A., \& ZAMINI, E. Enhancing the Tourism Experience through Mobile Augmented Reality: Challenges and Prospects. Artigo, International Journal of Engineering Business Management, Julho 2012.

LÖBACH, B. Design Industrial: bases para a configuração dos produtos industriais. São Paulo: Edgard Blücher, 2001.

CARDOSO, Rafael. Design para um mundo complexo. São Paulo: Cosac Naify, 2012. SALLES, Cecília Almeida. Redes de criação: Construção da obra de arte. Vinhedo: Ed. Horizonte, 2010.

SCHNEIDER, Beat. Design - pesquisa e ciência. In Design uma introdução. São Paulo; Blucher, 2010.

TORI, R. Desafios para o design de informação em ambientes de realidade aumentada. InfoDesign Revista Brasileira de Design da Informação, v. 6, n. 1, 2009. 


\section{Capítulo 18}

doi $10.37423 / 210403826$

\section{A CONTRIBUIÇÃO DA REALIDADE AUMENTADA PARA O DESENHO INDUSTRIAL}

\section{DANILO ÉMMERSON NASCIMENTO SILVA}

JOÃO ROBERTO GOMES DE FARIA

OSMAR VICENTE RODRIGUES

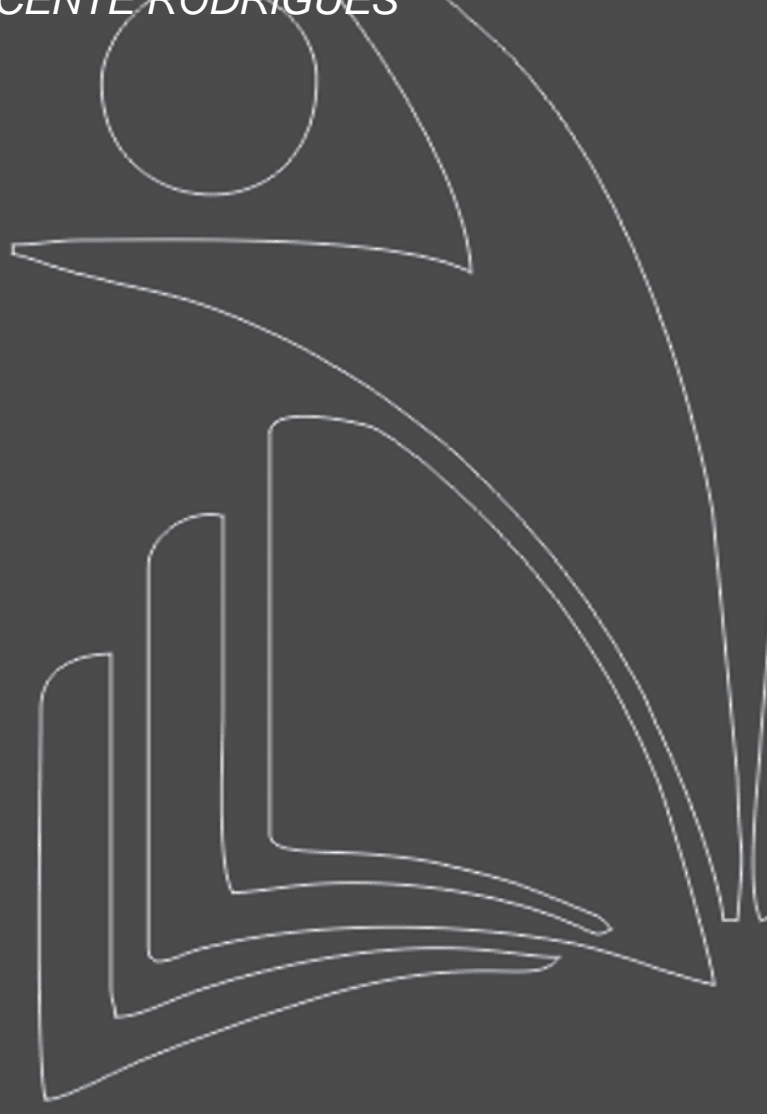

UNIVERSIDADE FEDERAL DE PERNAMBUCO

UNIVERSIDADE ESTADYAL PAULISTA JÚLIO DE MESQUITA FILHO

UNIVERSIDADE ESTADUALPAULISTA JÚLIO DE MESQUITA FILHO 


\section{A Contribuição Da Realidade Aumentada Para O Desenho Industrial}

Resumo: O propósito deste trabalho é estudar as novas tecnologias e suas formas de inserção na área projetual, em especial, no caso do desenho industrial e do desenvolvimento de produtos industriais. A partir da revisão literária, do estudo e da coleta de dados em campo e de laboratório pretende-se investigar como as novas tecnologias estão revolucionando a projetação de produtos. Esta transformação pode ser observada em países altamente industrializados seja entre os setores produtivos e empresariais ou no meio acadêmico. No Brasil, há indícios de algumas empresas adotarem esta implementação ou estarem atravessando por processos de migração de tecnologias inserindo a prototipagem rápida, a realidade virtual(RV)e realidade aumentada (RA)ou a holografia como instrumentos de apoio e auxílio durante o desenvolvimento de produtos. Mas e o ensino projetual? Como as instituições de ensino superior estão se preparando para essa revolução tecnológica durante a projetação de produtos? Este estudo tenta construir algumas respostas para essa questão.

Palavras-chave: realidade aumentada, novas tecnologias, desenho industrial. 


\section{INTRODUÇÃO}

O desenho industrial - design industrial - uma das áreas pertencentes à área projetual, além das engenharias e arquitetura, integra um conjunto de áreas responsáveis pelo desenvolvimento de produtos. Nas últimas décadas, tem sofrido uma mudança de paradigmas devido à inserção das novas tecnologias advindas dos campos da eletrônica, da cibernética e da computação (Bürdek, 2010).

O desenvolvimento de produtos, em especial, o desenho industrial, durante sua prática projetual sustentava-se pela adoção de técnicas criativas apoiadas em linguagens mecânicas e analógicas.

Todo o processo de desenho projetual contemplado pelas atividades de elaboração de esboços, debuxos e desenhos técnicos, da geração de modelos bi e tridimensionais, além da produção dos modelos, mocapes e protótipos, das análises, testes e simulações de uso, do manuseio e operacionalidade eram produzidos pela interação do intelecto com as habilidades manuais e instrumentos básicos e tradicionais.

A formação acadêmico-profissional, estruturada pelas grades e matrizes curriculares dos cursos de graduação em desenho industrial se pautava em torno desses instrumentos metodológicos e tecnológicos. Os investimentos institucionais para suprir estas demandas, basicamente, giravam em torno da implantação e oferta de laboratórios de desenho, salas de projeto, laboratório de modelos e protótipos e outros espaços correlatos como laboratório de fotografia (analógica) ou laboratório de ergonomia etc.

Os próprios investimentos individuais dos acadêmicos eram feitos entre materiais de desenho e de ilustração a mão-livre, de desenho geométrico e técnico, mesa de desenho, diversos tipos e formatos de papéis, máquina fotográfica analógica além de máquinas, equipamentos e ferramentas de trabalho manual e mecânico e dos diversos tipos de matéria- prima para execução dos modelos, mocapes e protótipos.

Atualmente, além dessas linguagens surge a linguagem digital como substituição, em alguns casos, ou pela sua complementaridade resultante das inúmeras contribuições da virtualização (Azevedo \& Conci, 2003). Várias técnicas empregadas na projetação de produtos como o desenho, a fotografia, a simulação, os testes e ensaios etc., receberam insumos das novas tecnologias. Além dos aplicativos de desenhos 2D e 3D e das plataformas de CAD, CAE e CAM, tem-se utilizado a digitalização 2D e 3D (Silva et al, 2006), o uso das tecnologias de prototipagem rápida (Barbosa \& Alencar, 2010; Volpato, 2007; Canciglieri Júnior, 2007; Forti, 2005; Rodrigues, Alencar \& Barata, 2012) - aditivas ou subtrativas -, e 
em aplicações, ainda, mais recentes e pontuais estão os casos das tecnologias de holografia (Aguillar \& López, 2004; Rosen, 2011), da realidade virtual (White, 2002; Craig, 2009) e da realidade aumentada (Tori; Kirner \& Siscoutto, 2006).

Este novo cenário implica em transformações educacionais e tecnológicas as quais já estão ocorrendo e necessitam de reflexões a serem produzidas no âmbito macro - das Instituições de Ensino Superior - e no micro - dos indivíduos e agentes envolvidos. Por exemplo, compete as IES disponibilizar espaços acadêmicos para que os alunos conheçam e experimentem a revolução tecnológica e não cheguem ao mercado profissional excluído tecnologicamente falando. Isso significa dizer equipar laboratórios de computação gráfica contendo equipamentos e programas computacionais adequados às demandas das áreas - gráfico, moda, produto e interiores - ainda que sejam investimentos de montante elevado, mas necessários. Necessário pelo que já foi exposto, mas ainda pelo fato dos próprios acadêmicos já conhecerem algumas dessas inovações quando ingressam no ensino superior. Alguns investimentos, nesse sentido, são realizados no núcleo familiar ou educacional de ensino anterior ao ingresso à universidade, à faculdade ou ao instituto de ensino. Esse investimento costuma ser mantido durante os anos seguintes à formação profissional, ou seja, os acadêmicos e familiares não medem esforços para proporcionar ao futuro profissional estes bens tecnológicos digitais ou virtuais, como computadores, impressoras, programas, máquinas fotográficas digitais, escâneres, mesas digitalizadoras dentre outros, uma vez que o processo de difusão tecnológica reduz os valores e facilita sua aquisição. Nascimento Silva et al (2013) se debruçou nessas questões reflexivas quanto ao âmbito das implicações da informática no ensino projetual com maior atenção e profundidade.

Portanto, as instituições de ensino superior que possuem cursos na área projetual devem mudar a percepção de que esses recursos a serem investidos são importantes e necessários. Se o problema reside em altos investimentos a IES deve construir estratégias criativas de alocação de recursos para o máximo de benefício a ser gerado, por exemplo, pelo uso coletivo entre áreas similares ou correlatas como engenharias e arquitetura ou engenharias e desenho industrial. Na mesma linha, os benefícios relativos aos investimentos devem estar claros para usufruir seja no ensino ou em projetos de pesquisa e da extensão. As parcerias com os segmentos industriais e produtivos também podem ser uma alternativa viável.

Há uma questão polêmica que, vez por outra, é levantada nos meios e ambientes em que surge a necessidade desses investimentos e diz respeito à preocupação e desconfiança no favorecimento de monopólios ou oligopólios de empresas ou empreendimentos que comercializam produtos ou serviços 
na área de informática e de computação. Isto, porque a cada ano ou temporada surgem novos modelos e versões renovadas algo que força e induz a pessoa física ou jurídica a se atualizar com as inovações tecnológicas lançadas no mercado. A pergunta que não quer calar é a seguinte: pretendese permanecer, na área projetual, independentemente do motivo, com os mesmos instrumentos metodológicos e operacionais, ou seja, o modus operandi da projetação se configurar da mesma maneira inalterada do período anterior à introdução da informatização? Caso alguma IES opte ao modelo anterior a essa nova era da virtualidade, dificilmente, o processo formativo se manterá in natura, em outras palavras, sem nenhuma interferência advinda da eletrônica, informática ou computação. Pode-se afirmar que isso jamais ocorrerá, pois o estado da arte e da tecnologia já alçou um patamar que, em princípio, no mínimo, ou na pior das hipóteses, ocorrerão pequenas ou menores intervenções no processo educacional.

\section{PROBLEMA}

A questão essencial dessa pesquisa reflete o modo como tem se comportado a área do desenho industrial e do desenvolvimento de produtos mediante as novas tecnologias interativas e imersivas. Este trabalho integra a estruturação da tese de doutorado, em andamento, pelo Programa de PósGraduação em Design da FAAC/UNESP, Bauru, Brasil. A tese intitulada O estudo da Engenharia Reversa como subsídio para a aplicação de técnicas analíticas de produtos em Desenho Industrial, além de outros aspectos, investiga o repositório instrumental e tecnológico advindo de outras áreas de cunho tecnológico e as possibilidades de sua contribuição ao desenho industrial.

\section{MÉTODOS}

O referido trabalho envolve uma revisão teórica, o uso de laboratórios como o Centro de Apoio ao Desenvolvimento de Produtos (CADEP/FAAC/UNESP), vide Figuras 1a, b, c e d, pela submissão de questionários e entrevistas e pela visitação a empresas e organizações de desenvolvimento de produtos, buscando identificar o estado da arte das novas tecnologias e a sua introdução no âmbito do desenho industrial e do processo de desenvolvimento de produtos. 


\section{A Contribuição Da Realidade Aumentada Para O Desenho Industrial}

Figuras 01a, b, c e d: Laboratório CADEP/UNESP; exemplos do uso de novas tecnologias de adição e subtração de matéria-prima em prototipagem rápida. Fonte: (Acervo usado com permissão dos autores Nascimento Silva, Rodrigues e Faria) (CADEP/FAAC/UNESP).

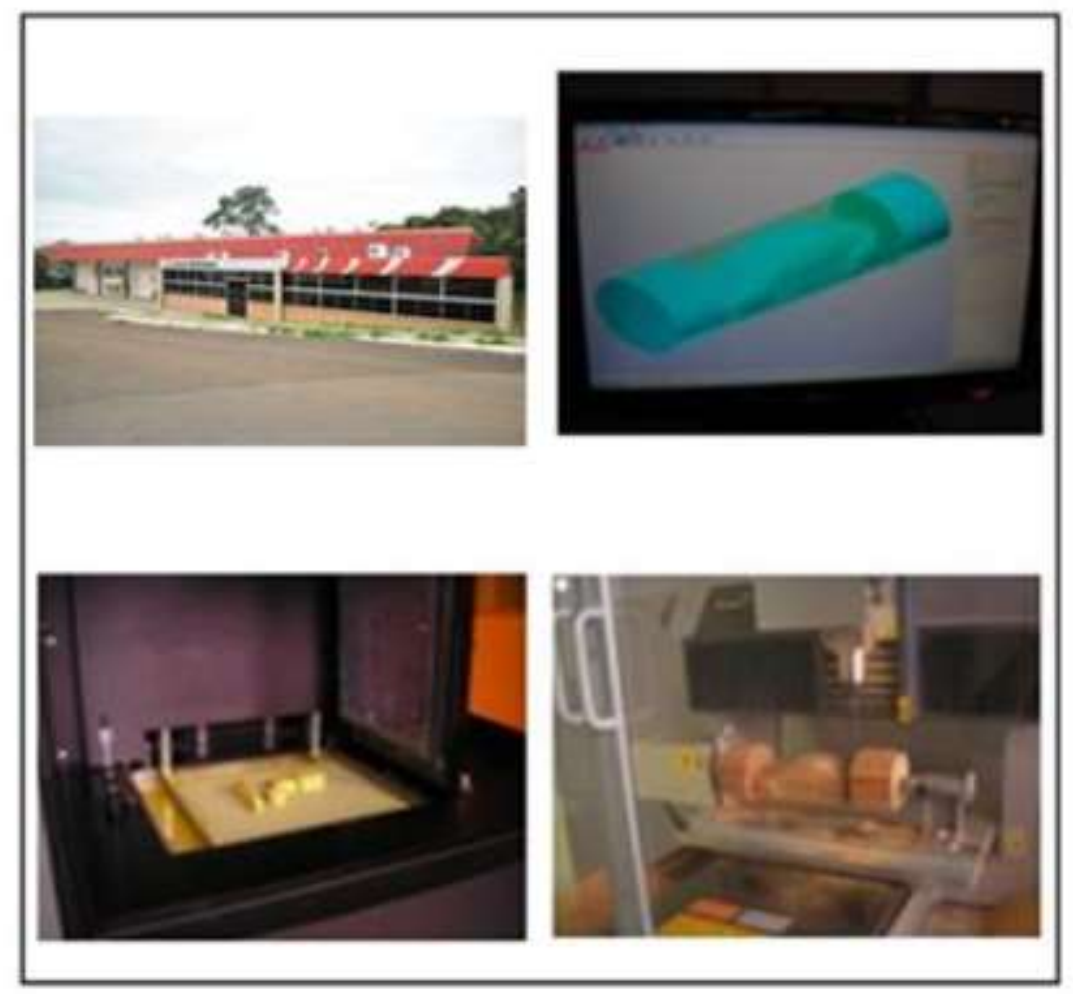

A coleta de dados, das diversas modalidades metodológicas apontadas anteriormente, encontra-se em processo de andamento com previsão de concluir-se durante o ano de 2014.

\section{RESULTADOS PARCIAIS}

Partindo-se da premissa de que uma das maiores aplicações da RV e da RA, tem a ver com a simulação de fenômenos de modo imersivo ou interativo, antecipando-se, ou atuando de modo paralelo à modelagem física dos produtos, trazendo, portanto, intervenções consideradas relevantes na atividade projetual, é que este estudo tem pautado suas discussões.

A realidade aumentada pode ser compreendida como um desdobramento da realidade virtual, no momento em que se utiliza dela para combinar imagens virtuais com cenários reais. Por esse motivo também pode ser conhecida por realidade mista, misturada ou combinada.

As interfaces de RA foram definidas por Azuma como interfaces que: 1) sobrepõem informação virtual sobre o mundo real (combinam objetos físicos e virtuais no mesmo espaço de interação); 2) são interativos em tempo real; e, 3) são espaciais - os objetos virtuais são registrados e interativos em 3D. (Azuma, 1997 apud Bowman et al, 2005:389). 
A detecção de falhas, de riscos, ou outros fatores relevantes como a produção, a montagem e a desmontagem dos componentes podem ser investigados virtualmente reduzindo os custos com protótipos ou moldes, por exemplo. Animações gráficas em RV e RA geram, com grande realismo, ambientes e cenários fictícios ou combinados com o real, como é o caso da realidade aumentada podendo simular desde aspectos de manuseio, operacionalidade, funcionamento e acionamento de um produto até a sua construção, por etapas, das peças e componentes.

Possivelmente, podem-se visualizar aspectos da fabricação como, por exemplo, da moldagem

- alimentação dos moldes por matérias-primas -, da retirada das peças dos moldes, acabamentos e tratamentos superficiais além de aplicação de soldas ou outras maneiras de uniões. Outras questões sustentáveis podem ser apreciadas com essas tecnologias como, por exemplo, gastos energéticos e eliminação de refugos durante a prototipação ou fabricação final dos produtos. A própria digitalização 3D de modelos físicos ou protótipos pode transportá-los para ambientes de RV ou RA, onde são feitas simulações virtuais.

Demonstrações convincentes de realidade virtual e aumentada estão sendo aplicados em um conjunto crescente de aplicações. A concepção iterativa é de suma importância, especialmente em testes de sistemas de manipulação direta avançadas, porque a novidade dessas abordagens pode levar a problemas inesperados para projetistas e usuários. (Shneiderman e Plaisant, 2005:258)

Várias empresas e organizações ligadas ao desenvolvimento de produtos (aviação, automobilismo, medicina, telefonia dentre outras) estão migrando e adotando a RV e a RA como instrumentos preciosos na busca da qualidade, eficiência, desempenho, treinamento, fabricação, divulgação e comercialização de seus produtos.

As figuras 2a e b ilustram alguns exemplos do emprego da realidade aumentada no programa versão livre Google Trimble Sketch Up. Alguns programas computacionais CAD ou 3D já desenvolvem atualizações (plugins) onde se pode explorar esse recurso tecnológico. No caso do Google Sketch Up o plugin é da ARmedia, uma ferramenta produzida pela Inglobe Technologies (http://www.inglobetechnologies.com/en/new_products/arplugin_su/info.php) 


\section{A Contribuição Da Realidade Aumentada Para O Desenho Industrial}

Figura 2a e b: Exemplos ilustrativos de simulação de RA com o aplicativo Trimble Sketch Up versão livre. Fonte: (Acervo usado com permissão dos autores Nascimento Silva, Rodrigues e Faria a partir de exemplos e modelos importados livremente do sítio

http://sketchup.google.com/3dwarehouse/search?scoring=p\&start=0).

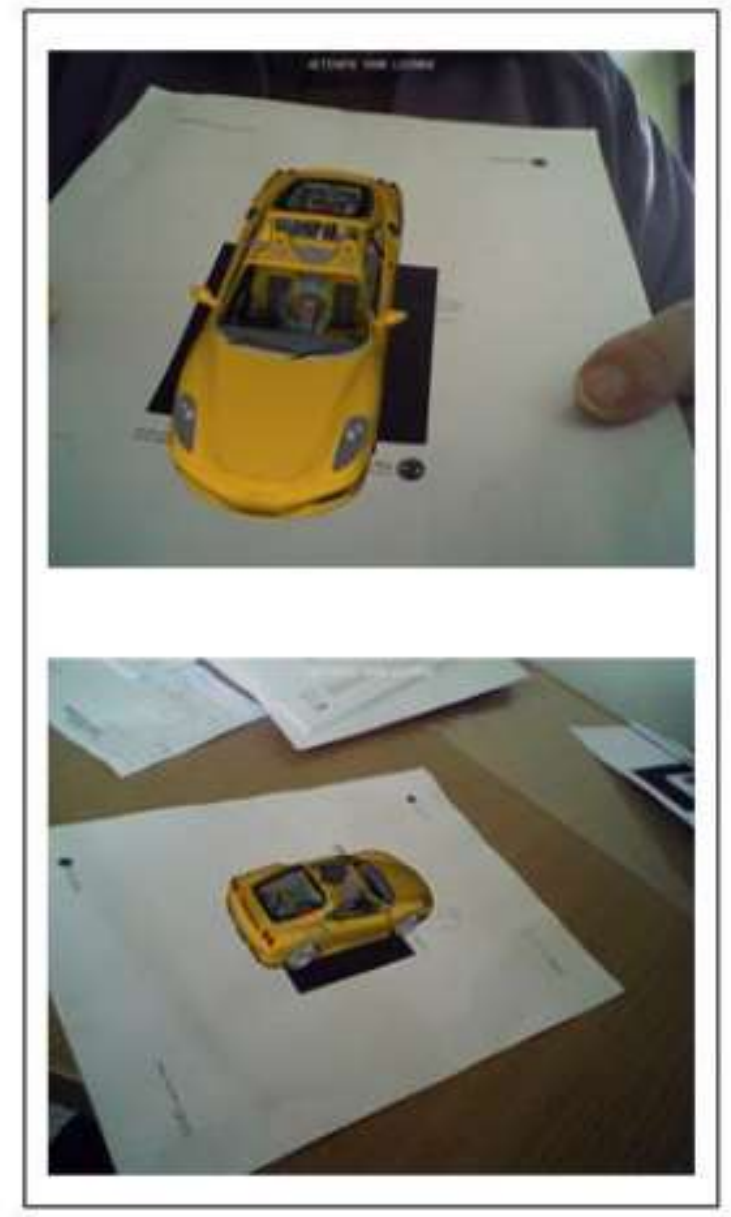

Basicamente, o princípio da RA parte de um aplicativo o qual transforma o projeto, a ideia ou o conceito de algo em um código - QR Code, do inglês Quick Response - evoluído dos códigos de barra, podendo ser reconhecido por câmeras conectadas transformando o "código" em imagens virtuais 3D interativas combinadas com o ambiente real. Uma das vantagens da RA diz respeito ao fato da eliminação de acessórios como luvas, óculos ou capacetes para visualizar ou interagir com as imagens geradas.

De modo análogo - ao que algumas empresas automobilísticas já adotam - ou seja, por intermédio de uma câmera de um tablet ou smartphone, é possível o proprietário do veículo receber instruções para manutenções básicas, um determinado engenheiro ou projetista de produto pode, durante a atividade de redesenho de produtos, munido com um aplicativo desenvolvido, fazer análise de "raio 
X" - investigando estruturas internas ou escondidas; simular cortes e seções; proceder montagens e desmontagens de produtos; simular comportamentos de esforços, cargas, tensões, momentos críticos e de falhas, superaquecimento de estruturas submetidas a calor etc.

Como verificado os limites e as possibilidades são difíceis de prever e determinar dependendo, quase que exclusivamente, do desenvolvimento de aplicativos para estas e outras finalidades inerentes à atividade projetual e de desenvolvimento de produtos industriais.

Com relação aos dados obtidos com a revisão literária, conseguiu-se estruturar a evolução das novas tecnologias, sua introdução e desdobramentos na área projetual. Foram abordados assuntos sobre a computação gráfica, a digitalização 3D, as tecnologias aditivas e subtrativas de prototipagem rápida a prototipagem, o molde e a manufatura - além da realidade virtual, da realidade aumentada e da holografia. Ainda que de posse de uma revisão literária, pode-se aferir uma forte tendência, durante a projetação de produtos, pela adoção das novas tecnologias em complementação, e não como substituta como alguns imaginavam, aos métodos e instrumentos tradicionais de desenvolvimento de produtos. O próprio CADEP/UNESP/FAAC acredita nessa hipótese ao adotar o uso das tecnologias tradicionais de desenvolvimento de protótipos atuando lado a lado com as tecnologias de prototipagem rápida (Rodrigues, Alencar \& Barata, 2012).

No que tange ao uso dos laboratórios, está prevista a realização e o atendimento de estágio supervisionado no CADEP/UNESP/FAAC onde serão colhidos dados mais consistentes de campo referentes à digitalização 3D e às tecnologias aditivas e subtrativas de prototipagem rápida.

A aplicação de dois instrumentos de coleta de dados de campo foi iniciada e continua ainda em andamento. Um instrumento encontra-se voltado ao meio acadêmico e o público é de docentes e estudantes de pós-graduação. O outro instrumento foi planejado para aplicar ao setor produtivo entre empresas e organizações que lidam com desenvolvimento de produtos industriais.

Ao final da coleta de dados, estima-se fazer um estudo comparativo entre a realidade do ensino projetual e a prática projetual no setor produtivo nacional no que diz respeito ao uso de ferramentas e de instrumentos metodológicos advindos das áreas tecnológicas e à aplicação de novas tecnologias nos referidos espaços sondados. 


\section{CONSIDERAÇÕES FINAIS}

Pretende-se buscar uma compreensão da área projetual, no caso com a chegada das novas tecnologias, e a inserção da realidade virtual e aumentada no campo do desenho industrial e do desenvolvimento de produtos industriais. Para, além disso, procura-se delinear um paralelo com o ensino em desenho industrial e como as instituições de ensino superior estão encarando ou se preparando para a possibilidade de adoção das tecnologias imersivas nos seus currículos plenos, haja vista que o ensino e a educação podem ser entendidos como processos formativos que prenunciam, refletem ou devem estar em perfeita sintonia com as transformações da sociedade quer sejam sócioculturais, econômicas, políticas, históricas ou tecnológicas.

Dentre as barreiras culturais do ensino superior no Brasil se faz necessária uma aproximação das instituições com os setores produtivos. No caso do ensino do desenho industrial e de áreas de cunho de inovação tecnológica parcerias podem ser firmadas com contribuições mútuas para ambas as partes. Existem alguns exemplos de sucesso no país, mas essa estratégia já faz parte da cultura de outras nações industrializadas há bastante tempo.

Além disso, acredita-se que as parcerias entre áreas de forte proximidade, como é o caso do desenho industrial e das engenharias, no que tange ao desenvolvimento de produtos industriais, também devam se concretizar reforçando os aspectos interdisciplinares e visando o distanciamento tecnológico com o mundo do trabalho.

\section{AGRADECIMENTO}

Ao Centro Acadêmico do Agreste e ao Curso de Design - Universidade Federal de Pernambuco, ao Programa de Pós-Graduação em Design - UNESP, à Coordenação de Aperfeiçoamento de Pessoal de Nível Superior - CAPES - à Fundação de Amparo à Ciência e Tecnologia do Estado de Pernambuco FACEPE. 


\section{REFERÊNCIAS}

BÜRDEK, B. E. 2010. Design: história, teoria e prática do design de produtos. São Paulo: Blücher.

AZEVEDO, E.; CONCI, A. 2003. Computação gráfica: teoria e prática. Rio de Janeiro: Elsevier.

SILVA et al, F. P. da. 2006. A digitalização tridimensional a laser como ferramenta para o desenvolvimento de novos produtos. In VII Congresso Brasileiro de Pesquisa e Desenvolvimento em Design, P\&D Design. Paraná.

BARBOSA, R.; ALENCAR, F. de. 2010. Design e prototipagem: conhecimento e uso da prototipagem digital no design brasileiro. In Anais do IX Congresso Brasileiro de Pesquisa e Desenvolvimento em Design. São Paulo: AEND-BR/Blücher/Universidade Anhembi Morumbi, p. 5845-58.

VOLPATO, N. et al. 2007. Prototipagem rápida: tecnologias e aplicações. São Paulo: Edgard Blücher.

CANCIGLIERI JÚNIOR, O. et al. 2007. Processos de prototipagem rápida por deposição ou remoção de material na concepção de novos produtos - uma abordagem comparativa. In: XXVII Encontro Nacional de Engenharia de Produção. Foz do Iguaçu: ENEGEP.

FORTI, F. S. D. 2005. Uma Avaliação do Ensino da Prototipagem Virtual nas Graduações de Design de Produto do Estado do Rio de Janeiro. Dissertação de mestrado apresentada à Universidade Federal do Rio de Janeiro, Programa de Pós-Graduação em Engenharia. Rio de Janeiro: COPPE/UFRJ.

RODRIGUES, O. V.; ALENCAR, F.; BARATA, T. Q. F. 2012. Combining rapid prototyping with more conventional production processes. In: 5th International PMI Conference Proceedings.

\section{1. Guent: University College Guent. P. 147-50.}

AGUILAR, J. H. A.; LÓPEZ, L. M. 2004. Holografía básica. México: Instituto Politécnico Nacional. In: <http://www.libros.publicaciones.ipn.mx/PDF/1495.pdf> 13/03/2013

ROSEN, J. 2011. Holography, research and technologies. Rijeka: Intech. In:

<http://www.intechopen.com/ > 22/05/2013

WHITE, J. 2002. Virtual reality and the built environment. Oxford: Architectural Press. In:

<http://pt.scribd.com/doc/70412500/Virtual-Reality-and-the-Built-Environment> 18/04/2013

CRAIG, A. et al. 2009. Developing Virtual Reality Applications: Foundations of Effective Design.

Burlington: Morgan Kaufmann. In: <http://www.downws.com/ebooks/104402-developing- virtualreality-applications-foundations-of-effective-design.html> 18/04/2013

TORI, R; KIRNER, C; SISCOUTTO, R [Editores]. 2006. Fundamentos e tecnologia de realidade virtual e aumentada. Livro do Pré-Simpósio - VIII Symposium on virtual reality, Belém (PA). Porto Alegre: SBC. In:

<http://www.ckirner.com/download/capitulos/Fundamentos_e_Tecnologia_de_Realidade_Vir tual_e_Aumentada-v22-11-06.pdf > 20/05/2013 


\section{A Contribuição Da Realidade Aumentada Para O Desenho Industrial}

NASCIMENTO SILVA, D. É. et al. 2013. Educação e informática na área projetual. In: IV Congresso Brasileiro de Educação - Ensino e aprendizagem na educação básica: desafios curriculares. Bauru: UNESP.

BOWMAN, D. A. et al. 2005. 3D user interfaces: theory and practice. Boston: Addison- Wesley/Pearson Education.

SHNEIDERMAN, B.; PLAISANT, C. 2005. Designing the user interface. Boston: Addison- Wesley/Pearson Education. 